\author{
UNIVERSIDADE DE SÃO PAULO \\ ESCOLA DE ENGENHARIA DE SÃO CARLOS \\ DEPARTAMENTO DE ENGENHARIA DE ESTRUTURAS
}

CAROLINE OLIVEIRA E OLIVEIRA

Estudo numérico e experimental da distribuição das fibras de aço em vigas de UHPFRC 

CAROLINE OLIVEIRA E OLIVEIRA

\title{
Estudo numérico e experimental da distribuição das fibras de aço em vigas de UHPFRC
}

\author{
VERSÃO CORRIGIDA
}

A versão original encontra-se na Escola de Engenharia de São Carlos

Tese apresentada ao Programa de Pós-Graduação em Engenharia de Estruturas da Escola de Engenharia de São Carlos da Universidade de São Paulo, como parte dos requisitos para obtenção do título de Doutor em Ciências.

Área de concentração: Engenharia Civil (Estruturas)

Orientador: Prof. Assoc. Ricardo Carrazedo

SÃO CARLOS 
AUTORIZO A REPRODUÇÃO TOTAL OU PARCIAL DESTE TRABALHO, POR QUALQUER MEIO CONVENCIONAL OU ELETRÔNICO, PARA FINS DE ESTUDO E PESQUISA, DESDE QUE CITADA A FONTE.

Ficha catalográfica elaborada pela Biblioteca Prof. Dr. Sérgio Rodrigues Fontes da EESC/USP com os dados inseridos pelo(a) autor(a).

Oliveira, Caroline Oliveira e
Estudo numérico e experimental da distribuição
das fibras de aço em vigas de UHPFC / Caroline
Oliveira e Oliveira; orientador Ricardo Carrazedo.
São Carlos, 2019.
Tese (Doutorado) - Programa de Pós-Graduação em
Engenharia Civil (Engenharia de Estruturas) e Área de
Concentração em Estruturas -- Escola de Engenharia de
São Carlos da Universidade de São Paulo, 2019.
1. UHpFRC. 2. Fibras. 3. Vigas. 4. Análise de
imagem. 5. Método dos elementos finitos. 6. Elementos
discretos embutidos. I. Título.

Eduardo Graziosi Silva - CRB - 8/8907 


\section{FOLHA DE JULGAMENTO}

Candidata: Engenheira CAROLINE OLIVEIRA E OLIVEIRA.

Título da tese: "Estudo numérico e experimental da distribuição das fibras de aço em vigas de UHPFRC".

Data da defesa: 02/12/2019.

Comissão Julgadora:

Prof. Associado Ricardo Carrazedo

(Orientador)

(Escola de Engenharia de São Carlos/EESC)

Prof. Associado Vladimir Guilherme Haach

(Escola de Engenharia de São Carlos/EESC)

Prof. Dr. Fernando Menezes de Almeida Filho

(Universidade Federal de São Carlos/UFSCar)

Prof. Associado Antonio Domingues de Figueiredo

(Escola Politécnica/EP-USP)

Prof. Dr. Romel Dias Vanderlei

(Universidade Estadual de Maringá/UEM)
Resultado:

AProvitos

APROVADA

APOONARE

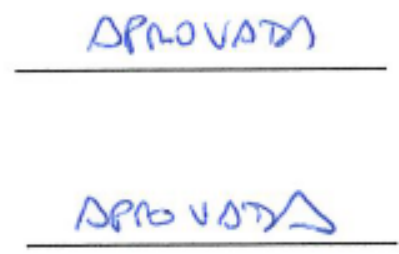

Coordenador do Programa de Pós-Graduação em Engenharia Civil (Engenharia de Estruturas):

Prof. Associado Vladimir Guilherme Haach

Presidente da Comissão de Pós-Graduação:

Prof. Titular Murilo Araujo Romero 

Dedico este trabalho aos meus pais, Anivaldo e Marlene. 



\section{AGRADECIMENTOS}

A Deus pela dádiva da vida e por guiar meus passos com sabedoria nesta importante caminhada.

À minha família pelo amor incondicional, apoio e compreensão em todos os momentos.

Ao professor Ricardo Carrazedo pela valiosa orientação, paciência e conhecimentos transmitidos.

Aos professores e funcionários do Departamento de Engenharia de Estruturas da Escola de Engenharia de São Carlos da Universidade de São Paulo (EESC-USP) pelo auxílio e suporte.

Aos meus amigos pela troca de experiência, companheirismo e momentos compartilhados.

Ao Conselho Nacional de Desenvolvimento Científico e Tecnológico (CNPq) pela concessão da bolsa de estudos.

Às empresas Holcim, Grace, Elkem e Mineração Jundu pela doação dos materiais.

Muito obrigada! 

"Na vida, não existe nada a temer, mas a entender" Marie Curie 



\section{RESUMO}

OLIVEIRA, C. O. Estudo numérico e experimental da distribuição das fibras de aço em vigas de UHPFRC. 2019. 153p. Tese (Doutorado em Engenharia Civil (Estruturas)) - Escola de Engenharia de São Carlos, Universidade de São Paulo, São Carlos, 2019.

O concreto de ultra-alto desempenho (UHPC, sigla em inglês) é um material que apresenta alta resistência à compressão e durabilidade. Quando reforçado com fibras de aço (UHPFRC, sigla em inglês), passa a exibir um comportamento dúctil, alta resistência à tração e à flexão. A distribuição das fibras influencia significativamente o comportamento mecânico e estrutural desse material, sendo fundamental considerá-la nos estudos experimentais e numéricos. Entretanto, experimentalmente, há poucas investigações sobre a distribuição das fibras em elementos estruturais de UHPFRC, e, numericamente, a maioria dos modelos consideram-no homogêneo, o que impossibilita representar adequadamente tal distribuição. Nesse sentido, esta pesquisa objetiva investigar experimentalmente a influência das fibras e propor um modelo numérico em elementos finitos para o UHPFRC com fibras discretizadas e embutidas na matriz. $\mathrm{Na}$ etapa experimental, foram realizados ensaios de caracterização do UHPC e UHPFRC (1\% e $2 \%$ de fibras) e de flexão em cinco vigas produzidas a partir desses concretos, cujos resultados confirmaram melhor desempenho ao UHPFRC (tanto no âmbito material quanto no estrutural). Além disso, foi realizada a análise de imagem por fotografia de alta resolução nas vigas de UHPFRC, que revelaram uma orientação preferencial das fibras. Numericamente, para possibilitar a representação da distribuição das fibras, visando a um menor custo computacional, elas foram discretizadas como elementos de treliça embutidos nos elementos que modelam a matriz (aderência perfeita). Assim, o deslizamento relativo da interface fibra/matriz foi representado no modelo constitutivo das fibras, por meio de uma lei tensão-deformação equivalente baseada no comportamento de arrancamento da fibra. A validação dessa estratégia numérica foi realizada modelando e simulando no ABAQUS os ensaios de caracterização (tração uniaxial e flexão a três pontos) e de flexão das vigas realizados experimentalmente. De modo geral, os resultados numéricos indicaram uma boa correlação com os resultados experimentais. Contudo, algumas sugestões foram propostas a fim de aprimorar o modelo numérico proposto.

Palavras-chave: UHPFRC. Fibras. Vigas. Análise de imagem. Método dos elementos finitos. Elementos discretos embutidos. 



\section{ABSTRACT}

OLIVEIRA, C. O. Numerical and experimental study of steel fibers distribution in UHPFRC beams. 2019. 153p. Thesis (PhD. in Civil Engineering (Structures)) - School of Engineering of São Carlos, University of São Paulo, São Carlos, 2019.

Ultra-high performance concrete (UHPC) is a material with high compressive strength and durability. When reinforced with steel fibers (UHPFRC) it becomes to exhibit a ductile behaviour and high tensile and flexural strength. Distribution of fibers significatively influences mechanical and structural behaviour of this material, and hence it has to be considered both in experimental and numerical studies. However, there are few experimental investigations on the fibers distribution in UHPFRC structural elements and, additionally, most of the numerical models consider this material as homogeneous, which makes it impossible to adequately represent such distribution. In this context, this research aims to experimentally investigate the influence of fibers distribution and to propose a numerical model by finite elements for UHPFRC with discretized and embedded fibers in the matrix. In the experimental stage, UHPC and UHPFRC ( $1 \%$ and $2 \%$ of fibers) were characterized as well as flexural tests were carried out in five beams produced with these concretes. The results confirmed UHPFRC has better performance both in material and structural analysis. Moreover, analysis of high resolution photographic images of UHPFRC beams revealed a preferential fibers orientation. In the numerical stage, in order to enable a representation of fibers distribution with the lowest computational cost, they were discretized as truss elements embedded in the modelling elements of the matrix (perfect bond). Thus, the relative slip of fiber/matrix interface was represented in the fibers constitutive model by means of a stress-strain equivalent law based on the pullout behaviour of fiber. This numerical strategy was validated by modelling and simulating in ABAQUS the experimental tests of characterization of material (by uniaxial tensile and three-point flexural tests) and of flexural of beams. Overall, the numerical results indicated a good correlation with the experimental results. Nevertheless, some measures were suggested in order to improve the proposed numerical model.

Keywords: UHPFRC. Fibers. Beams. Image analysis. Finite element method. Embedded discrete element. 



\section{SUMÁRIO}

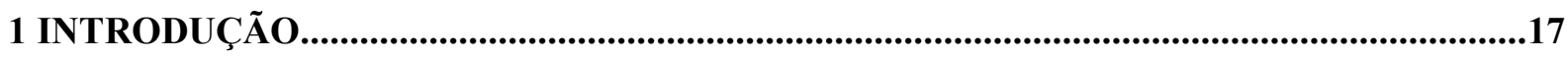

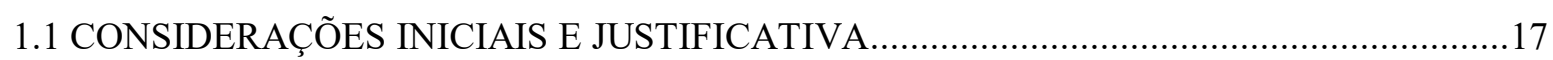

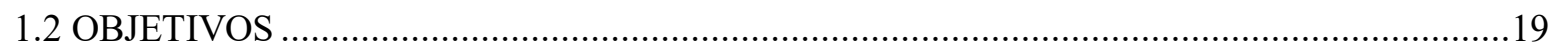

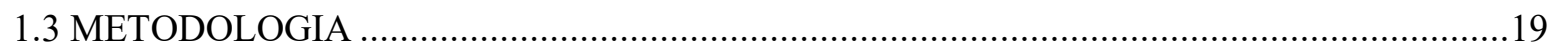

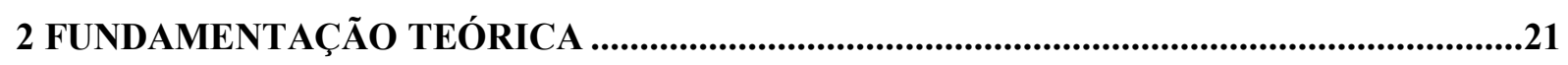

2.1 CONCRETO DE ULTRA-ALTO DESEMPENHO REFORÇADO COM FIBRAS .................21

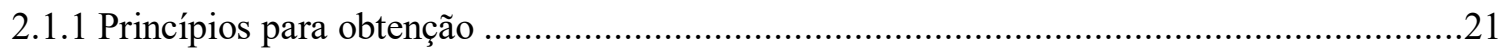

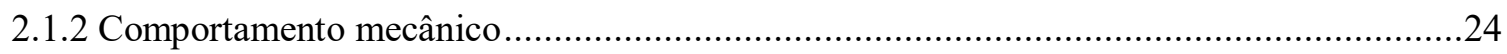

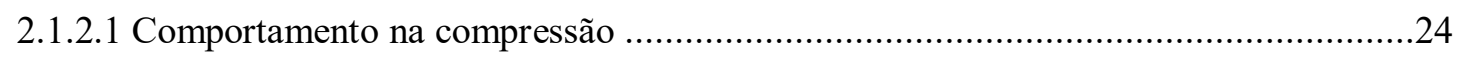

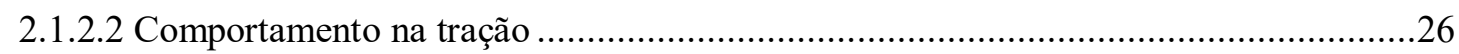

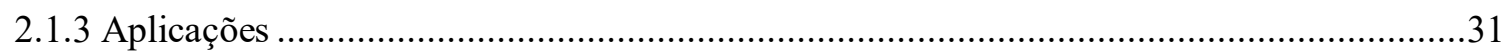

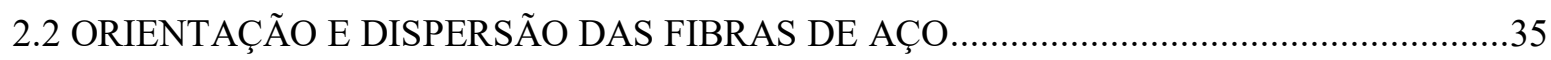

2.2.1 Caracterização da orientação e dispersão das fibras ............................................................36

2.3 COMPORTAMENTO DE ARRANCAMENTO DAS FIBRAS DE AÇO .............................43

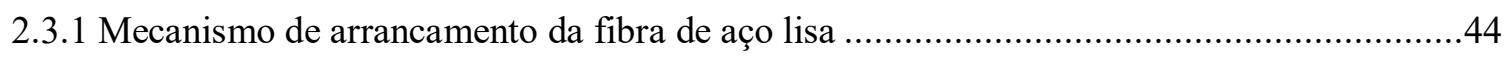

2.3.2 Modelo analítico do comportamento de arrancamento da fibra .......................................47

2.3.2.1 Comportamento de arrancamento da fibra de aço lisa e alinhada ..............................47

2.3.2.2 Comportamento de arrancamento da fibra de aço lisa e inclinada ..............................52

2.4 MODELAGEM NUMÉRICA EM ELEMENTOS FINITOS PARA UHPFRC ........................54

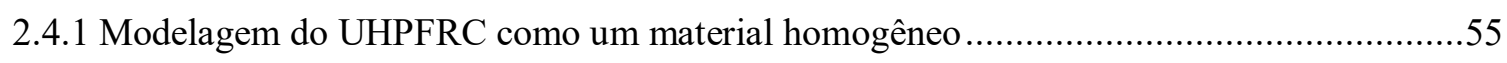

2.4.2 Modelagem do UHPFRC como um material heterogêneo bifásico .....................................60

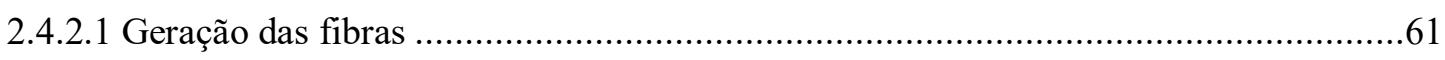

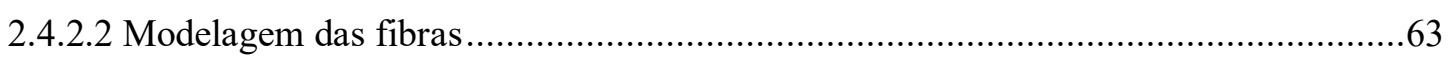

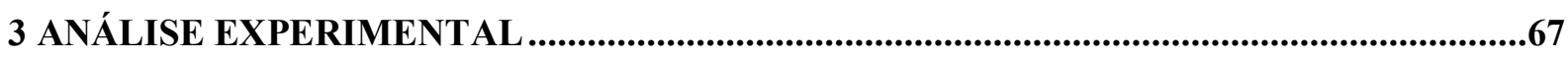

3.1 CONCRETO DE ULTRA-ALTO DESEMPENHO REFORÇADO COM FIBRAS .................67

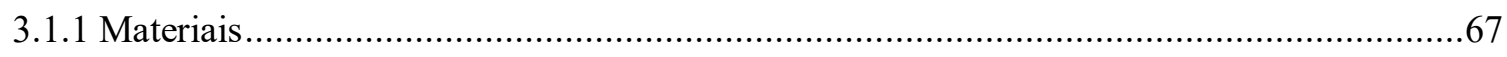

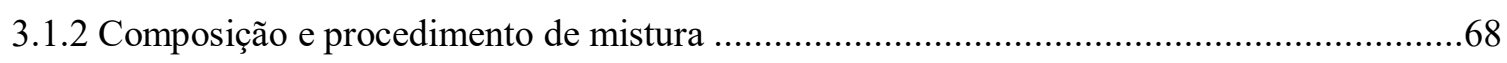

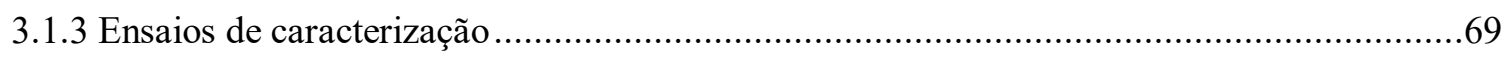

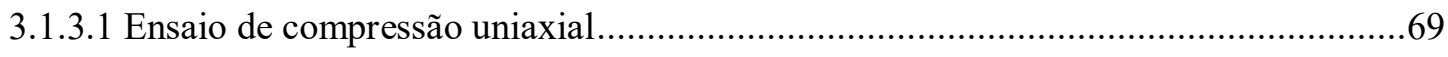

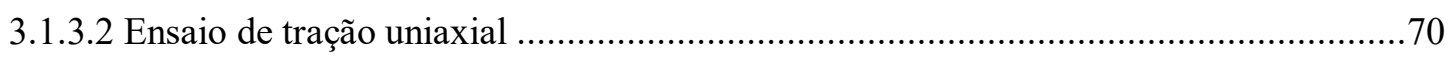

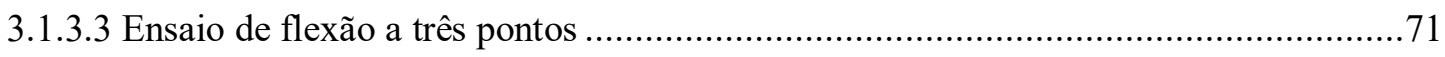

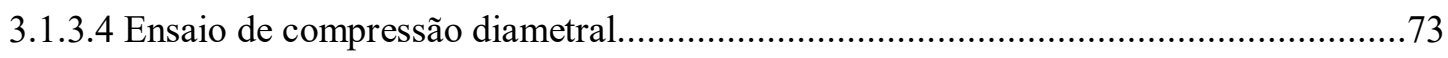




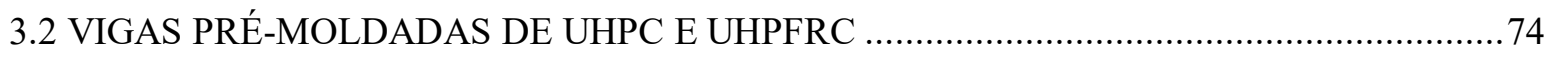

3.2.1 Geometria, dimensões e detalhamento das vigas............................................................ 74

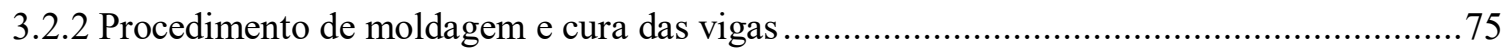

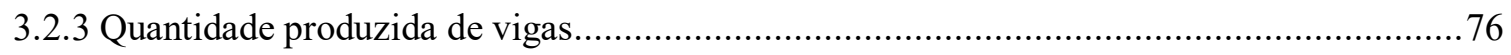

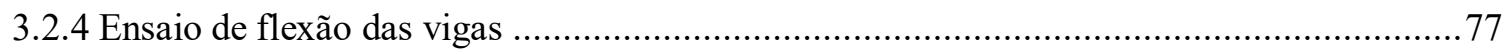

3.2.4.1 Configuração, instrumentação e procedimento do ensaio de flexão............................78

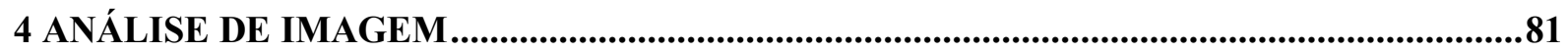

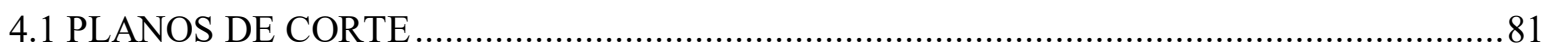

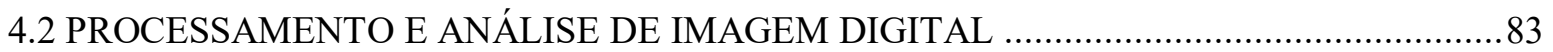

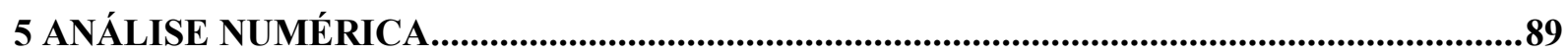

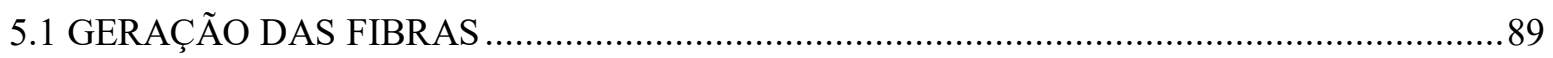

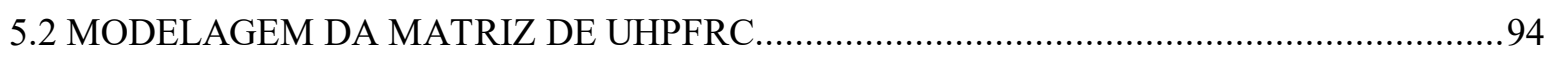

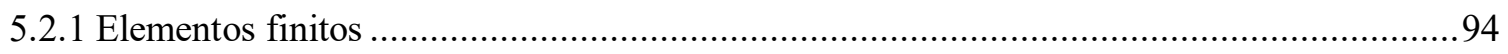

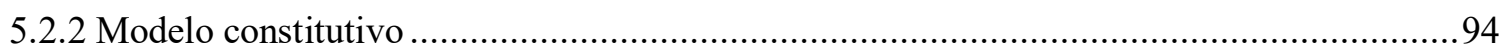

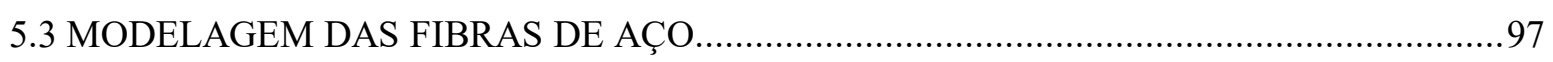

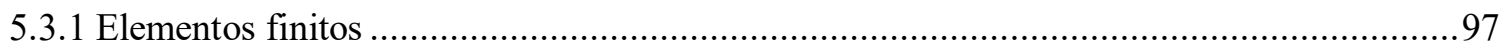

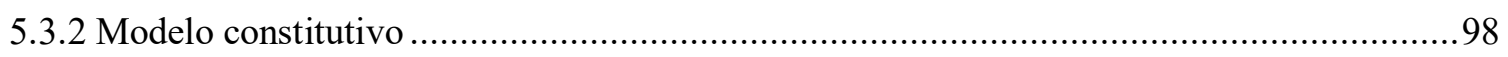

5.4 MODELAGEM DAS ARMADURAS LONGITUDINAIS E TRANSVERSAIS ....................102

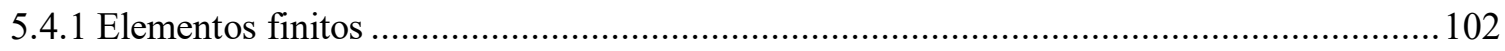

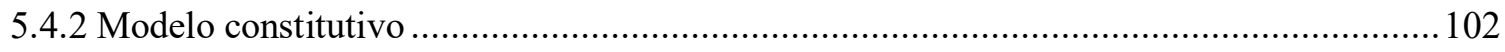

5.5 APLICAÇÃO E VALIDAÇÃO DO MODELO NUMÉRICO PROPOSTO............................103

5.5.1 Simulação numérica do ensaio de tração uniaxial ............................................................... 104

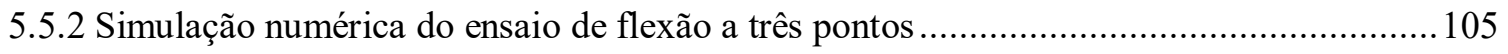

5.5.3 Simulação numérica do ensaio de flexão a quatro pontos................................................ 106

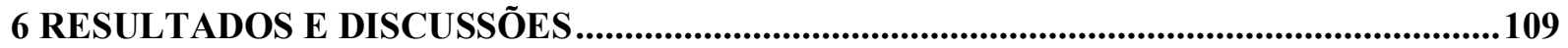

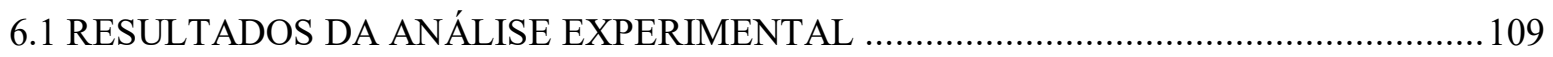

6.1.1 Ensaios de caracterização do UHPC e UHPFRC ............................................................. 109

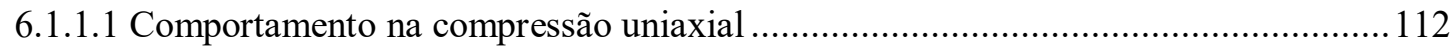

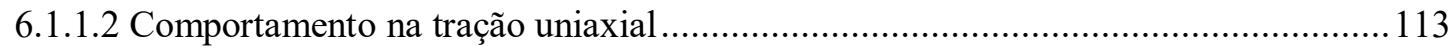

6.1.1.3 Comportamento na flexão a três pontos............................................................... 115

6.1.1.4 Comportamento na compressão diametral .......................................................... 117

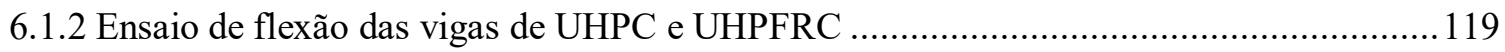

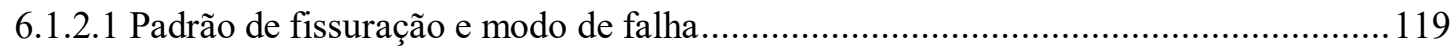

6.1.2.2 Curva força-deslocamento vertical no meio do vão ................................................. 120

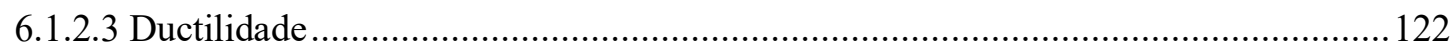


6.1.2.4 Curva força-deformação

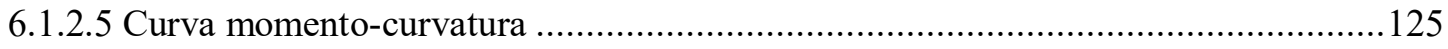

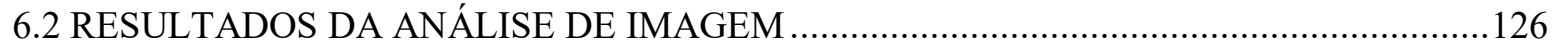

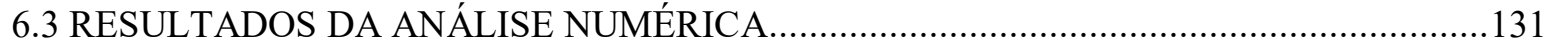

6.3.1 Simulação numérica do ensaio de tração uniaxial ..........................................................131

6.3.2 Simulação numérica do ensaio de flexão a três pontos .....................................................135

6.3.3 Simulação numérica do ensaio de flexão a quatro pontos ..................................................137

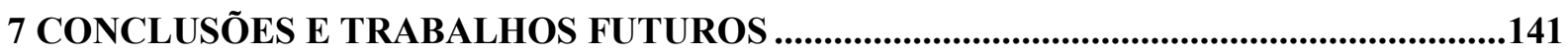

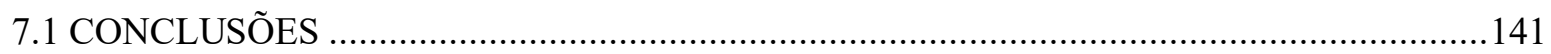

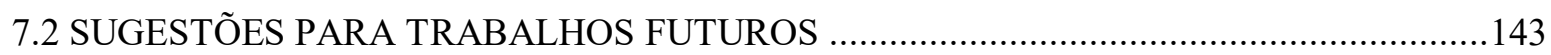

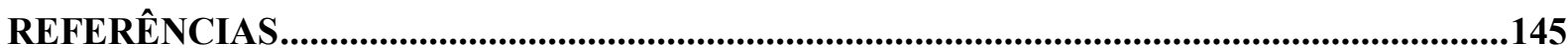





\section{INTRODUÇÃO}

\subsection{Considerações Iniciais e Justificativa}

O concreto de ultra-alto desempenho (UHPC) reforçado com fibras de aço (UHPFRC) é um compósito cimentício que exibe propriedades mecânicas e durabilidade excepcionais. A sua matriz densa, quando combinada com fibras de aço, confere ao material um comportamento dúctil com alta resistência à compressão, à tração e à flexão.

As propriedades mecânicas do UHPFRC, principalmente as resistências à tração e à flexão, são significativamente influenciadas pela orientação e dispersão das fibras. Assim, muitas pesquisas, com o propósito de maximizar essas propriedades e analisá-las racionalmente, dedicam-se a estudar experimentalmente a distribuição das fibras em amostras de UHPFRC (KANG et al., 2011; KANG; KIM, 2011; 2012; WILLE et al., 2014b; YOO et al., 2015; YOO et al., 2016a; 2016d; DUQUE; GRAYBEAL, 2017; ABRISHAMBAF et al, 2017; ZHOU; UCHIDA, 2017).

Nesse contexto, em se tratando de um elemento estrutural produzido de UHPFRC, é de se esperar que a orientação e dispersão das fibras também afetem o seu desempenho mecânico e estrutural. No entanto, a distribuição das fibras em elementos estruturais de UHPFRC carece de estudos, visto que os ensaios experimentais requerem um conjunto de recursos (materiais, equipamentos e mão de obra) que os torna dispendiosos e morosos, principalmente quando se trabalha com elementos em escala real.

Além disso, os modelos numéricos, que são uma boa alternativa aos ensaios experimentais, consideram, em sua maioria, o UHPFRC como material homogêneo (CHEN; GRAYBEAL, 2012; MAHMUD et al., 2013; MAO et al., 2014; AWINDA et al., 2016; THAI; KIM, 2016; AL-OSTA et al., 2017; SINGH et al., 2017; BAHIJ et al., 2018; HUSSEIN; AMLEH, 2018; KRAHL et al., 2018). Apesar de essa consideração ser representativa, o fato de não discretizar as fibras na matriz cimentícia impossibilita investigar adequadamente os efeitos da sua distribuição no comportamento do elemento modelado.

Algumas pesquisas buscam modelar o UHPFRC como um material heterogêneo trifásico (matriz, fibras e interface fibra/matriz). Contudo, devido ao alto custo computacional, 
essa abordagem numérica limita-se apenas a amostras (QSYMAH, 2016; ZHANG et al., 2018). Como alternativa, pesquisas não específicas para o UHPFRC, mas para o concreto reforçado com fibras (FRC, sigla em inglês), consideram-no um material heterogêneo bifásico (matriz e fibras), sendo o comportamento da interface representado no modelo constitutivo das fibras por meio de uma lei tensão-deformação equivalente (CUNHA et al., 2011; 2012; SOETENS et al., 2012; SOETENS; MATTHYS; 2012; 2014). Essa última abordagem numérica, apesar de apresentar um menor custo computacional, também se concentra apenas em amostras, não sendo investigada detalhadamente para o UHPFRC e nem aplicada em elementos estruturais.

Tendo em vista esse cenário, a motivação para o desenvolvimento desta pesquisa encontra-se justificada pelos seguintes aspectos:

- O estudo da orientação e dispersão das fibras é de suma importância para otimizar o comportamento mecânico e estrutural do UHPFRC. Contudo, o elevado custo e tempo de execução dos ensaios experimentais limitam o avanço dos estudos, principalmente em elementos estruturais em escala real. Tal fato motiva o desenvolvimento de modelos numéricos para o UHPFRC;

- A maioria dos modelos numéricos consideram o UHPFRC como material homogêneo, impossibilitando representar e investigar a distribuição das fibras numericamente. Além disso, modelar o UHPFRC como um material heterogêneo trifásico (matriz, fibra e interface) pode resultar em um alto custo computacional, dependendo da quantidade de fibras discretizadas. Assim, justifica-se a necessidade de desenvolverem-se modelos numéricos para o UHPFRC que possibilitem representar a distribuição das fibras, buscando também um custo computacional mais viável; e

- Prover continuidade à linha de pesquisa de concretos reforçados com fibras, em especial o UHPFRC, do Departamento de Engenharia de Estruturas da Escola de Engenharia de São Carlos da Universidade de São Paulo (EESC-USP). 


\subsection{Objetivos}

O objetivo geral desta pesquisa é investigar a influência das fibras sobre o comportamento mecânico e estrutural do UHPFRC e desenvolver, para esse material, um modelo numérico em elementos finitos com fibras discretizadas e embutidas na matriz cimentícia (material bifásico). Para alcançar tal objetivo, foram delineados os seguintes objetivos específicos:

- Caracterizar experimentalmente o comportamento mecânico do UHPC e UHPFRC;

- Caracterizar experimentalmente o comportamento à flexão das vigas pré-moldadas de UHPC e UHPFRC;

- Implementar o código de processamento e análise de imagem na linguagem MATLAB;

- Implementar o código de geração das fibras na linguagem Python;

- Definir o comportamento de arrancamento das fibras na matriz de UHPFRC, bem como a sua lei constitutiva equivalente; e

- Elaborar os modelos numéricos com fibras discretizadas e embutidas na matriz de UHPFRC no software de elementos finitos ABAQUS.

\subsection{Metodologia}

De forma sucinta, a metodologia utilizada nesta pesquisa, que engloba análise experimental, de imagem e numérica, é descrita a seguir.

$\mathrm{Na}$ análise experimental, foram definidas três composições de concreto de ultra-alto desempenho, variando apenas a fração volumétrica de fibras de aço: $0 \%$ (UHPC), 1\% (UHPFRC-1) e 2\% (UHPFRC-2). Com o intuito de investigar o comportamento mecânico desses concretos e alimentar o modelo numérico, foram realizados ensaios de caracterização mecânica (compressão e tração uniaxial, flexão a três pontos e compressão diametral). Além disso, objetivando estudar o comportamento mecânico do ponto de vista estrutural, bem como 
validar o modelo numérico proposto, foram produzidas vigas de UHPC, UHPFRC-1 e UHPFRC-2 em escala real e submetidas ao ensaio de flexão a quatro pontos.

Após os ensaios de flexão das vigas de UHPFRC-1 e UHPFRC-2, a fim de investigar os padrões de orientação das fibras e possibilitar representá-los no modelo numérico proposto, foi realizada a análise de imagem por fotografia de alta resolução em planos de corte próximos ao de fissuração principal. Para tanto, foi desenvolvido um código de processamento e análise de imagem na linguagem MATLAB. Esse código possibilitou quantificar as características de distribuição das fibras nos planos de corte (número total de fibras, número de fibras por unidade de área, ângulo de orientação e coeficiente de orientação).

$\mathrm{Na}$ análise numérica, com o intuito de representar a distribuição das fibras, o UHPFRC foi modelado como um material heterogêneo bifásico (matriz e fibras). Dessa forma, estratégias numéricas foram adotadas para a geração das fibras e para a consideração do comportamento da interface fibra/matriz no modelo.

Para geração das fibras dentro de um determinado do volume, foi desenvolvido um código na linguagem Python. Nesse código, as fibras foram representadas por linhas retas com espessura nula, sendo empregada uma distribuição normal (gaussiana) para estimar a sua orientação real no plano de fissuração. Além disso, as coordenadas de extremidades das fibras geradas (suficientes para representar seus nós e elementos finitos no modelo) foram salvas em um arquivo de saída com extensão .inp, que, posteriormente, foi importado para o ABAQUS.

No modelo numérico proposto, as fibras foram modeladas como elementos de treliça embutidos, ou seja, aderidas perfeitamente aos elementos que modelam a matriz. Assim, para considerar o deslizamento relativo da interface fibra/matriz, foi atribuída às fibras uma lei constitutiva tensão-deformação equivalente, obtida a partir do seu comportamento de arrancamento, conforme proposto por Soetens et al. (2012). O comportamento de arrancamento da fibra de aço na matriz de UHPFRC foi determinado por meio do modelo analítico proposto por Lee et al. (2010), em que foram considerados também os efeitos pino e de fragmentação da matriz ocorrentes nas fibras inclinadas.

Por fim, aplicando as estratégias numéricas descritas acima, foram modelados e simulados no ABAQUS os ensaios de caracterização (tração uniaxial e flexão a três pontos) e de flexão a quatro pontos das vigas de UHPFRC-1 e UHPFRC-2. Os resultados numéricos foram então confrontados com os experimentais, visando validar o modelo numérico proposto. 


\section{FUNDAMENTAÇÃO TEÓRICA}

\subsection{Concreto de Ultra-Alto Desempenho Reforçado com Fibras}

\subsubsection{Princípios para obtenção}

O concreto de ultra-alto desempenho (UHPC) reforçado com fibras (UHPFRC) é oriundo de pesquisas realizadas na França por Pierre Richard, considerado o inventor desse tipo concreto, na década de 1990, a partir do estudo do concreto de alto desempenho (CAD) (TUTIKIAN et al., 2011).

O UHPFRC é composto por materiais granulares ultrafinos, com diâmetro máximo menor que $2 \mathrm{~mm}$, como o cimento Portland, a areia fina, a sílica ativa e o pó de quartzo. Materiais granulares com diâmetro maior que $2 \mathrm{~mm}$, como o agregado graúdo, provocam heterogeneidade no concreto, causando fissuras na zona de transição na interface pasta/agregado e, consequentemente, reduzindo a resistência à compressão do concreto. Assim, para eliminar esse e outros inconvenientes, o agregado graúdo é eliminado do UHPFRC (MEHTA; MONTEIRO, 2008). Além dos materiais granulares ultrafinos, é necessário incorporar à composição o aditivo superplastificante para garantir uma baixa relação água/aglomerante, na ordem de 0,10 a 0,20 em massa (TUTIKIAN et al., 2011). A Figura 2.1 ilustra os materiais e os tamanhos médios das partículas geralmente utilizados no UHPFRC.

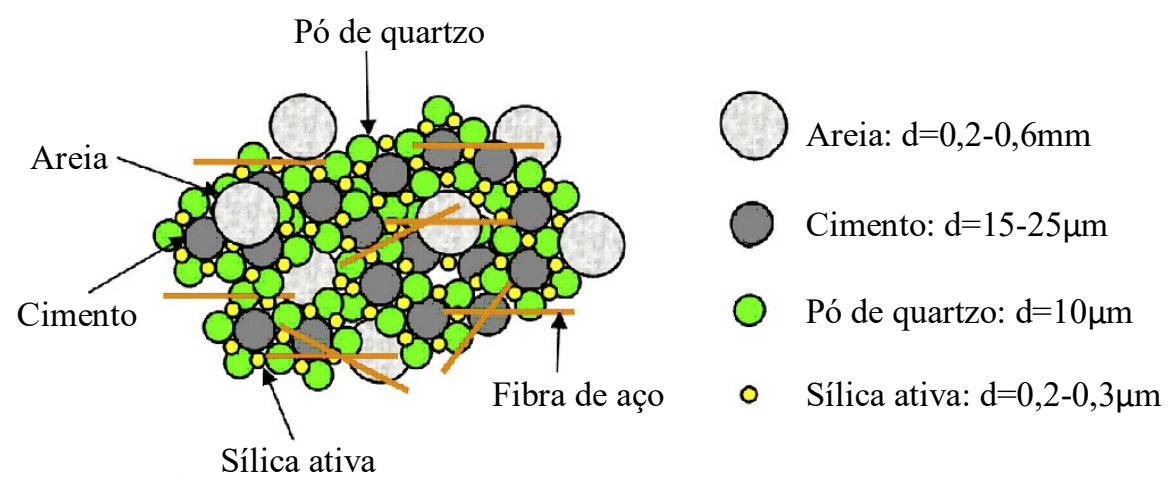

Figura 2.1 - Materiais granulares e tamanho médio das partículas geralmente utilizados no UHPFRC (Fonte: Adaptado de YOO et al., 2015) 
A seleção e dosagem dos componentes do concreto exerce grande influência em suas propriedades; porém, quando se trata do UHPFRC, essa questão se torna primordial. Para a produção do UHPFRC, é aconselhável realizar uma dosagem baseada no conceito de empacotamento de partículas, em que serão otimizados os componentes granulares do concreto, visando misturas com alta densidade de empacotamento, ou seja, com baixa porosidade e, consequentemente, com elevada resistência à compressão e durabilidade. É também de grande importância determinar o teor ótimo de aditivo superplastificante, para que a relação água/aglomerante seja reduzida até o limite mínimo, melhorando as propriedades mecânicas do UHPFRC, além de garantir fluidez adequada à mistura.

Segundo Richard e Cheyrezy (1995), os princípios básicos para a obtenção do UHPFRC são:

- aumento da homogeneidade pela eliminação de agregados graúdos;

- aumento da densidade de empacotamento pela otimização dos componentes granulares do concreto e/ou aplicação de pressão no preparo;

- fortalecimento da microestrutura utilizando tratamento térmico durante a cura; e

- aumento da ductilidade pela incorporação de fibras de aço de pequenas dimensões.

A homogeneidade e a densidade de empacotamento são os principais atributos do UHPFRC, devendo sempre ser empregadas para esse tipo de concreto. Já a pressão no preparo e o tratamento térmico durante a cura, realizados para potencializar o desempenho do concreto, são opcionais, dependendo da aplicação do UHPFRC. Além disso, vale ressaltar que o emprego dos três primeiros princípios produz um concreto com alta resistência à compressão e alta durabilidade, mas com baixa ductilidade. Para suprir esse problema, podem-se incorporar fibras de aço no concreto (quarto princípio), o que também proporciona melhoria na resistência à tração e à flexão (RICHARD; CHEYREZY, 1995; KANG; KIM, 2011).

Vários tipos de fibras podem ser incorporados na composição do UHPFRC (Figura 2.2); porém, as fibras mais comumente utilizadas são as fibras de aço lisas e curtas, com comprimento de $13 \mathrm{~mm}$ e diâmetro de $0,2 \mathrm{~mm}$, revestidas de cobre, apresentando resistência à tração e módulo de elasticidade de aproximadamente $2500 \mathrm{MPa}$ e $200 \mathrm{GPa}$, respectivamente (Figura 2.3). Com relação à quantidade de fibras de aço, grandes teores podem gerar um efeito negativo sobre a homogeneidade e trabalhabilidade da mistura de concreto. Assim, em geral, a quantidade indicada para assegurar um comportamento dúctil ao UHPFRC, além de proporcionar um aumento satisfatório da resistência à tração e à flexão, é de $2 \%$ em volume (MEHTA; MONTEIRO, 2008; BARNETT et al., 2010; KANG; KIM, 2012). 
Fibras lisas

Fibras deformadas nas extremidades

Com pá nas extremidades

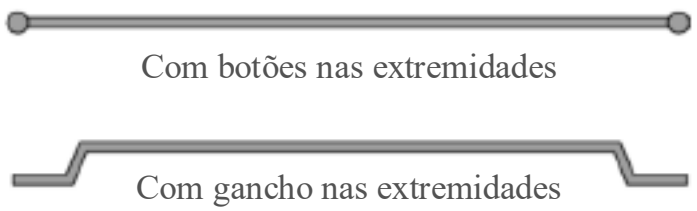

Fibras deformadas ao longo do comprimento

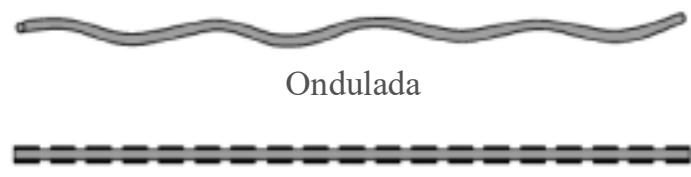

Superfície chanfrada

Torcida

Figura 2.2 - Tipos de fibras de aço utilizadas no UHPFRC

(Fonte: Adaptado de WILLE; NAAMAM, 2012)

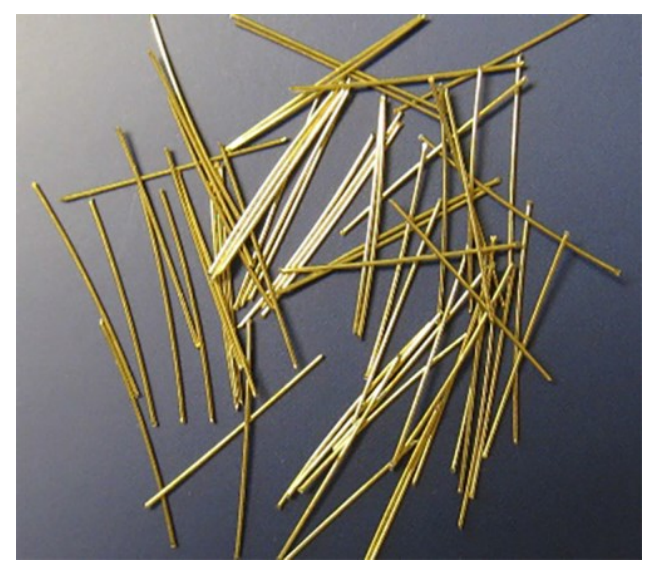

Figura 2.3 - Fibras de aço lisas e curtas geralmente utilizadas no UHPFRC

(Fonte: NAAMAM, 2018)

A utilização de materiais granulares ultrafinos, aditivo superplastificante e a baixa relação água/aglomerante proporcionou ao UHPFRC um significativo aumento da resistência à compressão. Sabe-se que o concreto convencional pode resistir até $50 \mathrm{MPa}$, que o CAD atinge resistências entre $50 \mathrm{MPa}$ e $120 \mathrm{MPa}$, e que o UHPFRC está numa faixa de resistência à compressão entre 120 MPa e 800 MPa (VANDERLEI, 2004; VOO; FOSTER, 2010).

Segundo a AFGC/SETRA (2013), a principal característica do UHPFRC é a sua elevada resistência à compressão, superior a $150 \mathrm{MPa}$. Contudo, em 2016, a norma francesa AFNOR NF P 18-470 passou a incluir UHPFRC com resistência à compressão superior a $130 \mathrm{MPa}$. Atualmente, pode-se dizer que a resistência à compressão típica do UHPFRC está na faixa de 130 a $200 \mathrm{MPa}$. 
Outra característica prevalecente no UHPFRC é alta resistência à tração e à flexão. Dependendo da quantidade, do tipo e da orientação das fibras, o UHPFRC pode apresentar resistência à tração na faixa de 7 a $15 \mathrm{MPa}$ (FEHLING et al., 2004; GU et al., 2015) e resistência à flexão da ordem de 15 a $40 \mathrm{MPa}$ (FEHLING et al., 2014). Segundo Wang et al. (2015), dependendo da composição, do processo de produção e do procedimento de cura do UHPFRC, as resistências à compressão, à tração e à flexão podem atingir uma faixa de 200 a $800 \mathrm{MPa}$, de 25 a $150 \mathrm{MPa}$ e de 30 a $140 \mathrm{MPa}$, respectivamente.

Segundo Vanderlei (2004), o UHPFRC possui altíssima resistência à compressão e, quando adicionadas fibras de aço à sua composição, também à tração e à flexão. Além de apresentar excelentes propriedades mecânicas, a microestrutura desse concreto é completamente fechada, prevenindo a invasão de qualquer agente agressivo. Tal característica fornece ao material desempenho de ultra-alta durabilidade, o que proporciona maior vida útil com manutenção reduzida (BRANDÃO, 2005).

\subsubsection{Comportamento mecânico}

Existem duas grandes motivações para compreender o comportamento mecânico dos materiais. Uma delas é otimizar as suas propriedades mecânicas, adequando os tipos e proporções dos componentes constituintes, e a outra é desenvolver modelos constitutivos dos materiais para prever a resposta mecânica dos elementos produzidos a partir deles, tanto em análises analíticas quanto numéricas. Exposto isso, em sequência, é abordado o comportamento à compressão e à tração do UHPC e UHPFRC.

\subsubsection{Comportamento na compressão}

A matriz densa do UHPC e UHPFRC confere ao material uma alta resistência à compressão e também maior rigidez (expressa em módulo de elasticidade). Em ensaios de compressão uniaxial, o UHPC (ou seja, sem fibras) é caraterizado por um comportamento elástico linear até cerca de $70 \%$ a $80 \%$ da resistência à compressão e módulo de elasticidade geralmente na faixa de 45 a $55 \mathrm{GPa}$. A elevada resistência à compressão do UHPC é acompanhada por um comportamento frágil, observado na forma de uma falha brusca e explosiva (MA et al., 2004; FEHLING et al., 2014; HOANG; FEHLING, 2017). A Figura 2.4 
ilustra um esquema típico da curva tensão-deformação do UHPC em ensaio de compressão uniaxial.

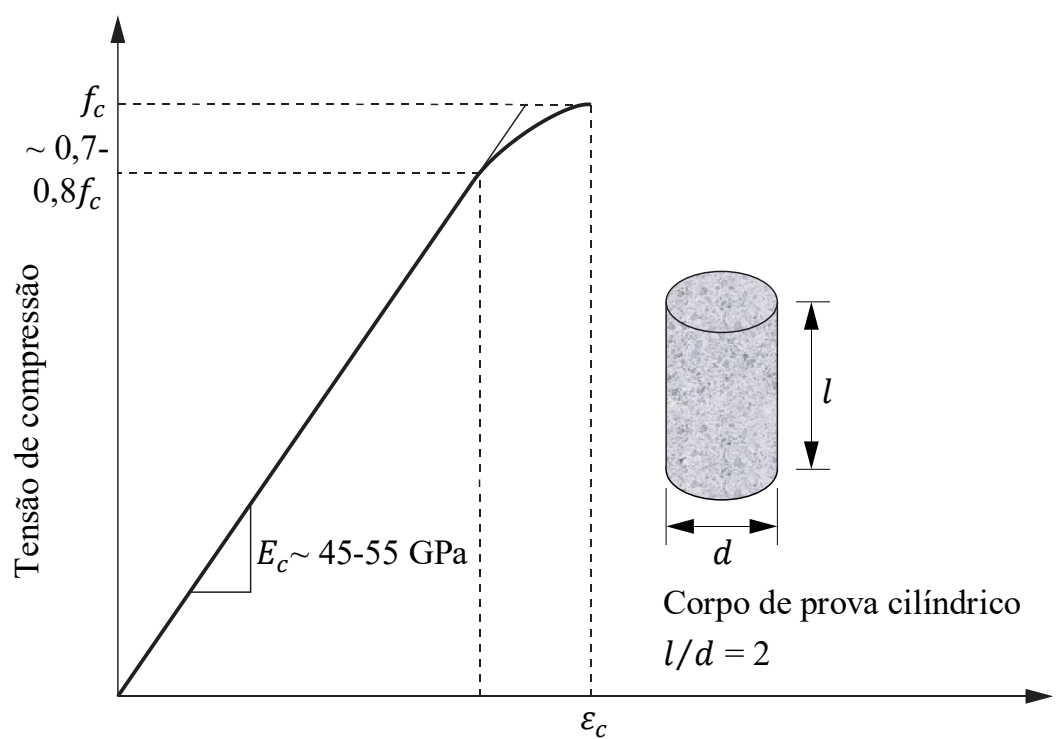

Deformação longitudinal

Figura 2.4 - Curva tensão-deformação do UHPC em ensaio de compressão uniaxial (Fonte: Adaptado de FEHLING et al., 2014)

Segundo Graybeal (2007), a relação entre o módulo de elasticidade e a resistência à compressão do UHPC pode ser expressa pela Equação (2.1). Para Ma (2010), o valor do módulo de elasticidade do UHPC composto por materiais granulares finos pode ser estimado pela Equação (2.2).

$$
\begin{aligned}
& E_{c}=3840 f_{c}^{1 / 2} \\
& E_{c}=8800 f_{c}^{1 / 3}
\end{aligned}
$$

sendo: $E_{c}$ o módulo de elasticidade e $f_{c}$ a resistência à compressão do UHPC em MPa.

A deformação correspondente à resistência à compressão $\left(\varepsilon_{c}\right)$ do UHPC está na faixa de 3,4 a 4,4\% (GRAYBEAL, 2007; FEHLING et al., 2014). Hoang e Fehling (2017) apresentam uma série de equações para a estimar o valor da deformação $\varepsilon_{c}$ por meio da resistência à compressão. O coeficiente de Poisson é semelhante ao do concreto convencional $(v=0,2)$.

A incorporação de fibras de aço no UHPC melhora consideravelmente o comportamento pós-pico na compressão, o UHPFRC passa a exibir um comportamento dúctil, como pode ser observado na Figura 2.5. O trecho ascendente da curva tensão-deformação dificilmente sofre efeito com a incorporação de fibras de aço. Alguns estudos mostram que o UHPFRC com fração volumétrica de fibras de $2 \%$ não apresenta aumento significativo da resistência à compressão e 
do módulo de elasticidade (FEHLING et al., 2014; HOANG; FEHLING, 2017). Por outro lado, o trecho descendente (pós-pico) da curva pode apresentar diferentes inclinações, pois é influenciado por muitos fatores, como a quantidade, geometria e orientação das fibras, e a aderência entre elas e a matriz (Figura 2.5). Por isso, a determinação do trecho descendente da curva tensão-deformação de um determinado UHPFRC geralmente requer ensaios laboratoriais.

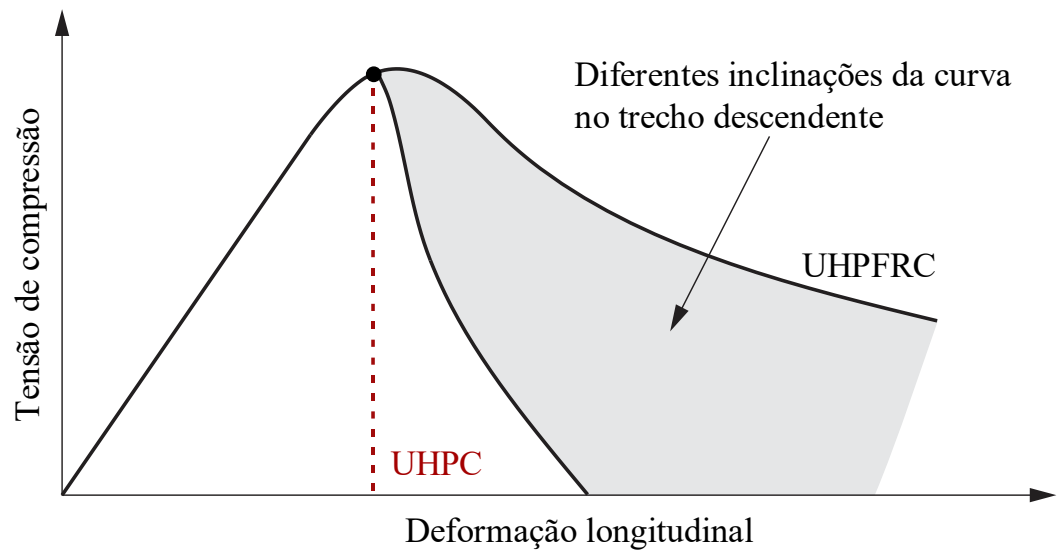

Figura 2.5 - Curvas tensão-deformação na compressão do UHPC e UHPFRC

(Fonte: Adaptado de FEHLING et al., 2004)

\subsubsection{Comportamento na tração}

\section{- Tração uniaxial ou tração direta}

O comportamento do UHPC e UHPFRC na tração pode ser determinado diretamente por ensaios de tração uniaxial. Segundo Fehling et al. (2014), ensaios com corpos de prova não entalhados são adequados para determinar a resistência à tração e a curva tensão-deformação. Já ensaios com corpos de prova entalhados são mais adequados para determinar a curva tensãoabertura de fissura e a energia de fratura.

O UHPC apresenta um comportamento frágil na tração, o que dificulta medir o trecho descendente da curva tensão-deformação ou tensão-abertura de fissura. A incorporação de fibras de aço proporciona ao UHPFRC um comportamento dúctil e melhoria na resistência à tração, como pode ser observado na Figura 2.6. Até a primeira fissura, a matriz resiste às tensões de tração, e o comportamento é caracterizado como elástico linear, tanto para o UHPC quanto para o UHPFRC. Após a primeira fissura, as fibras são ativadas e atuam como ponte de transferência de tensões por essa fissura (Figura 2.7), redistribuindo as tensões de tração nas 
regiões adjacentes e, consequentemente, provocando múltiplas fissuras na matriz. Esse fenômeno inibe a propagação das fissuras e proporciona um aumento da tensão de tração (comportamento de enrijecimento). Quando a tensão de tração atinge seu valor máximo, uma macrofissura se forma e se inicia o arrancamento das fibras da matriz, provocando a queda da tensão (comportamento de suavização). Dependendo da quantidade, geometria e orientação das fibras, e da aderência entre elas e a matriz, a capacidade de transferência de tensões das fibras pode ser reduzida, e o UHPFRC pode apresentar apenas o comportamento de suavização após a primeira fissura (Figura 2.6). Assim, do mesmo modo que na compressão, para um determinado UHPFRC, a previsão do comportamento tensão-deformação na tração geralmente requer ensaios laboratoriais (GRAYBEAL; BABY, 2013; FEHLING et al., 2014).

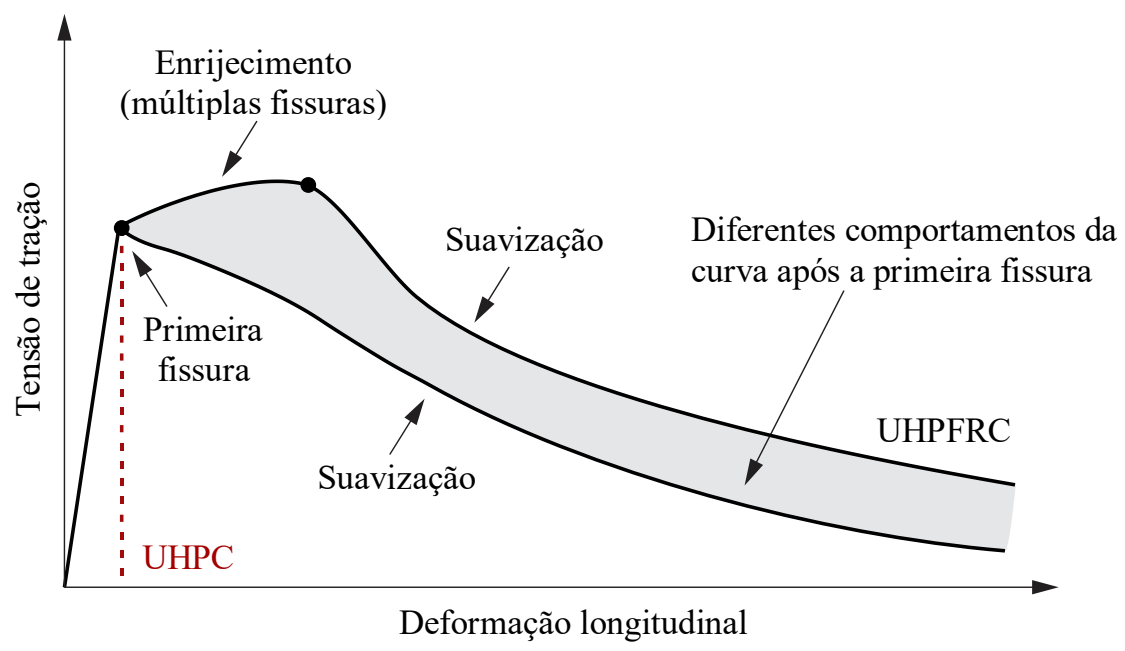

Figura 2.6 - Curvas tensão-deformação na tração do UHPC e UHPFRC

(Fonte: Adaptado de WILLE et al., 2014a)

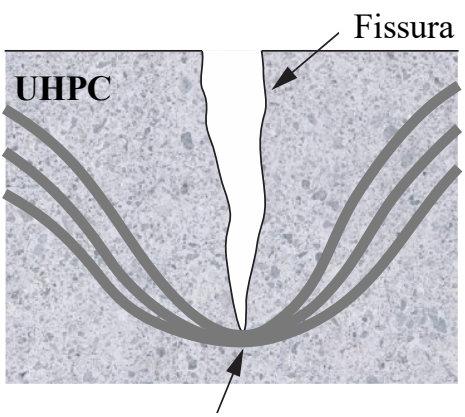

Concentração de tensões na frente de propagação da fissura

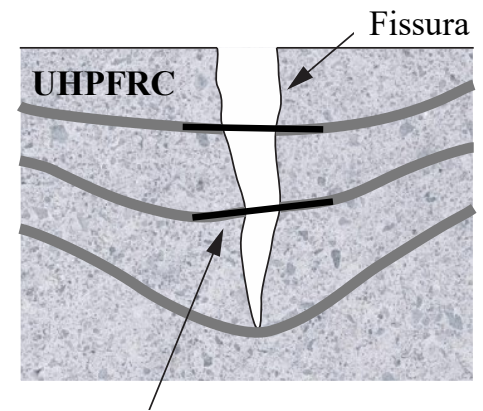

Fibras como ponte de transferência de tensões (menor concentração de tensões)

Figura 2.7 - Fibras atuando como ponte de transferência de tensões pela fissura (Fonte: Adaptado de NUNES; AGOPYAN, 1998) 
Em ensaios de tração uniaxial, a energia de fratura do UHPFRC vem sendo quantificada em corpos de prova não entalhados, apesar de ser mais adequado em corpos de prova entalhados (FEHLING et al., 2004; WILLE, NAAMAN, 2010; XU; WILLE, 2015). Nesse caso, a energia de fratura corresponde à área sob a curva tensão-deslocamento longitudinal, excluindo a área correspondente à região elástica linear (energia elástica), como mostrado na Figura 2.8. Segundo Fehling et al. (2004), a energia de fratura para o UHPC é da ordem de 0,05 N/mm. Para o UHPFRC, está na faixa 8 a 20 N/mm, dependendo da quantidade, do tipo e da orientação das fibras.

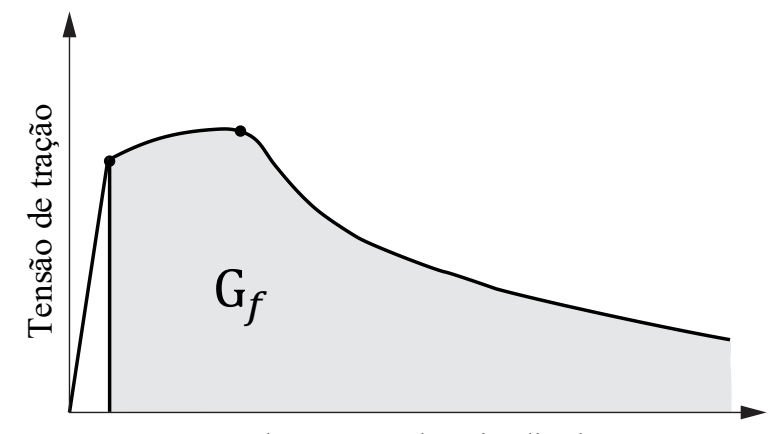

Deslocamento longitudinal

(a)

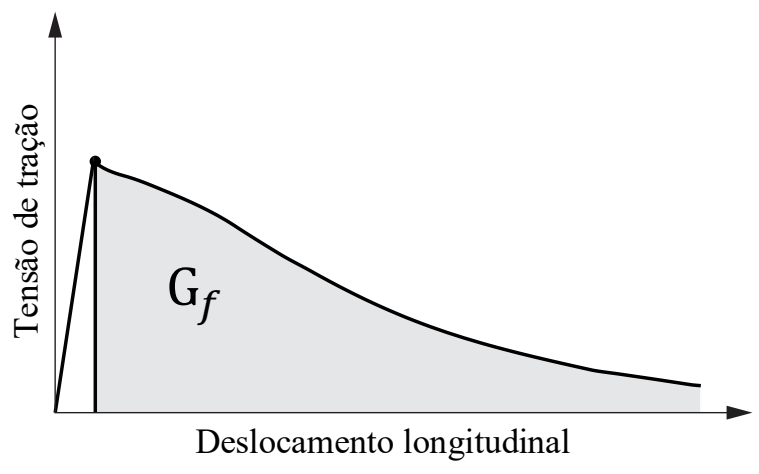

(b)

Figura 2.8 - Energia de fratura $\left(G_{f}\right)$ em ensaios de tração uniaxial sem entalhe: (a) UHPFRC com comportamento de enrijecimento e suavização e (b) UHPFRC com comportamento de suavização (Fonte: Adaptado de XU; WILLE, 2015)

\section{- Flexão}

Ensaios de flexão são normalmente escolhidos para determinar o comportamento do UHPC e UHPFRC na tração, pois podem ser mais facilmente realizados com uma máquina de ensaio de compressão e não requerem nenhum arranjo elaborado para a aplicação da força, diferentemente dos ensaios de tração uniaxial (tração direta).

Segundo Fehling et al. (2014) e a AFGC/SETRA (2013), ensaios de flexão a quatro pontos em prismas não entalhados são indicados para determinar a resistência à tração na flexão. Já ensaios de flexão a três pontos com entalhe são mais adequados para determinar a curva tensão-abertura de fissura e a energia de fratura. No caso da quantificação da resistência à flexão (máxima tensão de flexão), tanto ensaios a quatro pontos (ASTM C1609/C1609M-12, 2012) quanto ensaios a três pontos (RILEM TC 162-TDF, 2002) podem ser empregados. 
Assim como na tração uniaxial, o UHPC apresenta um comportamento frágil na flexão e, com a incorporação de fibras de aço, o UHPFRC passa a exibir um comportamento dúctil. A Figura 2.9 apresenta as curvas força-deslocamento vertical no meio do vão para o UHPC e UHPFRC, típicas de ensaios de flexão. A força aumenta linearmente até a primeira fissura, tanto para o UHPC quanto para o UHPFRC. Após a primeira fissura, o UHPFRC apresenta um comportamento de enrijecimento, ou seja, ocorre um aumento da força por conta da atuação das fibras como ponte de transferência de tensões pelas fissuras. Em sequência, a queda da força, provocada pelo surgimento de uma macrofissura, caracteriza o comportamento de suavização. Dependendo da quantidade, geometria e orientação das fibras, e da aderência entre elas e a matriz, o UHPFRC pode apresentar um comportamento de suavização após a primeira fissura (Figura 2.9) (NGUYEN et al., 2013; WU et al., 2016b; REN et al., 2018).

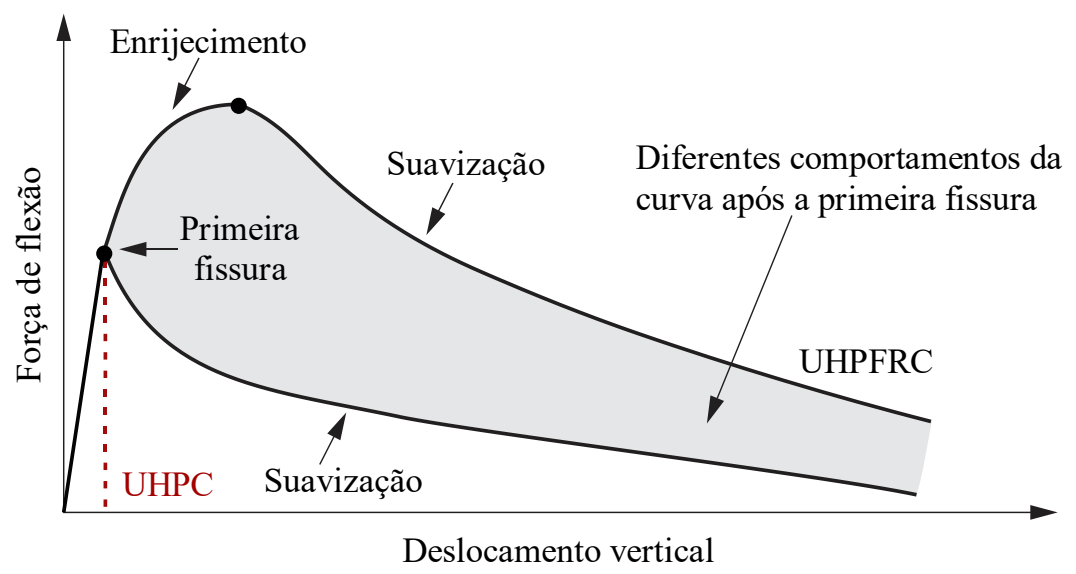

Figura 2.9 - Curvas força-deslocamento vertical na flexão do UHPC e UHPFRC (Fonte: Adaptado de REN et al., 2018)

Em ensaios de flexão a quatro pontos em prismas não entalhados, a resistência à tração na flexão do UHPC e UHPFRC é determinada por meio da força correspondente à perda de linearidade (primeira fissura, ver Figura 2.9) da curva força-deslocamento vertical no meio do vão (AFGC/SETRA, 2013). Em geral, a resistência à tração na flexão é maior que a resistência à tração uniaxial. Segundo a AFGC/SETRA (2013), a resistência à tração uniaxial pode ser estimada aplicando um fator de correção sobre a resistência à tração na flexão. Esse fator leva em consideração o efeito de escala.

É importante destacar que o comportamento do UHPC e UHPFRC na flexão é bastante influenciado pelo efeito de escala. Fehling et al. (2014) relatou que a resistência à tração na flexão do UHPC em prismas de $40 \times 40 \times 160 \mathrm{~mm}$ atingiu uma faixa de 13 a $17 \mathrm{MPa}$, enquanto a mesma composição só atingiu valores de 7 a $10 \mathrm{MPa}$ para prismas de $150 \times 150 \times 700 \mathrm{~mm}$. 
Nguyen et al. (2013) investigou o comportamento do UHPFRC na flexão para três tamanhos diferentes de prismas. Para uma composição com $2 \%$ de fibra de aço, as resistências à tração na flexão foram de 14,3 MPa, 11,4 MPa e 10,6 MPa para os seguintes tamanhos de prismas: 50 $\times 50 \times 150 \mathrm{~mm}, 100 \times 100 \times 300 \mathrm{~mm}$ e $150 \times 150 \times 450 \mathrm{~mm}$, respectivamente. Portanto, um efeito de escala significativo pode ser observado sobre o comportamento à flexão.

Segundo Máca et al. (2013) e Ren et al. (2018), em ensaios de flexão a três pontos em prismas entalhados, a energia de fratura do UHPC e UHPFRC pode ser determinada por meio da curva força-deslocamento vertical no meio do vão, conforme proposto pelo RILEM 50 FMC (1985), que define energia de fratura como sendo a energia necessária para formar uma fissura de área unitária.

\section{- Compressão diametral ou tração indireta}

O ensaio de compressão diametral, realizado conforme a ABNT NBR 7222 (2011) ou a ASTM C496/C496M-04 (2004), pode ser utilizado para determinar indiretamente a resistência à tração do concreto. Para o UHPC, segundo Fehling et al. (2014), a resistência à tração por compressão diametral (máxima tensão) corresponde aproximadamente à resistência à tração uniaxial. Em contrapartida, para o UHPFRC, a tensão máxima obtida no ensaio de compressão diametral não pode ser correlacionada com a sua resistência à tração, pois a presença das fibras provoca um aumento da tensão após a falha do material (HASSAN et al., 2012). Assim, alguns estudos, como Graybeal (2005) e Shafieifar et al. (2017), sugerem que a resistência à primeira fissura na compressão diametral pode ser utilizada para caracterizar a resistência à tração do UHPFRC. A tensão correspondente à primeira fissura pode ser determinada pela descontinuidade presente na curva tensão-deslocamento lateral, como mostrado na Figura 2.10.

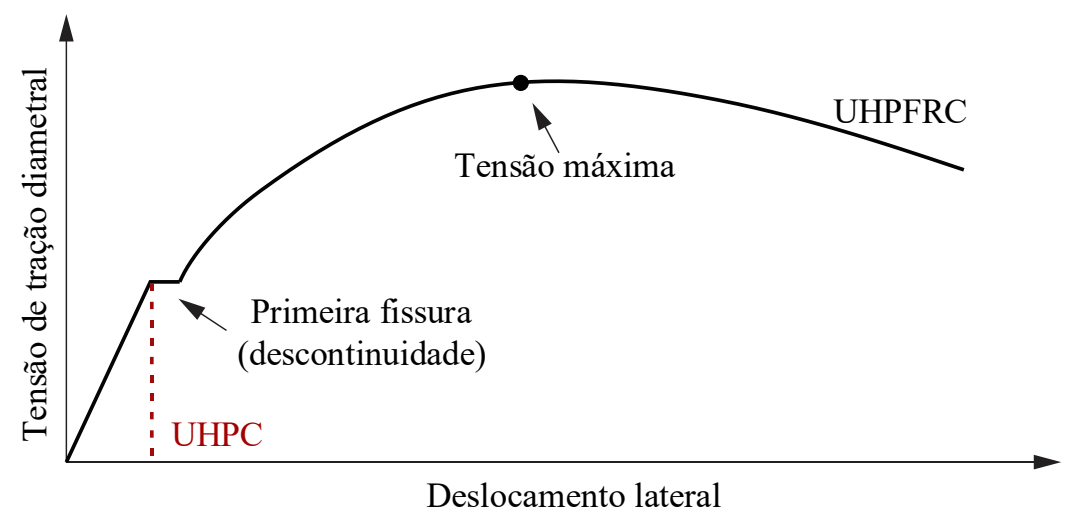

Figura 2.10 - Curva tensão-deslocamento lateral na compressão diametral do UHPFRC

(Fonte: Adaptado de GRAYBEAL, 2005) 
Pode ser observado na Figura 2.10 que o UHPC apresenta um comportamento frágil na compressão diametral, ou seja, com o surgimento da primeira fissura, ocorre a falha do material (divisão do corpo de prova em duas partes). A incorporação de fibras de aço proporciona ao UHPFRC um comportamento dúctil; assim, após a primeira fissura, é observado um aumento significativo da tensão. Porém, pode-se dizer que a falha por compressão diametral do UHPFRC ocorre no instante da primeira fissura; após esse ponto, o concreto começa a sofrer esmagamento, e o ganho de tensão está mais relacionado à tenacidade do que ao aumento da resistência à tração (SHAFIEIFAR et al., 2017).

\subsubsection{Aplicações}

Nos últimos anos, devido ao elevado desempenho do UHPFRC, suas aplicações estão aumentando na França, Alemanha, Suíça, Japão, Coreia do Sul, Canadá e Estados Unidos. Entretanto, ainda é um desafio torná-lo uma opção viável tecnologicamente e economicamente para a construção civil em muitos outros países, como no Brasil (GU et al., 2015; TUTIKIAN et al., 2011).

O alto custo do UHPFRC está relacionado principalmente aos altos preços da fibra de aço e do aditivo superplastificante, além do custo adicional para realizar a cura térmica, se necessária. Em particular, a redução da quantidade de fibras pode ser uma das soluções mais promissoras para diminuir o custo do UHPFRC, pois o valor das fibras de aço é consideravelmente elevado em comparação aos outros componentes desse concreto. Segundo Yoo et al. (2016a), 2\% em volume de fibras de aço lisas e curtas ocupam aproximadamente $33 \%$ do custo total do UHPFRC.

Entre as diversas aplicações do UHPFRC, destaca-se a sua utilização em estruturas de concreto pré-moldado, pois as suas características, como a altíssima resistência à compressão e a elevada durabilidade, possibilitam a redução das seções transversais dos elementos estruturais (Figura 2.11), resultando em estruturas mais esbeltas e mais leves - facilidade de produção, transporte e montagem - com baixo custo de manutenção e maior vida útil (EL DEBS, 2000; CHRIST, 2014; SHI et al., 2015). 


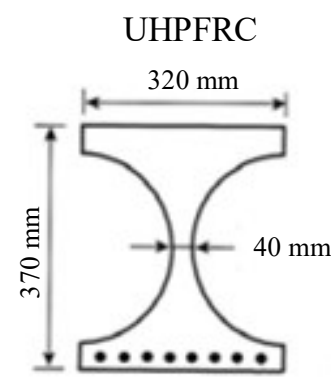

Peso: $140 \mathrm{~kg} / \mathrm{m}^{2}$

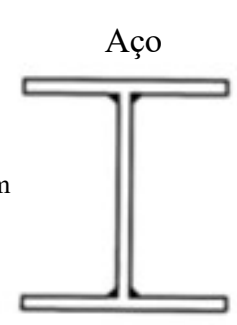

$112 \mathrm{~kg} / \mathrm{m}^{2}$

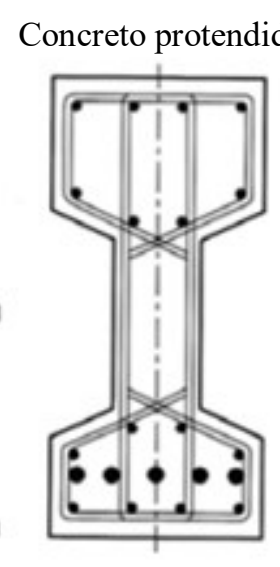

$467 \mathrm{~kg} / \mathrm{m}^{2}$

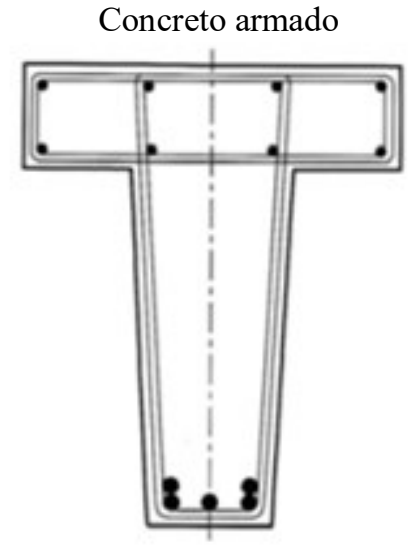

$560 \mathrm{~kg} / \mathrm{m}^{2}$

Figura 2.11 - Seções transversais de elementos estruturais com mesma capacidade portante: UHPFRC, aço, concreto protendido e concreto armado

(Fonte: WALRAVEN, 1999 apud TUTIKIAN et al., 2011)

O UHPFRC, em particular, tem sido atraente para uso em elementos estruturais em que a flexão prevalece, devido à sua excelente ductilidade pós-fissuração sob tensão de tração na flexão. Assim, o emprego do UHPFRC em vigas pré-moldadas é bastante satisfatório, pois se sabe que vigas são elementos estruturais projetados para trabalhar predominantemente à flexão (YANG et al., 2010; YOO; YOON, 2015; YOO et al., 2016b; SINGH et al., 2017; HASGUL et al., 2018; YANG et al., 2018). A Figura 2.12 e a Figura 2.13 são exemplos de aplicação do UHPFRC em vigas pré-moldadas de pontes rodoviárias.
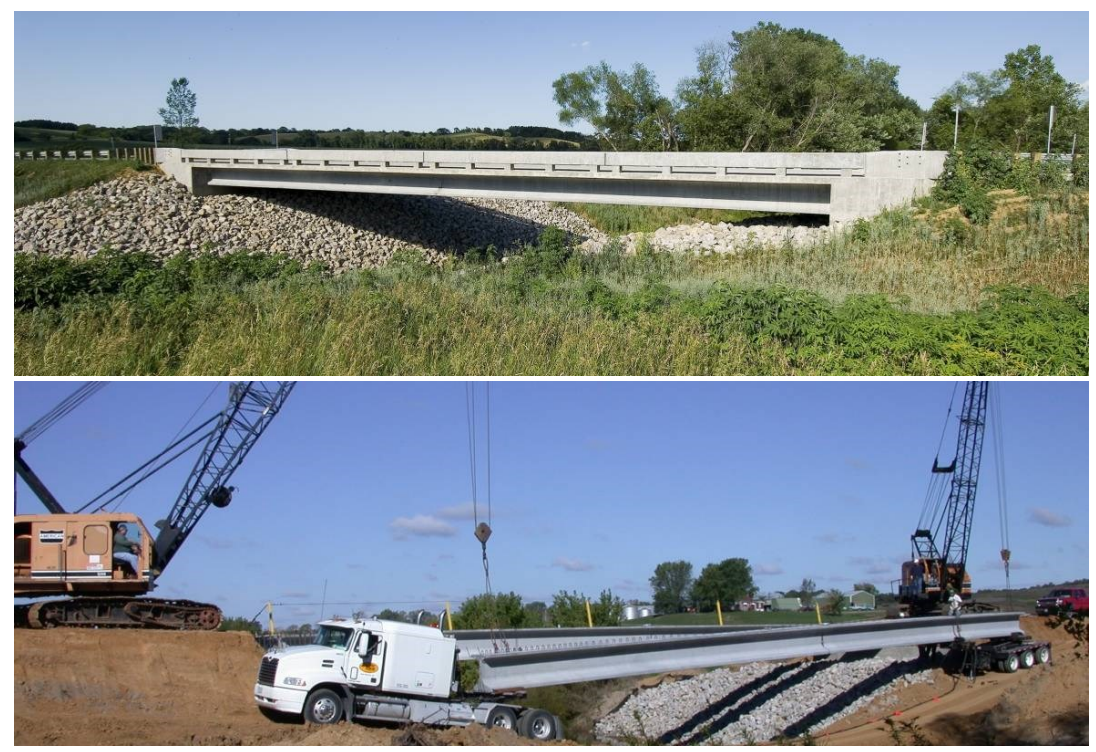

Figura 2.12 - Mars Hill Bridge (EUA): ponte rodoviária composta de vigas pré-moldadas de UHPFRC com 33,5 m de comprimento sem armadura transversal

(Fonte: www.ductal.com) 


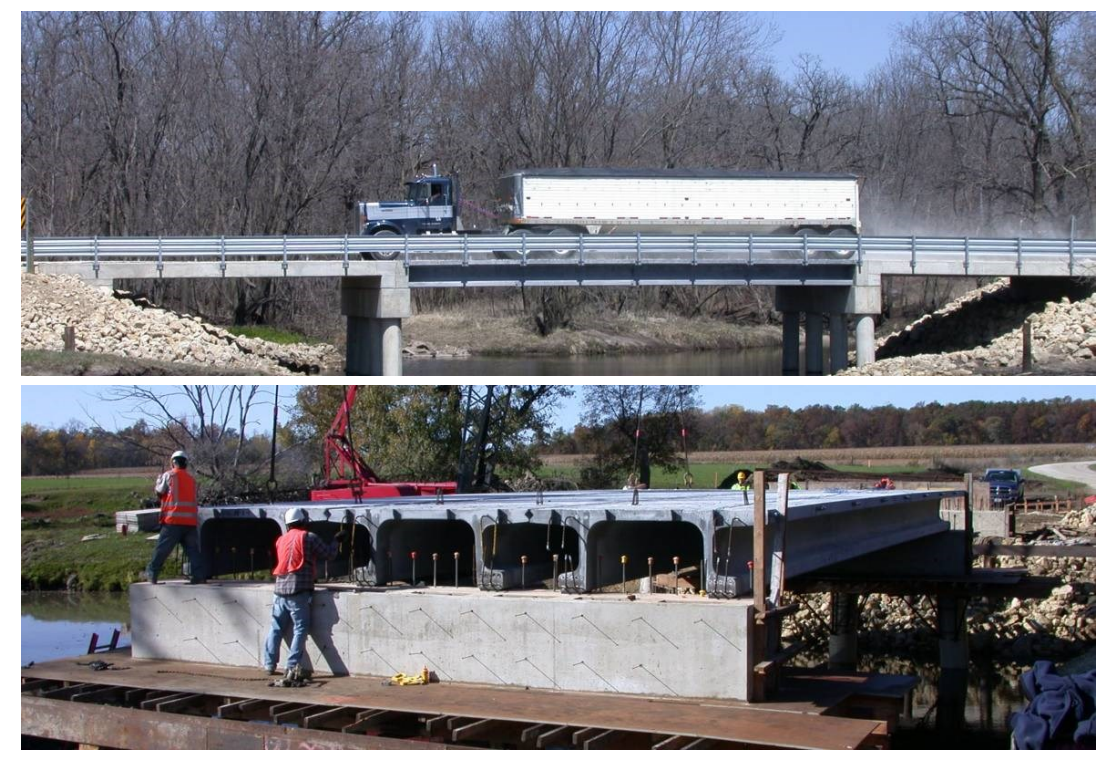

Figura 2.13 - Jakway Park Bridge (EUA): ponte rodoviária composta de vigas pré-moldadas de UHPFRC com 15 metros de comprimento

(Fonte: www.ductal.com)

Para aplicar o UHPFRC em estruturas reais, numerosos estudos foram realizados em muitos países da Europa, Ásia e América de Norte. Em 2002, a primeira recomendação técnica sobre UHPFRC, englobando propriedades do material e projeto estrutural, foi desenvolvida pela Associação Francesa de Engenharia Civil (AFGC/SETRA, 2002). Desde então, várias estruturas de UHPFRC, pontes em especial, foram projetadas e executadas, o que motivou a atualização da recomendação francesa (AFGC/SETRA, 2013) e o desenvolvimento de novas recomendações técnicas, como a recomendação japonesa (JSCE, 2008) e alemã (DAfStb 561, 2008). Em 2016, foram publicadas as duas primeiras normas de UHPFRC na França, AFNOR NF P 18-470 (voltada para produção do material) e AFNOR NF P 18-710 (voltada para projeto estrutural).

Além de aplicações em elementos estruturais, o UHPFRC vem sendo bastante empregado em elementos arquitetônicos, como painéis de fachada, brises, cobogós, marquises e coberturas leves. O elevado desempenho do material permite reproduzir elementos com formas diferenciadas, leves e esbeltos. A Figura 2.14 apresenta alguns exemplos de elementos arquitetônicos produzidos com UHPFRC. 


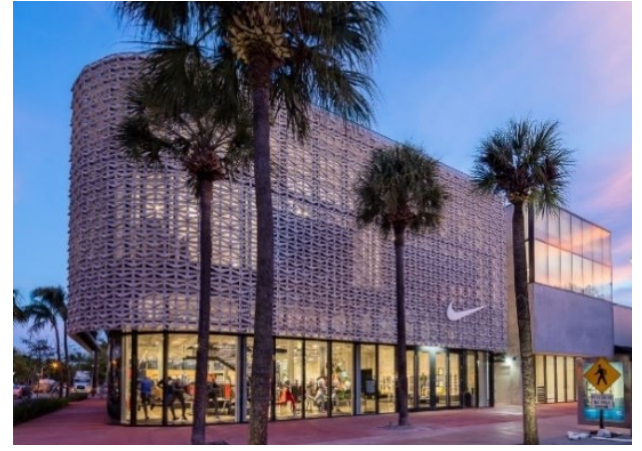

Brise (EUA)

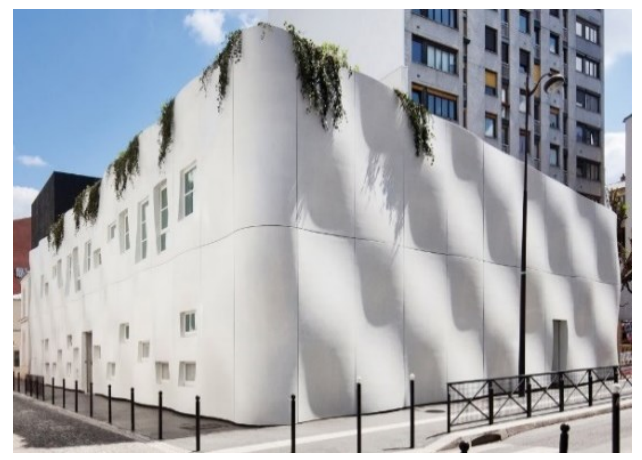

Painel de fachada curvo (França)

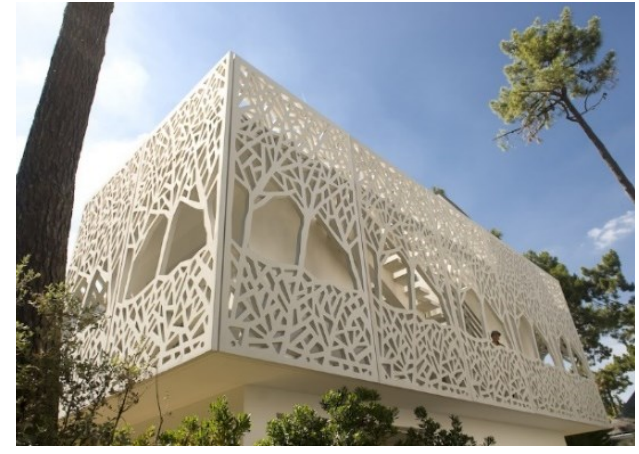

Painel de fachada perfurado (França)

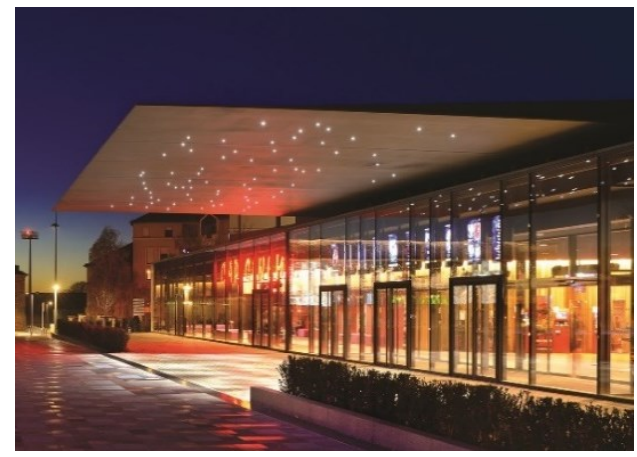

Cobertura leve (França)

Figura 2.14 - Elementos arquitetônicos produzidos com UHPC e UHPFRC

(Fonte: www.ductal.com)

No Brasil, como já exposto, a aplicação do UHPFRC é limitada. Até o momento, o material foi empregado em apenas duas construções localizadas na cidade de São Paulo. A primeira, concluída em 2016, o UHPFRC foi utilizado na produção do painel de fachada do edifício ocupado pelo Escritório de Representação do Ministério das Relações Exteriores (ERESP) (Figura 2.15a). Em 2017, a Casa Japão foi inaugurada contendo em seu exterior um painel de UHPFRC em forma de cobogó (Figura 2.15b). Em termos de elemento estrutural, ainda não há aplicação do UHPFRC no Brasil.

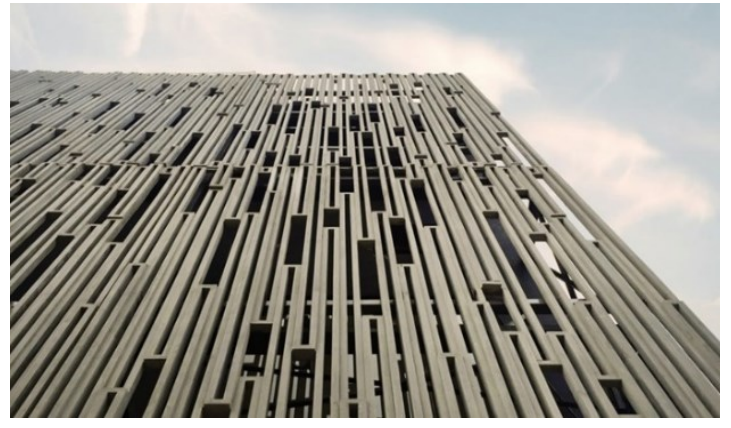

(a)

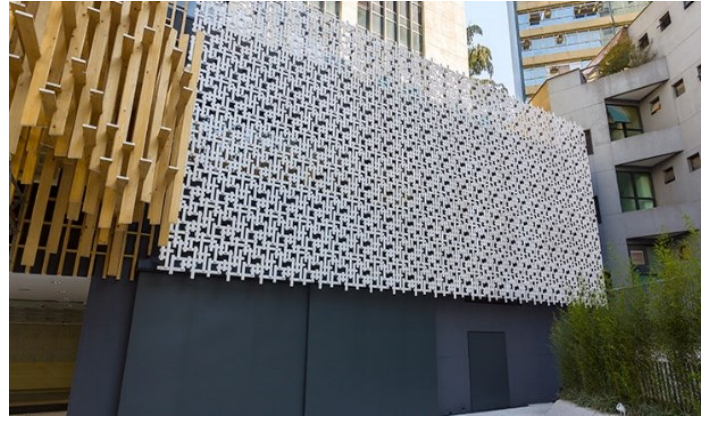

(b)

Figura 2.15 - Elementos arquitetônicos produzidos com UHPFRC no Brasil: (a) painel de fachada perfurado do edifício do ERESP e (b) cobogó da Casa Japão

(Fonte: www.stone.ind.br/ductal) 


\subsection{Orientação e Dispersão das Fibras de Aço}

O UHPC, quando reforçado com fibras de aço (UHPFRC), promove melhorias em algumas de suas propriedades, como aumento da ductilidade, da resistência à tração e da resistência à flexão, como supracitado. Essas melhorias podem ser maximizadas por meio da orientação e dispersão das fibras de aço no concreto.

A distribuição das fibras de aço pode ocorrer em diferentes configurações no concreto. As fibras podem estar orientadas em uma única direção (fibras alinhadas) ou orientadas aleatoriamente (orientação totalmente ou parcialmente aleatória). Com relação à dispersão, as fibras podem se apresentar homogeneamente ou de modo significativamente polarizado no concreto. A Figura 2.16 exemplifica duas diferentes configurações de distribuição das fibras em um plano de corte. Na Figura 2.16a, as fibras estão orientadas preferencialmente em uma única direção e dispersas de forma mais homogênea, enquanto, na Figura 2.16b, as fibras apresentam orientação e dispersão mais aleatória e polarizada, respectivamente.

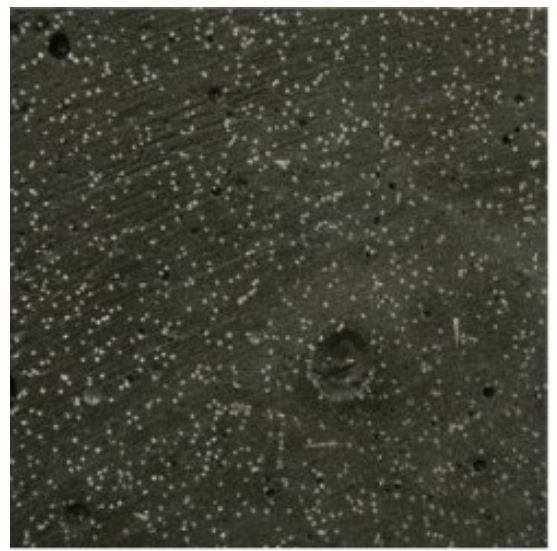

(a)

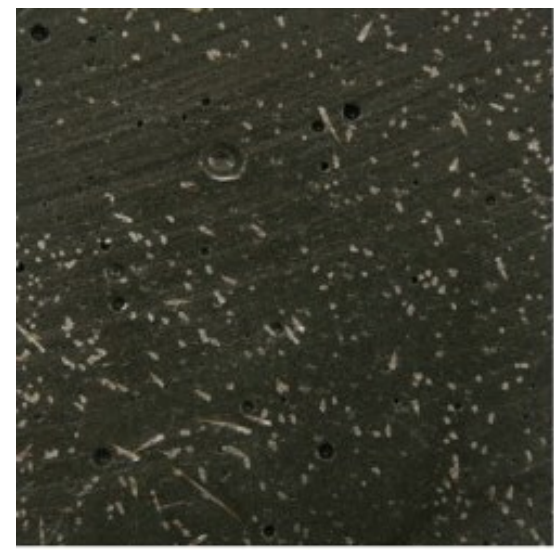

(b)

Figura 2.16 - Exemplos de diferentes configurações de distribuição das fibras no plano: (a) orientação preferencial em uma direção e dispersão homogênea e (b) orientação aleatória e dispersão polarizada (Fonte: KANG; KIM, 2011)

Muitos estudos têm como objetivo investigar as diferentes configurações de orientação e dispersão das fibras e os seus efeitos provocados sobre o desempenho mecânico do UHPFRC. De modo geral, os estudos mostram que a orientação das fibras é o parâmetro que mais influencia os comportamentos à tração e à flexão dos concretos reforçados com fibras. As fibras alinhadas à direção das tensões de tração proporcionam maiores incrementos das resistências à 
tração e à flexão do que aquelas orientadas aleatoriamente no concreto (KANG et al., 2011; KANG; KIM, 2011; 2012; YOO et al., 2014; YOO et al., 2015; BOULEKBACHE et al., 2016).

Geralmente, as fibras são consideradas orientadas de forma aleatória e dispersas homogeneamente no concreto, o que possibilita a obtenção de um material com comportamento mais homogêneo e isotrópico. No entanto, a orientação e a dispersão reais das fibras no UHPFRC são afetadas por muitos fatores, como o tipo de fibra (tamanho e forma), a quantidade de fibras, o tamanho e a geometria da forma, a fluidez e compactação do concreto, e o modo de lançamento do concreto na forma (GETTU et al., 2005; KANG et al., 2011; YOO et al., 2014; DUQUE; GRAYBEAL, 2017).

Grande parte das pesquisas que estudam a orientação e dispersão das fibras em UHPFRC procuram variar um ou mais fatores para verificar a sua influência sobre as configurações de distribuição das fibras. O UHPFRC normalmente apresenta caraterísticas de um concreto autoadensável (CAA). Desse modo, a sua elevada fluidez permite uma melhor dispersão das fibras e favorece o alinhamento delas na direção do fluxo do concreto (WILLE et al., 2014b; BOULEKBACHE et al., 2016). A compactação por vibração do UHPFRC, quando necessária, também provoca uma orientação preferencial das fibras (GETTU et al., 2005). O tamanho e geometria da forma afetam indiretamente a orientação, uma vez que as fibras são forçadas a alinhar-se ao longo das superfícies moldadas (DUPONT; VANDEWALLE, 2005). Quando o UHPFRC é lançado de maneira que flua, as fibras exibem um alinhamento na direção do fluxo do concreto (YOO et al., 2016c).

Segundo Abrishambaf et al. (2017), considerando todos os fatores que afetam a distribuição das fibras, a sua orientação ao longo de uma determinada direção provavelmente ocorrerá, levando a um comportamento anisotrópico do concreto. Assim, é essencial que a distribuição real das fibras no UHPFRC seja estudada e caracterizada.

\subsubsection{Caracterização da orientação e dispersão das fibras}

As características de distribuição das fibras, ou seja, as configurações de orientação e dispersão, podem ser avaliadas qualitativamente, por meio de análise de imagens (observação visual) e/ou de resultados experimentais (espectroscopia de impedância, indução magnética, resistividade elétrica, entre outros) ou quantitativamente, por meio de análise de imagens com uma abordagem analítica. 
Entre as técnicas disponíveis para avaliar as características de distribuição das fibras no UHPFRC, a análise de imagens é a técnica mais aplicável e confiável, pois possibilita realizar tanto uma apreciação qualitativa quanto quantitativa. As imagens da distribuição das fibras podem ser obtidas por método de ensaio destrutivo, em que as amostras são cortadas e fotografadas com câmera de alta resolução, ou por método de ensaio não destrutivo, como a tomografia computadorizada por raios $\mathrm{X}$.

Os trabalhos de Kang et al. (2011), Kang e Kim (2011; 2012), Wille et al. (2014b), Yoo et al. (2014; 2015; 2016a; 2016c; 2016d), Duque e Graybeal (2017) e Abrishambaf et al. (2017) utilizaram a técnica de análise de imagens por fotografia de alta resolução para avaliar as características de distribuição das fibras no UHPFRC. As amostras de UHPRFC foram cortadas em planos de interesse definidos em cada trabalho, as superfícies foram polidas, e as imagens foram obtidas a partir de fotografias de alta resolução em cada plano de corte. Para detectar as fibras isoladas de outros componentes nos planos de corte, as imagens coloridas RGB foram convertidas em imagens em escala de cinza e, posteriormente, em imagens binárias, conforme a Figura 2.17.

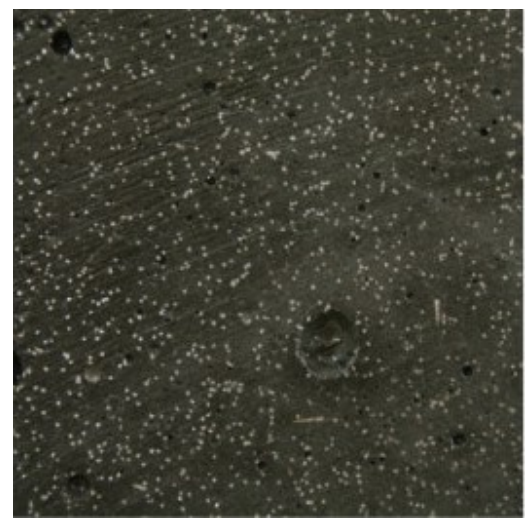

(a)

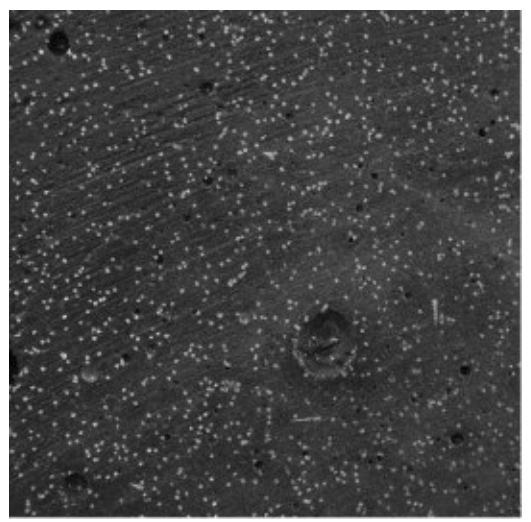

(b)

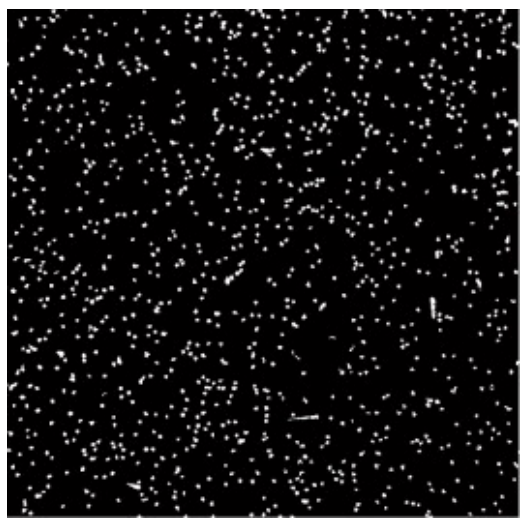

(c)

Figura 2.17 - Conversão de imagem para detecção das fibras no UHPFRC: (a) imagem RGB, (b) imagem em escala de cinza e (c) imagem binária

(Fonte: KANG; KIM, 2011)

Quantitativamente, as características de orientação e dispersão das fibras podem ser avaliadas por meio dos coeficientes de distribuição. Esses coeficientes são baseados nas coordenadas e forma das fibras no plano de corte e podem ser determinados com o auxílio da técnica de processamento e análise de imagens. Segundo Kang et al. (2011), Kang e Kim (2011) e Yoo et al. $(2014 ; 2015 ; 2016$ a), tais coeficientes e outros parâmetros relacionados com a distribuição das fibras, sugeridos por Lee et al. (2009), são: 
- Número de fibras por unidade de área

O número de fibras por unidade de área é expresso pela Equação (2.3).

$$
F_{n}=\frac{n_{f}}{A}
$$

sendo: $n_{f}$ o número total de fibras na imagem (plano de corte) e $A$ é a área da imagem.

\section{- Ângulo de orientação das fibras}

As fibras de aço com forma cilíndrica são projetadas como elipses no plano de corte, com eixo menor igual ao diâmetro da fibra $\left(d_{f}\right)$, como mostra a Figura 2.18a. Assim, a Equação (2.4) pode ser empregada para determinar o ângulo de orientação/inclinação da fibra $(\theta)$, ou seja, o ângulo entre o seu eixo longitudinal e a direção normal ao plano de corte (Figura 2.18b).

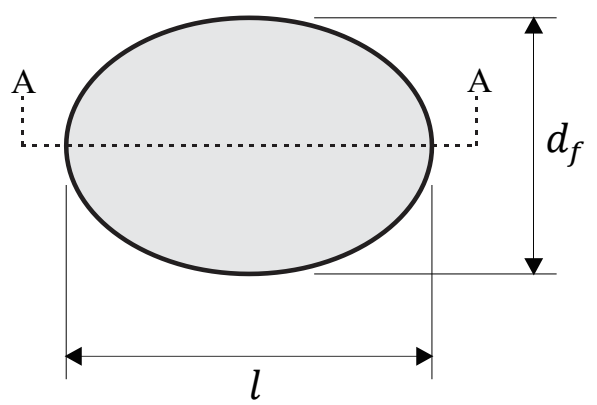

(a)

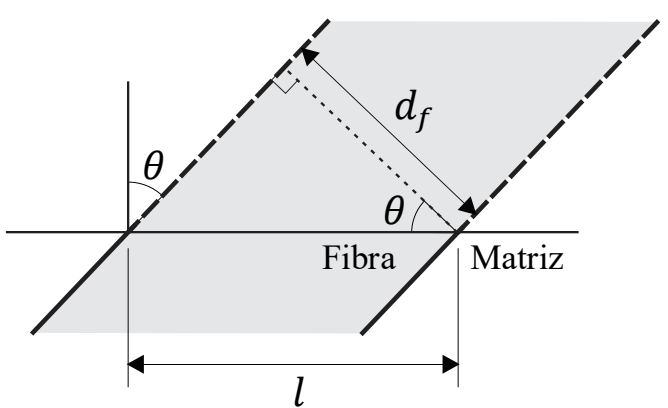

(b)

Figura 2.18 - Representação de uma fibra no plano de corte: (a) vista em planta do plano de corte (fibra projetada como elipse) e (b) vista lateral da seção A-A

(Fonte: Adaptado de YOO et al., 2016a)

$$
\theta=\arccos \left(\frac{d_{f}}{l}\right)
$$

sendo: $d_{f}$ e $l$ o comprimento do menor e do maior eixo da elipse que representa a fibra no plano de corte. $\left(d_{f} / l\right)=1$ indica uma fibra circular, paralela à direção normal ao plano de corte, e $\left(d_{f} / l\right)=0$, uma fibra extremamente alongada, perpendicular à direção normal ao plano de corte. 


\section{- Coeficiente de orientação das fibras}

O coeficiente de orientação das fibras $\left(\eta_{\theta}\right)$ depende de muitos fatores. No entanto, se for considerada, por simplificação, apenas a disposição geométrica das fibras, ele pode ser definido pela Equação (2.5).

$$
\eta_{\theta}=\int_{\theta_{\min }}^{\theta_{\max }} p(\theta) \cos ^{2} \theta d \theta
$$

sendo: $\theta$ o ângulo entre o eixo longitudinal da fibra e a direção normal ao plano de corte e $p(\theta)$ a função de densidade de probabilidade da orientação da fibra (FDP).

Alguns trabalhos, como Wille et al. (2014b), Duque e Graybeal (2017), Abrishambaf et al. (2017) e Zhou e Uchida (2017), fazem uma abordagem diferente desse coeficiente. Nessa abordagem, o coeficiente de orientação, também chamado de número de orientação, pode ser considerado como uma orientação média das fibras, conforme a Equação (2.6).

$$
\eta_{\theta}=\frac{1}{n_{f}} \sum_{i=1}^{n_{f}} \cos \theta_{i}
$$

sendo: $n_{f}$ o número total de fibras na imagem e $\theta$ o ângulo entre o eixo longitudinal da fibra e a direção normal ao plano de corte. $\eta_{\theta}=1$ indica que todas as fibras estão paralelas à direção normal ao plano de corte, e $\eta_{\theta}=0$, que todas as fibras estão perpendiculares à direção normal ao plano de corte. Além disso, $\eta_{\theta}=1 / 2$ para orientação aleatória de fibras no plano (2D) e $\eta_{\theta}=1 / 3$ para orientação aleatória de fibras no espaço (3D).

\section{- Coeficiente de dispersão das fibras}

O coeficiente de dispersão das fibras $\left(\alpha_{f}\right)$ determina o grau em que as fibras estão homogeneamente dispersas no concreto, conforme a Equação (2.7).

$$
\alpha_{f}=\exp \left[-\sqrt{\frac{\sum\left(x_{i}-1\right)^{2}}{n_{f}}}\right]
$$

sendo: $n_{f}$ o número total de fibras na imagem e $x_{i}$ o número de fibras na $i$-ésima unidade, que é uma parcela quadrada alocada à $i$-ésima fibra, assumindo que a dispersão das fibras é perfeitamente homogênea, como mostrado na Figura 2.19. $\alpha_{f}=1$ indica uma dispersão homogênea de fibras, e $\alpha_{f}=0$, uma dispersão significativamente polarizada. 


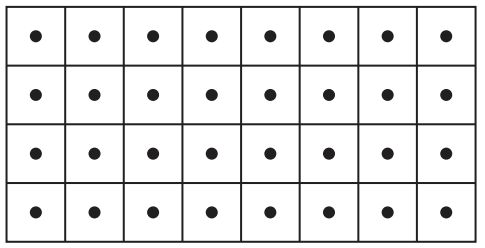

(a)

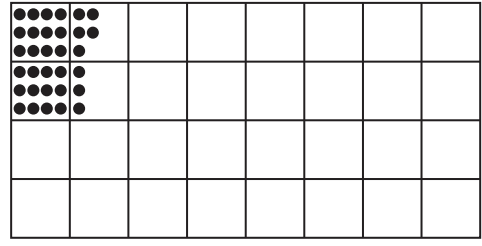

(b)

Figura 2.19 - Imagens de distribuição das fibras em um plano de análise: (a) dispersão perfeitamente homogênea $\left(\alpha_{f}=1\right)$ e (b) dispersão significativamente polarizada $\left(\alpha_{f}=0,041\right)$

(Fonte: Adaptado de LEE et al., 2009)

A Figura 2.20, resultado do trabalho desenvolvido por Kang e Kim (2011), apresenta imagens da distribuição das fibras e seus respectivos coeficientes de distribuição. A partir dessas imagens, é possível avaliar qualitativa e quantitativamente as suas características. Qualitativamente, ou seja, visualmente, as amostras PL, em comparação às amostras TL, apresentaram uma dispersão mais homogênea das fibras. Além disso, a maioria das fibras nas amostras PL tenderam ao alinhamento mais paralelo à direção normal ao plano de corte. Quantitativamente, os coeficientes de orientação $\left(\eta_{\theta}\right)$ e de dispersão $\left(\alpha_{f}\right)$ apresentaram maiores valores para as amostras PL, confirmando a análise qualitativa.

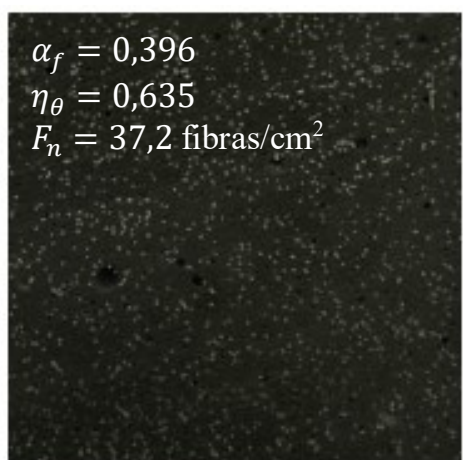

PL1

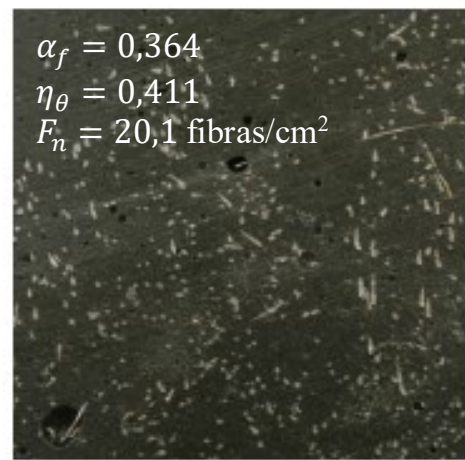

TL1

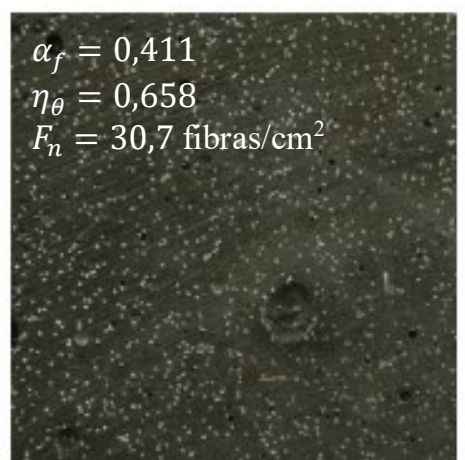

PL2

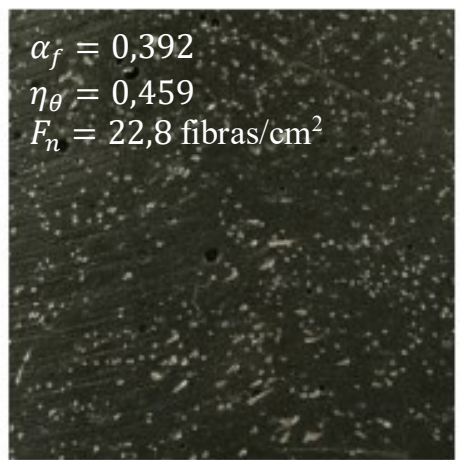

TL2

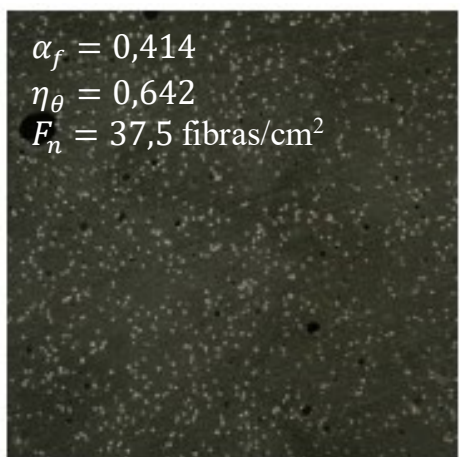

PL3

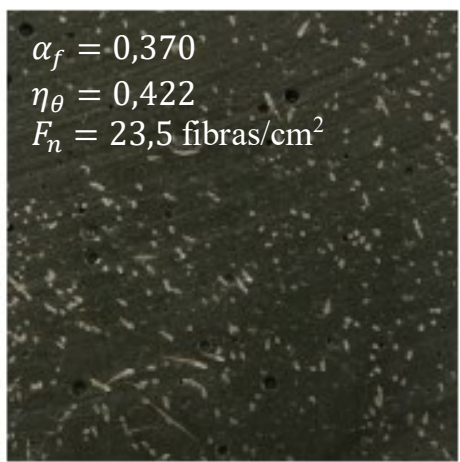

TL3

Figura 2.20 - Imagens dos planos de corte e coeficientes de distribuição das fibras: lançamento do concreto paralelamente (PL) e transversalmente (TL) à direção longitudinal das amostras 1,2 e 3

(Fonte: Adaptado de KANG; KIM, 2011) 
Além dos coeficientes de distribuição, a função de densidade de probabilidade da orientação das fibras (FDP), utilizada na determinação do coeficiente de orientação $\left(\eta_{\theta}\right.$, Equação (2.5)), também pode indicar a configuração de orientação das fibras. A Figura 2.21 apresenta as curvas FDP das amostras PL1 e TL3 (KANG; KIM, 2011). Curvas deslocadas para a esquerda, como a curva da amostra PL1, indicam que as fibras tendem a ser mais paralelas à direção normal ao plano de corte. Inversamente, curvas deslocadas para a direita, como a curva da amostra TL3, implicam um alinhamento mais perpendicular à direção normal ao plano de corte. Além disso, a Figura 2.21 também apresenta curvas FDP idealizadas para uma orientação aleatória de fibras no plano (2D) e no espaço (3D). As curvas FDP reais das amostras PL1 e PL2 são bem discrepantes das curvas idealizadas. Essa discrepância ocorre em razão dos fatores que afetam a distribuição real das fibras (tipo e quantidade de fibras, tamanho e geometria da forma, fluidez, compactação e lançamento do concreto, entre outros).

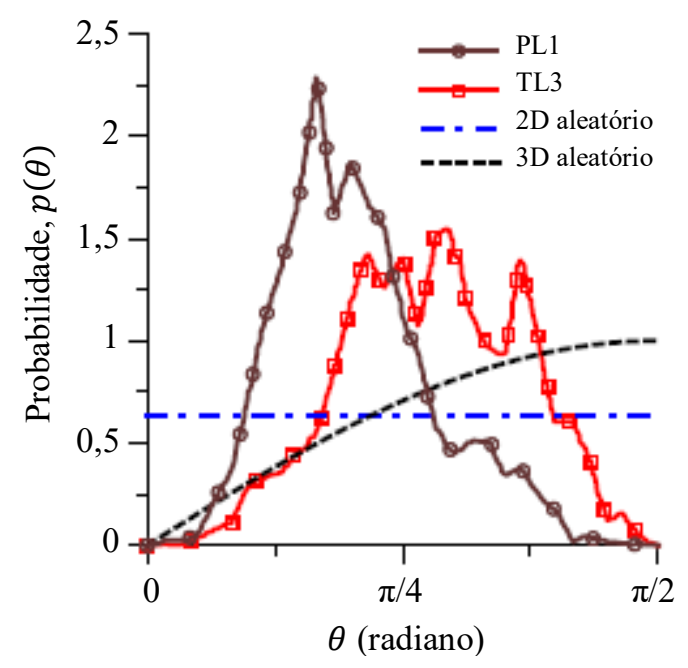

Figura 2.21 - Função de densidade de probabilidade da orientação das fibras: amostras PL1 e TL3 (Fonte: Adaptado de KANG; KIM, 2011)

Como já exposto, as propriedades mecânicas do UHPFRC, principalmente os comportamentos à tração e à flexão, estão diretamente relacionadas à orientação e dispersão das fibras de aço no concreto. Assim, muitas pesquisas, além de avaliar qualitativa e quantitativamente as características de distribuição real das fibras em amostras de UHPFRC, buscam correlacionar os coeficientes de distribuição com as propriedades mecânicas desse concreto. De modo geral, amostras com maiores coeficientes de orientação $\left(\eta_{\theta}\right)$ e de dispersão $\left(\alpha_{f}\right)$ nos planos de fissuração apresentam maiores resistências à tração e à flexão. Os maiores valores de $\eta_{\theta}$ e $\alpha_{f}$ indicam que a fibras estão mais alinhadas à direção das tensões de tração e 
dispersas de forma mais homogênea, o que favorece o desempenho do UHPFRC na tração e na flexão (KANG et al., 2011; KANG; KIM, 2011; 2012; WILLE et al., 2014b; YOO et al., 2014; YOO et al., 2015; YOO et al., 2016a; 2016c, ABRISHAMBAF et al., 2017; DUQUE; GRAYBEAL, 2017; ZHOU; UCHIDA, 2017).

É importante ressaltar que, quando a técnica de análise de imagens é realizada com o propósito de correlacionar as características de orientação e dispersão das fibras com as propriedades mecânicas à tração e à flexão do UHPFRC, o plano de corte é realizado o mais próximo possível do plano de fissuração e perpendicular à direção das tensões de tração. Wille et al. (2014b) recomendam que o plano de análise seja cortado a uma distância de 1,5 vezes o comprimento da fibra da fissura principal, evitando, assim, fibras faltantes que foram retiradas durante o ensaio. Caso contrário, quando se deseja apenas determinar e avaliar as características de orientação e dispersão das fibras em amostras de UHPFRC, a análise de imagens em diferentes planos de corte é válida e interessante para verificar as configurações de distribuição das fibras ao longo das amostras, como realizado por Barnett et al. (2010), Kang et al. (2011) e Zhou e Uchida (2017).

Algumas pesquisas (KANG et al., 2011; KANG; KIM, 2011; 2012; WILLE et al., 2014b; ABRISHAMBAF et al., 2017) também propõem modelos analíticos para prever o comportamento mecânico à tração ou à flexão do UHPFRC, levando em consideração as características de distribuição das fibras. Kang et al. (2011) propuseram uma formulação para estimar a resistência à flexão a partir do coeficiente de orientação da fibra $\left(\eta_{\theta}\right)$ obtido por análise de imagens. As resistências estimadas representaram bem os resultados experimentais. No mesmo estudo, foi estimada também a resistência à flexão assumindo uma orientação aleatória das fibras, ou seja, um coeficiente de orientação idealizado $\left(\eta_{\theta}=1 / 2\right)$. Nesse caso, observou-se uma diferença notável entre as resistências estimadas e experimentais, o que implica que a simples suposição de uniformidade das fibras, isto é, orientação aleatória e dispersão homogênea, pode levar a um erro considerável na predição do comportamento mecânico do UHPFRC. Isso corrobora, portanto, a importância de estudar a orientação e dispersão reais das fibras em elementos produzidos com esse concreto. 


\subsection{Comportamento de Arrancamento das Fibras de Aço}

Além da orientação e dispersão das fibras, as propriedades do UHPFRC também são muito influenciadas pela interface fibra/matriz. O conhecimento do comportamento interfacial é de fundamental importância para bem compreender e modelar o comportamento mecânico do concreto.

Nas últimas décadas, pesquisas foram realizadas para investigar o comportamento interfacial entre a fibra e a matriz por meio de ensaios de arrancamento da fibra (NAAMAN; NAJM, 1991; NAAMAN et al., 1991a; 1991b; CUNHA, 2010; DENG et al., 2010). Recentemente, com o desenvolvimento do UHPFRC, várias pesquisas dedicaram-se especificamente a estudar o comportamento de arrancamento das fibras de aço em matrizes de UHPFRC (LEE et al., 2010; WILLE; NAAMAN, 2012; YOO et al., 2013; 2017; PARK et al., 2014; TAI et al., 2016; XU et al., 2016; MENG; KHAYAT, 2016; WU et al., 2018).

Diversas configurações de ensaio foram desenvolvidas para obter a resposta de arrancamento das fibras, expressa por força de arrancamento-deslizamento da fibra. Segundo Lee et al. (2010), o ensaio de arrancamento pode ser classificado de acordo com o número de fibras (ensaio de fibra única ou de múltiplas fibras) e de acordo com o embutimento da fibra na matriz (ensaio unilateral ou bilateral), como apresentado na Figura 2.22.

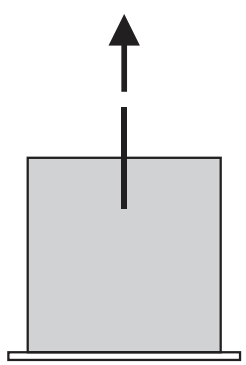

(a)

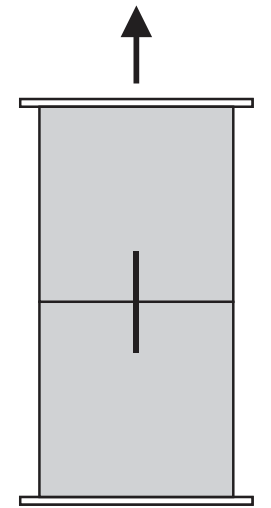

(b)

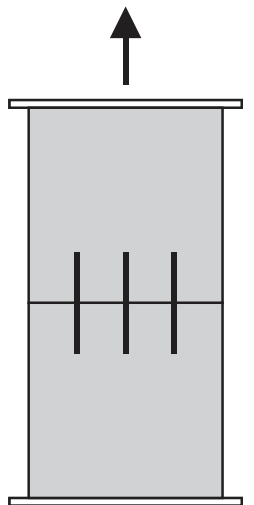

(c)

Figura 2.22 - Configurações de ensaio de arrancamento da fibra: (a) ensaio unilateral de fibra única, (b) ensaio bilateral de fibra única e (c) ensaio bilateral de múltiplas fibras 
Até o momento, ainda não foi estipulada uma configuração padrão. Porém, o ensaio de arrancamento unilateral de fibra única (Figura 2.22a) é o mais realizado devido à sua simplicidade de execução. Nesse ensaio, cuja configuração é apresentada na Figura 2.23, a fibra de aço é incorporada à matriz cimentícia com um comprimento de embutimento estabelecido $\left(L_{E}\right)$, e o deslizamento da fibra (s) é medido ao passo em que a força de arrancamento $(F)$ é aplicada na extremidade livre da fibra. Para tanto, são necessários equipamentos capazes de fixar a matriz e a extremidade livre da fibra, além de um transdutor de deslocamento (LVDT) ou laser para registrar o deslizamento.
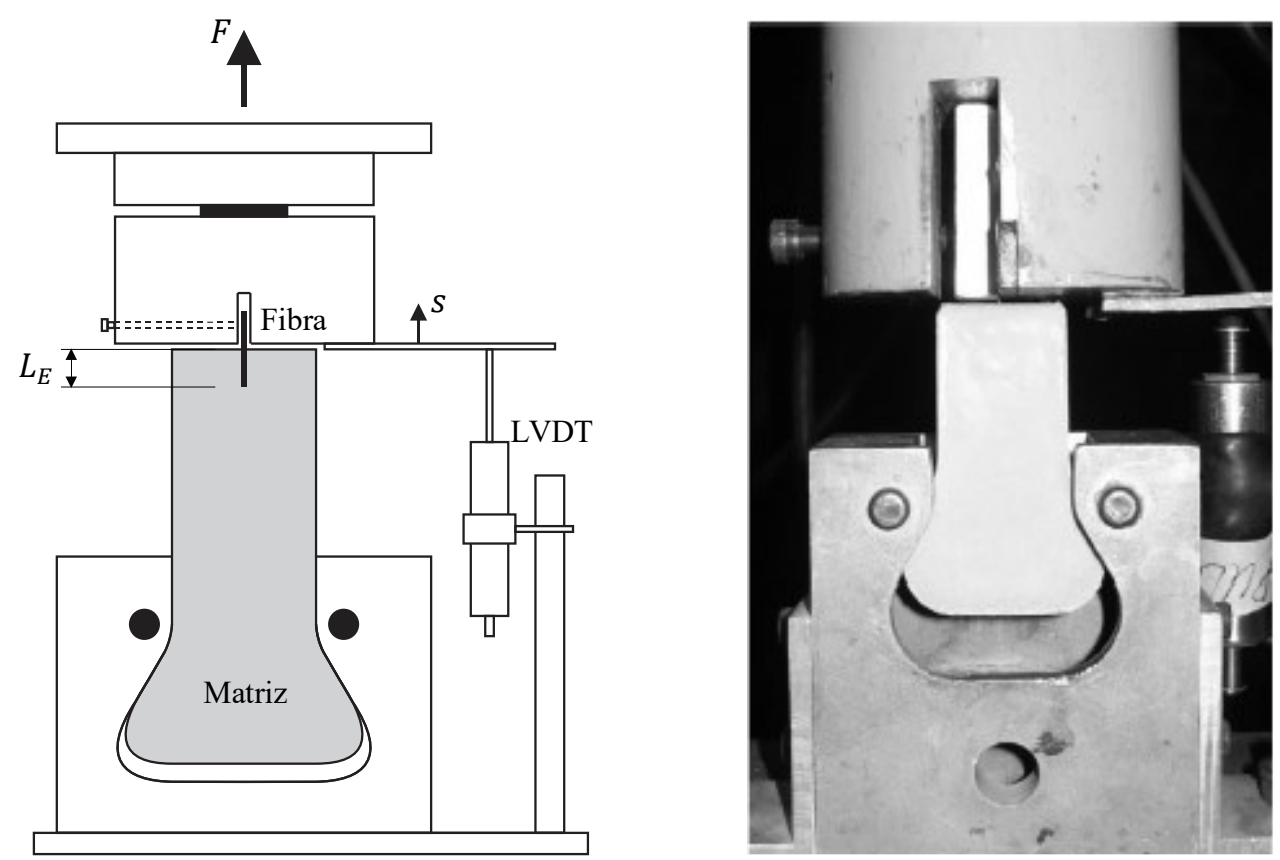

Figura 2.23 - Configuração de ensaio de arrancamento unilateral de fibra única

(Fonte: Adaptado de WILLE; NAAMAN, 2012)

\subsubsection{Mecanismo de arrancamento da fibra de aço lisa}

O comportamento de arrancamento da fibra em matrizes cimentícias envolve a ação combinada de vários mecanismos de aderência. Para Cunha (2010), o comportamento geral de uma fibra aço lisa, comumente utilizada no UHPFRC, alinhada em relação à força aplicada pode ser descrito como a combinação de dois mecanismos: adesão (aderência química) e atrito (aderência física). A adesão é o primeiro mecanismo a ser ativado durante o processo de arrancamento. Durante essa fase inicial, as deformações da fibra e da matriz são compatíveis; logo, a interface fibra/matriz não sofre nenhum dano. Com a perda da aderência por adesão, 
ocorre o descolamento da fibra, e as tensões de atrito são geradas devido ao atrito e ao processo de compactação da interface simultaneamente ao deslizamento da fibra dentro da matriz.

Segundo Lee et al. (2010), o comportamento típico de arrancamento da fibra de aço lisa e alinhada em uma matriz de UHPFRC (Figura 2.24) pode ser dividido em três fases:

- Primeira fase (região perfeitamente aderida): inicialmente, prevalece a aderência por adesão. Assim, existe uma interface intacta (não danificada) entre a fibra e a matriz, e o trecho ascendente linear $\mathrm{AB}$ representa apenas uma pequena parcela do deslizamento total;

- Segunda fase (região parcialmente descolada): com o aumento da força de arrancamento, a aderência por adesão ao longo da interface é parcialmente danificada, provocando o descolamento da fibra e o surgimento da tensão de atrito. Dessa forma, a tensão de atrito da zona descolada trabalha em conjunto com a tensão de adesão da zona intacta. A não linearidade do trecho ascendente $\mathrm{BC}$ indica a propagação de fissuras interfaciais (danificação da interface); e

- Terceira fase (região totalmente descolada): quando a força máxima é atingida (ponto C) ocorre a descolagem completa da fibra e, em sequência, o seu arrancamento da matriz (trecho $\mathrm{CD}$ ), prevalecendo, assim, a aderência por atrito.

Ressalta-se que as características das fibras de aço comumente utilizadas no UHPFRC (lisas, curtas e com alta resistência à tração) tende ao modo de falha por arrancamento, e não por ruptura da fibra (LEE et al., 2010; WILLE; NAAMAN, 2012; YOO et al., 2013; 2017; TAI et al., 2016).
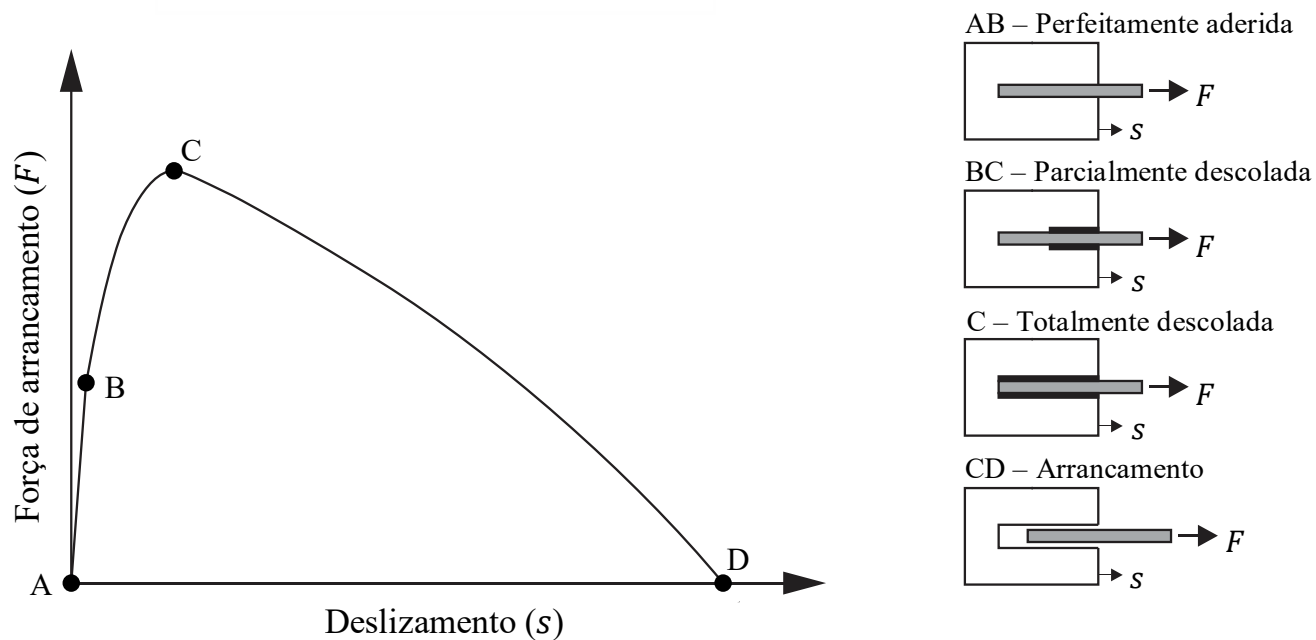

Figura 2.24 - Curva força de arrancamento-deslizamento e processo de arrancamento da fibra lisa e alinhada em matriz de UHPFRC

(Fonte: Adaptado de LEE et al., 2010; CUNHA, 2010) 
Segundo Cunha (2010) e Deng et al. (2018), o comportamento de arrancamento da fibra é influenciado por vários fatores, como o tipo de fibra e de matriz cimentícia, o comprimento de embutimento e, especialmente, a inclinação da fibra.

De modo geral, o comportamento de arrancamento da fibra lisa é predominantemente controlado pela aderência físico-química, enquanto, na fibra deformada (Figura 2.2), também ocorre a aderência mecânica, que provoca um atrito adicional. Matrizes cimentícias densas, como a do UHPFRC, proporcionam maior aderência por atrito, em comparação a matrizes de concretos convencionais. Com relação ao comprimento de embutimento, o seu aumento resulta em maior área de contato superficial entre a fibra e a matriz e, portanto, uma maior resistência ao atrito é obtida na interface entre esses dois materiais (CUNHA, 2010; WILLE; NAAMAN, 2012; QSYMAH, 2016).

Quanto à fibra inclinada em relação à força aplicada, além dos mecanismos observados na fibra alinhada, ocorrem também os efeitos pino e de fragmentação da matriz (LEE et al., 2010; CUNHA, 2010; DENG et al., 2018; ZHANG et al., 2018). Quando uma fibra inclinada atravessa uma fissura, durante o seu processo de arrancamento, as restrições geométricas provocam o mecanismo conhecido como efeito pino (Figura 2.25a). Segundo Lee et al. (2010), a força de arrancamento e o deslizamento correspondente aumentam devido a esse efeito (Figura 2.26). Além disso, a fibra inclinada gera uma concentração de tensões na sua saída, danificando localmente a matriz de suporte (efeito de fragmentação, Figura 2.25b). A região danificada aumenta com um ângulo de inclinação maior, provocando uma diminuição da força e um acréscimo do deslizamento correspondente (Figura 2.26). O efeito de fragmentação da matriz pode reduzir a eficiência da fibra, sendo importante a sua consideração em conjunto com o efeito pino.

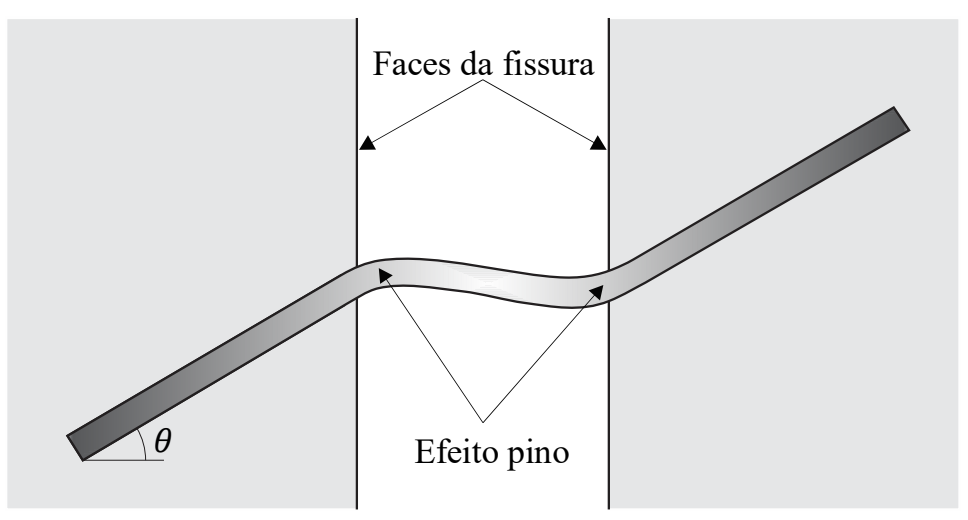

(a)

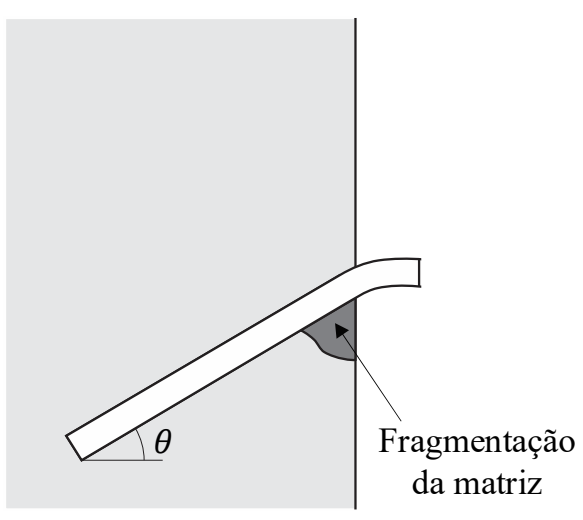

(b)

Figura 2.25 - Mecanismos adicionais da fibra inclinada: (a) efeito pino e (b) fragmentação da matriz (Fonte: Adaptado de CUNHA, 2010) 


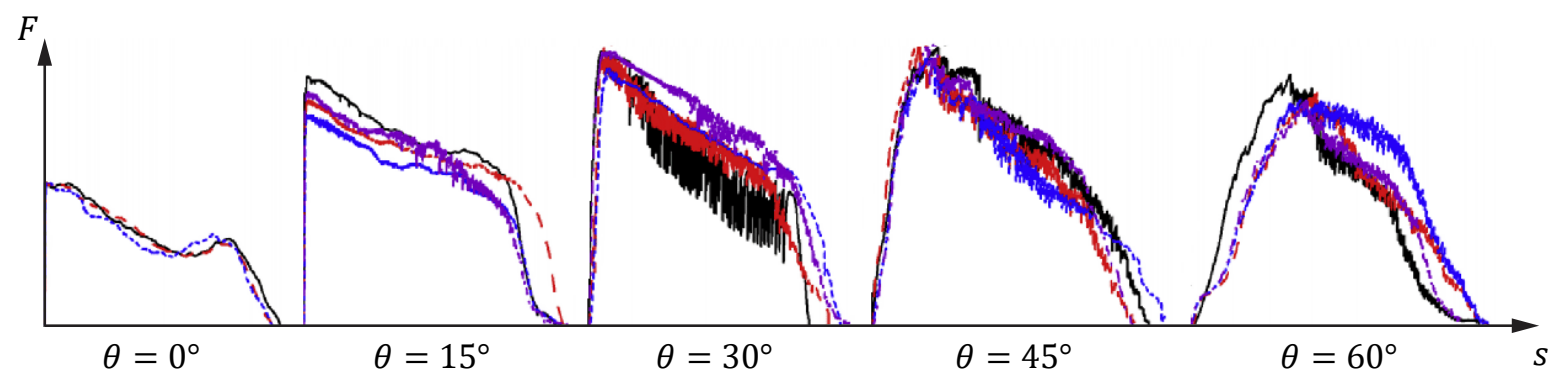

Figura 2.26 - Curvas força de arrancamento-deslizamento da fibra de aço em matriz de UHPFRC

(Fonte: Adaptado de LEE et al., 2010)

\subsubsection{Modelo analítico do comportamento de arrancamento da fibra}

A caracterização experimental do comportamento de arrancamento da fibra requer uma grande quantidade de ensaios para garantir a confiabilidade dos resultados, devido à sua grande dispersão. Além disso, para a execução dos ensaios, são necessários equipamentos apropriados, nem sempre disponíveis, como equipamentos capazes de fixar a amostra e a extremidade livre da fibra (no caso dos ensaios uniaxiais). Diante do exposto, modelos analíticos de arrancamento foram desenvolvidos para diferentes tipos de fibras e matrizes cimentícias (NAMMUR; NAAMAN, 1989, NAAMAN et al., 1991a; ALWAN et al., 1999; SUJIVORAKUL et al., 2000; LEE et al., 2010; WILLE; NAAMAN, 2012; ZHAN; MESCHKE, 2014; DENG et al., 2018).

Lee et al. (2010), com base no modelo desenvolvido por Naaman et al. (1991a), propuseram um modelo analítico para prever o comportamento de arrancamento da fibra de aço em uma matriz de UHPFRC. Esse modelo é apresentado a seguir, considerando inicialmente o comportamento de arrancamento da fibra de aço lisa e alinhada; em sequência, o efeito do ângulo de inclinação da fibra é introduzido no modelo de arrancamento.

\subsubsection{Comportamento de arrancamento da fibra de aço lisa e alinhada}

A Figura 2.27 representa um esquema do modelo de arrancamento de uma fibra de aço lisa e alinhada com a força de arrancamento $(F)$ aplicada em sua extremidade livre. A fibra possui diâmetro $d_{f}$, área de seção transversal $A_{f}$, módulo de elasticidade $E_{f}$, coeficiente de Poisson $v_{f}$ e está embutida com um comprimento $L_{E}$ em uma matriz cimentícia com área de seção transversal $A_{m}$, módulo de elasticidade $E_{m}$ e coeficiente de Poisson $v_{m}$. 


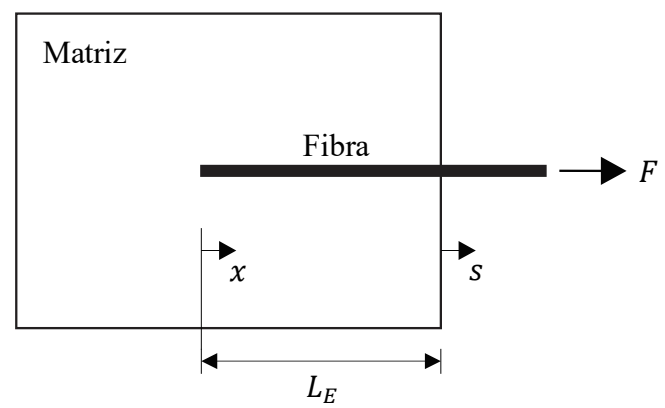

Figura 2.27 - Modelo de arrancamento de uma fibra de aço lisa e alinhada em uma matriz cimentícia (Fonte: Adaptado de NAAMAN et al., 1991a)

Segundo Naaman et al. (1991a), a relação entre tensão de cisalhamento e deslizamento relativo assumida na interface fibra/matriz é apresentada na Figura 2.28a. A curva tensão de cisalhamento-deslizamento é elástica linear até o ponto em que a tensão de cisalhamento por adesão atinge seu valor máximo $\left(\tau_{\max }\right)$. Após $\tau_{\max }$ ser alcançada, uma condição de atrito puro prevalece, com uma tensão de cisalhamento por atrito constante $\left(\tau_{f}\right)$. Com base nessa relação, Naaman et al. (1991a) propuseram um modelo analítico para prever o comportamento de arrancamento da fibra de aço lisa e alinhada em uma matriz cimentícia convencional, representado pela curva força de arrancamento-deslizamento da fibra (Figura 2.28b). Para modelar tal comportamento em uma matriz de UHPFRC, Lee et al. (2010) aplicaram o modelo desenvolvido por Naaman et al. (1991a), efetuando as adaptações necessárias.

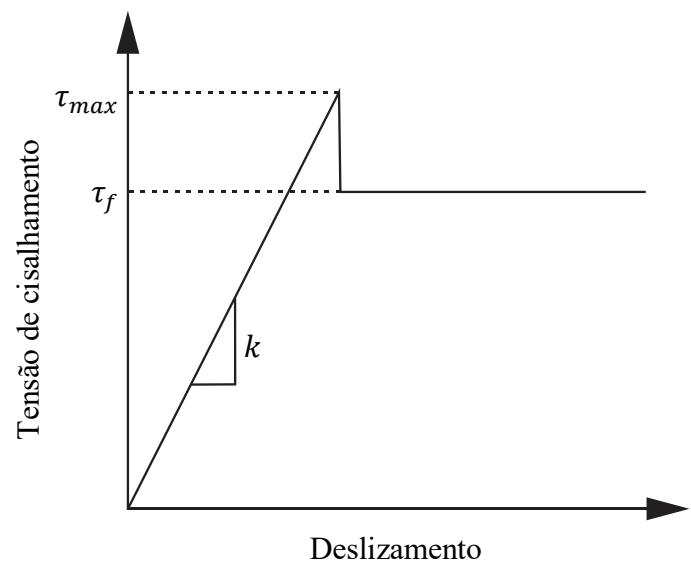

(a)

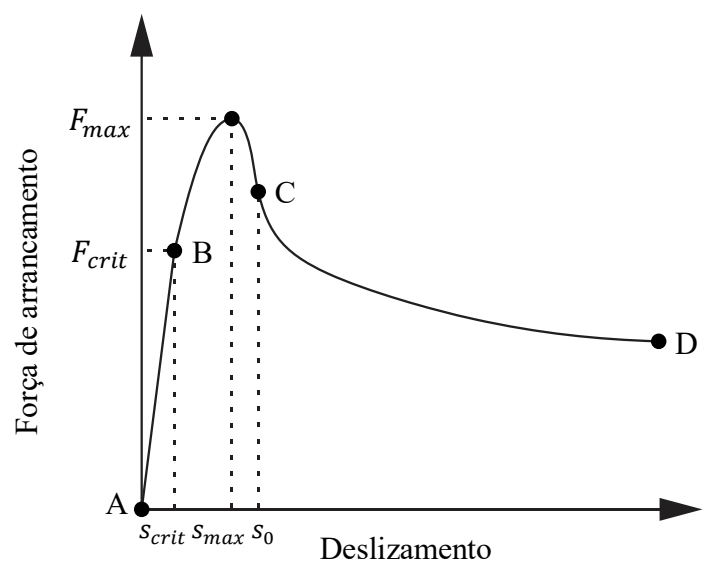

(b)

Figura 2.28 - (a) Curva tensão de cisalhamento-deslizamento na interface fibra/matriz e (b) curva força de arrancamento-deslizamento da fibra aço lisa e alinhada em matriz cimentícia convencional (Fonte: Adaptado de NAAMAN et al., 1991a) 
Como mencionado anteriormente, o comportamento de arrancamento da fibra de aço (Figura 2.28b) pode ser dividido em três regiões: região perfeitamente aderida (trecho $A B$ ), região parcialmente descolada (trecho $\mathrm{BC}$ ) e região totalmente descolada (trecho $\mathrm{CD}$ ). As equações básicas do modelo de arrancamento para cada região são apresentadas a seguir. A demonstração matemática detalhada é encontrada nos trabalhos de Naaman et al. (1991a) e Lee et al. (2010).

\section{- Região perfeitamente aderida}

A força crítica $\left(F_{\text {crit }}\right)$, definida pela Equação $(2.8)$, representa a força quando a tensão de cisalhamento atuante na interface fibra/matriz em $x=L_{E}$ atinge seu valor máximo $\left(\tau_{\text {max }}\right)$ (Figura 2.29a), dando início ao descolamento da fibra da matriz.

$$
F_{\text {crit }}=\frac{\pi d_{f} \tau_{\max }}{\lambda}\left[\frac{1-e^{-2 \lambda L_{E}}}{\left(1-\frac{1}{Q}\right)\left(1+e^{-2 \lambda L_{E}}\right)+\left(\frac{1}{Q}\right) 2 e^{-\lambda L_{E}}}\right]
$$

sendo: $\lambda=\sqrt{K Q}, Q=1+\left(A_{m} E_{m} / A_{f} E_{f}\right), K=\pi d_{f} k / A_{m} E_{m}$ e $k$ o módulo de adesão, que corresponde à inclinação inicial da curva tensão de cisalhamento-deslizamento (Figura 2.28a). Em Lee et al. (2010), a constante $k$ foi determinada comparando a inclinação da curva força de arrancamento-deslizamento da região perfeitamente aderida aos resultados experimentais. Com relação à área da matriz $\left(A_{m}\right)$, segundo Naaman et al. (1991b), o modelo analítico não é muito sensível a esse parâmetro. Assim, essa área pode ser considerada igual a 100 vezes a área da seção transversal da fibra $\left(A_{m}=100 A_{f}\right)$.

Quando $F \leq F_{\text {crit }}$, a fibra permanece totalmente aderida à matriz. Nesse caso, a relação entre a força de arrancamento e o deslizamento é linear e pode ser definida pela Equação (2.9).

$$
\frac{F}{S}=\left(\frac{\lambda A_{m} E_{m}}{Q-2}\right)\left(\frac{1+e^{-\lambda L_{E}}}{1-e^{-\lambda L_{E}}}\right)
$$

sendo: $F$ a força de arrancamento da fibra e $s$ o deslizamento correspondente. 


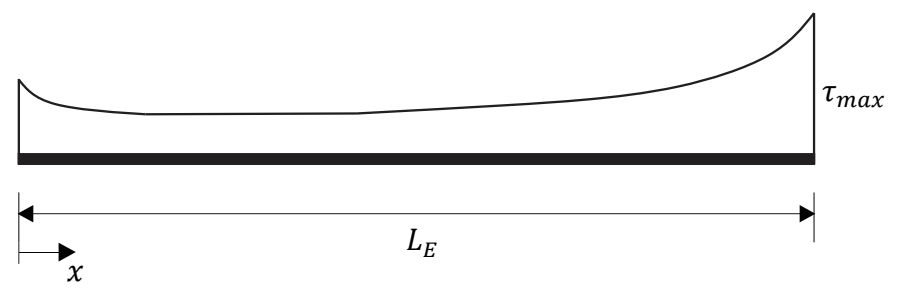

(a)

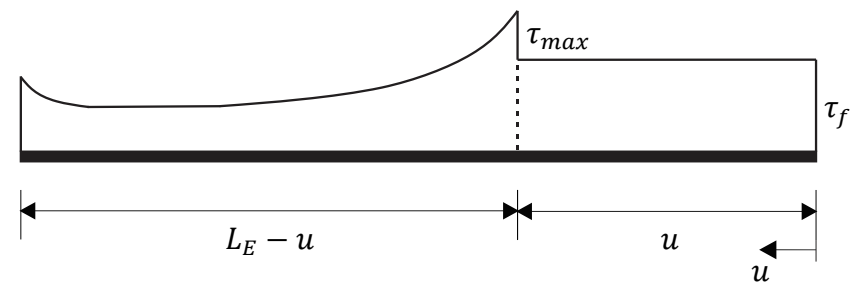

(b)

Figura 2.29 - Distribuição típica da tensão de cisalhamento na interface fibra/matriz durante o arrancamento da fibra para os casos: (a) $F=F_{\text {crit }}$, (b) $F>F_{\text {crit }}$ (Fonte: Adaptado de NAAMAN et al., 1991a)

\section{- Região parcialmente descolada}

Quando $F>F_{\text {crit }}$, uma parte da fibra é descolada da matriz, enquanto a outra ainda está totalmente aderida. Em outras palavras, haverá duas zonas interfaciais entre a fibra e a matriz, como mostra a Figura 2.29b. Na zona descolada, com comprimento $u$, prevalece na interface a tensão de cisalhamento por atrito $\left(\tau_{f}\right)$; já na zona com comprimento $\left(L_{E}-u\right)$, a tensão de cisalhamento interfacial ainda não atingiu o seu valor máximo $\left(\tau_{\max }\right)$, mantendo a fibra aderida à matriz. Assim, a força de arrancamento - que é composta por duas parcelas: uma referente à zona descolada, e a outra, à zona aderida - e o deslizamento correspondente são definidos pelas Equações (2.10) e (2.11), respectivamente.

$$
\begin{aligned}
& F=\pi d_{f} \tau_{f} u+\frac{\pi d_{f} \tau_{\max }}{\lambda}\left[\frac{1-e^{-2 \lambda\left(L_{E}-u\right)}}{\left(1-\frac{1}{Q}\right)\left(1+e^{-2 \lambda\left(L_{E}-u\right)}\right)+\left(\frac{1}{Q}\right) 2 e^{-\lambda\left(L_{E}-u\right)}}\right] \\
& s=\frac{F(Q-1) u-\frac{\pi d_{f} \tau_{f} u^{2}}{2}(Q-2)+\left(F-\pi d_{f} \tau_{f} u\right)\left(\frac{1-e^{-\lambda\left(L_{E}-u\right)}}{1+e^{-\lambda\left(L_{E}-u\right)}}\right) \frac{Q-2}{\lambda}-\pi d_{f} \tau_{f} u L_{E}}{A_{m} E_{m}}
\end{aligned}
$$

Em geral, se a tensão de cisalhamento por atrito for menor que a tensão de cisalhamento máxima $\left(\tau_{f}<\tau_{\max }\right)$, uma queda repentina da força de arrancamento ocorre após atingir a força máxima, como mostra a Figura 2.28b. De acordo com os resultados experimentais de Lee et al. (2010), não foi observada uma queda repentina da força (ver Figura 2.24). Portanto, para uma matriz de UHPFRC, a tensão de cisalhamento por atrito pode ser assumida como sendo igual a 
tensão máxima $\left(\tau_{f}=\tau_{\max }\right)$, e a força de arrancamento máxima $\left(F_{\max }\right)$ é alcançada no instante em que a fibra é descolada completamente da matriz.

\section{- Região totalmente descolada}

O comprimento da zona descolada $u$ na interface fibra/matriz (Figura 2.29b) percorre valores desde zero (início da descolagem) até $L_{E}$ (descolagem completa). Quando a descolagem completa ocorre $\left(u=L_{E}\right)$, a interface fibra/matriz é governada apenas pela tensão de cisalhamento por atrito. Para esse caso, o comportamento de arrancamento da fibra pode ser expresso pelas Equações (2.12) e (2.13).

$$
\begin{aligned}
& F=\pi d_{f} \tau_{f d}(s) x \\
& s=\left(L_{E}-x\right)+\left(\frac{x}{L_{E}}\right) s_{0}
\end{aligned}
$$

sendo: $x$ o comprimento embutido da fibra, que varia de $L_{E}$ para zero, $s_{0}$ o deslizamento da fibra no fim da descolagem completa, que pode ser calculado substituindo $u=L_{E}$ na Equação (2.11), e $\tau_{f d}(s)$ a tensão de cisalhamento por atrito equivalente para o deslizamento $s$.

A suposição de um valor constante $\left(\tau_{f}\right)$ para a tensão de cisalhamento por atrito pode ser feita para pequenos deslizamentos (região parcialmente descolada). Porém, para grandes deslizamentos (região totalmente descolada), essa suposição não é representativa, pois o comportamento de arrancamento da fibra de aço nessa região não é linear (NAAMAN et al., 1991a; LEE et al., 2010). Para modelar o comportamento de arrancamento da fibra de aço em uma matriz de UHPFRC, segundo Lee et al. (2010), a tensão de cisalhamento por atrito equivalente pode ser determinada por meio da Equação (2.14).

$$
\tau_{f d}(s)=\tau_{f} e^{\left[-\eta\left(s-s_{0}\right)^{\alpha}\right]} \frac{\left\{1-\exp \left[\frac{-4 v_{f} \mu x}{E_{f} d_{f}\left(\frac{1+v_{m}}{E_{m}}+\frac{1-v_{f}}{E_{f}}\right)}\right]\right\}}{\left\{1-\exp \left[\frac{-4 v_{f} \mu L_{E}}{E_{f} d_{f}\left(\frac{1+v_{m}}{E_{m}}+\frac{1-v_{f}}{E_{f}}\right)}\right]\right\}}
$$

sendo: $\alpha$ e $\eta$ constantes relacionadas à inclinação e à forma exponencial da região totalmente descolada, respectivamente, e $\mu$ o coeficiente de atrito. No estudo de Lee et al. (2010) foram assumidos $\mu=0,3$ e $\eta=0,05$, enquanto que a constante $\alpha$ foi determinada comparando a inclinação da curva força de arrancamento-deslizamento da região totalmente descolada aos resultados experimentais. 
2.3.2.2 Comportamento de arrancamento da fibra de aço lisa e inclinada

Como já exposto, o comportamento de arrancamento da fibra inclinada sofre a influência de dois efeitos combinados: efeito pino e efeito de fragmentação da matriz (Figura 2.25). Com base nisso, Lee et al. (2010) propuseram um modelo modificado para prever o comportamento de arrancamento da fibra de aço lisa e inclinada em uma matriz de UHPFRC. Nesse modelo, para considerar os efeitos pino e de fragmentação da matriz, foram introduzidos a tensão de cisalhamento aparente $\left(\tau_{a p p}\right)$ e o coeficiente de deslizamento $(\beta)$, que são descritos em função do ângulo de orientação da fibra, por meio das Equações (2.15) e (2.16).

$$
\begin{aligned}
& \tau_{a p p}(\theta)=e^{f \theta}(\cos \theta)^{\omega} \tau(\theta=0) \\
& \beta(\theta)=1+\gamma\left(\frac{2 \theta}{\pi}\right)^{n}
\end{aligned}
$$

sendo: $f, \omega, n$ e $\gamma$ coeficientes relacionados aos efeitos pino e de fragmentação da matriz, $\theta$ o ângulo de inclinação da fibra expresso em radiano e $\tau(\theta=0)$ o valor da tensão de cisalhamento correspondente à fibra alinhada. Uma comparação com os resultados experimentais revelou que $n=2, \gamma=100, f=1,6$ e $\omega=1,8$ podem ser aplicados para a fibra de aço em uma matriz de UHPFRC (LEE et al., 2010).

As equações básicas do modelo modificado sugerido por Lee et al. (2010) para cada região - região perfeitamente aderida, região parcialmente descolada e região totalmente descolada - são apresentadas a seguir. A demonstração matemática detalhada é encontrada no trabalho de Lee et al. (2010). Ressalta-se que, como o modelo de arrancamento da fibra inclinada é uma extensão do modelo de arrancamento da fibra alinhada, os valores das constantes e dos coeficientes ( $k, \alpha, \eta$ e $\mu$ ) determinados por Lee et al. (2010) para a fibra alinhada em uma matriz de UHPFRC podem ser aplicados para o caso da fibra inclinada, independe do valor do ângulo de orientação.

\section{- Região perfeitamente aderida}

O comportamento de arrancamento da fibra de aço inclinada na região perfeitamente aderida pode ser representado pelas Equações (2.17) e (2.18). Nota-se que a tensão de cisalhamento máxima aparente $\left(\tau_{\max (a p p)}\right)$ e o coeficiente de deslizamento $(\beta)$, que refletem os efeitos do ângulo de orientação da fibra tanto na força de arrancamento quanto no deslizamento, são introduzidos nas formulações. 


$$
\begin{aligned}
& F_{\text {crit }}(\theta)=\frac{\pi d_{f} \tau_{\max (a p p)}(\theta)}{\lambda}\left[\frac{1-e^{-2 \lambda L_{E}}}{\left(1-\frac{1}{Q}\right)\left(1+e^{-2 \lambda L_{E}}\right)+\left(\frac{1}{Q}\right) 2 e^{-\lambda L_{E}}}\right] \\
& \frac{F}{S}(\theta)=\frac{1}{\beta(\theta)}\left(\frac{\lambda A_{m} E_{m}}{Q-2}\right)\left(\frac{1+e^{-\lambda L_{E}}}{1-e^{-\lambda L_{E}}}\right)
\end{aligned}
$$

\section{- Região parcialmente descolada}

As tensões de cisalhamento por atrito e a máxima aparente, que podem ser assumidas como sendo iguais para uma matriz de UHPFRC $\left(\tau_{f(a p p)}=\tau_{\max (a p p)}\right)$, e o coeficiente de deslizamento também são considerados nas Equações (2.19) e (2.20), que definem a região parcialmente descolada.

$$
\begin{aligned}
& F(\theta)=\pi d_{f} \tau_{f(a p p)}(\theta) \\
& +\frac{\pi d_{f} \tau_{\max (a p p)}(\theta)}{\lambda}\left[\frac{1-e^{-2 \lambda\left(L_{E}-u\right)}}{\left(1-\frac{1}{Q}\right)\left(1+e^{-2 \lambda\left(L_{E}-u\right)}\right)+\left(\frac{1}{Q}\right) 2 e^{-\lambda\left(L_{E}-u\right)}}\right] \\
& s(\theta)=\frac{\beta(\theta)}{A_{m} E_{m}}\left[F(\theta)(Q-1) u-\frac{\pi d_{f} \tau_{f(a p p)}(\theta) u^{2}}{2}(Q-2)\right. \\
& +\left(F(\theta)-\pi d_{f} \tau_{f(a p p)}(\theta) u\right)\left(\frac{1-e^{-\lambda\left(L_{E}-u\right)}}{1+e^{-\lambda\left(L_{E}-u\right)}}\right) \frac{Q-2}{\lambda} \\
& \left.-\pi d_{f} \tau_{f(a p p)}(\theta) u L_{E}\right]
\end{aligned}
$$

\section{- Região totalmente descolada}

Na região totalmente descolada, a força de arrancamento da fibra de aço inclinada e o deslizamento correspondente podem ser expressos pelas Equações (2.21) e (2.22), como no caso da fibra de aço alinhada. A tensão de cisalhamento por atrito aparente é introduzida na Equação (2.23), referente ao cálculo da tensão de cisalhamento equivalente $\tau_{f d}$. Já o coeficiente de deslizamento é considerado no cálculo do deslizamento $s_{0}$ por meio da Equação (2.20), no fim da descolagem completa $\left(u=L_{E}\right)$. 


$$
\begin{aligned}
& F(\theta)=\pi d_{f} \tau_{f d}(s, \theta) x \\
& s(\theta)=\left(L_{E}-x\right)+\left(\frac{x}{L_{E}}\right) s_{0}(\theta) \\
& \tau_{f d}(s, \theta)=\tau_{f(a p p)}(\theta) e^{\left[-\eta\left(s(\theta)-s_{0}(\theta)\right)^{\alpha}\right]} \frac{\left\{1-\exp \left[\frac{-4 v_{f} \mu x}{\left.\left.E_{f} d_{f}\left(\frac{1+v_{m}}{E_{m}}+\frac{1-v_{f}}{E_{f}}\right)\right]\right\}}\right.\right.}{\left\{1-\exp \left[\frac{-4 v_{f} \mu L_{E}}{E_{f} d_{f}\left(\frac{1+v_{m}}{E_{m}}+\frac{1-v_{f}}{E_{f}}\right)}\right]\right\}}
\end{aligned}
$$

\subsection{Modelagem Numérica em Elementos Finitos para UHPFRC}

Embora os resultados de uma análise experimental sejam bastante precisos, principalmente quando obtidos em escala real, muitas pesquisas utilizam a análise numérica para complementá-los, identificando fenômenos que não puderam ser diretamente medidos durante o experimento, ou para realizar estudo paramétrico, ou seja, analisar outras situações não investigadas experimentalmente. Além disso, em comparação aos modelos numéricos, os ensaios experimentais são mais dispendiosos, demandam mais tempo e recursos humanos para serem executados.

A maioria dos modelos numéricos em elementos finitos existentes para UHPFRC consideram a matriz cimentícia e as fibras de aço um único material, ou seja, o UHPFRC é modelado como um material homogêneo (CHEN; GRAYBEAL, 2012; MAHMUD et al., 2013; MAO et al., 2014; AWINDA et al., 2016; THAI; KIM, 2016; FOGLAR et al., 2017; AL-OSTA et al., 2017; SINGH et al., 2017; BAHIJ et al., 2018; HUSSEIN; AMLEH, 2018; KRAHL et al., 2018). Tal abordagem, apesar de representar de forma satisfatória os resultados experimentais, impossibilita investigar os efeitos de alguns parâmetros relacionados às fibras, como o tipo (tamanho e forma), a quantidade e, principalmente, a orientação. Sabe-se que esses parâmetros têm grande influência no comportamento mecânico do material e, consequentemente, no do elemento estrutural; por isso, sua investigação se mostra essencial.

Recentemente, visando a contornar as limitações do modelo supracitado, algumas pesquisas se concentraram no desenvolvimento de modelos numéricos com fibras discretizadas na matriz cimentícia. Em Qsymah (2016) e Zhang et al. (2018), o UHPFRC é modelado como 
um material heterogêneo trifásico: matriz cimentícia, fibras e interface fibra/matriz. No entanto, essa abordagem pode implicar um alto custo computacional quando há um grande número de fibras discretizadas. Além disso, existem dificuldades em modelar efetivamente o comportamento interfacial fibra/matriz. Assim, uma outra alternativa apresentada por Cunha et al. (2011; 2012), Soetens et al. (2012) e Soetens e Matthys (2012; 2014) - não especificamente para o UHPFRC, mas para o concreto reforçado com fibras (FRC) - é considerar esse compósito um material heterogêneo bifásico: matriz cimentícia e fibras. Nesse caso, o comportamento da interface fibra/matriz é representado no modelo constitutivo das fibras, por meio de uma lei tensão-deformação equivalente baseada no comportamento de arrancamento da fibra.

A seguir, são apresentadas com mais detalhes as abordagens numéricas para modelar o UHPFRC como um material homogêneo e como um material heterogêneo bifásico.

\subsubsection{Modelagem do UHPFRC como um material homogêneo}

Um dos modelos constitutivos mais utilizados para modelar o comportamento do UHPFRC como um material homogêneo é o Concrete Damaged Plasticity (CDP), disponível no software de elementos finitos ABAQUS (CHEN; GRAYBEAL, 2012; MAHMUD et al., 2013; AL-OSTA et al., 2017; SINGH et al., 2017; BAHIJ et al., 2018; HUSSEIN; AMLEH, 2018; KRAHL et al., 2018). Esse modelo de dano acoplado à plasticidade proposto por Lubliner et al. (1989) e modificado por Lee e Fenves (1998) é adequado para representar o concreto e outros materiais frágeis, como argamassa, cerâmica e rocha, em análises com carregamento monotônico, cíclico ou dinâmico.

Para uma melhor compreensão, uma visão geral dos principais conceitos referentes ao modelo CDP, como a lei de enrijecimento/suavização, o critério de plastificação, o potencial plástico e a regularização viscoplástica, é abordada a seguir.

\section{- Lei de enrijecimento/suavização}

No modelo CDP, a lei de enrijecimento/suavização, que define a evolução da superfície de plastificação, é descrita pelo comportamento uniaxial do material na compressão e na tração. Tais comportamentos, representados na Figura 2.30, são caracterizados pela plasticidade danificada, na qual dois parâmetros de dano independentes, um relacionado ao esmagamento por compressão $\left(d_{c}\right)$ e outro à fissuração por tração $\left(d_{t}\right)$, são introduzidos no modelo. Esses 
parâmetros, que caracterizam degradação da rigidez elástica, podem assumir valores entre 0 (material não danificado) e 1 (material completamente danificado).

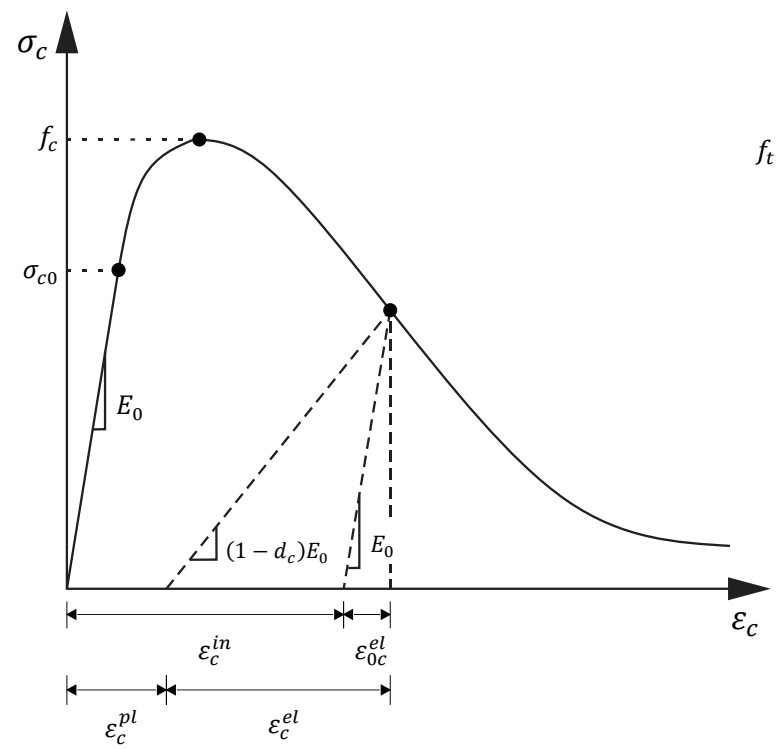

(a)

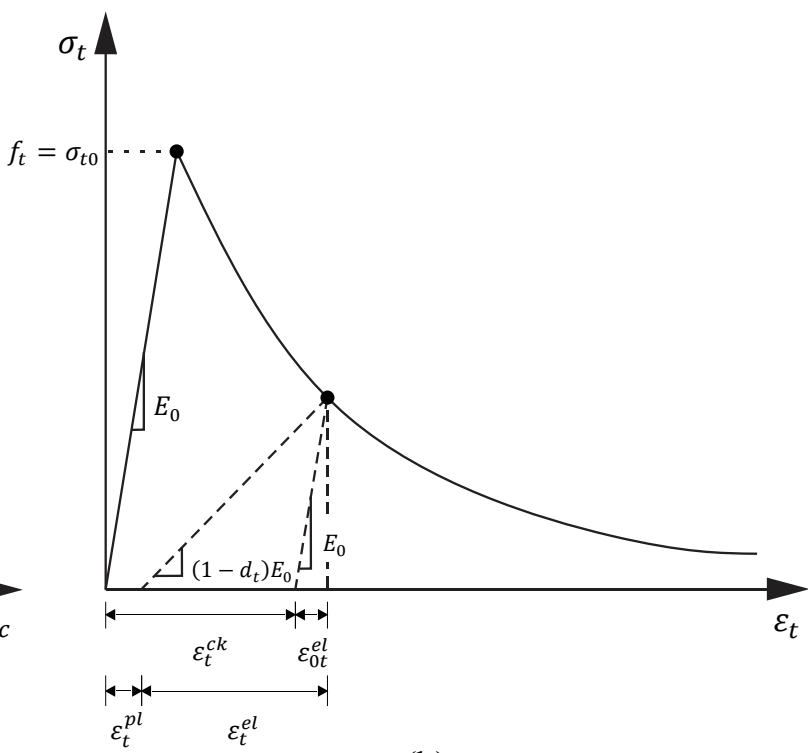

(b)

Figura 2.30 - Curvas tensão-deformação para o estado uniaxial (a) na compressão e (b) na tração, indicando as componentes de deformação e os parâmetros de dano

(Fonte: Adaptado do manual ABAQUS 6.14)

Para o estado uniaxial, a relação entre a tensão de compressão $\left(\sigma_{c}\right)$ e a deformação inelástica $\left(\varepsilon_{c}^{i n}\right)$ (Figura 2.30a), bem como a relação entre a tensão de tração $\left(\sigma_{t}\right)$ e a deformação de fissuração $\left(\varepsilon_{t}^{c k}\right)$ (Figura 2.30b), requeridas pelo modelo CDP, podem ser descritas pelas Equações (2.24) e (2.25), respectivamente.

$$
\begin{aligned}
& \varepsilon_{c}^{i n}=\varepsilon_{c}-\frac{\sigma_{c}}{E_{0}} \\
& \varepsilon_{t}^{c k}=\varepsilon_{t}-\frac{\sigma_{t}}{E_{0}}
\end{aligned}
$$

sendo: $\varepsilon_{c}$ e $\varepsilon_{t}$ as deformações totais na compressão e na tração, respectivamente, e $E_{0}$ o módulo de elasticidade inicial do material (sem danificação).

A conversão dos valores de deformação inelástica e de deformação de fissuração em valores de deformação plástica é realizada automaticamente pelo ABAQUS (Equações (2.26) e (2.27)), considerando-se os parâmetros de dano de compressão e de tração especificados no modelo. Na ausência do dano, assume-se que as deformações plásticas são iguais às deformações inelásticas e às deformações de fissuração. 


$$
\begin{aligned}
& \varepsilon_{c}^{p l}=\varepsilon_{c}^{i n}-\frac{d_{c}}{\left(1-d_{c}\right)} \frac{\sigma_{c}}{E_{0}} \\
& \varepsilon_{t}^{p l}=\varepsilon_{t}^{c k}-\frac{d_{t}}{\left(1-d_{t}\right)} \frac{\sigma_{t}}{E_{0}}
\end{aligned}
$$

sendo: $\varepsilon_{c}^{p l}$ e $\varepsilon_{t}^{p l}$ as deformações plásticas na compressão e na tração, respectivamente.

Com base nas expressões apresentadas acima, as tensões efetivas de compressão $\left(\bar{\sigma}_{c}\right)$ e de tração $\left(\bar{\sigma}_{t}\right)$, responsáveis por definir o tamanho da superfície de plastificação, podem ser determinadas pelas Equações (2.28) e (2.29), respectivamente.

$$
\begin{aligned}
& \bar{\sigma}_{c}=\frac{\sigma_{c}}{\left(1-d_{c}\right)}=E_{0}\left(\varepsilon_{c}-\varepsilon_{c}^{p l}\right) \\
& \bar{\sigma}_{t}=\frac{\sigma_{t}}{\left(1-d_{t}\right)}=E_{0}\left(\varepsilon_{t}-\varepsilon_{t}^{p l}\right)
\end{aligned}
$$

Em particular, além da relação tensão-deformação, o comportamento uniaxial na tração também pode ser representado no modelo CDP pela relação tensão-abertura de fissura ou, alternativamente, a energia de fratura pode ser especificada diretamente como uma propriedade do material.

\section{- Critério de plastificação}

O modelo CDP utiliza o critério de plastificação proposto por Lubliner et al. (1989) e as modificações propostas por Lee e Fenves (1998) para definir o estado de tensão em que ocorrerá o início da plastificação do material. A função que define esse critério, em termos de tensões efetivas, é expressa pela Equação (2.30). A superfície de plastificação (representação geométrica do critério) no estado plano de tensões é apresentada na Figura 2.31.

$$
F\left(\bar{\sigma}, \varepsilon^{p l}\right)=\frac{1}{1-\alpha}\left(\bar{q}-3 \alpha \bar{p}+\beta\left(\varepsilon^{p l}\right)\left\langle\bar{\sigma}_{\max }\right\rangle-\gamma\left\langle-\bar{\sigma}_{\max }\right\rangle\right)-\bar{\sigma}_{c}\left(\varepsilon_{c}^{p l}\right) \leq 0
$$

sendo: $\bar{\sigma}$ o tensor de tensões efetivas, $\varepsilon^{p l}$ o tensor de deformações plásticas, $\bar{p}$ a tensão hidrostática efetiva, $\bar{q}$ a tensão de von Mises equivalente efetiva e $\bar{\sigma}_{\max }$ o máximo autovalor do tensor de tensões efetivas, ou seja, a máxima tensão principal efetiva. O operador de Macauley corresponde a $\langle x\rangle=\frac{1}{2}(|x|+x)$. 


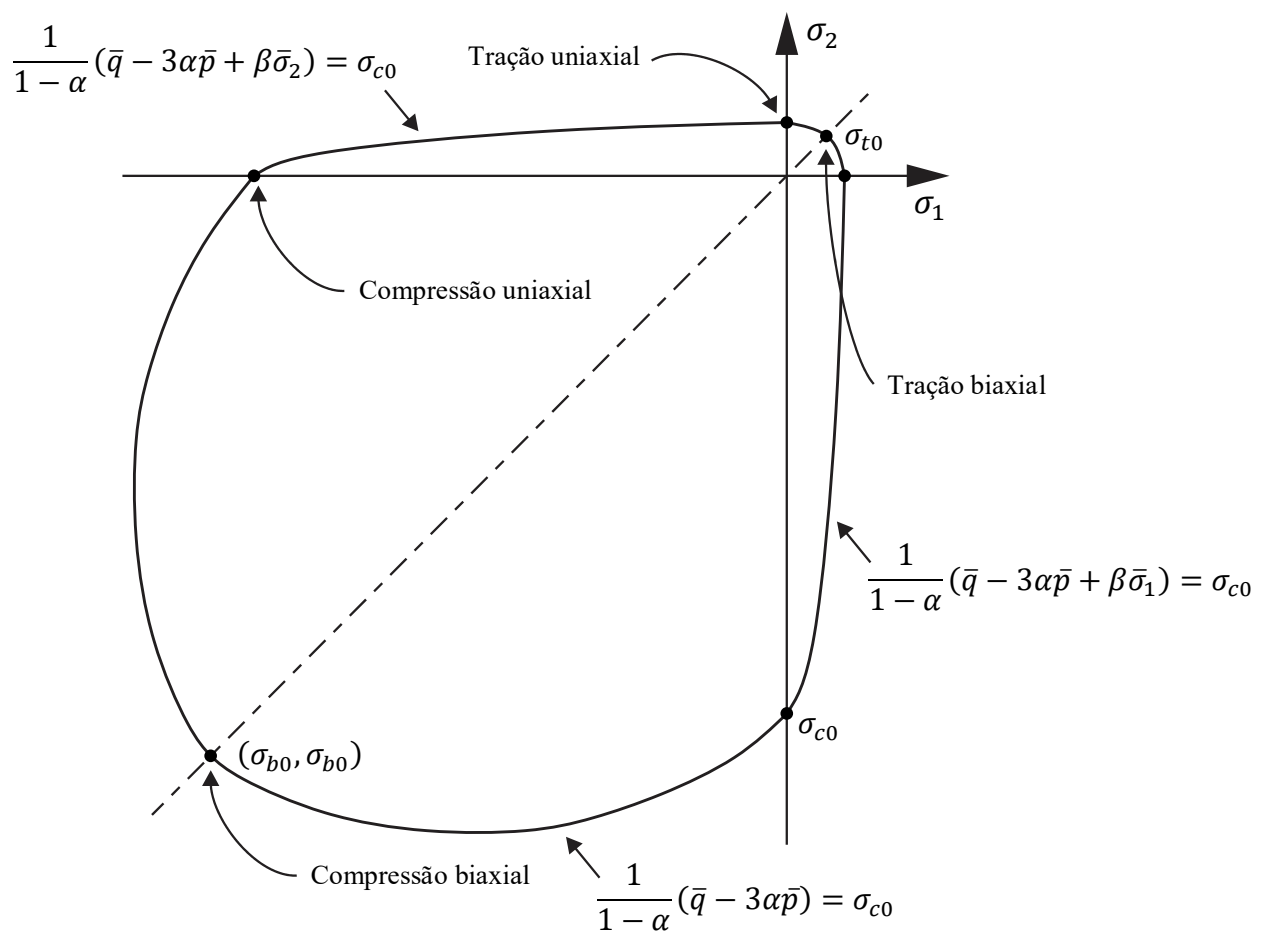

Figura 2.31 - Superfície de plastificação no estado plano de tensões

(Fonte: Adaptado do manual ABAQUS 6.14)

A constante $\alpha$ é determinada a partir das tensões de escoamento de compressão no estado uniaxial $\left(\sigma_{c 0}\right)$ e biaxial $\left(\sigma_{b 0}\right)$, conforme a Equação (2.31). De acordo com Lubliner et al. (1989), para o concreto, a relação $\sigma_{b 0} / \sigma_{c 0}$ pode variar de 1,10 a 1,16. Para o UHPFRC, estudos indicam que essa relação pode assumir valores entre 1,05 e 1,16.

$$
\alpha=\frac{\sigma_{b 0}-\sigma_{c 0}}{2 \sigma_{b 0}-\sigma_{c 0}}
$$

A função $\beta\left(\varepsilon^{p l}\right)$ é definida pela Equação (2.32).

$$
\beta\left(\varepsilon^{p l}\right)=\frac{\bar{\sigma}_{c}\left(\varepsilon_{c}^{p l}\right)}{\bar{\sigma}_{t}\left(\varepsilon_{t}^{p l}\right)}(1-\alpha)-(1+\alpha)
$$

sendo: $\bar{\sigma}_{c}\left(\varepsilon_{c}^{p l}\right)$ e $\bar{\sigma}_{t}\left(\varepsilon_{t}^{p l}\right)$ as tensões efetivas de compressão e de tração no estado uniaxial, respectivamente.

A constante $\gamma$ é determinada pela comparação entre o meridiano de compressão e o meridiano de tração, conforme a Equação (2.33). 


$$
\gamma=\frac{3\left(1-K_{c}\right)}{2 K_{c}-1}
$$

sendo: $K_{c}$ a constante que define a forma da superfície de plastificação no plano desviador, expressa pela relação entre a distância do eixo hidrostático ao meridiano de tração (TM) e de compressão (CM) (Figura 2.32). A constante $K_{c}$ pode variar de 0,5 a 1,0. Para o concreto, incluindo o UHPFRC, é recomendado o valor de $2 / 3$.

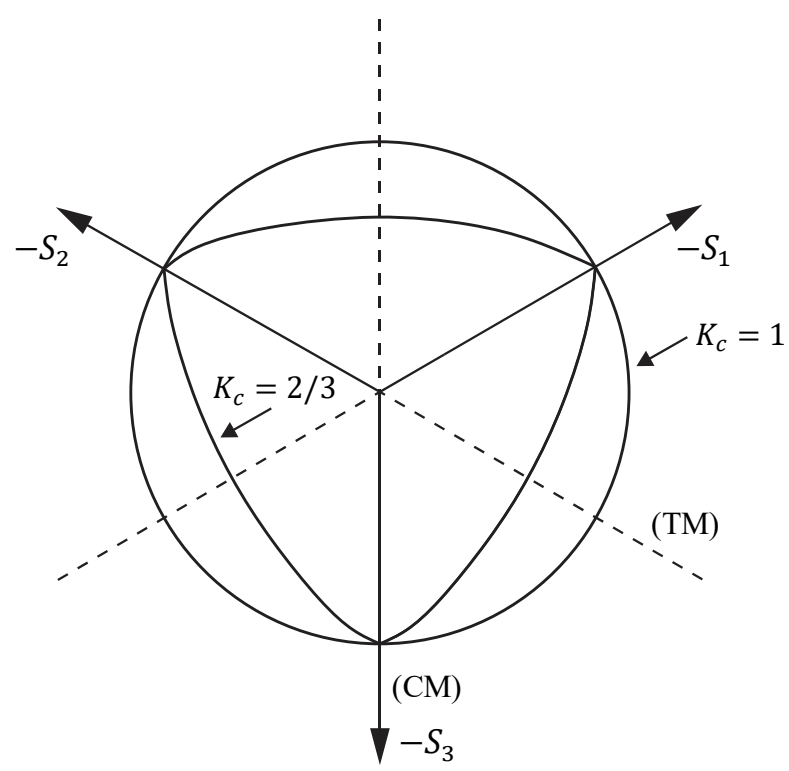

Figura 2.32 - Superfície de plastificação no plano desviador (plano de Nadai)

(Fonte: Adaptado do manual ABAQUS 6.14)

\section{- Potencial plástico}

A partir da função do potencial plástico, são determinadas as intensidades e as direções das deformações plásticas. No modelo CDP, o potencial plástico assume um fluxo não associativo, no qual é utilizada a função hiperbólica de Drucker-Prager (Equação (2.34)), em termos de tensões efetivas.

$$
G=\sqrt{\left(\in \sigma_{t 0} \tan \psi\right)^{2}+\bar{q}^{2}}-\bar{p} \tan \psi
$$

sendo: $\sigma_{t 0}$ a tensão de escoamento de tração no estado uniaxial, $\epsilon$ a excentricidade que define a taxa em que a função hiperbólica se aproxima de uma reta assintótica e $\psi$ o ângulo de dilatação medido no plano meridional em alta pressão de confinamento (Figura 2.33). Para o concreto, incluindo o UHPFRC, o valor usual da excentricidade é de 0,1 . Já o ângulo de dilatação pode variar de $36^{\circ}$ a $56^{\circ}$. 


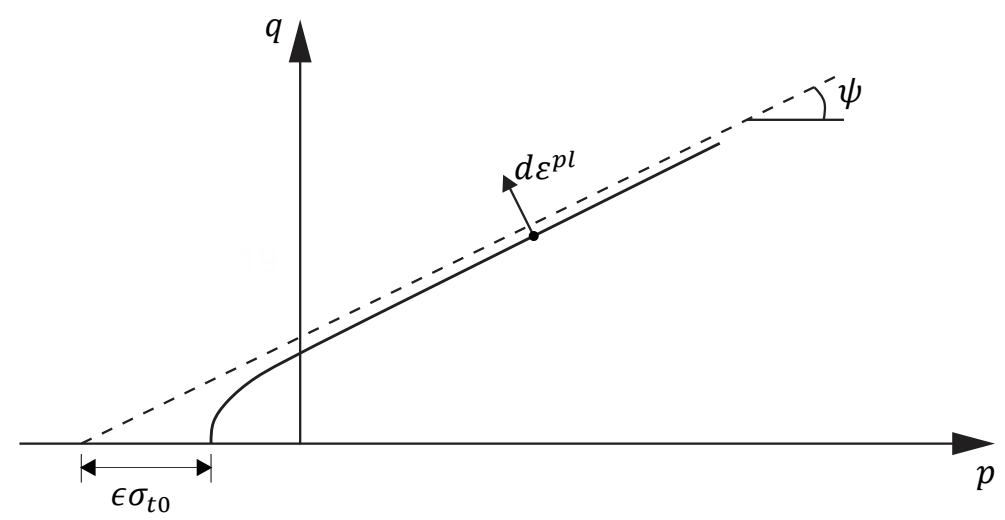

Figura 2.33 - Superfície de plastificação no plano meridional

(Fonte: Adaptado do manual ABAQUS 6.14)

\section{- Regularização viscoplástica}

Modelos de materiais que exibem comportamento de suavização e degradação de rigidez muitas vezes apresentam dificuldades de convergência. Para superar esse tipo de problema, o modelo CDP utiliza a regularização viscoplástica, permitindo que as tensões excedam ligeiramente a superfície de plastificação.

O parâmetro de viscosidade $(\mu)$, especificado no modelo CDP, pode assumir valores entre 0 (nenhuma regularização viscoplástica é realizada) e 1. Segundo o manual do ABAQUS 6.14, admitir um valor pequeno para $\mu$ (pequeno comparado ao incremento de tempo característico) geralmente ajuda a melhorar a taxa de convergência do modelo no regime de suavização, sem comprometer os resultados.

\subsubsection{Modelagem do UHPFRC como um material heterogêneo bifásico}

Para considerar a distribuição das fibras em um modelo numérico em elementos finitos, o UHPFRC pode ser assumido como um material heterogêneo, composto pela fase matriz cimentícia e pela fase fibras de aço. Porém, estratégias numéricas devem ser adotadas para representar o comportamento interfacial fibra/matriz. Com base nisso, são apresentadas a seguir as estratégias adotadas por Cunha et al. (2011; 2012), Soetens et al. (2012) e Soetens e Matthys (2012; 2014) para modelar o FRC como um material heterogêneo bifásico. Tais estratégias foram estendidas para o UHPFRC nesta pesquisa.

Em geral, as abordagens conduzidas por Cunha et al. (2011; 2012), Soetens et al. (2012) e Soetens e Matthys (2012; 2014) são bastante semelhantes: inicialmente, as fibras são geradas 
aleatoriamente com um algoritmo baseado no método de Monte Carlo e, posteriormente, inseridas em uma malha tridimensional de elementos finitos sólidos, que modela a matriz cimentícia (Figura 2.34). O comportamento da matriz é representado por um modelo constitutivo de fissuração distribuída, enquanto as fibras, modeladas com elementos de treliça tridimensionais embutidos, são representadas por uma lei constitutiva equivalente, obtida por meio do comportamento de arrancamento.

As estratégias adotadas pelos autores para geração e modelagem das fibras, que são as fundamentais para o desenvolvimento da presente pesquisa, são detalhadas nas seções que seguem.

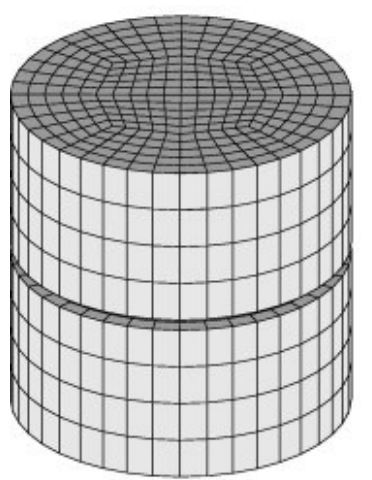

(a)

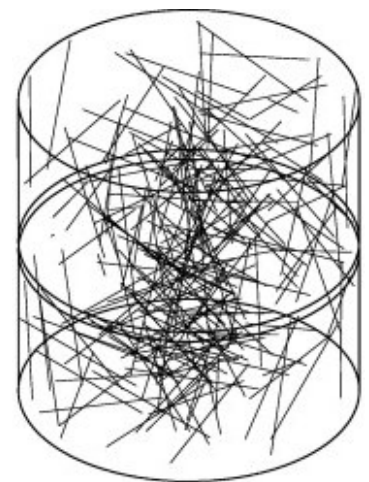

(b)

Figura 2.34 - Corpo de prova cilíndrico com entalhe destinado a ensaio de tração: (a) malha tridimensional de elementos finitos (matriz cimentícia) e (b) fibras discretizadas na matriz (Fonte: CUNHA et al., 2011)

\subsubsection{Geração das fibras}

As fibras discretizadas na matriz cimentícia podem ser geradas aleatoriamente pelo método de Monte Carlo, como realizado por Cunha et al. (2011; 2012), Soetens et al. (2012) e Soetens e Matthys (2012; 2014). Segundo Gu et al. (2016), para considerar a aleatoriedade das fibras em um volume configurado em um sistema de coordenadas cartesianas (Figura 2.35a), cinco parâmetros independentes são necessários: as coordenadas do ponto médio da fibra $\left(x_{m}, y_{m}, z_{m}\right)$ e os ângulos de orientação $\alpha$ e $\beta$. As coordenadas do ponto médio são geradas aleatoriamente dentro do domínio do volume. Já os ângulos de orientação, definidos em um sistema esférico local cujo centro coincide com o ponto médio da fibra (Figura 2.35b), são gerados aleatoriamente dentro dos seguintes intervalos: $\alpha \in[0, \pi]$ e $\beta \in[0,2 \pi]$, respeitando uma distribuição uniforme em cada intervalo. 


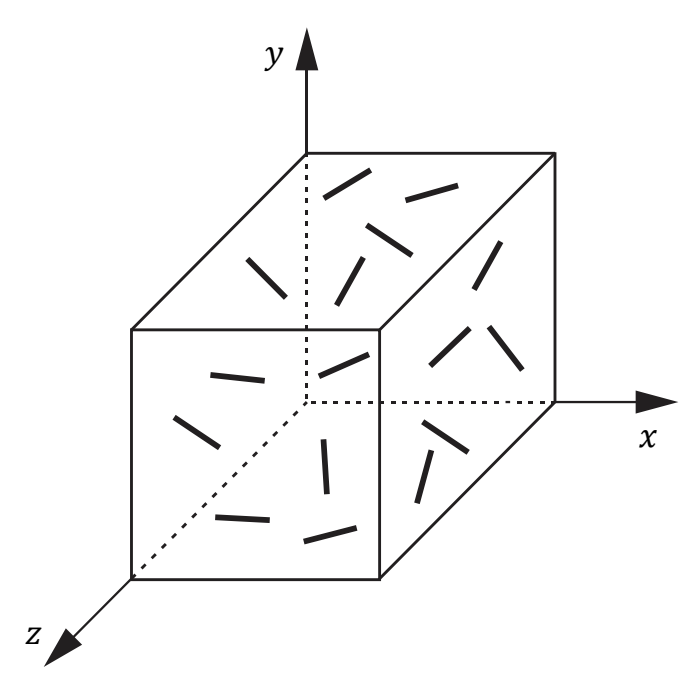

(a)

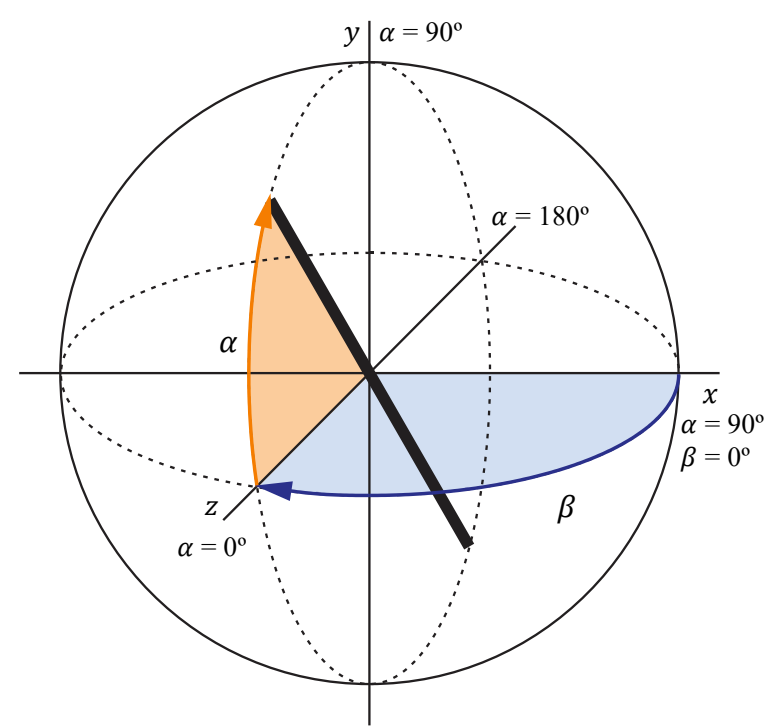

(b)

Figura 2.35 - (a) Sistema de coordenadas cartesianas para o volume com fibras e (b) Sistema de coordenadas esféricas locais para uma fibra

(Fonte: Adaptado de GU et al., 2016)

Uma vez determinados os cinco parâmetros independentes e imposto o comprimento total da fibra $\left(L_{f}\right)$, as suas coordenadas de extremidades $(x, y, z)$ podem ser calculadas conforme as Equações (2.35), (2.36) e (2.37).

$$
\begin{aligned}
& x=x_{m} \pm \frac{L_{f}}{2} \operatorname{sen} \alpha \cos \beta \\
& y=y_{m} \pm \frac{L_{f}}{2} \operatorname{sen} \alpha \operatorname{sen} \beta \\
& z=z_{m} \pm \frac{L_{f}}{2} \cos \alpha
\end{aligned}
$$

Contudo, segundo Soetens e Matthys (2014), a consideração da orientação real das fibras no plano de fissuração é fundamental para garantir uma boa representatividade dos resultados numéricos. Assim, para a geração das fibras tomando tal consideração, o ângulo $\alpha$, que, de acordo com as formulações acima, representa o ângulo de inclinação da fibra $(\theta)$ no suposto plano de fissuração ( $x y$, Figura 2.35a), pode ser determinado por uma distribuição normal (gaussiana), conforme a Equação (2.38). O ângulo $\beta$ continua assumindo valores uniformemente distribuídos no intervalo de 0 a $2 \pi$. 


$$
\alpha=z \sigma_{\theta}+\theta_{m}
$$

sendo: $\theta_{m}$ e $\sigma_{\theta}$ o ângulo de orientação médio das fibras no plano de fissuração e o desvio padrão de $\theta$, respectivamente, e $z$ a variável padrão reduzida da distribuição normal.

O ângulo de orientação médio e o desvio padrão podem ser determinados experimentalmente por meio da análise de imagem em um plano próximo ao de fissuração, como abordado na Seção 2.2.1. Entretanto, na falta de resultados experimentais, esses parâmetros (em graus) podem ser estimados a partir das Equações (2.39) e (2.40), propostas por Laranjeira et al. (2011).

$$
\begin{aligned}
& \theta_{m}=\arccos \left(\eta_{\theta}\right) \\
& \sigma_{\theta}=90 \cdot \eta_{\theta}\left(1-\eta_{\theta}\right)
\end{aligned}
$$

sendo: $\eta_{\theta}$ o coeficiente de orientação das fibras definido com base em análises de imagens realizadas em outras pesquisas, conforme detalhado na Seção 2.2.1.

\subsubsection{Modelagem das fibras}

Em Cunha et al. (2011; 2012), Soetens et al. (2012) e Soetens e Matthys (2012; 2014), as fibras de aço foram modeladas com elementos de treliça tridimensionais embutidos nos elementos sólidos que representam a matriz cimentícia. Como o emprego de elementos embutidos assume uma aderência perfeita entre as fibras e a matriz, o comportamento de deslizamento relativo da interface foi modelado de forma indireta, por meio de uma lei constitutiva tensão-deformação equivalente atribuída às fibras.

\section{- Lei tensão-deformação equivalente}

A lei tensão-deformação equivalente pode ser obtida a partir do comportamento de arrancamento da fibra (Figura 2.36), em que a relação força de arrancamento-deslizamento é convertida em uma relação tensão-deformação equivalente por meio das Equações (2.41) e (2.42), propostas por Soetens et al. (2012). Como resultado dessa abordagem, para garantir uma deformação constante ao longo de todo o comprimento da fibra, é necessário que cada fibra seja modelada por um único elemento de treliça, ou seja, com nós apenas nas suas extremidades. 


$$
\begin{gathered}
\sigma_{f}=\frac{F}{A_{f}} \\
\varepsilon_{f}=\frac{s}{L_{f}}
\end{gathered}
$$

sendo: $\sigma_{f}$ e $\varepsilon_{f}$ a tensão normal e a deformação equivalentes da fibra, respectivamente; $F$ e $s$ a força de arrancamento e o deslizamento da fibra, respectivamente; e $A_{f}$ e $L_{f}$ a área da seção transversal e o comprimento total da fibra, respectivamente.
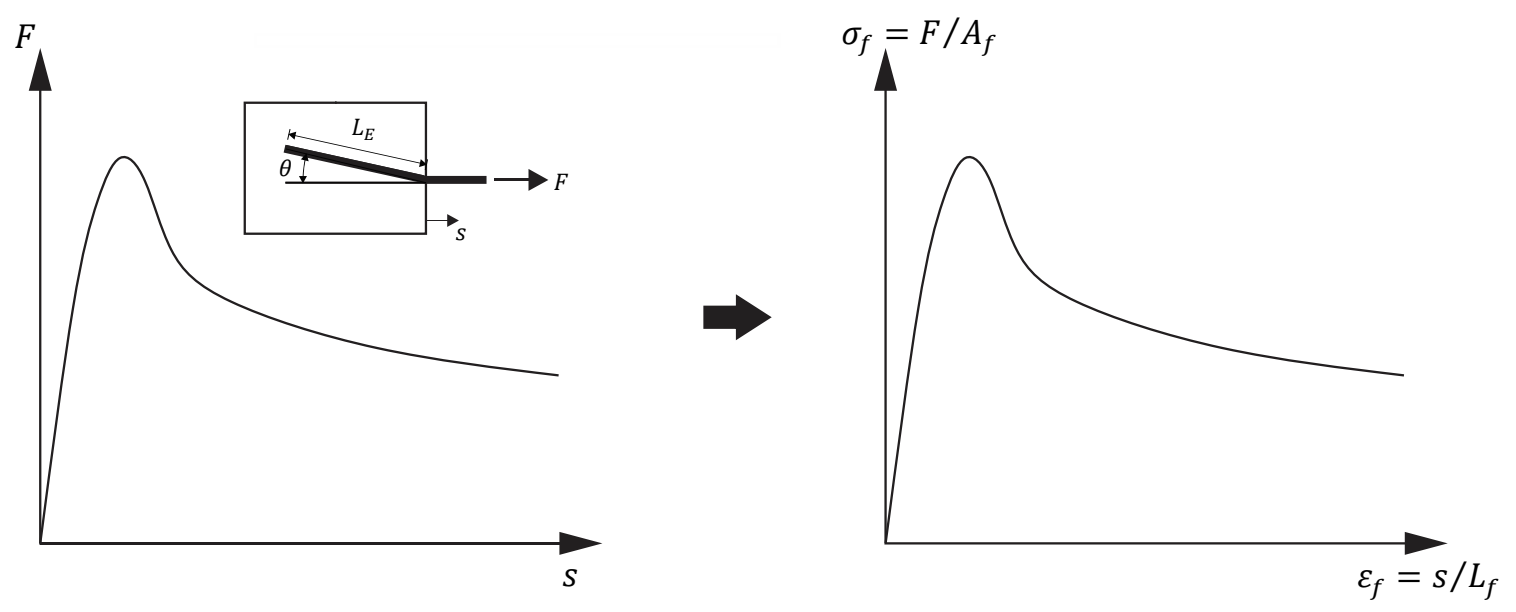

Figura 2.36 - Determinação da curva tensão-deformação equivalente a partir da curva força de arrancamento-deslizamento da fibra

(Fonte: Adaptado de CUNHA et al., 2011)

Como exposto na Seção 2.3.1, o comportamento de arrancamento depende do comprimento de embutimento $\left(L_{E}\right)$ e do ângulo de inclinação $(\theta)$ da fibra. Em ensaios de arrancamento, esses parâmetros são facilmente definidos. No entanto, no caso de elementos com múltiplas fibras distribuídas na matriz cimentícia, a definição desses parâmetros se torna complexa, pois eles assumem valores aleatórios para cada fibra que atravessa o plano de fissuração, como mostra a Figura 2.37.

A seguir, são discutidas as estratégias adotadas por Cunha et al. (2011;2012), Soetens et al. (2012) e Soetens e Matthys $(2012 ; 2014)$ para definir esses dois parâmetros nos modelos numéricos com fibras discretizadas na matriz cimentícia. 


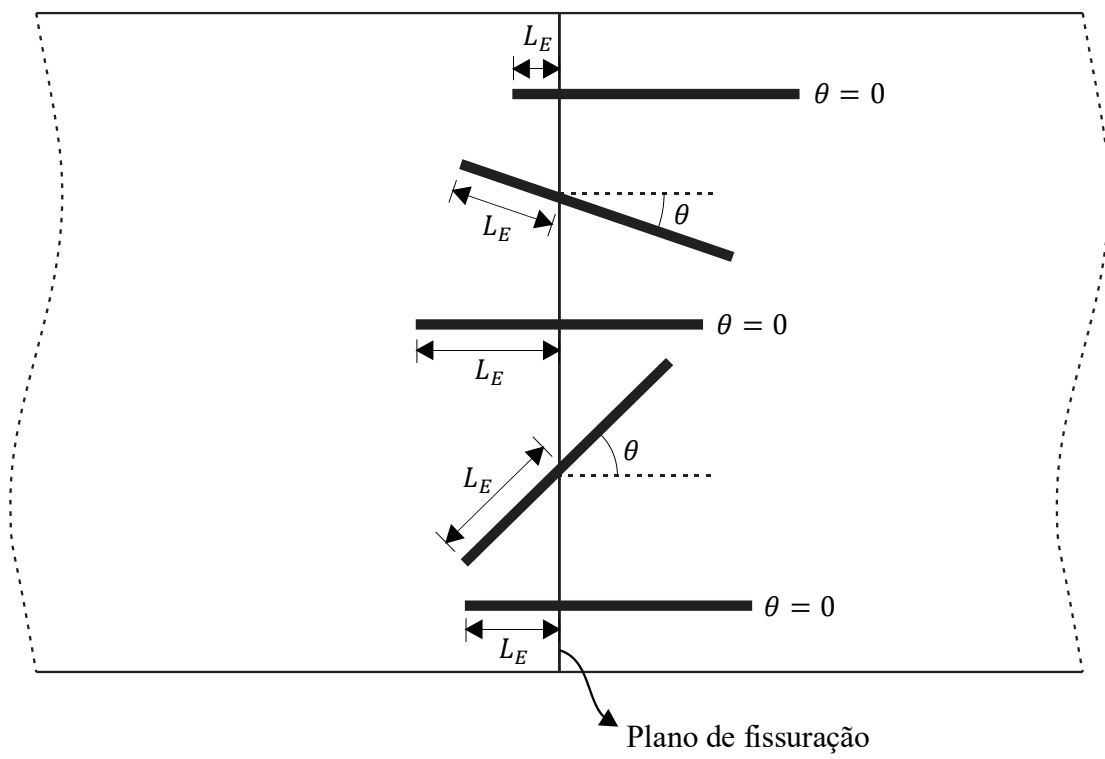

Figura 2.37 - Representação do comprimento de embutimento e do ângulo de inclinação das fibras que atravessam o plano de fissuração

\section{- Comprimento de embutimento}

Teoricamente, o comprimento de embutimento máximo de uma fibra que atravessa o plano de fissuração não pode exceder à metade do seu comprimento total. Assim, $L_{E}$ pode assumir valores quaisquer no intervalo de 0 a $L_{f} / 2$. Isso torna esse parâmetro de difícil definição nos modelos numéricos com fibras discretizadas.

Segundo Cunha et al. (2011; 2012), a influência do comprimento de embutimento no comportamento de arrancamento não é tão significativa quanto o efeito do ângulo de inclinação da fibra. Desse modo, como simplificação, os autores assumiram um único valor: $L_{E}=L_{f} / 4$. Esse valor corresponde ao valor médio teórico do comprimento de embutimento de uma fibra que atravessa o plano de fissuração, ou seja, a esperança estatística de $L_{E}$, conforme a Equação (2.43).

$$
E\left[L_{E}\right]=\sum_{i=1}^{n} L_{E_{i}} p\left(L_{E_{i}}\right), \operatorname{com} n \rightarrow \infty
$$

sendo: $L_{E_{i}}$ um comprimento de embutimento dentro do intervalo de 0 a $L_{f} / 2$ (em que $L_{E_{1}}=0$ e $\left.L_{E_{n}}=L_{f} / 2\right)$ e $p\left(L_{E_{i}}\right)$ a sua respectiva probabilidade de ocorrência, idêntica para todos os $L_{E_{i}}$ (nesse caso, $\left.p\left(L_{E_{i}}\right)=1 / n\right)$. Dessa forma, tem-se: $E\left[L_{E}\right]=(1 / n) \sum_{i=1}^{n} L_{E_{i}}=(1 / n)$. $\left[\left(L_{E_{1}}+L_{E_{n}}\right) n / 2\right]=L_{f} / 4$. 
Diferentemente de Cunha et al. (2011; 2012), os trabalhos de Soetens et al. (2012) e Soetens e Matthys $(2012$; 2014) consideraram para o comprimento de embutimento um conjunto de valores dentro do intervalo de 0 a $L_{f} / 2$. Assim, ao determinar o comportamento de arrancamento das fibras, a cada uma foi atribuído um valor de $L_{E}$, de modo a respeitar uma distribuição uniforme. Essa abordagem, apesar de mais realista, apresenta maior dificuldade de implementação computacional.

\section{- Ângulo de inclinação}

A representação das fibras no modelo numérico com elementos de treliça embutidos não é capaz de modelar os efeitos pino e de fragmentação da matriz ocorrentes nas fibras inclinadas que atravessam o plano de fissuração. No entanto, ao levar em conta o ângulo de inclinação da fibra em seu comportamento de arrancamento, a lei tensão-deformação equivalente passa a considerar, além do comportamento de deslizamento relativo da interface, os efeitos pino e de fragmentação da matriz.

Assim, para cada fibra, existe uma lei tensão-deformação equivalente de acordo com o seu ângulo de inclinação em relação ao plano de fissuração, mas tal implementação levaria a um modelo muito complexo. Para contornar esse obstáculo, o ângulo de inclinação pode ser divido em intervalos e, para cada um, é definido um comportamento de arrancamento (CUNHA et al., 2011; 2012; SOETENS et al., 2012; SOETENS; MATTHYS; 2012; 2014). Como exemplificação, em Cunha et al. $(2011 ; 2012)$, as fibras foram divididas em três intervalos de acordo com o seu ângulo de inclinação: $\left[0^{\circ}, 15^{\circ}\left[,\left[15^{\circ}, 45^{\circ}\left[\right.\right.\right.\right.$ e $\left[45^{\circ}, 75^{\circ}[\right.$. Três leis tensãodeformação equivalentes foram então definidas a partir dos comportamentos de arrancamento da fibra para os ângulos de inclinação $0^{\circ}, 30^{\circ}$ e $60^{\circ}$, e atribuídas para cada intervalo, respectivamente. A contribuição das fibras $\operatorname{com} \theta$ no intervalo $\left[75^{\circ}, 90^{\circ}\right]$ foi negligenciada no modelo. 


\section{ANÁLISE EXPERIMENTAL}

Com o intuito de investigar o comportamento do UHPC e UHPFRC no âmbito material e estrutural, e de validar o modelo numérico proposto nesta pesquisa - modelo com fibras discretizadas e embutidas na matriz cimentícia de UHPFRC -, esta seção fornece uma apresentação detalhada dos ensaios experimentais realizados: ensaios de caraterização dos concretos e ensaio de flexão das vigas.

\subsection{Concreto de Ultra-Alto Desempenho Reforçado com Fibras}

\subsubsection{Materiais}

Foi utilizado na composição do UHPFRC o cimento Portland de alta resistência inicial (CPV ARI) com massa específica de $3,16 \mathrm{~g} / \mathrm{cm}^{3}$. O agregado miúdo utilizado foi a areia industrial fina com massa específica de $2,64 \mathrm{~g} / \mathrm{cm}^{3}$, sendo o componente granular de maior dimensão da composição (diâmetro máximo de $0,42 \mathrm{~mm}$ ). $\mathrm{O}$ agregado graúdo foi eliminado com o intuito de melhorar a homogeneidade do concreto. O pó de quartzo com massa específica de $2,72 \mathrm{~g} / \mathrm{cm}^{3}$ foi empregado para preencher a falha granulométrica entre a areia fina e o cimento. A sílica ativa não densificada com massa específica de $2,22 \mathrm{~g} / \mathrm{cm}^{3}$ foi o menor componente granular utilizado, sendo seu diâmetro pequeno suficiente para preencher os vazios entre o cimento e o pó de quartzo. A fluidez proporcionada pela baixa relação água/cimento foi assegurada pela utilização do aditivo superplastificante à base de policarboxilato com massa específica de $1,06 \mathrm{~g} / \mathrm{cm}^{3}$. As fibras de aço incorporadas à composição foram as lisas e curtas revestidas de cobre. As características das fibras de aço estão listadas na Tabela 3.1. 
Tabela 3.1 - Caraterísticas das fibras de aço utilizadas no UHPFRC

\begin{tabular}{cccccc}
\hline$L_{f}(\mathrm{~mm})$ & $d_{f}(\mathrm{~mm})$ & $f_{t, f}(\mathrm{MPa})$ & $E_{f}(\mathrm{GPa})$ & $v_{f}$ & $\rho_{f}\left(\mathrm{~g} / \mathrm{cm}^{3}\right)$ \\
\hline 13 & 0,2 & 2850 & 200 & 0,3 & 7,8
\end{tabular}

sendo: $L_{f}$ o comprimento, $d_{f}$ o diâmetro, $f_{t, f}$ a resistência à tração, $E_{f}$ o módulo de elasticidade, $v_{f} \mathrm{o}$ coeficiente de Poisson e $\rho_{f}$ a massa específica da fibra.

\subsubsection{Composição e procedimento de mistura}

A composição utilizada nesta pesquisa, apresentada na Tabela 3.2, foi baseada no estudo desenvolvido por Sobuz et al. (2016), com algumas adaptações relacionadas à quantidade de água e aditivo superplastificante, necessárias para proporcionar fluidez à mistura. Três frações volumétricas de fibras de aço foram consideras: 0\% (UHPC), 1\% (UHPFRC-1) e 2\% (UHPFRC-2), resultando em três diferentes composições.

Tabela 3.2 - Composição da matriz do concreto de ultra-alto desempenho reforçado com fibra

\begin{tabular}{cccccccc}
\hline \multicolumn{8}{c}{ Consumo de materiais $\left(\mathrm{kg} / \mathrm{m}^{3}\right.$ de concreto) } \\
\hline Cimento & Areia fina & Pó de quartzo & Sílica ativa & Água & $\begin{array}{c}\text { Aditivo } \\
\text { superplastificante }\end{array}$ & a/c & a/agl \\
\hline 757,2 & 833,0 & 378,6 & 189,3 & 159,0 & 68,2 & 0,21 & 0,12 \\
\hline
\end{tabular}

Observação: porcentagem de fibra em volume: $0 \%$ (UHPC), 1\% (UHPFRC-1) e 2\% (UHPFRC-2).

Para a produção do UHPC, UHPFRC-1 e UHPFRC-2, o procedimento de mistura foi realizado em um misturador de eixo de rotação vertical (capacidade de 250 litros). Inicialmente, a areia fina e um quarto da água foram misturados por 1 minuto. Em seguida, foram adicionados o cimento, a sílica ativa, o pó de quartzo e mais um quarto da água, e misturados por mais 3 minutos. Após esse processo, o restante da água foi adicionado, misturando-se por mais 4 minutos. Para obter uma mistura fluida, foi então adicionado o aditivo superplastificante, misturando-se por mais 15 minutos (para o UHPC) e 10 minutos (para o UHPFRC). Por fim, as fibras foram incorporadas à mistura, misturando-se por mais 5 minutos (para o UHPFRC). 


\subsubsection{Ensaios de caracterização}

Para caracterizar os concretos, foram realizados os seguintes ensaios: ensaio de compressão uniaxial, ensaio de tração uniaxial, ensaio de flexão a três pontos e ensaio de compressão diametral. Além de obter as propriedades mecânicas dos concretos, a caracterização também teve como objetivo compreender o comportamento mecânico dos mesmos para alimentar o modelo numérico proposto nesta pesquisa. Assim, os ensaios de caraterização foram realizados próximos da data dos ensaios de flexão das vigas pré-moldadas de UHPC e UHPFRC, aproximadamente aos 56 dias de idade. É importante ressaltar também que os corpos de prova utilizados foram mantidos nas mesmas condições de cura que as vigas: cura úmida por 28 dias (molhagem uma vez ao dia).

A Tabela 3.3 apresenta a quantidade de corpos de prova utilizada em cada ensaio para cada composição de concreto.

Tabela 3.3 - Quantidade de corpos de prova utilizada nos ensaios de caracterização aos 56 dias

\begin{tabular}{cccc}
\hline Ensaio & UHPC & UHPFRC-1 & UHPFRC-2 \\
\hline Compressão uniaxial & 5 & 10 & 10 \\
\hline Tração uniaxial & 6 & 6 & 6 \\
\hline Flexão a três pontos & 4 & 4 & 4 \\
\hline Compressão diametral & 3 & 3 & 3 \\
\hline
\end{tabular}

\subsubsection{Ensaio de compressão uniaxial}

O ensaio de compressão foi realizado em corpos de prova cilíndricos de $50 \mathrm{~mm}$ de diâmetro e $100 \mathrm{~mm}$ de altura. A força de compressão foi aplicada utilizando uma máquina de ensaio universal servo-hidráulica com capacidade máxima de $1500 \mathrm{kN}$ por meio do controle de deslocamento a uma taxa de $0,005 \mathrm{~mm} / \mathrm{s}$. No ensaio, foram determinados a resistência à compressão, o módulo de elasticidade e a curva tensão-deformação. Para obter o trecho linear da curva tensão-deformação, bem como o módulo de elasticidade, dois extensômetros tipo clipgage foram fixados no corpo de prova. Cada clip-gage mede o deslocamento longitudinal do corpo de prova, sendo a base de medida de $50 \mathrm{~mm}$. Além disso, para obter o trecho não linear da curva tensão-deformação, dois transdutores de deslocamento (LVDT) foram posicionados 
entre as placas de aço da máquina de ensaio, sendo a base de medida de $100 \mathrm{~mm}$. A configuração detalhada do ensaio de compressão uniaxial é mostrada na Figura 3.1.
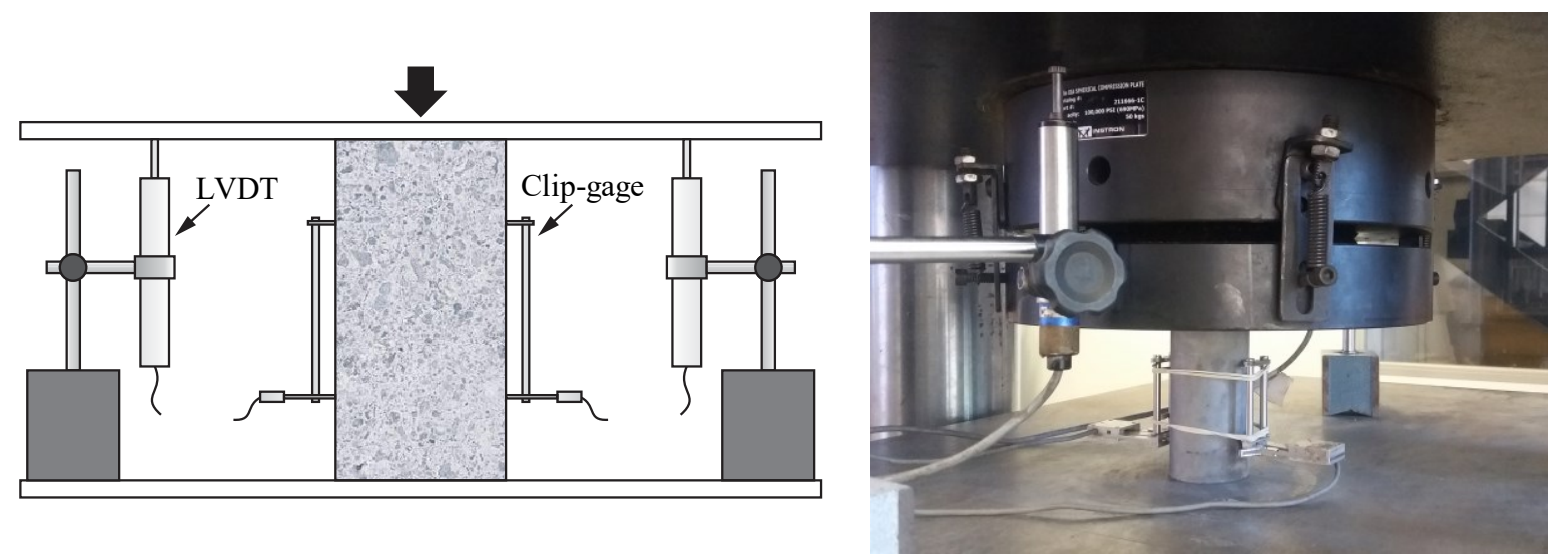

Figura 3.1 - Configuração do ensaio de compressão uniaxial

O módulo de elasticidade foi determinado segundo a ASTM C469/C469M-14 (2014), pela Equação (3.1).

$$
E_{c}=\frac{0,4 f_{c}-f_{1}}{\varepsilon_{2}-0,00005}
$$

sendo: $E_{c}$ o módulo de elasticidade, $f_{c}$ a resistência à compressão, $f_{1}$ a tensão de compressão correspondente à deformação longitudinal de $0,00005 \mathrm{~mm} / \mathrm{mm}$ e $\varepsilon_{2}$ a deformação correspondente à tensão de $0,4 f_{c}$.

A inclinação inicial das curvas tensão-deformação obtidas pelo clip-gage e pelo LVDT é diferente, pois o LVDT registra as acomodações entre a máquina e o corpo de prova no início do ensaio. A Equação (3.2) permite corrigir esse efeito (OSORIO et al., 2013).

$$
\varepsilon_{1}=\varepsilon_{1, L V D T}-\frac{\left(E_{\text {clip }}-E_{L V D T}\right)}{E_{\text {clip }}-E_{L V D T}} \sigma_{1}
$$

sendo: $\varepsilon_{1}$ a deformação longitudinal corrigida, $\varepsilon_{1, L V D T}$ a deformação longitudinal média obtida pelos LVDTs, $\sigma_{1}$ a tensão de compressão correspondente à deformação $\varepsilon_{1, L V D T}, E_{c l i p}$ e $E_{L V D T}$ os módulos de elasticidade obtidos pelo clip-gage e pelo LVDT, respectivamente.

\subsubsection{Ensaio de tração uniaxial}

O ensaio de tração uniaxial foi realizado em corpos de prova não entalhados em forma de dog-bone com dimensões apresentadas na Figura 3.2. A força de tração foi aplicada sob controle de deslocamento a uma taxa de $0,005 \mathrm{~mm} / \mathrm{s}$ utilizando a mesma máquina do ensaio de 
compressão uniaxial. No ensaio, foram determinadas a resistência à tração, a energia de fratura e a curva tensão-deformação. Para obter a curva tensão-deformação, dois LVDTs foram posicionados na região central do corpo de prova sendo a base de medida de $80 \mathrm{~mm}$. A configuração detalhada do ensaio de tração uniaxial é exposta na Figura 3.2.

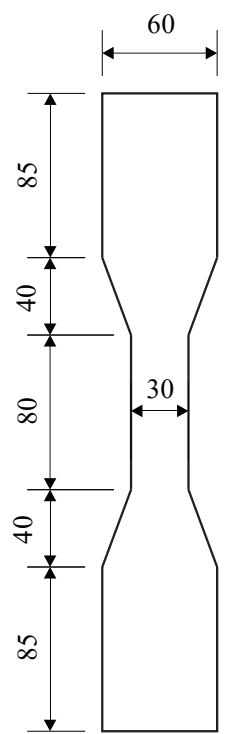

Vista frontal

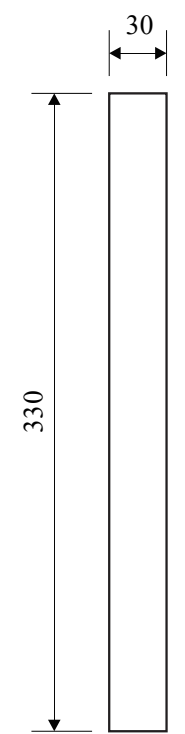

Vista lateral (unidade: $\mathrm{mm}$ )
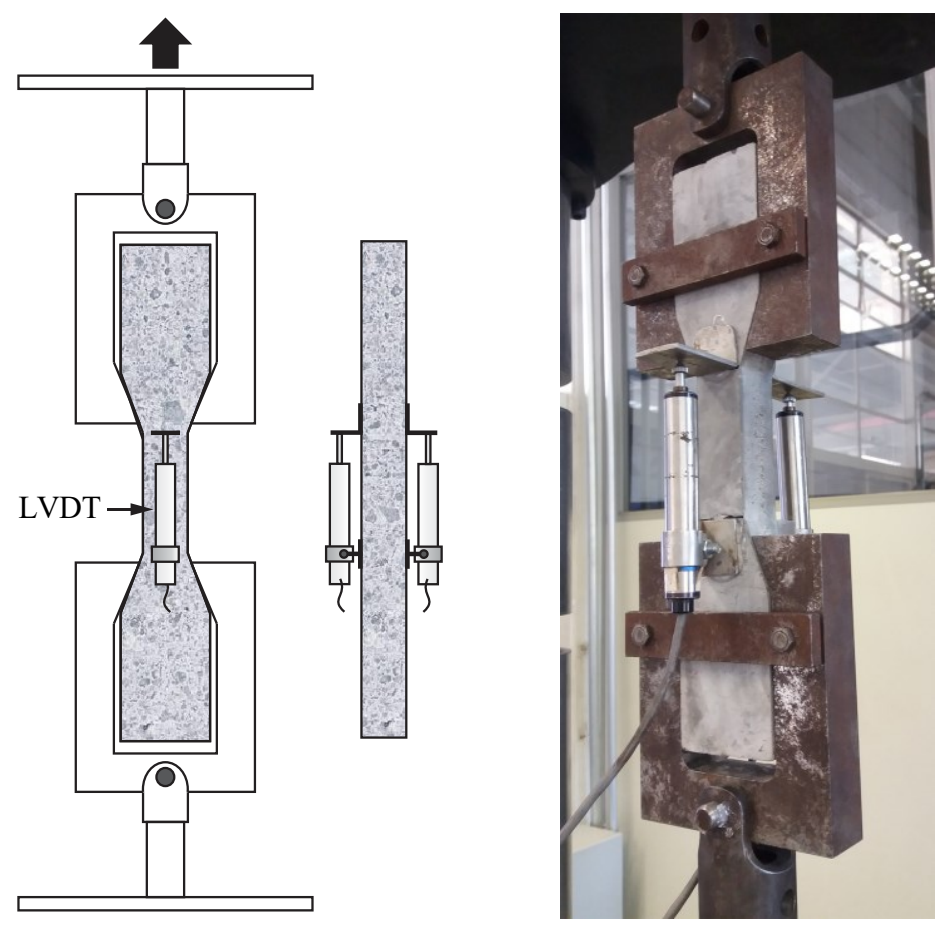

Figura 3.2 - Dimensões dos corpos de prova (dog-bone) e configuração do ensaio de tração uniaxial

A energia de fratura no ensaio de tração uniaxial sem entalhe foi determinada conforme realizado por Wille e Naaman (2010) e Xu e Wille (2015), sendo a área sob a curva tensãodeslocamento longitudinal, excluindo a área correspondente à região elástica linear (energia elástica), ver Figura 2.8.

\section{1.3.3 Ensaio de flexão a três pontos}

No caso do ensaio de flexão a três pontos, foram ensaiados corpos de prova prismáticos $150 \times 150 \times 450 \mathrm{~mm}$ com entalhe de $30 \mathrm{~mm}$ de altura no meio do vão, de acordo com a Figura 3.3. Em geral, os prismas são rotacionados $90^{\circ}$ a partir da sua posição de concretagem, para reduzir a rugosidade superficial durante a aplicação da força. Nesta pesquisa, no entanto, para considerar adequadamente os padrões de distribuição das fibras de acordo com a direção da concretagem, os prismas foram ensaiados sem a rotação, sendo a região de aplicação da força (superfície rugosa) retificada com auxílio de uma lixadeira. O ensaio, realizado na mesma 
máquina do ensaio de compressão uniaxial, foi controlado pelo deslocamento da abertura de fissura (CMOD) a uma taxa inicial de $0,0001 \mathrm{~mm} / \mathrm{s}$; para isso, foi fixado um extensômetro tipo clip-gage no entalhe. No ensaio, foram determinadas a resistência à flexão, a energia de fratura e as curvas força-abertura de fissura e força-deslocamento vertical no meio do vão. Para obter o deslocamento vertical no meio do vão, foram posicionados dois LVDTs na região central do corpo de prova. A configuração detalhada do ensaio de flexão a três pontos é apresentada na Figura 3.3.

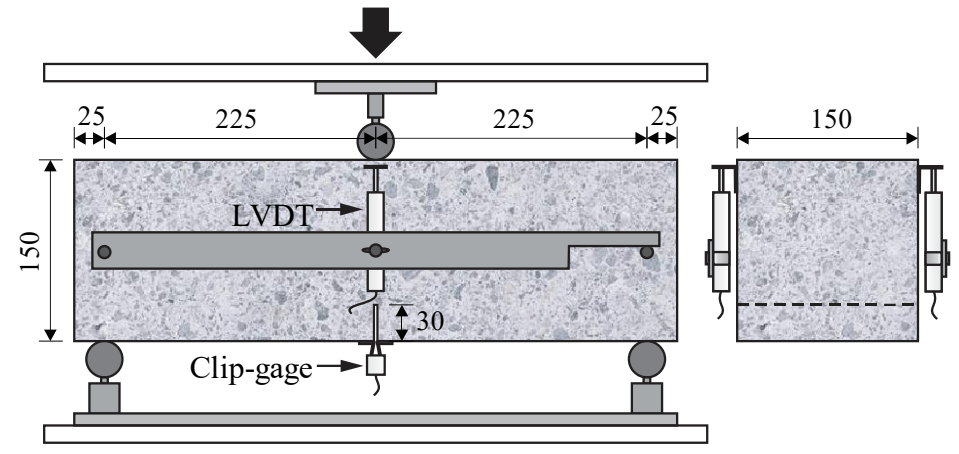

(unidade: $\mathrm{mm}$ )

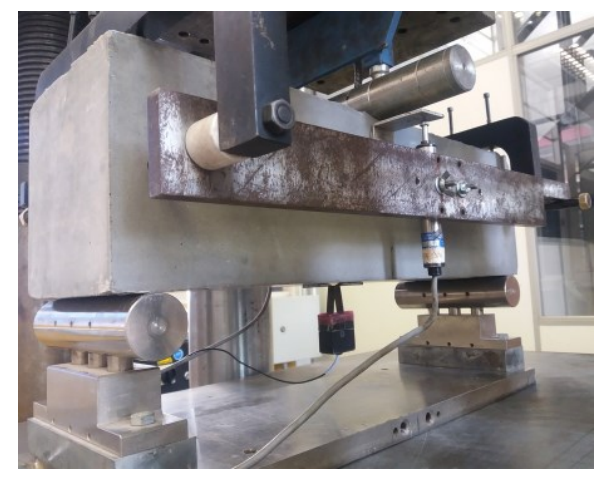

Figura 3.3 - Configuração do ensaio de flexão a três pontos

As tensões de flexão foram determinadas segundo o RILEM TC 162-TDF (2002), pela Equação (3.3).

$$
\sigma=\frac{3 F L}{2 b\left(h-a_{0}\right)^{2}}
$$

sendo: $\sigma$ a tensão de flexão, $F$ a força aplicada, $L$ o comprimento do vão, $b$ a largura do prisma, $h$ a altura do prisma e $a_{0}$ a altura do entalhe.

A energia de fratura no ensaio de flexão a três pontos com entalhe foi quantificada conforme proposto pelo RILEM 50 FMC (1985), pela Equação (3.4).

$$
G_{f}=\frac{W_{0}+m_{0} g \delta_{0}}{b\left(h-a_{0}\right)}
$$

sendo: $G_{f}$ a energia de fratura, $W_{0}$ a área sob a curva força-deslocamento vertical no meio do vão, $m_{0}$ a massa do prisma entre os apoios, incluindo a massa do equipamento acoplado ao prisma, $g$ a aceleração da gravidade, $\delta_{0}$ o deslocamento último, $b$ a largura do prisma, $h$ a altura do prisma e $a_{0}$ a altura do entalhe. 


\subsubsection{Ensaio de compressão diametral}

O ensaio de compressão diametral foi realizado em corpos de prova cilíndricos de 50 $\mathrm{mm}$ de diâmetro e $100 \mathrm{~mm}$ de altura e conduzido sob o controle de força a uma taxa de 0,35 $\mathrm{kN} / \mathrm{s}$, utilizando a mesma máquina do ensaio de compressão uniaxial. No ensaio, foram determinadas a resistência à tração por compressão diametral e a curva tensão-deslocamento vertical. Para obter o deslocamento vertical, dois LVDTs foram posicionados entre as placas de aço da máquina de ensaio. A configuração detalhada do ensaio de compressão diametral é exposta na Figura 3.4.
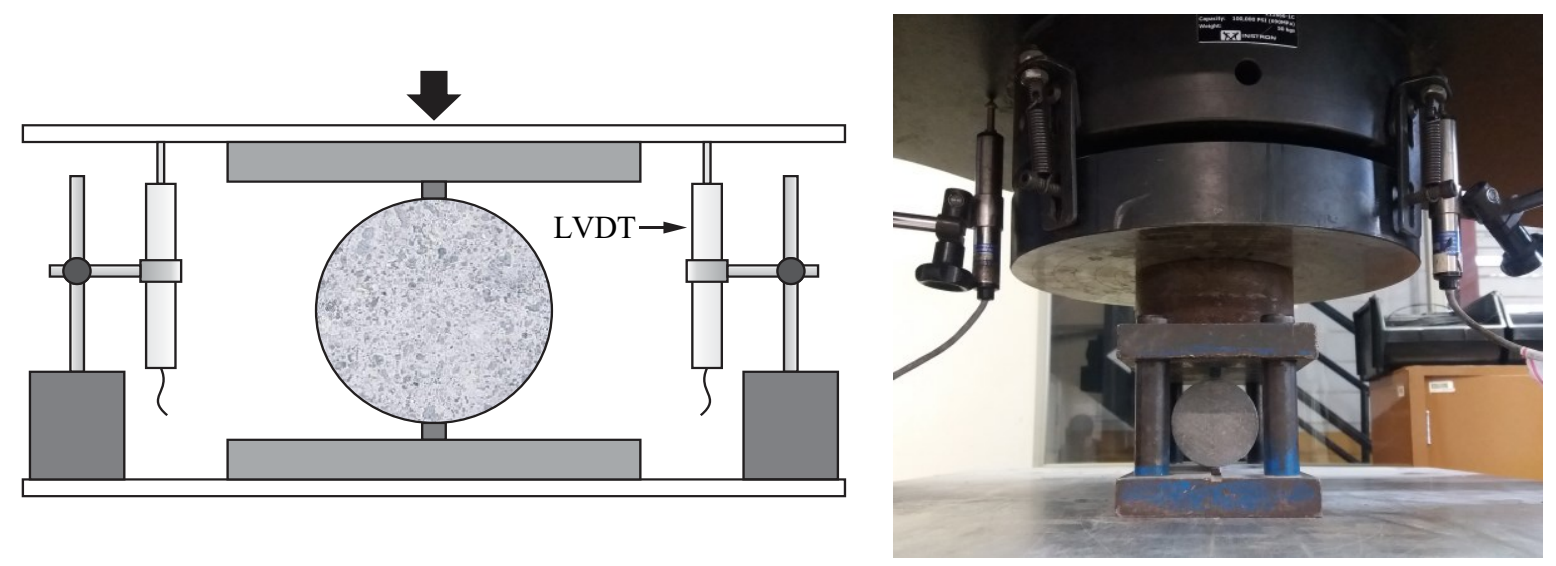

Figura 3.4 - Configuração do ensaio de compressão diametral

As tensões de tração por compressão diametral foram determinadas segundo a ABNT NBR 7222 (2011), pela Equação (3.5).

$$
\sigma=\frac{2 F}{\pi d l}
$$

sendo: $\sigma$ a tensão de tração por compressão diametral, $F$ a força aplicada, $d$ e $l$ o diâmetro e comprimento do corpo de prova, respectivamente. 


\subsection{Vigas Pré-Moldadas de UHPC e UHPFRC}

\subsubsection{Geometria, dimensões e detalhamento das vigas}

O dimensionamento de elementos estruturais de UHPFRC está fora do escopo desta pesquisa. Em razão disso, as vigas pré-moldadas de UHPC e UHPFRC foram similares às do trabalho desenvolvido por Yoo e Yoon (2015), com algumas adaptações relacionadas ao comprimento das vigas e à locação da armadura transversal (estribos). Todas as vigas possuíram seção transversal retangular de $150 \times 220 \mathrm{~mm}$ e comprimento de $2000 \mathrm{~mm}$, como apresentado na Figura 3.5.
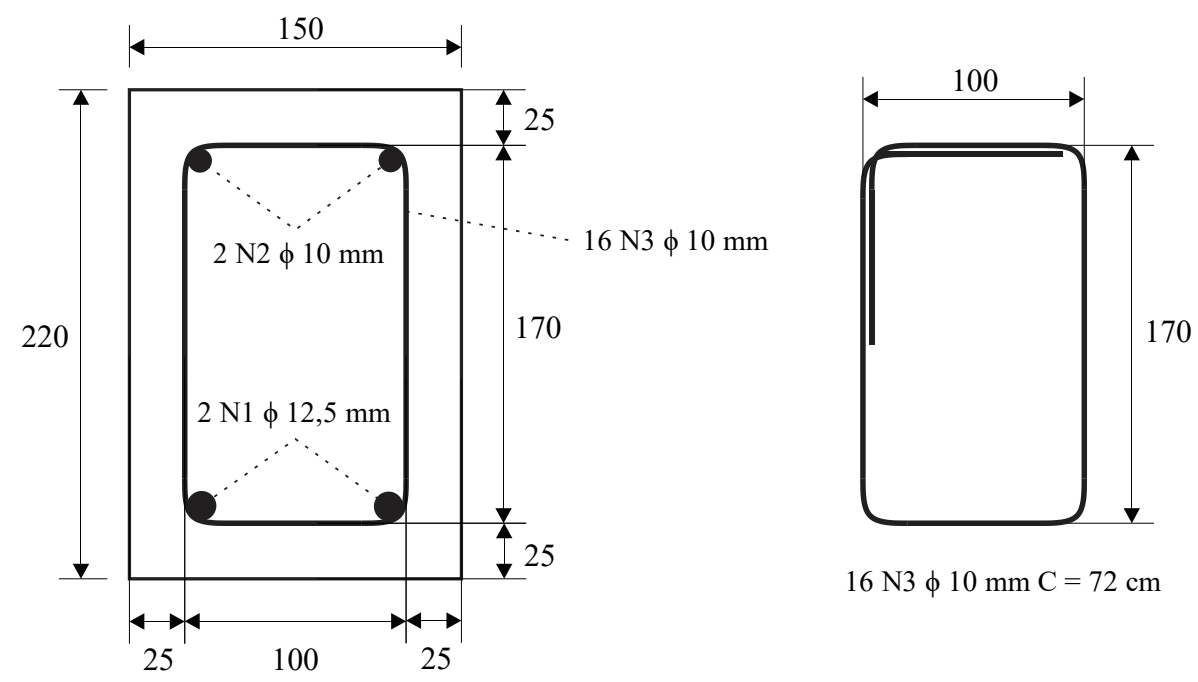

$16 \mathrm{~N} 3 \phi 10 \mathrm{~mm} \mathrm{C}=72 \mathrm{~cm}$

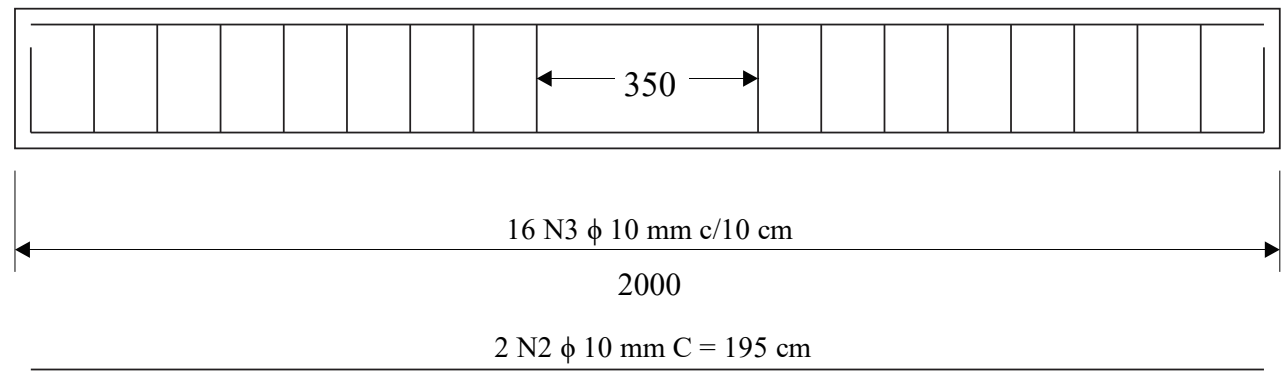

$2 \mathrm{~N} 1 \phi 12,5 \mathrm{~mm} \mathrm{C}=221 \mathrm{~cm}$

(unidade: $\mathrm{mm}$ )

Figura 3.5 - Geometria, dimensões e detalhamento das vigas 
A Tabela 3.4 resume as características das armaduras longitudinais e transversais, ambas de aço CA-50, utilizadas nas vigas de UHPC e UHPFRC.

Tabela 3.4 - Características das armaduras de aço utilizadas nas vigas

\begin{tabular}{ccccccc}
\hline Armadura de aço & Nomenclatura & $d_{s}(\mathrm{~mm})$ & $A_{s}\left(\mathrm{~mm}^{2}\right)$ & $f_{y}(\mathrm{MPa})$ & $E_{s}(\mathrm{GPa})$ & $v_{s}$ \\
\hline Longitudinal & $\mathrm{N} 1$ & 12,5 & 122,7 & 540 & 200 & 0,3 \\
\cline { 2 - 7 } & $\mathrm{N} 2$ & 10 & 78,5 & 553 & 200 & 0,3 \\
\hline Transversal & $\mathrm{N} 3$ & 10 & 78,5 & 553 & 200 & 0,3 \\
\hline
\end{tabular}

sendo: $d_{s}$ o diâmetro, $A_{s}$ a área da seção transversal, $f_{y}$ a resistência ao escoamento, $E_{s}$ o módulo de elasticidade e $v_{s}$ o coeficiente de Poisson da armadura.

A adaptação do comprimento das vigas foi necessária devido à capacidade máxima do misturador utilizado: Yoo e Yoon (2015) estudaram vigas com $2500 \mathrm{~mm}$ de comprimento; nesta pesquisa, para possibilitar a produção das vigas, juntamente com os corpos de prova para a caracterização do material, o comprimento foi reduzido para $2000 \mathrm{~mm}$.

Sobre a locação da armadura transversal, Yoo (2014) estudou o comportamento à flexão de vigas de seção retangular de UHPFRC reforçadas apenas com armadura longitudinal, ou seja, sem estribos. $\mathrm{O}$ autor concluiu que as vigas apresentaram falha tanto por flexão quanto por cisalhamento. Diante desse fato, Yoo e Yoon (2015), que desenvolveram um estudo semelhante ao de Yoo (2014), alocaram estribos ao longo de todo comprimento das vigas, para assegurar falha unicamente por flexão. Nesta pesquisa, como as vigas foram submetidas a ensaio de flexão a quatro pontos e, posteriormente, realizada a análise de imagem em seções sob flexão pura (para verificar os padrões de orientação das fibras), optou-se por alocar a armadura transversal apenas nas regiões com esforços cortantes, pois, segundo Yoo e Yoon (2015), os estribos podem dificultar a análise de imagem por fotografia de alta resolução.

\subsubsection{Procedimento de moldagem e cura das vigas}

Realizada a preparação das formas com armaduras nelas alocadas (Figura 3.6a), o concreto foi lançado ao longo do comprimento, respeitando o seguinte procedimento: a cada um terço da altura da forma preenchida com concreto, foi realizada a vibração de mesa (Figura $3.6 \mathrm{~b})$ por 10 segundos, conforme esquematizado na Figura 3.7. Ressalta-se que o método lançamento do UHPFRC na forma tem grande influência sobre a orientação e dispersão das fibras e, consequentemente, sobre o comportamento à flexão. Assim, o lançamento do concreto 
foi padronizado e realizado com precisão durante a moldagem das vigas, a fim de assegurar uma boa repetição entre elas.

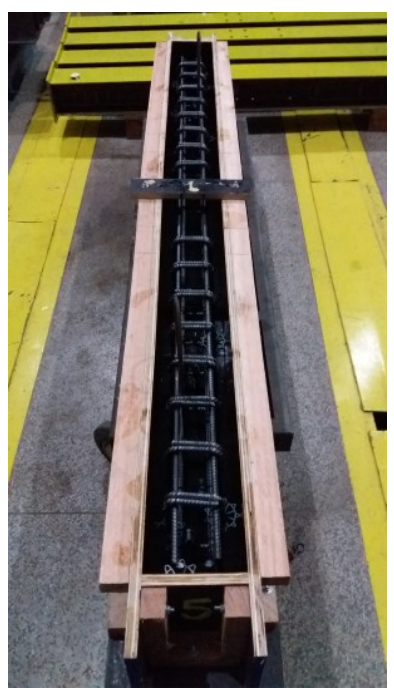

(a)

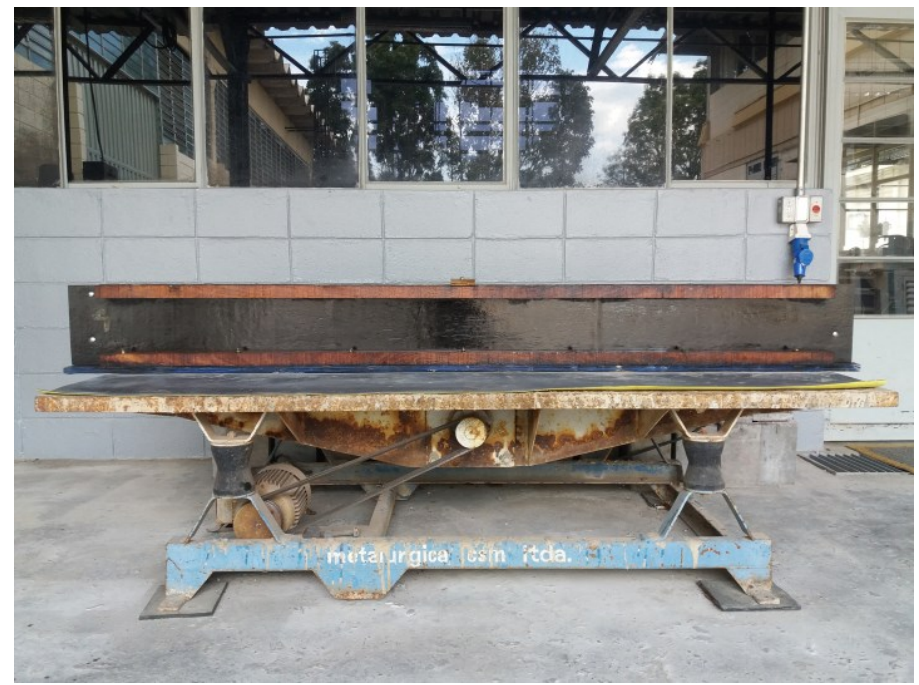

(b)

Figura 3.6 - Procedimento de moldagem das vigas: (a) forma com armaduras e (b) mesa vibratória

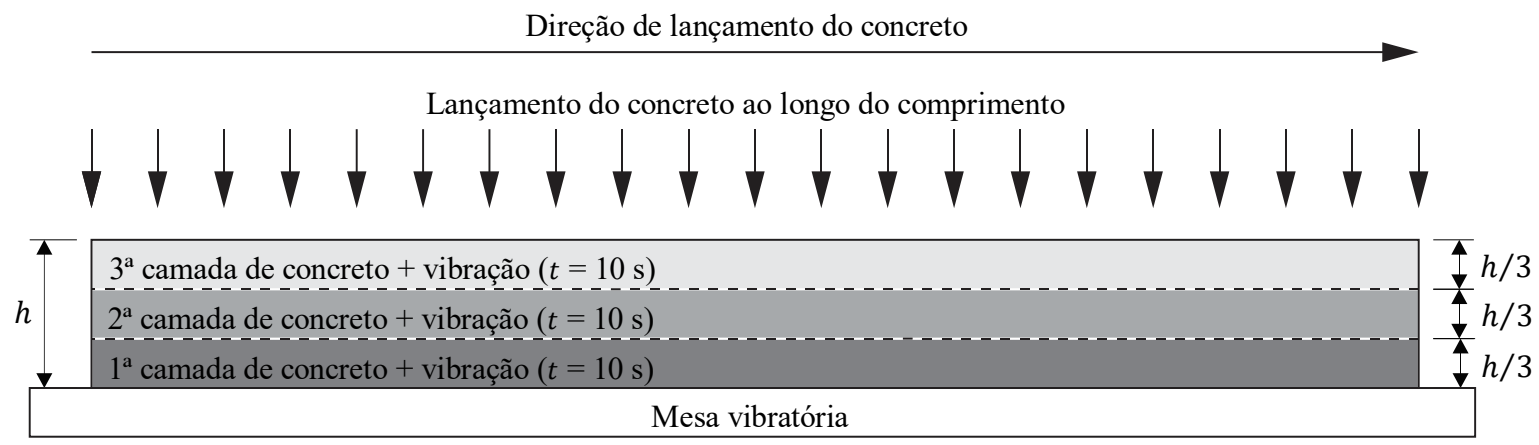

Figura 3.7 - Procedimento de moldagem das vigas: método de lançamento do concreto na forma

Após lançamento do concreto, as vigas foram cobertas com plástico por 36 horas. O procedimento de cura iniciou-se em seguida, mantendo as vigas nas formas e as cobrindo com espumas. Foi realizada a cura úmida por molhagem uma vez ao dia, durante 28 dias. Ao fim, as vigas foram desmoldadas e mantidas em temperatura ambiente até a data dos ensaios de flexão (aproximadamente aos 56 dias de idade).

\subsubsection{Quantidade produzida de vigas}

Cinco vigas pré-moldadas foram produzidas e ensaiadas à flexão a quatro pontos, sendo uma de UHPC, duas de UHPFRC-1 e duas de UHPFRC-2, conforme apresentado na Tabela 
3.5. A variação da fração volumétrica de fibras de aço foi adotada com o intuito de investigar a sua influência sobre o comportamento à flexão das vigas.

Tabela 3.5 - Quantidade produzida de vigas de UHPC e UHPFRC

\begin{tabular}{cccc}
\hline \multirow{2}{*}{ Concreto } & Porcentagem de fibra em volume & \multicolumn{2}{c}{ Viga } \\
\cline { 3 - 4 } & $0 \%$ & Quantidade & Nomenclatura \\
\hline UHPC & $1 \%$ & 2 & V0 \\
\hline UHPFRC-1 & $2 \%$ & 2 & V1-1 \\
\hline UHPFRC-2 & & 2 & V2-1 \\
\hline
\end{tabular}

A Figura 3.8 mostra as vigas e os corpos de prova de UHPC e UHPFRC produzidos para os ensaios de flexão e de caracterização, respectivamente, em temperatura ambiente, ou seja, após o procedimento de cura de 28 dias.

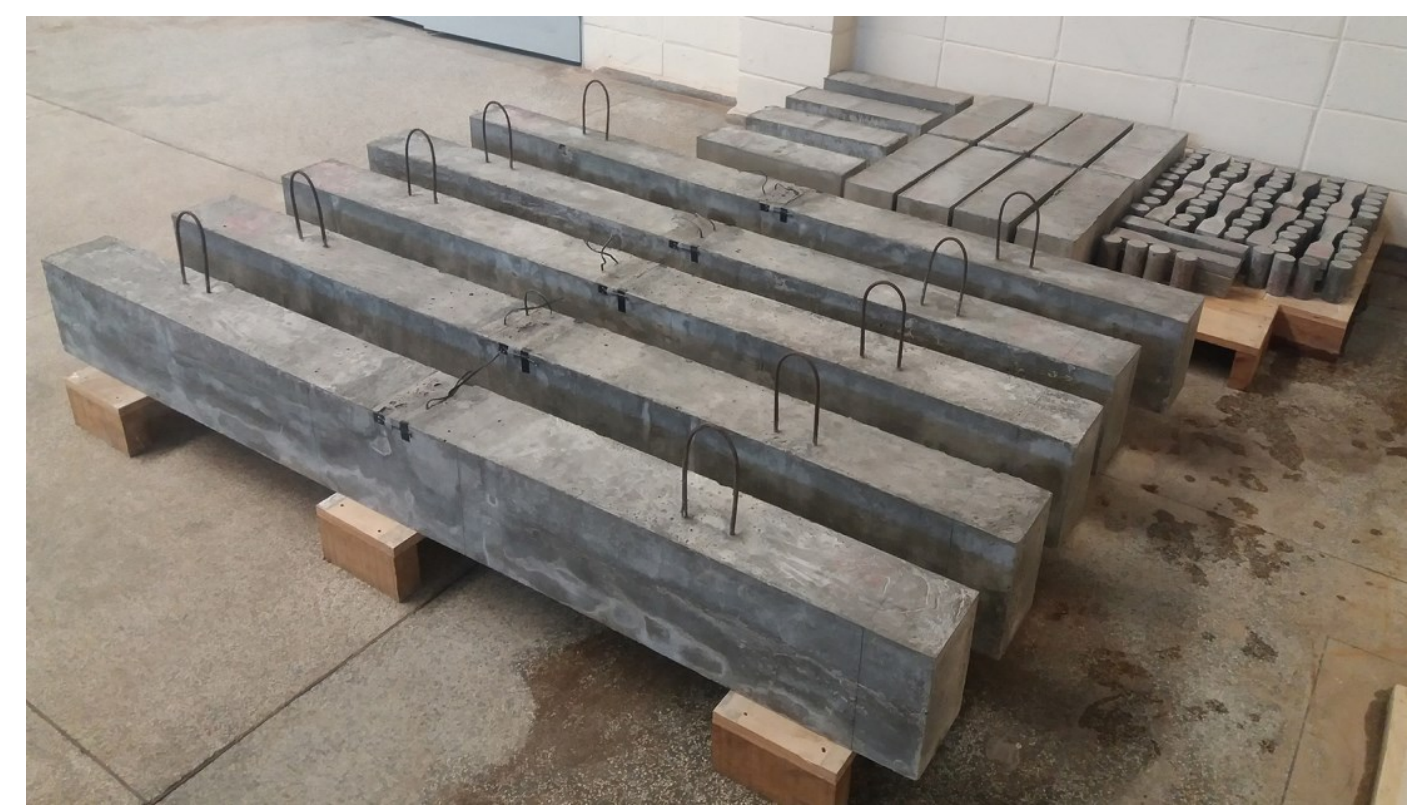

Figura 3.8 - Vigas e corpos de provas de UHPC e UHPFRC produzidos para os ensaios de flexão e de caracterização, respectivamente

\subsubsection{Ensaio de flexão das vigas}

As vigas pré-moldadas de UHPC e UHPFRC foram submetidas a ensaio de flexão a quatro pontos com o intuito de caracterizar o comportamento à flexão, que abrange: o padrão 
de fissuração, o modo de falha, a ductilidade e as curvas força-deslocamento vertical no meio do vão, força-deformação e momento-curvatura. Como já exposto, os ensaios de flexão foram realizados aproximadamente aos 56 dias de idade das vigas.

\subsubsection{Configuração, instrumentação e procedimento do ensaio de flexão}

A Figura 3.9 e a Figura 3.10 apresentam a configuração e o posicionamento da instrumentação utilizada no ensaio de flexão a quatro pontos das vigas de UHPC e UHPFRC.
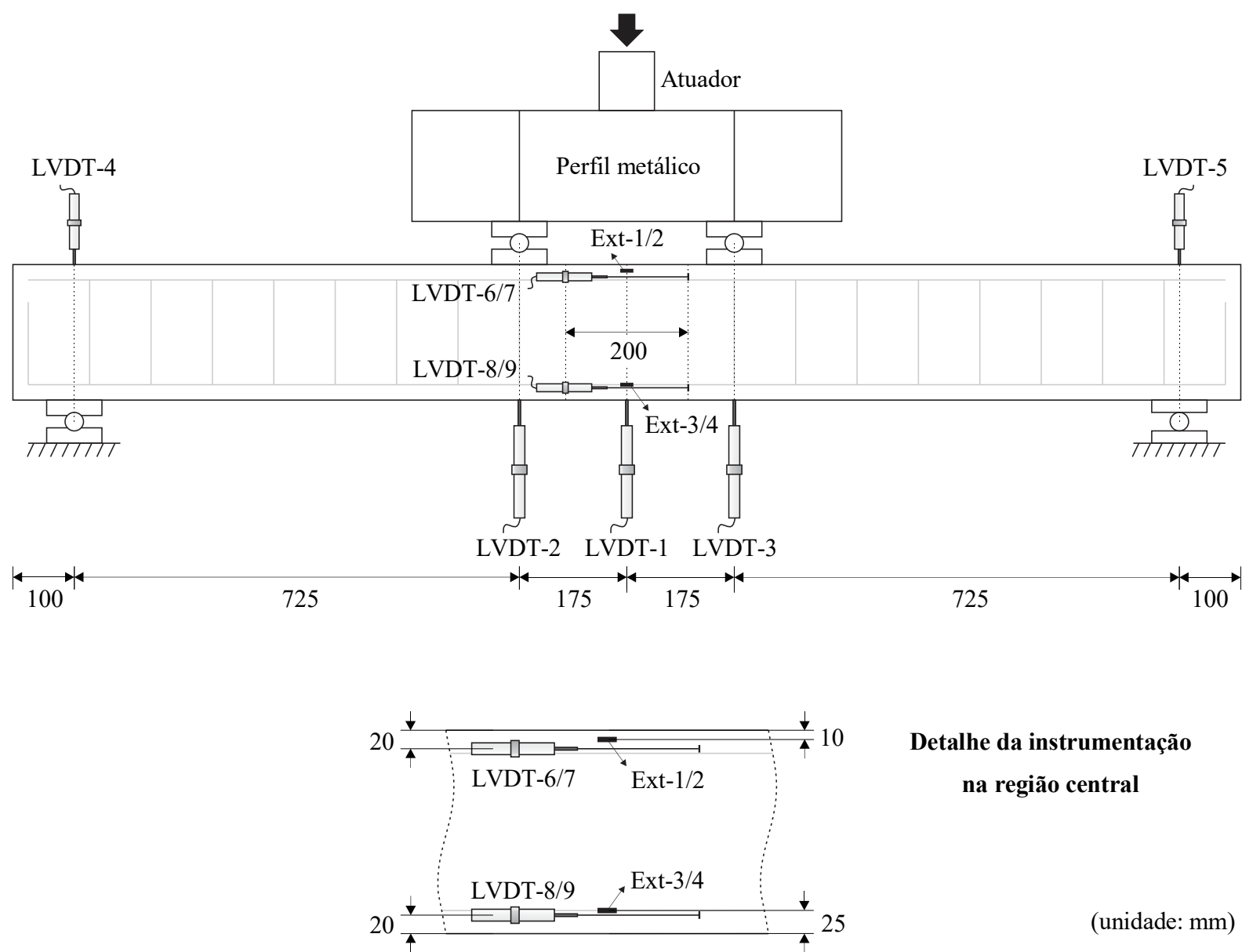

Detalhe da instrumentação

na região central

(unidade: $\mathrm{mm}$ )

Figura 3.9 - Configuração e posição da instrumentação do ensaio de flexão a quatro pontos

("LVDT": transdutor de deslocamento e "Ext:" extensômetro elétrico de resistência) 


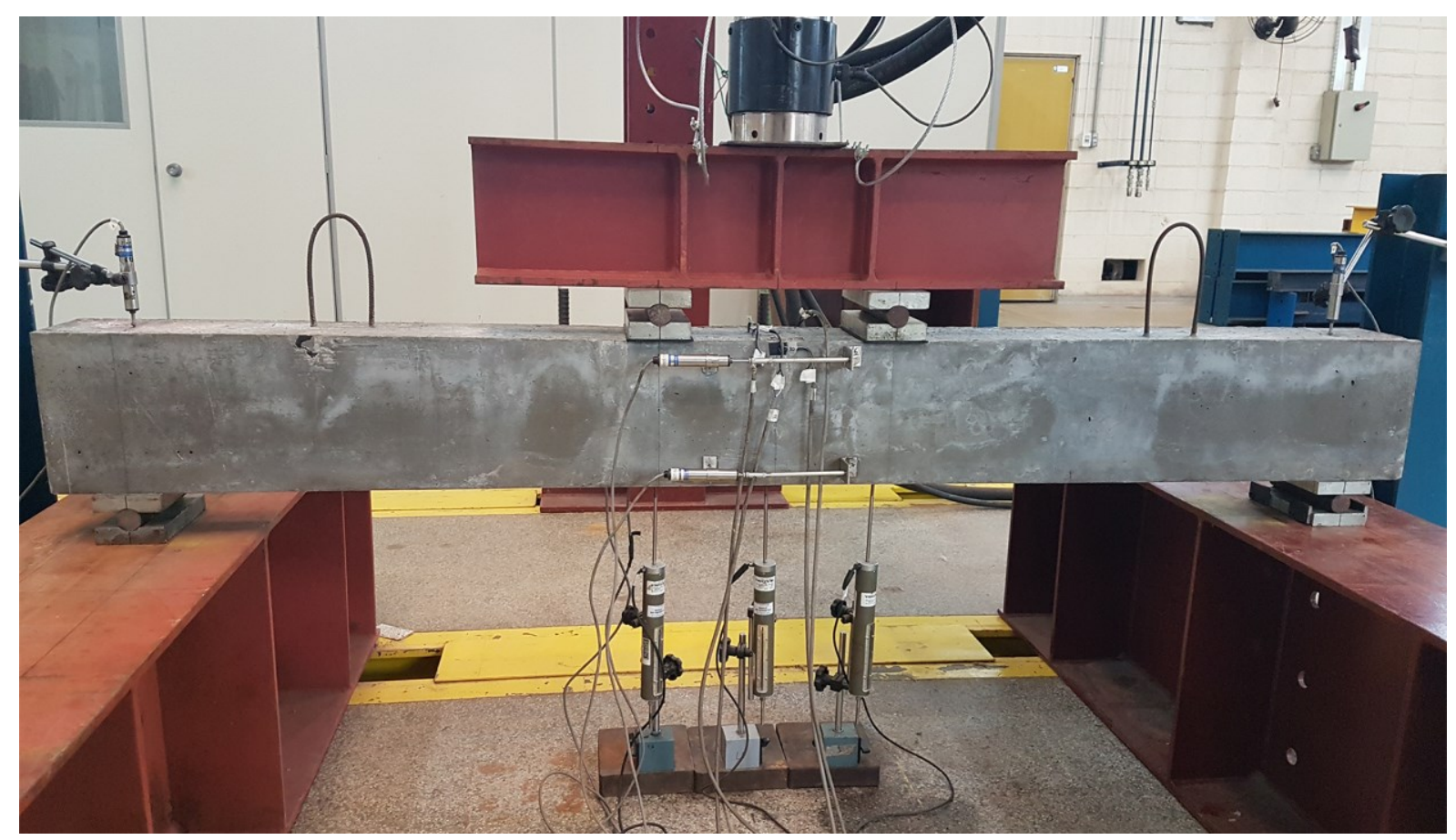

Figura 3.10 - Configuração e instrumentação do ensaio de flexão a quatro pontos

As vigas foram solicitadas à flexão a quatro pontos por meio de carregamento monotônico. Durante o ensaio, foram registradas as forças aplicadas, os deslocamentos verticais e longitudinais correspondentes, e as deformações do concreto e do aço.

Para solicitar as vigas à flexão, foi empregado um atuador servo-hidráulico com capacidade para $500 \mathrm{kN}$ e curso do pistão de $150 \mathrm{~mm}$. Um perfil metálico foi utilizado entre as vigas e o atuador para dividir a força em dois pontos de aplicação, como ilustrado na Figura 3.9 e Figura 3.10. Os ensaios foram conduzidos sob controle de deslocamento a uma taxa de 1,5 $\mathrm{mm} / \mathrm{min}$, e as forças aplicadas foram medidas pela célula de carga acoplada ao atuador.

Os deslocamentos verticais foram monitorados por transdutores de deslocamento posicionados no meio do vão (LVDT-1), nos pontos de aplicação das forças (LVDT-2/3) e nos apoios (LVDT-4/5) das vigas, como indicado na Figura 3.9. Além disso, para registrar os deslocamentos longitudinais (convertidos posteriormente em deformações), foram posicionados, em ambos os lados das vigas, transdutores de deslocamentos nas regiões do concreto comprimindo (LVDT-6/7) e tracionado (LVDT-8/9).

Para monitorar as deformações do concreto e das armaduras longitudinais, foram utilizados extensômetros elétricos de resistência. Os extensômetros foram posicionados na região do concreto comprimido, em ambos os lados (Ext-1/2), e no centro das duas armaduras longitudinais tracionadas (Ext-3/4), conforme apresentado na Figura 3.9. 



\section{ANÁLISE DE IMAGEM}

A fim de estimar o comportamento à flexão das vigas de UHPFRC por meio do modelo numérico com fibras discretizadas proposto nesta pesquisa, os padrões de orientação das fibras foram analisados quantitativamente após o ensaio de flexão das vigas, utilizando-se a técnica de análise de imagem por fotografia de alta resolução em planos de corte próximos ao de fissuração principal.

A seguir, são apresentadas a definição e a forma de obtenção dos planos de corte (planos de análise), bem como a técnica de processamento e análise de imagem para determinação das características de distribuição das fibras nos referidos planos.

\subsection{Planos de Corte}

Para cada viga de UHPFRC, as características de distribuição das fibras foram analisadas em dois planos de corte próximos ao plano de fissuração principal e perpendiculares à direção das tensões de tração, como ilustra a Figura 4.1. As distâncias $d_{1}$ e $d_{2}$ foram definidas de modo que: (a) a orientação das fibras nos planos de corte fosse representativa do plano de fissuração, sendo, portanto, o mais próximas possível deste; e (b) os cortes fossem realizados em posições sem interferência do arrancamento das fibras, causado pela fissuração.

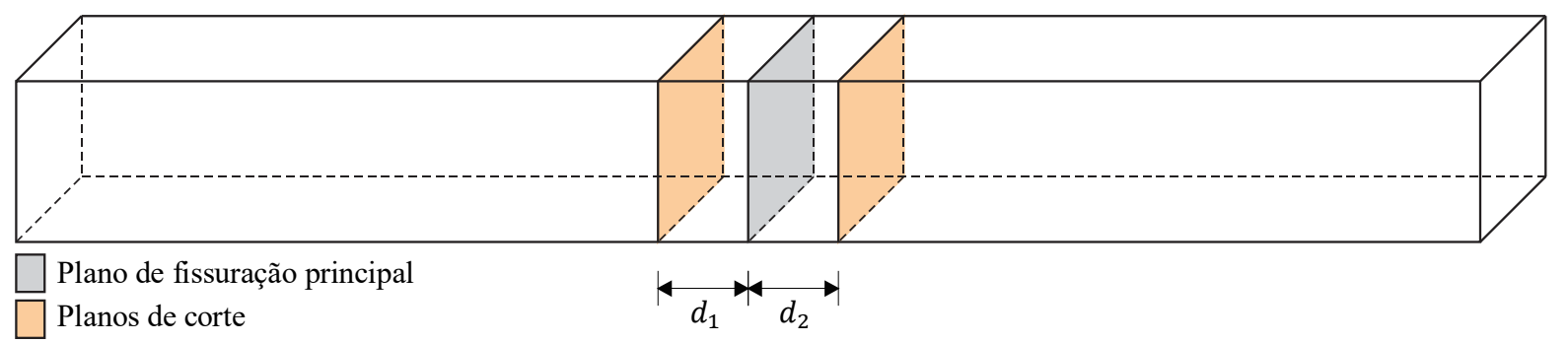

Figura 4.1 - Representação dos planos de corte e de fissuração principal nas vigas de UHPFRC submetidas à flexão a quatro pontos (falha por flexão) 
Após o ensaio de flexão, com o auxílio de uma serra de piso, as extremidades das vigas foram cortadas para facilitar o transporte (Figura 4.2a). Em sequência, para obter uma superfície plana e perpendicular à direção das tensões de tração, os cortes próximos ao plano de fissuração principal foram realizados com precisão utilizando uma serra de bancada (Figura 4.2b). Por fim, para regularizar a forma das fibras de aço, danificada durante o processo de corte, as superfícies dos cortes foram polidas em uma retífica plana de bancada (Figura 4.2c). A Figura 4.3a mostra os planos de corte das vigas de UHPFRC após os processos de corte e polimento.

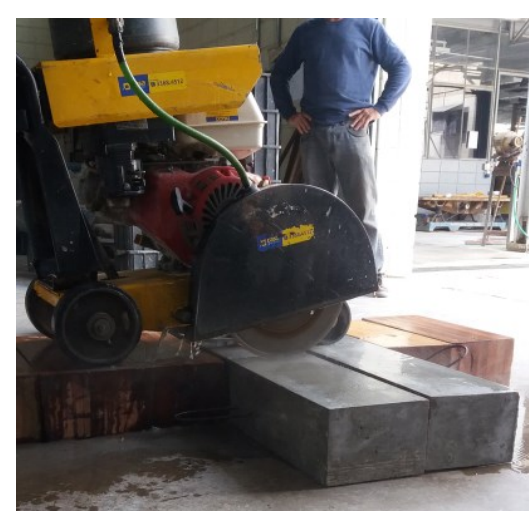

(a)

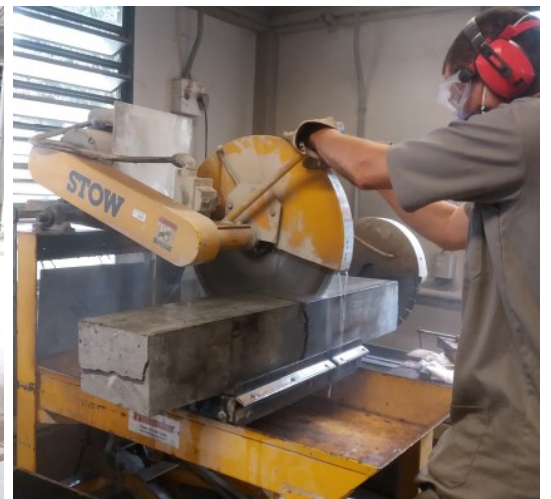

(b)

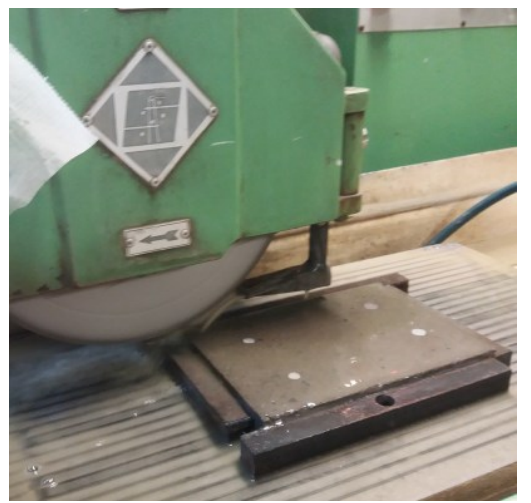

(c)

Figura 4.2 - Obtenção dos planos de corte: (a) corte das extremidade das vigas, (b) corte dos planos próximos ao de fissuração principal e (c) polimento da superfície de corte

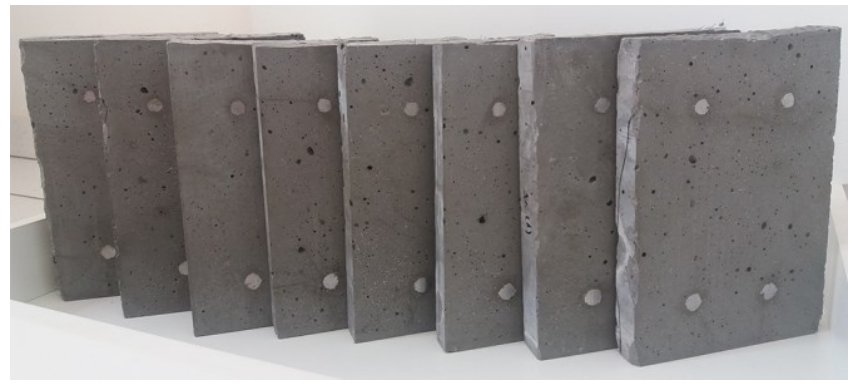

(a)
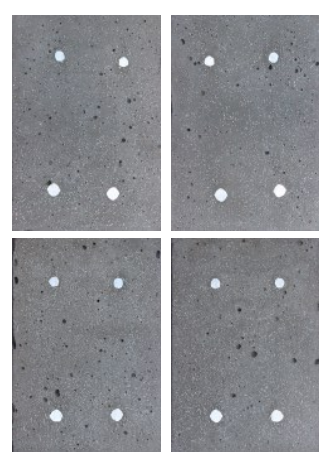

(b)

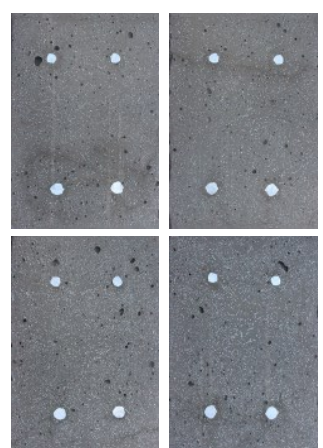

Figura 4.3 - Planos de corte das vigas de UHPFRC: (a) após os processos de corte e polimento e (b) obtidos por fotografias de alta resolução

As imagens dos planos de corte (Figura 4.3b) foram obtidas utilizando uma câmera digital de alta resolução (Canon EOS Rebel T3i). Para gerar contraste luminoso entre as fibras e a matriz de UHPFRC (isto é, destacar as fibras, mantendo-se uma iluminação uniforme em todo o plano de corte), as fotografias foram realizadas em condições de iluminação natural e 
em um curto intervalo de tempo (aproximadamente 15 minutos) entre a primeira e a última, a fim de manter o mesmo padrão de iluminação em todas elas.

\subsection{Processamento e Análise de Imagem Digital}

As imagens dos planos de corte foram analisadas em um algoritmo de processamento e análise de imagem desenvolvido na linguagem de programação MATLAB. Por meio desse algoritmo, foi possível detectar as fibras e determinar as suas características de distribuição nas vigas de UHPFRC.

O algoritmo de processamento e análise de imagem desenvolvido é apresentado na Figura 4.4 e detalhado na sequência.

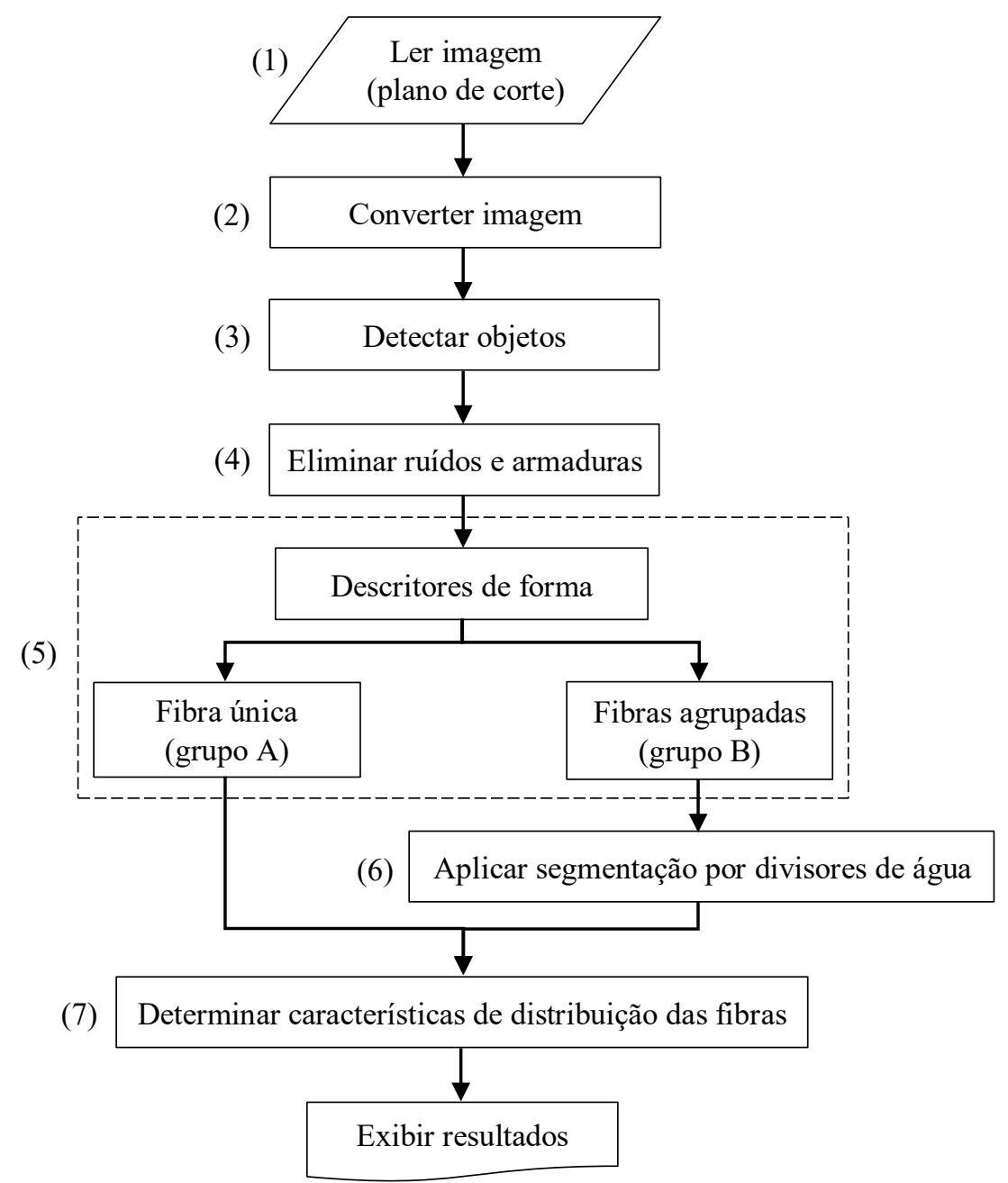

Figura 4.4 - Algoritmo implementado em MATLAB para o processamento e análise de imagem 
(1) A imagem do plano de corte obtida por fotografia de alta resolução (imagem RGB) é importada utilizando a função imread. No MATLAB, uma imagem digital é uma matriz de valores em que cada elemento é chamado pixel. No caso da imagem colorida RGB, cada pixel possui três valores inteiros entre 0 (cor preta) e 255 (cor branca), um para cada canal de cor: $\mathrm{R}$ (vermelho), G (verde) e B (azul). Assim, a cor de cada pixel é resultante da combinação das três cores RGB, o que gera aproximadamente 16 milhões de possibilidades de cores.

(2) A imagem RGB é convertida em imagem em escala de cinza empregando a função rgb2gray. Na imagem em escala de cinza, cada pixel assume um valor inteiro entre 0 (cor preta) e 255 (cor branca), permitindo uma imagem com até 256 tons de cinza. A função rgb2gray converte os valores RGB em valores em escala de cinza utilizando uma soma ponderada, conforme a Equação (4.1).

$$
I=0,2989 R+0,587 G+0,144 B
$$

sendo: $R, G$ e $B$ os valores em escala de vermelho, verde e azul, respectivamente, e $I$ o valor em escala de cinza de um pixel da imagem.

Em sequência, para possibilitar a detecção das fibras, a imagem em escala de cinza é convertida em binária utilizando a função imbinarize. Na imagem binária, os únicos valores de pixel possíveis são 0 (cor preta) ou 1 (cor branca). A função imbinarize converte os valores em escala de cinza em valores binários a partir de um valor limite definido pelo método de Otsu (1979), em que todos os valores acima desse limite são substituídos por 1, e os demais, por 0 .

A Figura 4.5 apresenta a conversão da imagem RGB (Figura 4.5a) em escala de cinza (Figura 4.5b) e em binária (Figura 4.5c) para um plano de corte de uma viga de UHPFRC.

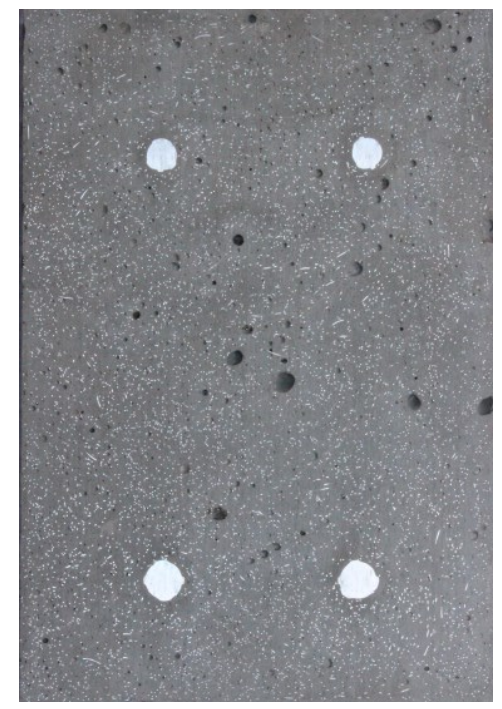

(a)

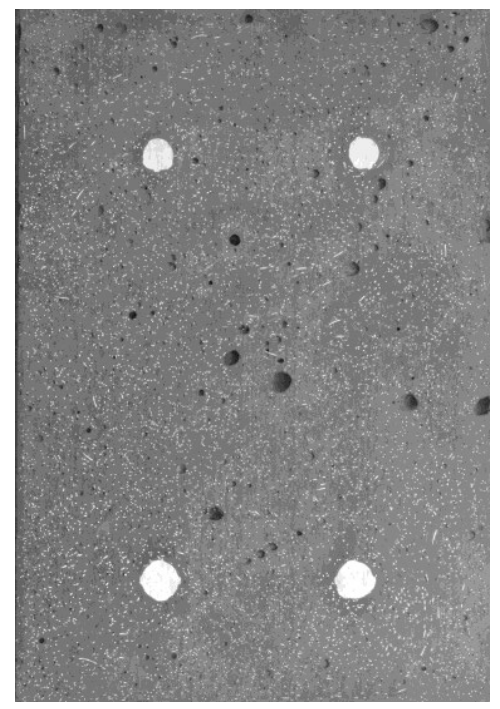

(b)

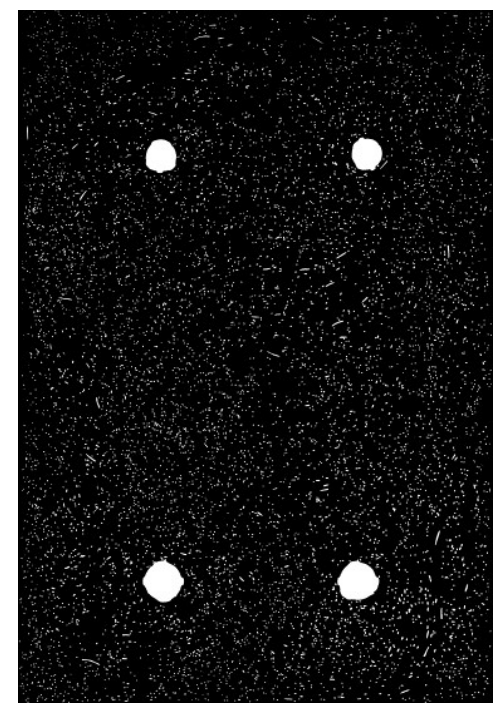

(c)

Figura 4.5 - Conversão de imagem para a análise da distribuição das fibras nas vigas de UHPFRC:

(a) imagem RGB, (b) imagem em escala de cinza e (c) imagem binária 
(3) Os objetos são detectados na imagem binária utilizando a função bwboundaries, que identifica e rotula os conjuntos de pixels conectados que formam os objetos.

(4) Os ruídos (objetos com área menor que a área mínima da fibra) e as armaduras são eliminados da imagem binária. A função regionprops é empregada para determinar a área dos objetos detectados. Se a área do objeto for menor que a área mínima da fibra (Equação (4.2)), ou maior ou igual a área mínima da armadura (Equação (4.3)), o objeto é eliminado da imagem.

$$
\begin{aligned}
& A_{f, \text { min }}=\frac{\pi d_{f}^{2}}{4} \\
& A_{s, \text { min }}=\frac{\pi d_{s, \text { min }}^{2}}{4}
\end{aligned}
$$

sendo: $d_{f}$ e $d_{s, \min }$ o diâmetro da fibra e o menor diâmetro da armadura em pixel, respectivamente. Como o processamento de imagem no MATLAB tem como padrão a unidade pixel, para o cálculo das áreas mínimas, o diâmetro da fibra e o da armadura são convertidos para essa unidade, utilizando como referência a altura da viga em milímetro e em pixel (obtida pela função length, que retorna o comprimento da maior dimensão da imagem em pixel).

(5) Após eliminar os ruídos e as armaduras, os demais objetos detectados na imagem binária são divididos em dois grupos: fibra única (grupo A) e fibras agrupadas (grupo B), como exemplificado na Tabela 4.1. Nota-se na Tabela 4.1 que os exemplos do grupo A, corretamente detectados como um único objeto, apresentam formas bastante diferentes. Isso é atribuído ao ângulo de orientação das fibras em relação à direção normal ao plano de corte, como exposto na Seção 2.2.1. Além disso, os exemplos do grupo B, detectados incorretamente como um único objeto, na realidade são compostos por duas ou mais fibras agrupadas. Nesse caso, para separar essas fibras e obter uma análise mais precisa, é aplicada a técnica de segmentação por divisores de água.

Tabela 4.1 - Exemplos de fibra única (grupo A) e fibras agrupadas (grupo B) detectadas em um plano de corte de uma viga de UHPFRC

\begin{tabular}{cccccc}
\hline Grupo & Descrição & $\begin{array}{c}\text { Número provável } \\
\text { de fibras }^{\text {a }}\end{array}$ & $\begin{array}{c}\text { Número de } \\
\text { objetos detectados }\end{array}$ & $\begin{array}{c}\text { Segmentação } \\
\text { por divisores } \\
\text { de água }\end{array}$ & Exemplos \\
\hline A & $\begin{array}{c}\text { Fibra } \\
\text { única }\end{array}$ & 1 & 1 & Não & Sim \\
\hline B & $\begin{array}{c}\text { Fibras } \\
\text { agrupadas }\end{array}$ & Mais de 1 & 1 & & \\
\hline
\end{tabular}

a Número definido a partir de observação visual. 
A divisão dos objetos nos grupos A e B é realizada por meio dos descritores de forma básicos (Figura 4.6), determinados pela função regionprops: área do objeto $\left(A_{o b}\right)$, área do menor polígono convexo que contém o objeto $\left(A_{c h}\right)$ e comprimento dos eixos da elipse que circunscreve o objeto $\left(d_{f}\right.$ e $\left.l\right)$. A partir desses descritores, são extraídas duas medidas invariantes à rotação, translação e escala - a solidez (Equação (4.4)) e a densidade de empacotamento (Equações (4.5)) -, utilizadas para classificar os objetos como fibra única (grupo A) ou fibras agrupadas (grupo B).

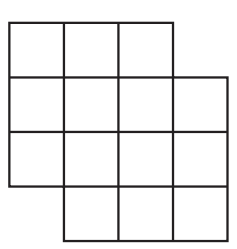

(a)

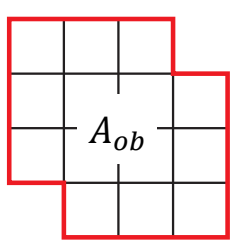

(b)

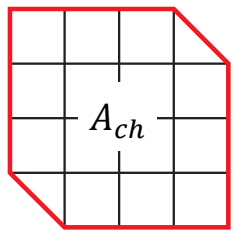

(c)

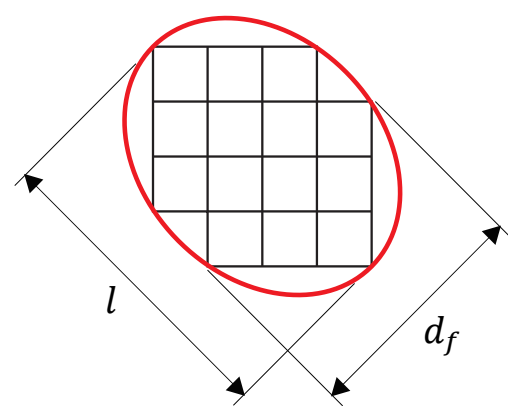

(d)

Figura 4.6 - Exemplificação dos descritores de forma: (a) objeto detectado, (b) área do objeto, (c) área do menor polígono convexo e (d) comprimento dos eixos da elipse circunscrita

$$
F_{S}=\frac{A_{o b}}{A_{c h}}
$$

sendo: $A_{o b}$ a área do objeto e $A_{c h}$ a área do menor polígono convexo que contém o objeto. $F_{S} \cong 1$ indica um objeto sólido, ou seja, uma única fibra.

$$
F_{c}=\frac{d_{f}}{l}
$$

sendo: $d_{f}$ e $l$ o comprimento do menor e do maior eixo da elipse que circunscreve o objeto, respectivamente. $F_{c} \cong 1$ indica um objeto circular e $F_{c} \cong 0$, um objeto extremamente alongado, ambos classificados como uma única fibra.

(6) As fibras agrupadas são separadas aplicando a segmentação por divisores de água. O processo de segmentação dos objetos na imagem binária (Figura 4.7a) é iniciado com a função $b w d i s t$, que calcula a transformada de distância euclidiana do complemento da imagem binária, ou seja, para cada pixel da imagem binária complementar, é atribuído um novo valor, que corresponde à distância entre esse pixel e o pixel diferente de zero mais próximo, resultando na imagem da Figura $4.7 \mathrm{~b}$. 
A imagem negativa da transformada de distância (Figura 4.7c) pode ser interpretada como uma superfície topográfica, composta por divisores de água (pontos de máximos locais) e bacias de captação (pontos de mínimos locais), em que os pixels claros representam altas elevações e os pixels escuros representam baixas elevações. Dessa forma, a função watershed é empregada para localizar as linhas divisoras de água, que definem a separação dos objetos (Figura 4.7d). Para isso, o princípio da gota de água é considerado: as linhas divisoras são traçadas nos pontos onde uma gota de água pode escorrer para mínimos locais diferentes (MEYER, 1994).

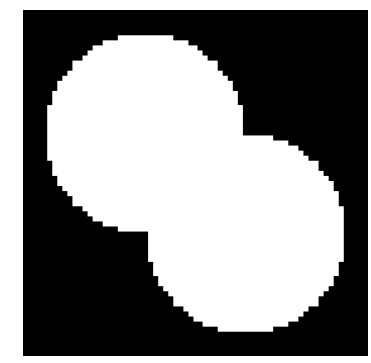

(a)

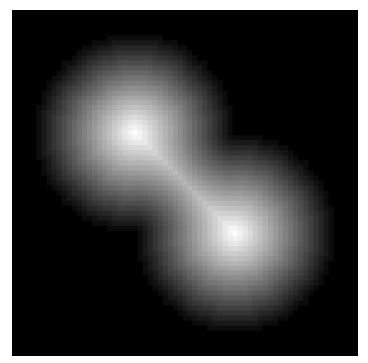

(b)

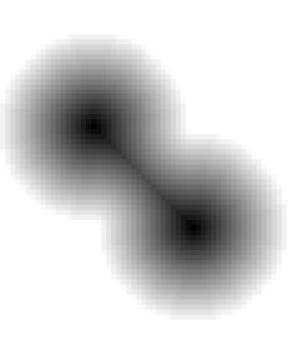

(c)

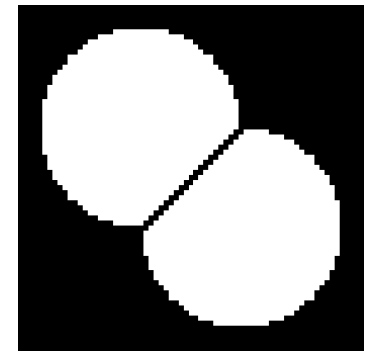

(d)

Figura 4.7 - Segmentação por divisores de água: (a) imagem binária, (b) transformada de distância,

(c) negativo da transformada de distância e (d) segmentação dos objetos por divisores de água (Fonte: Manual do MATLAB R2017b)

A Figura 4.8 apresenta os exemplos de fibras agrupadas da Tabela 4.1 (detectadas em um plano de corte de uma viga de UHPFRC) após aplicar a técnica de segmentação por divisores de água.
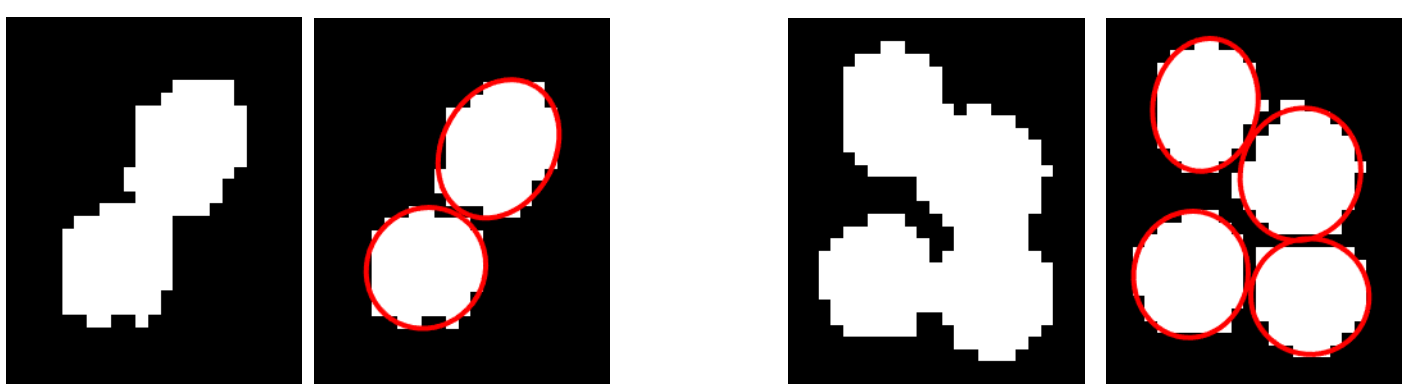

Figura 4.8 - Aplicação da técnica de segmentação por divisores de água em fibras agrupadas detectadas em um plano de corte de uma viga de UHPFRC 
(7) Por fim, as características de distribuição das fibras nos planos de corte das vigas de UHPFRC são determinadas quantitativamente por meio seguintes parâmetros:

- Número total de fibras $\left(n_{f}\right)$;

- Número de fibras por unidade de área $\left(F_{n}\right.$, Equação (2.3));

- Ângulo de orientação das fibras ( $\theta$, Equação (2.4)); e

- Coeficiente de orientação ( $\eta_{\theta}$, Equação (2.6)).

Ressalta-se que, para a determinação das características de distribuição, as fibras detectadas foram representadas pelas elipses que as circunscrevem, como mostra a Figura 4.8, tendo suas propriedades geométricas (comprimento dos eixos) definas pela função regionprops. 


\section{ANÁLISE NUMÉRICA}

Esta seção apresenta a abordagem numérica desenvolvida nesta pesquisa para modelar o UHPFRC com fibras discretizadas e embutidas na matriz cimentícia, utilizando o software de elementos finitos ABAQUS. Tal abordagem possibilita considerar o tamanho das fibras, a sua fração volumétrica e o seu padrão de orientação.

Visando a um menor custo computacional, o UHPFRC foi assumido como um material heterogêneo composto por duas fases: matriz cimentícia e fibras de aço. Dessa forma, o comportamento da interface fibra/matriz foi representado no modelo constitutivo das fibras, por meio de uma lei tensão-deformação equivalente baseada no comportamento de arrancamento da fibra. Para o UHPFRC, essa abordagem numérica é bastante recente e, em termos de elemento estrutural em escala real, o autor desconhece trabalhos aplicando-a.

A seguir, são apresentadas as estratégias utilizadas para a geração das fibras, modelagem da matriz cimentícia e das fibras de aço, bem como a consideração da interface fibra/matriz, e os exemplos empregados para a validação do modelo numérico proposto.

\subsection{Geração das Fibras}

Para gerar as fibras dentro de um determinado volume, um algoritmo foi implementado na linguagem de programação Python. Como simplificação, as fibras foram representadas por linhas retas com espessura nula, e a sobreposição entre elas não foi verificada, sendo, portanto, permitida. Após a geração das fibras, há a necessidade de inseri-las na malha tridimensional de elementos finitos sólidos que modela a matriz de UHPFRC. Esse processo foi realizado por meio do arquivo .inp do ABAQUS.

O algoritmo desenvolvido para gerar as fibras é apresentado na Figura 5.1 e detalhado na sequência. 


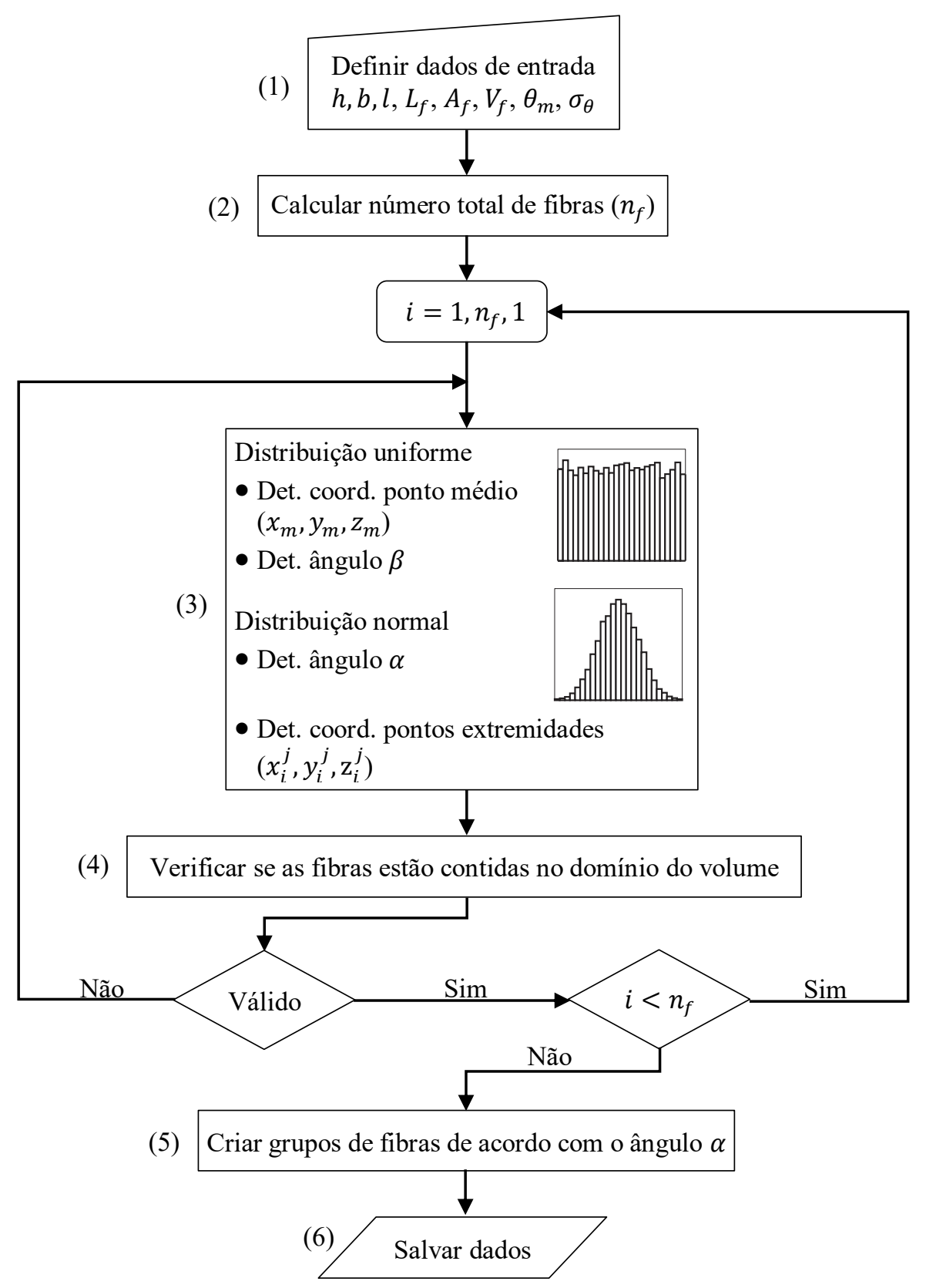

Figura 5.1 - Algoritmo implementado em Python para geração das fibras

(1) As variáveis do problema são impostas. A geometria e as dimensões do modelo de UHPFRC (Figura 5.2) são informadas para definir, no sistema de coordenadas cartesianas, o volume que contém as fibras. Os dados relacionados às fibras, como o comprimento total $\left(L_{f}\right)$, a área da seção transversal $\left(A_{f}\right)$ e a fração volumétrica $\left(V_{f}\right)$, também são fornecidos para possibilitar o cálculo do número total de fibras. Além disso, ângulo de orientação médio das fibras $\left(\theta_{m}\right)$ no plano de fissuração e o desvio padrão $\left(\sigma_{\theta}\right)$, necessários para definir a distribuição normal, também são informados. 


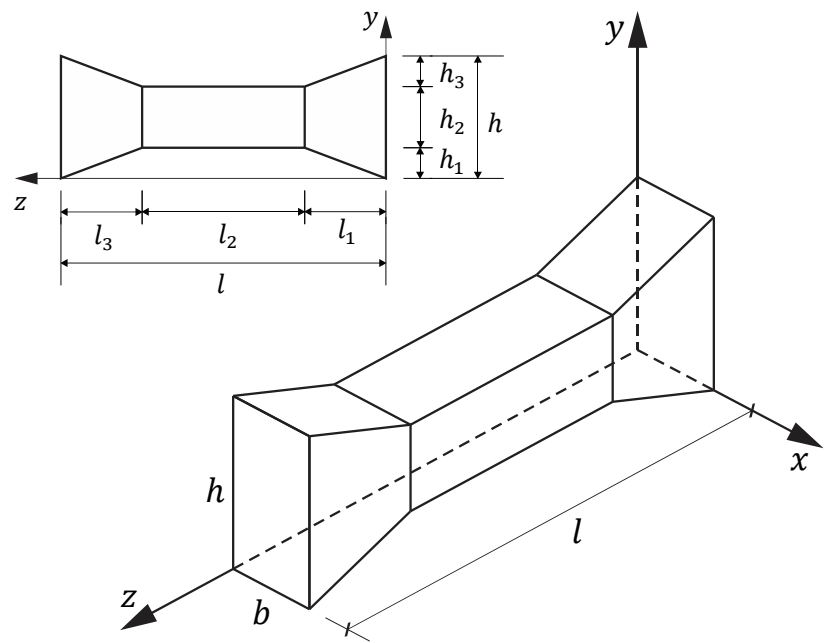

(a)

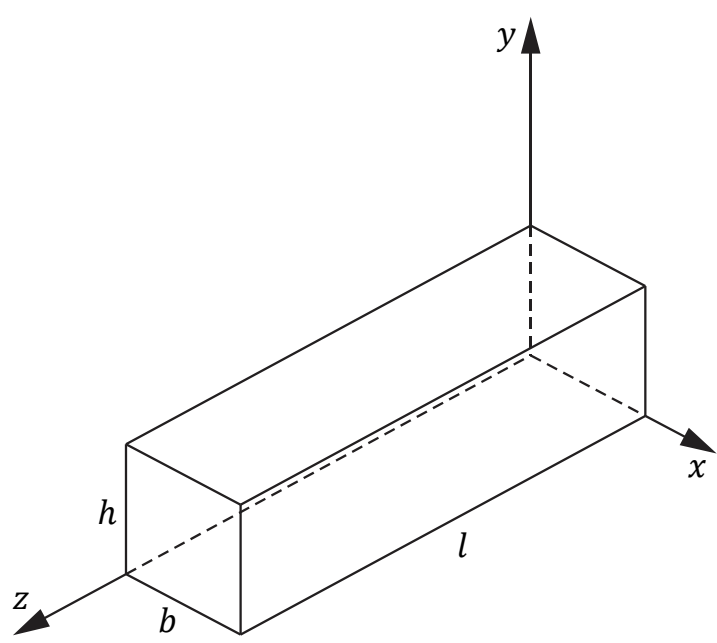

(b)

Figura 5.2 - Geometria e dimensões do modelo de UHPFRC que definem o volume no sistema de coordenadas cartesianas: (a) dog-bone e (b) prisma ou viga de seção retangular

(2) O número total de fibras $\left(n_{f}\right)$ que serão geradas dentro de um determinado volume (Figura 5.2) é calculado conforme a Equação (5.1).

$$
n_{f}=\frac{V_{f} V_{c}}{100\left(A_{f} L_{f}\right)}
$$

sendo: $V_{c}$ o volume de concreto calculado com base na geometria e nas dimensões do modelo de UHPFRC fornecidas no passo (1).

(3) Para determinar as coordenadas dos pontos de extremidade da $i$-ésima fibra, é necessário definir com antecedência as coordenadas do seu ponto médio e os ângulos de orientação $\beta$ e $\alpha$, como realizado por Gu et al. (2016).

Tanto as coordenadas do ponto médio da fibra $\left(x_{m}, y_{m}, z_{m}\right)$ quanto o ângulo de orientação $\beta$ são gerados aleatoriamente, utilizando uma distribuição uniforme. Para isso, a função np.random.random(), que retorna números aleatórios uniformes no intervalo de 0 a 1 , é empregada. Assim, as coordenadas $\left(x_{m}, y_{m}, z_{m}\right)$, contidas no domínio do volume definido no passo (1), e o ângulo $\beta$, contido no intervalo $[0,2 \pi]$, são determinados por meio das Equações (5.2), (5.3), (5.4) e (5.5). 


$$
\begin{aligned}
& x_{m}=b \xi_{x} \\
& y_{m}=h \xi_{y} \\
& z_{m}=l \xi_{z}
\end{aligned}
$$

sendo: $\xi_{x}, \xi_{y}$ e $\xi_{z}$ números aleatórios gerados pela função $n p$.random.random(). As dimensões $b, h$ e $l$ definem o domínio do volume, como mostra a Figura 5.2. Porém, no caso do dog-bone, o valor de $h$ varia ao longo do eixo $z$, conforme Figura 5.2a. Assim, a partir da coordenada $z_{m}$, determina-se geometricamente o valor de $h$ e, por conseguinte, calcula-se a coordenada $y_{m}$ pela Equação (5.3).

$$
\beta=2 \pi \xi
$$

sendo: $\xi$ um número aleatório gerado pela função np.random.random().

Para considerar a orientação real das fibras no plano de fissuração ( $x y$, Figura 5.2), o ângulo de orientação $\alpha$ é definido por uma distribuição normal ( Equação (5.6)), com realizado por Soetens e Matthys (2014). Para tanto, é utilizada a função np.random.randn(), que retorna números aleatórios no intervalo de $-\infty$ a $+\infty$ (respeitando uma distribuição normal padrão).

$$
\alpha=z \sigma_{\theta}+\theta_{m}
$$

sendo: $z$ um número aleatório gerado pela função np.random.randn(). A definição dos parâmetros $\theta_{m}$ e $\sigma_{\theta}$, impostos no passo (1), será abordada na Seção 5.5 para cada modelo de UHPFRC simulado nesta pesquisa (dog-bone, prisma e viga de seção retangular).

Por fim, no sistema cartesiano, as coordenadas dos pontos de extremidade da $i$-ésima fibra $\left(x_{i}^{j}, y_{i}^{j}, z_{i}^{j}\right)$ são calculadas a partir das Equações (5.7), (5.8) e (5.9).

$$
\begin{aligned}
& x_{i}^{j}=x_{m} \pm \frac{L_{f}}{2} \operatorname{sen} \alpha \cos \beta \\
& y_{i}^{j}=y_{m} \pm \frac{L_{f}}{2} \operatorname{sen} \alpha \operatorname{sen} \beta \\
& z_{i}^{j}=z_{m} \pm \frac{L_{f}}{2} \cos \alpha
\end{aligned}
$$

sendo: $j$ o índice que se refere a qual extremidade as coordenadas pertencem. Dessa forma, $\left(x_{i}^{1}, y_{i}^{1}, z_{i}^{1}\right)$ e $\left(x_{i}^{2}, y_{i}^{2}, z_{i}^{2}\right)$ são as coordenadas das extremidades 1 e 2 da $i$-ésima fibra, respectivamente.

(4) As coordenadas de extremidade da $i$-ésima fibra são verificadas em relação à sua posição dentro do domínio do volume definido no passo (1), conforme as Equações (5.10), (5.11) e (5.12). Se ao menos uma coordenada não satisfizer a verificação, a fibra é descartada e uma nova geração é realizada. 


$$
\begin{aligned}
& 0 \leq x_{i}^{j} \leq b \\
& 0 \leq y_{i}^{j} \leq h \\
& 0 \leq z_{i}^{j} \leq l
\end{aligned}
$$

Nota: no caso do dog-bone, como já mencionado, o valor de $h$ não é constante. Assim, a partir da coordenada $z_{i}^{j}$, determina-se geometricamente o valor de $h$ e, posteriormente, verifica-se a Equação (5.11).

Os passos (3) e (4) do algoritmo são repetidos até que o número total de fibras seja atingido, ou seja, $i=n_{f}$.

(5) As fibras geradas são divididas em cinco grupos de acordo com o seu ângulo de

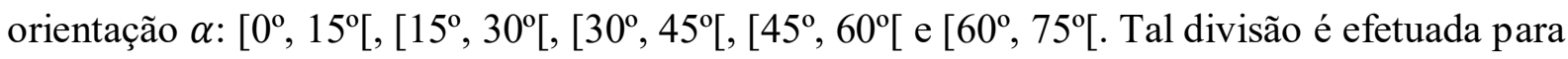
possibilitar que cada grupo de fibras, quando importado para o ABAQUS, possa receber diferentes leis constitutivas, como será abordado mais adiante.

(6) Em um arquivo de saída com extensão .inp, as coordenadas dos pontos de extremidade das fibras de cada grupo são salvas de forma a representar os seus nós e elementos, como exemplificado na Figura 5.3. Nota-se que, em tal figura, as coordenadas de extremidade de cada fibra definem os seus nós, e a conexão entre eles define o seu elemento. Esse arquivo .inp é posteriormente importado para o ABAQUS.

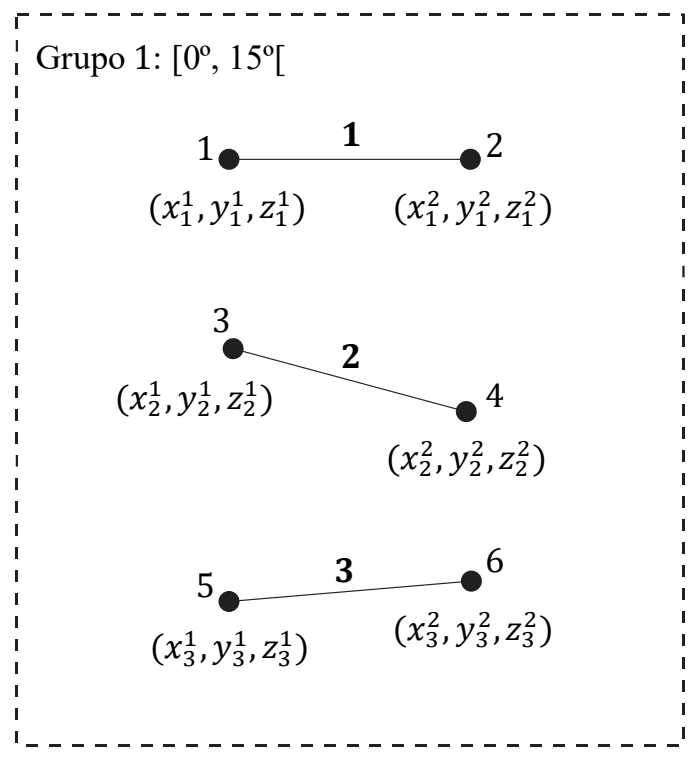

\section{Arquivo .inp}

\section{Grupo 1}

Nó $\quad$ coord. $x \quad$ coord. $y \quad$ coord. $z$

$1, \quad x_{1}^{1}, \quad y_{1}^{1}, \quad z_{1}^{1}$

$2, \quad x_{1}^{2}, \quad y_{1}^{2}, \quad z_{1}^{2}$

$3, \quad x_{2}^{1}, \quad y_{2}^{1}, \quad z_{2}^{1}$

$4, \quad x_{2}^{2}, \quad y_{2}^{2}, \quad z_{2}^{2}$

$5, \quad x_{3}^{1}, \quad y_{3}^{1}, \quad z_{3}^{1}$

6, $\quad x_{3}^{2}, \quad y_{3}^{2}, \quad z_{3}^{2}$

$\begin{array}{ccc}\text { Elemento } & \text { nó } 1 & \text { nó } 2 \\ 1, & 1, & 2 \\ 2, & 3, & 4 \\ 3, & 5, & 6\end{array}$

Figura 5.3 - Exemplificação de como as fibras geradas pelo algoritmo são salvas no arquivo .inp 


\subsection{Modelagem da Matriz de UHPFRC}

\subsubsection{Elementos finitos}

A matriz de UHPFRC foi modelada com elementos sólidos lineares tridimensionais com oito nós e sem integração reduzida (C3D8), como ilustrado na Figura 5.4a. Cada nó do elemento tipo C3D8 possui três graus de liberdade de translação. A escolha de um modelo tridimensional tem como intuito não perder informações relacionadas à distribuição das fibras no plano de fissuração.

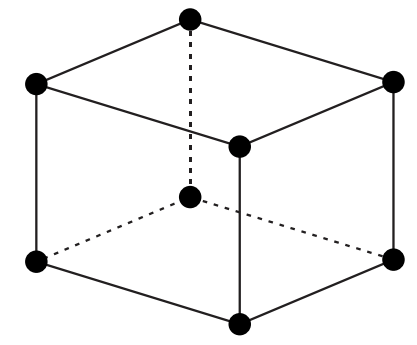

(a)

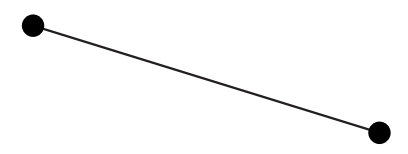

(b)

Figura 5.4 - Elementos finitos tridimensionais utilizados na modelagem numérica: (a) elemento sólido com oito nós (C3D8) e (b) elemento de treliça com dois nós (T3D2), disponíveis no ABAQUS

\subsubsection{Modelo constitutivo}

Para representar o comportamento da matriz de UHPFRC, o modelo constitutivo adotado foi o Concrete Damaged Plasticity, disponível no ABAQUS. Os parâmetros necessários para definir o modelo CDP (explanados na Seção 2.4.1) são apresentados a seguir.

\section{- Comportamento uniaxial na compressão e na tração}

Para caracterizar o comportamento uniaxial da matriz de UHPFRC na compressão, foi utilizada a relação entre a tensão de compressão $\left(\sigma_{c}\right)$ e a deformação total $(\varepsilon)$, definida a partir dos dados experimentais do ensaio de compressão uniaxial, descrito na Seção 3.1.3.1. O trecho ascendente da curva tensão-deformação (Figura 5.5a) foi representado por um comportamento elástico linear até $80 \%$ da resistência à compressão, seguido por um comportamento não linear, 
descrito pelas Equações (5.13) e (5.14), propostas por Carreira e Chu (1985). Após atingir a resistência à compressão, a matriz de UHPFRC apresenta uma falha brusca e explosiva; porém, a representação do trecho descendente por uma queda repentina da tensão pode provocar problemas de convergência no modelo numérico. Assim, o trecho descendente também foi descrito pelo modelo de Carreira e Chu (1985). Ressalta-se que, como parâmetro de entrada no modelo CDP, a deformação total foi convertida em deformação inelástica, como exposto na Seção 2.4.1.

$$
\begin{aligned}
& \sigma_{c}=f_{c}\left[\frac{\beta \frac{\varepsilon}{\varepsilon_{c}}}{\beta-1+\left(\frac{\varepsilon}{\varepsilon_{c}}\right)^{\beta}}\right] \\
& \beta=\frac{1}{1-\frac{f_{c}}{\varepsilon_{c} E_{c}}}
\end{aligned}
$$

sendo: $f_{c}, \varepsilon_{c}$ e $E_{c}$ a resistência à compressão, a deformação correspondente e o módulo de elasticidade da matriz de UHPFRC determinados experimentalmente, respectivamente.

Para caracterizar o comportamento uniaxial da matriz de UHPFRC na tração, foi utilizada a relação entre a tensão de tração $\left(\sigma_{t}\right)$ e a abertura de fissura $(w)$, definida a partir dos resultados experimentais dos ensaios de tração uniaxial e de flexão a três pontos, apresentados nas Seções 3.1.3.2 e 3.1.3.3, respectivamente. A curva tensão-abertura de fissura (Figura 5.5b) foi descrita pelo modelo de Hordijk (1991), conforme as Equações (5.15) e (5.16).

$$
\begin{aligned}
& \frac{\sigma_{t}}{f_{t}}=\left[1+\left(c_{1} \frac{w}{w_{c r}}\right)^{3}\right] e^{\left(-c_{2} \frac{w}{w_{c r}}\right)}-\frac{w}{w_{c r}}\left(1+c_{1}^{3}\right) e^{-c_{2}} \\
& w_{c r}=5,14 \frac{G_{f}}{f_{t}}
\end{aligned}
$$

sendo: $f_{t}$ e $G_{f}$ a resistência à tração e a energia de fratura da matriz de UHPFRC determinadas experimentalmente, respectivamente. As constantes $c_{1}=3,0$ e $c_{2}=6,93$ foram definidas por Hordijk (1991). 


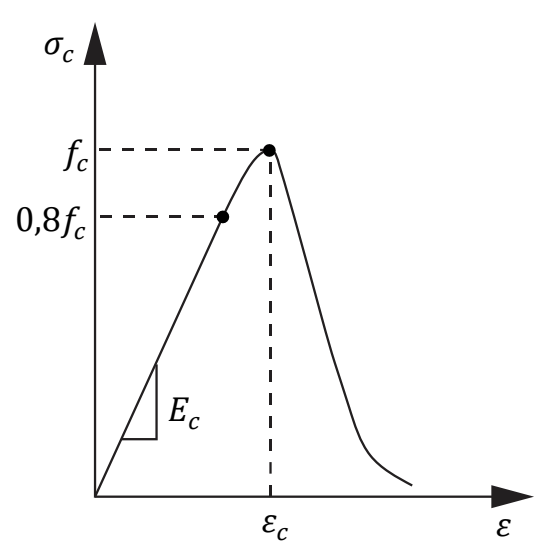

(a)

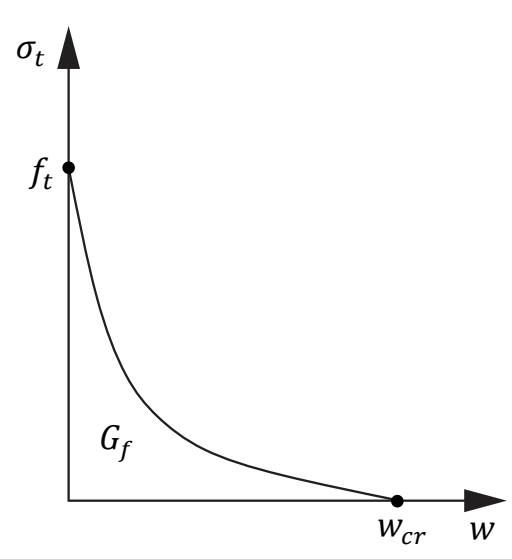

(b)

Figura 5.5 - Representação do comportamento uniaxial da matriz de UHPFRC: (a) curva tensão de compressão-deformação e (b) curva tensão de tração-abertura de fissura

Os parâmetros de dano de compressão $\left(d_{c}\right)$ e tração $\left(d_{t}\right)$, que caracterizam a degradação da rigidez, foram estimados por meio das Equações (5.17) e (5.18), respectivamente (MAHMUD et al., 2013; QSYMAH, 2016; SINGH et al, 2017). Porém, verificou-se que a introdução desses parâmetros não alterou a resposta numérica dos modelos simulados nesta pesquisa, isso indica que: (a) o material não sofreu descarregamento na compressão ou na tração; (b) o material sofreu descarregamento, mas as tensões atuantes eram inferiores às tensões de escoamento iniciais (ou seja, não estava no regime plástico). Em ambos os casos, os parâmetros de dano não são ativados, não sendo necessária a sua definição no modelo CDP.

$$
\begin{aligned}
& d_{c}=1-\frac{\sigma_{c}}{f_{c}} \\
& d_{t}=1-\frac{\sigma_{t}}{f_{t}}
\end{aligned}
$$

\section{- Parâmetros complementares}

Além do comportamento uniaxial na compressão e na tração, outros cinco parâmetros, relacionados ao critério de plastificação, ao potencial plástico e à regularização viscoplástica são necessários para definir completamente o modelo CDP. Os valores assumidos para esses parâmetros, apresentados na Tabela 5.1, foram baseados em estudos que utilizaram o modelo CDP para representar matrizes de UHPFRC (QSYMAH, 2016; ZHANG et al., 2018). 
Tabela 5.1 - Parâmetros do modelo CDP utilizados para representar a matriz de UHPFRC

\begin{tabular}{ccc}
\hline Parâmetro & Valor & Descrição \\
\hline$\psi\left(^{\circ}\right)$ & 36 & Ângulo de dilatação \\
\hline$\epsilon$ & 0,1 & Excentricidade \\
\hline$\frac{\sigma_{b 0}}{\sigma_{c 0}}$ & 1,16 & $\begin{array}{c}\text { Relação entre as tensões de escoamento iniciais de } \\
\text { compressão biaxial e uniaxial }\end{array}$ \\
\hline$K_{c}$ & 0,6667 & $\begin{array}{c}\text { Relação entre o segundo invariante de tensão no } \\
\text { meridiano de tração e no meridiano de compressão }\end{array}$ \\
\hline$\mu$ & 0,000001 & Parâmetro de viscosidade \\
\hline
\end{tabular}

\subsection{Modelagem das Fibras de Aço}

\subsubsection{Elementos finitos}

Visando a um menor custo computacional, as fibras foram modeladas com elementos de treliça lineares tridimensionais com dois nós (T3D2, Figura 5.4b) embutidos nos elementos sólidos que modelam a matriz cimentícia.

Cada nó do elemento tipo T3D2 possui três graus de liberdade de translação. Porém, a representação das fibras como elementos de treliça embutidos não adiciona graus de liberdade ao modelo numérico, pois, no ABAQUS, os graus de liberdade de translação dos nós dos elementos embutidos (fibras) são eliminados, e esses nós se tornam "nós embutidos". Os graus de liberdade de translação dos "nós embutidos" são restringidos aos valores interpolados dos correspondentes graus de liberdade do elemento hospedeiro (matriz cimentícia). Dessa forma, tal representação implica que as fibras estão aderidas perfeitamente à matriz cimentícia.

Além disso, por meio dessa representação, as fibras funcionam como enrijecedores, aumentando a rigidez total do meio reforçado. Isso significa, na aproximação numérica por elementos finitos, que as fibras estarão contribuindo com a rigidez dos elementos em que estão embutidas. Assim, a matriz de rigidez do meio reforçado é composta pelas matrizes de rigidez do elemento de concreto (matriz de UHPFRC) e dos elementos das fibras (VANALLI; CODA, 2006; CUNHA et al., 2012). 


\subsubsection{Modelo constitutivo}

Como exposto acima, ao representar as fibras como elementos de treliça embutidos, uma condição de aderência perfeita é assumida. Assim, o comportamento de deslizamento relativo da interface fibra/matriz foi modelado de forma indireta, por meio de uma lei constitutiva tensão-deformação equivalente atribuída às fibras (CUNHA et al., 2011; 2012; SOETENS et al., 2012; SOETENS; MATTHYS; 2012; 2014). Essa lei constitutiva equivalente tem como propósito substituir a necessidade de considerar molas ou elementos de interface entre as fibras e a matriz.

A lei tensão-deformação equivalente, que descreve o comportamento constitutivo das fibras de aço no critério de plastificação de von Mises, foi obtida a partir do comportamento de arrancamento da fibra, como mostra a Figura 5.6. A conversão da relação força de arrancamento-deslizamento em uma relação tensão-deformação equivalente foi realizada conforme proposto por Soetens et al. (2012) (Equações (2.41) e (2.42)).

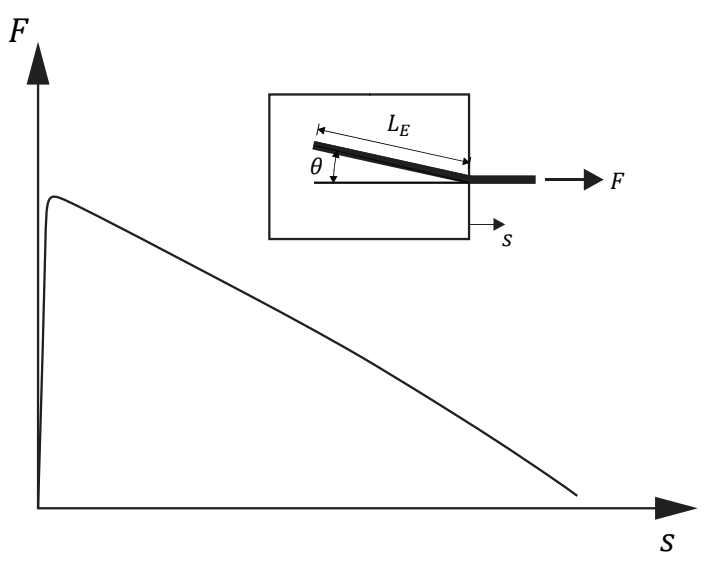

(a)

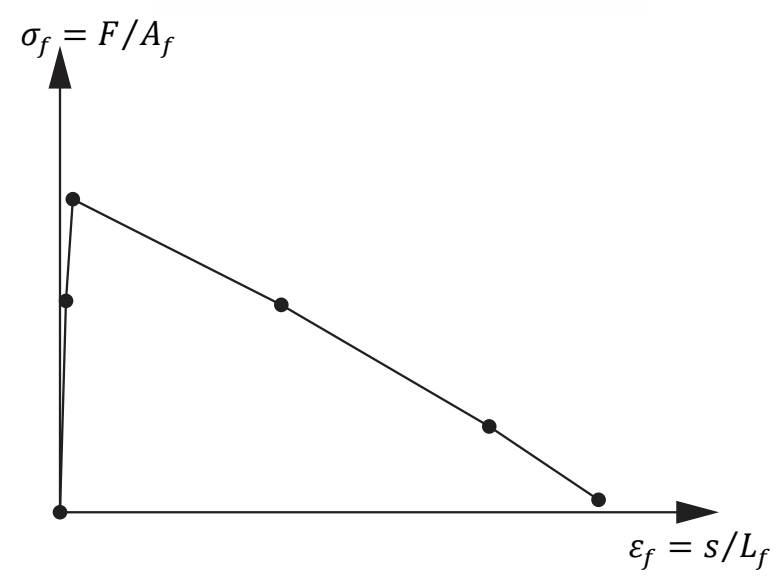

(b)

Figura 5.6 - Determinação do comportamento constitutivo das fibras de aço: (a) curva força de arrancamento-deslizamento da fibra e (b) curva tensão-deformação equivalente

O comportamento de arrancamento das fibras de aço na matriz de UHPFRC foi determinado analiticamente por meio do modelo de arrancamento proposto por Lee et al. (2010), descrito na Seção 2.3.2. Os parâmetros utilizados para sua definição são apresentados na Tabela 5.2. Os valores assumidos para a tensão de cisalhamento máxima $\left(\tau_{\max }\right)$ e para o módulo de adesão $(k)$ foram baseados em estudos que investigaram o arrancamento de fibras de aço em matrizes de UHPFRC (LEE et al., 2010; YOO et al., 2013; TAI et al., 2016; YOO et al., 2017). Além disso, os valores das constantes e coeficientes determinados por Lee et al. 
(2010) foram aqui empregados, pois foi verificado que eles se adequam a outras matrizes de UHPFRC (diferentes traços, curas, resistências, entre outros) e com diferentes comprimentos de embutimento, como demonstra a Figura 5.7.

As características das fibras necessárias para o modelo de arrancamento já foram expostas na Tabela 3.1, e as características da matriz de UHPFRC foram determinadas experimentalmente nesta pesquisa, conforme apresentado na Seção 3.1.3.

Tabela 5.2 - Parâmetros utilizados no modelo de arrancamento proposto por Lee et al. (2010)

\begin{tabular}{ccc}
\hline Parâmetro & Valor & Descrição \\
\hline$\tau_{\text {max }}(\mathrm{MPa})$ & 5,2 & Tensão de cisalhamento máxima por adesão \\
\hline$k(\mathrm{MPa} / \mathrm{mm})$ & 1500 & Módulo de adesão \\
\hline$\mu$ & 0,3 & Coeficiente de atrito \\
\hline$\alpha$ & 1,1 & $\begin{array}{c}\text { Constante relacionada à inclinação da } \\
\text { região totalmente descolada }\end{array}$ \\
\hline$\eta$ & 0,05 & $\begin{array}{c}\text { Constante relacionada à forma exponencial } \\
\text { da região totalmente descolada }\end{array}$ \\
\hline$\omega$ & 1,6 & $\begin{array}{c}\text { Coeficiente relacionado ao efeito pino } \\
\text { Coeficiente relacionado ao efeito de } \\
\text { fragmentação da matriz }\end{array}$ \\
\hline$\gamma$ & 1,8 & $\begin{array}{c}\text { Constante utilizada no cálculo do } \\
\text { coeficiente de deslizamento }\end{array}$ \\
\hline$\gamma$ & 2 & $\begin{array}{c}\text { Constante utilizada no cálculo do } \\
\text { coeficiente de deslizamento }\end{array}$ \\
\hline
\end{tabular}

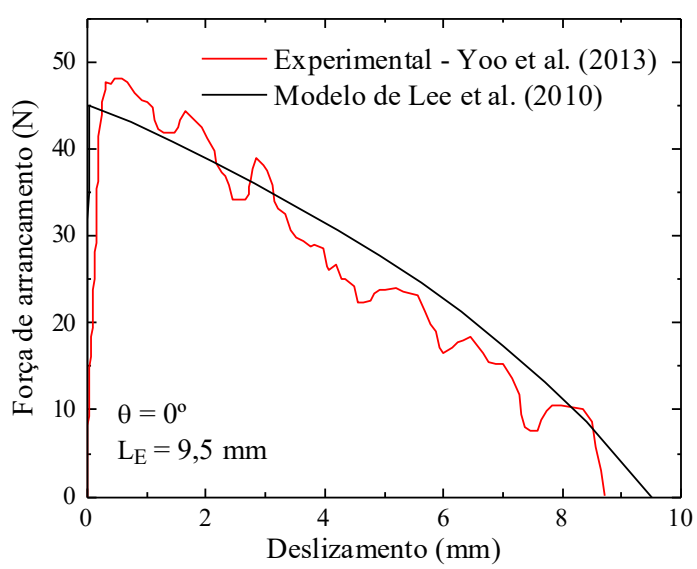

(a)

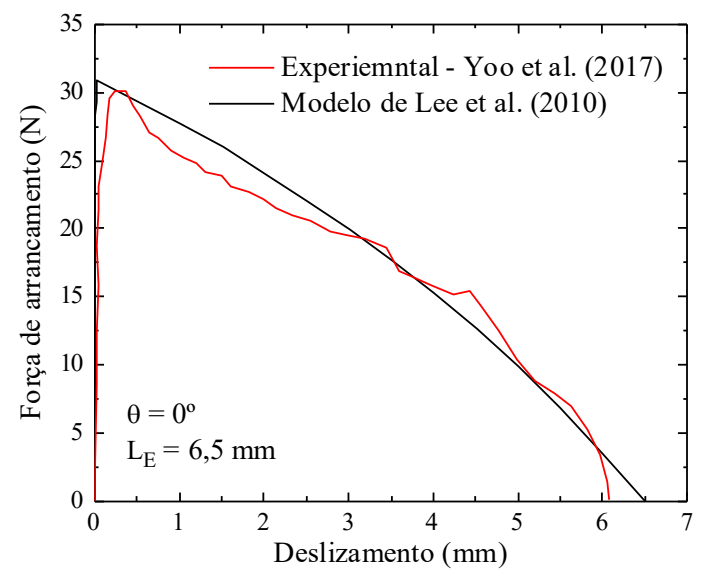

(b)

Figura 5.7 - Adequação das curvas experimentais força de arrancamento-deslizamento da fibra às curvas do modelo analítico de Lee et al. (2010) 
Além dos parâmetros apresentados na Tabela 5.2, o comportamento de arrancamento, determinado pelo modelo de Lee et al. (2010), depende do comprimento de embutimento $\left(L_{E}\right)$ e do ângulo de inclinação $(\theta)$ da fibra. A definição desses dois parâmetros não é tão simples no modelo numérico proposto nesta pesquisa, pois, como abordado na Seção 2.4.2.2, em elementos com múltiplas fibras distribuídas na matriz cimentícia, esses parâmetros podem assumir valores aleatórios para cada fibra que atravessa o plano de fissuração ( $x y$, Figura 5.8). Dessa forma, as estratégias adotadas para definir o comprimento de embutimento e o ângulo de inclinação no modelo numérico proposto são apresentadas a seguir.

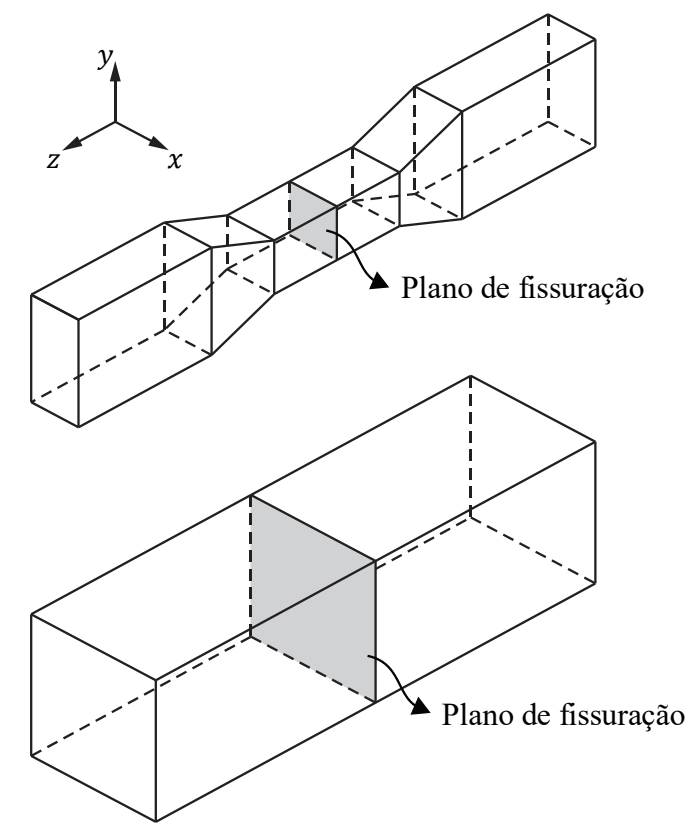

(a)

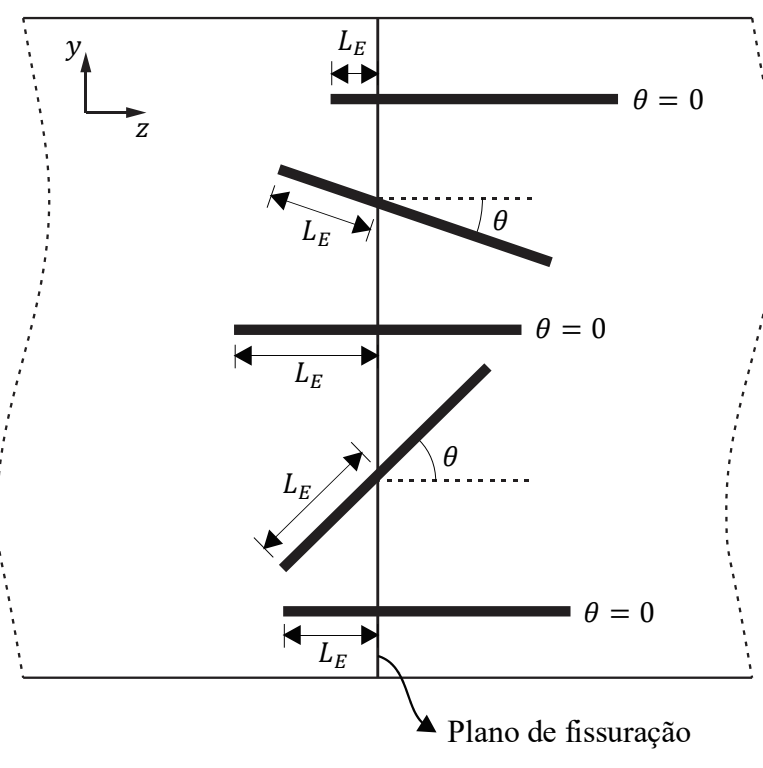

(b)

Figura 5.8 - Representações (a) do plano de fissuração nos modelos de UHPFRC simulados nesta pesquisa (dog-bone, prisma e viga de seção retangular) e (b) do comprimento de embutimento e do ângulo de inclinação das fibras que atravessam o plano de fissuração

\section{- Comprimento de embutimento}

O comprimento de embutimento de cada fibra que atravessa o plano de físsuração pode assumir um valor aleatório no intervalo de 0 a $L_{f} / 2$, o que torna esse parâmetro complexo e de difícil implementação no modelo numérico proposto.

Objetivando simplificar a implementação e, consequentemente, otimizar o tempo computacional, um único valor de $L_{E}$ foi admitido para determinar o comportamento de arrancamento das fibras. Assim como realizado por Cunha et al. (2011; 2012), esse valor foi 
tomado como o valor médio teórico do comprimento de embutimento de uma fibra que atravessa o plano de fissuração, isto é, $L_{E}=L_{f} / 4$, conforme deduzido pela Equação (2.43).

\section{- Ângulo de inclinação}

Ao modelar as fibras como elementos de treliça embutidos, apenas as suas deformações axiais são consideradas, o que não inclui os efeitos pino (deformação transversal) e de fragmentação da matriz ocorrentes nas fibras inclinadas que atravessam o plano de fissuração. Devido a isso, esses efeitos foram inseridos na lei tensão-deformação equivalente, a partir da consideração do ângulo de inclinação da fibra no seu comportamento de arrancamento (CUNHA et al., 2011; 2012; SOETENS et al., 2012; SOETENS; MATTHYS; 2012; 2014). Assim, a lei constitutiva equivalente torna-se capaz de representar o deslizamento relativo da interface fibra/matriz e também os efeitos pino e de fragmentação da matriz das fibras inclinadas.

Devido à complexidade de implementar uma lei tensão-deformação equivalente para cada uma das fibras, essas foram divididas em cinco grupos de acordo com o seu ângulo de inclinação em relação ao plano de fissuração: $\left[0^{\circ}, 15^{\circ}\left[,\left[15^{\circ}, 30^{\circ}\left[,\left[30^{\circ}, 45^{\circ}\left[\right.\right.\right.\right.\right.\right.$, [45, $60^{\circ}\left[\right.$ e $\left[60^{\circ}\right.$, $75^{\circ}$. Tal divisão foi realizada no algoritmo de geração das fibras, como exposto no passo (5) da Seção 5.1. Assim, empregando o modelo analítico de Lee et al. (2010), cinco comportamentos de arrancamento, posteriormente convertidos em cinco leis tensãodeformação equivalentes (Figura 5.9), foram determinados para os ângulos de orientação $0^{\circ}$, $15^{\circ}, 30^{\circ}, 45^{\circ}$ e $60^{\circ}$, e então atribuídos para cada grupo de fibras, respectivamente. O grupo referente ao intervalo $\left[75^{\circ}, 90^{\circ}\right]$ foi negligenciado no modelo numérico, pois as fibras com orientação nesse intervalo praticamente não contribuem na rigidez do elemento de UHPFRC. 


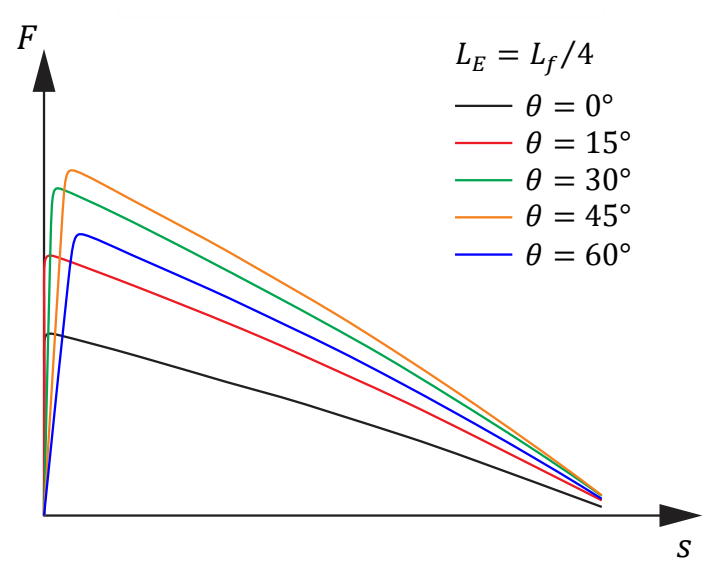

(a)

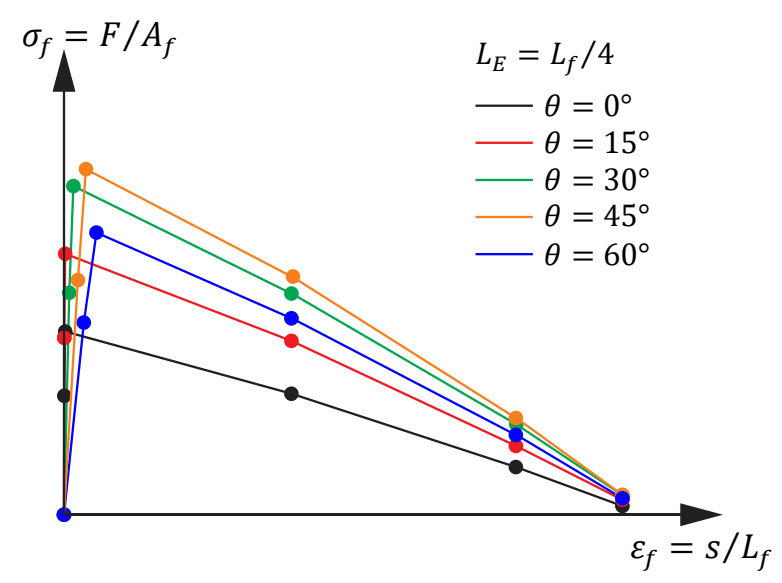

(b)

Figura 5.9 - (a) Curvas força de arrancamento-deslizamento da fibra para os diferentes ângulos de orientação e $L_{E}=L_{f} / 4$, determinadas pelo modelo analítico de Lee et al. (2010), e (b) as respectivas curvas tensão-deformação equivalentes, determinadas conforme proposto por Soetens et al. (2012)

\subsection{Modelagem das Armaduras Longitudinais e Transversais}

\subsubsection{Elementos finitos}

As armaduras longitudinais e transversais empregadas nas vigas de UHPFRC foram modeladas com elementos de treliça lineares tridimensionais com dois nós (T3D2) embutidos nos elementos sólidos que modelam a matriz cimentícia, assim como realizado para as fibras de aço. Dessa forma, uma condição de aderência perfeita é assumida entre as armaduras e a matriz cimentícia.

\subsubsection{Modelo constitutivo}

O comportamento constitutivo do aço das armaduras longitudinais e transversais, associado ao critério de plastificação de von Mises, foi definido experimentalmente por meio do ensaio de tração nas barras de aço, conforme as recomendações da ABNT NBR 7480 (2007). 
A Figura 5.10 apresenta as curvas tensão-deformação determinadas para as armaduras de aço CA-50 com diâmetro 10 e 12,5 mm. As demais características das armaduras já foram expostas na Tabela 3.4 .

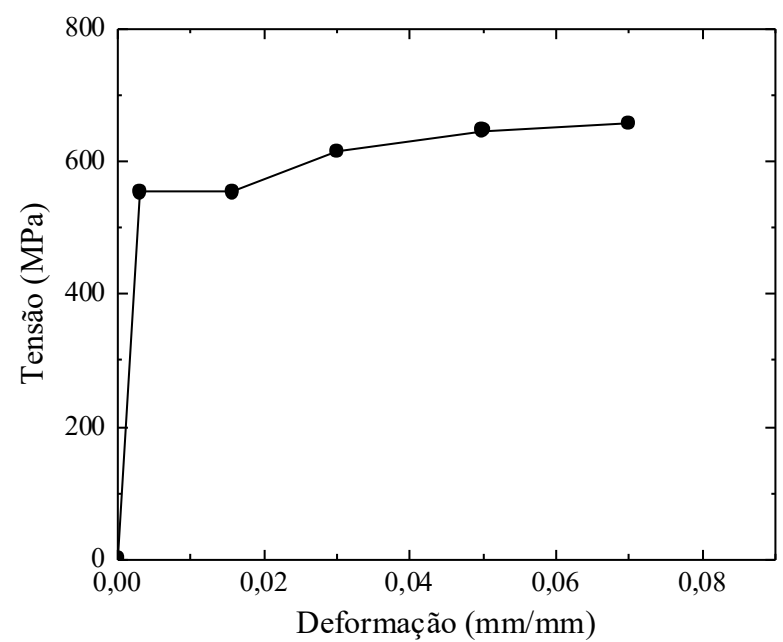

(a)

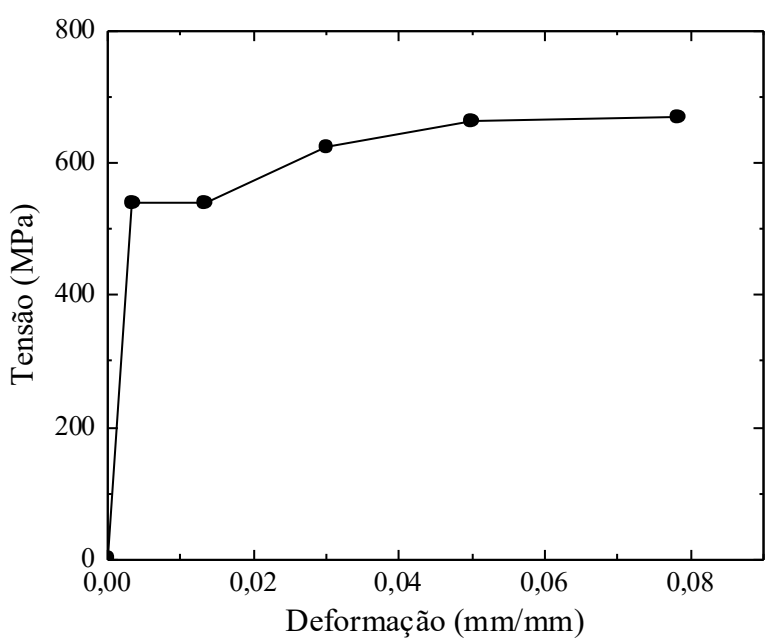

(b)

Figura 5.10 - Curva tensão-deformação das armaduras com diâmetro: (a) $10 \mathrm{~mm}$ e (b) 12,5 mm

\subsection{Aplicação e Validação do Modelo Numérico Proposto}

Com o intuito de demonstrar a aplicação e conduzir a validação do modelo numérico proposto para o UHPFRC com fibras discretizadas e embutidas (material bifásico), foram simulados os ensaios de caracterização de tração uniaxial e de flexão a três pontos, e o ensaio de flexão a quatro pontos das vigas, apresentados na Seção 3.

O tipo de elemento finito e o modelo constitutivo utilizados para modelar a matriz cimentícia de UHFPRC, as fibras de aço e as armaduras longitudinais e transversais já foram discorridos nas seções anteriores. Dessa forma, esta seção detalha outros aspectos da modelagem, tais como: malhas de elementos finitos e condições de contorno. 


\subsubsection{Simulação numérica do ensaio de tração uniaxial}

O ensaio de tração uniaxial em corpos de prova não entalhados em forma de dog-bone, apresentado na Seção 3.1.3.2, foi simulado numericamente considerando as frações volumétricas de fibras de aço de 1\% (UHPFRC-1) e 2\% (UHPFRC-2).

Para gerar a malha das fibras, como exposto na Seção 5.1 (passo 3), é necessário informar o ângulo de orientação médio das fibras $\left(\theta_{m}\right)$ no plano de fissuração e o desvio padrão $\left(\sigma_{\theta}\right)$. A definição desses parâmetros foi realizada por meio do coeficiente de orientação $\left(\eta_{\theta}\right)$, segundo as Equações (2.39) e (2.40), propostas por Laranjeira et al. (2011). Para os dog-bones, considerando o tamanho e a geometria da forma (efeito parede) e o emprego da vibração de mesa, que favorecem o alinhamento das fibras na direção normal ao plano de fissuração, foi adotado um coeficiente de orientação igual a 0,9 .

A Figura 5.11 apresenta a malha tridimensional de elementos finitos utilizada para modelar a matriz cimentícia (Figura 5.11a) e as fibras de aço do UHPFRC-1 (Figura 5.11b). Como pode ser observado na Figura 5.11b, visando a um menor custo computacional, as fibras foram distribuídas apenas na região central do dog-bone, ou seja, na região onde a fissuração ocorre. Essa simplificação não provoca influência na simulação numérica, uma vez que a contribuição das fibras fora dessa região é ínfima.

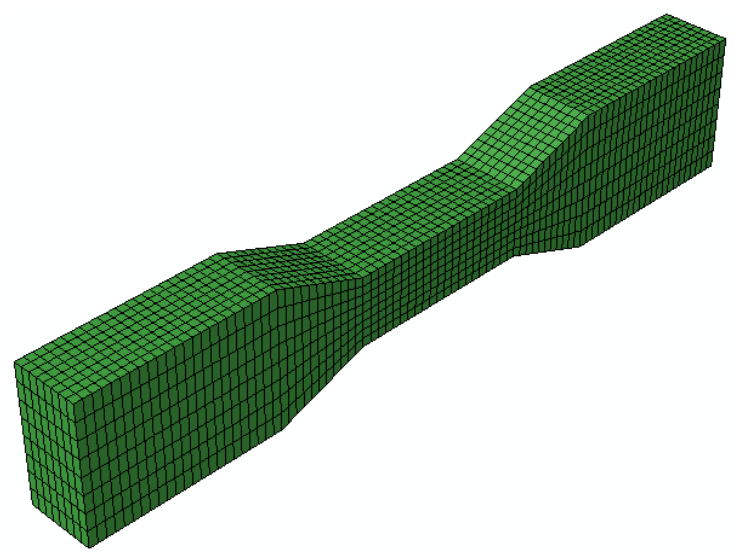

(a)

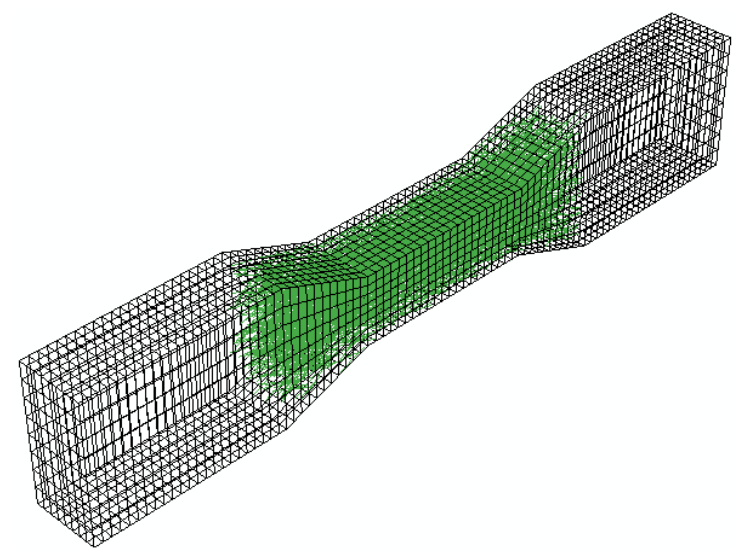

(b)

Figura 5.11 - Malha tridimensional de elementos finitos do ensaio de tração uniaxial: (a) matriz cimentícia e (b) fibras de aço discretizadas $\left(V_{f}=1 \%\right)$

Semelhante à configuração experimental do ensaio de tração uniaxial, a Figura 5.12 apresenta as condições de contorno de deslocamento aplicadas no modelo numérico. No lado direito do dog-bone, foram restritos os deslocamentos nas direções $x, y$ e $z$, enquanto, no 
esquerdo, foi imposto um deslocamento na direção $z$ em incrementos, e as direções $x$ e $y$ foram restritas.

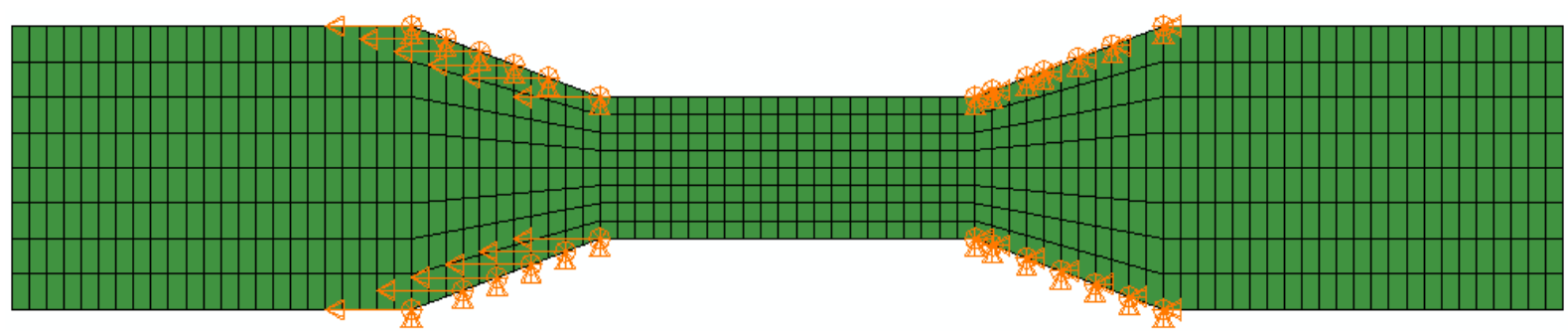

Figura 5.12 - Condições de contorno do ensaio de tração uniaxial no dog-bone

\subsubsection{Simulação numérica do ensaio de flexão a três pontos}

O ensaio de flexão a três pontos em corpos de prova prismáticos com entalhe, apresentado na Seção 3.1.3.3, foi simulado numericamente para o UHPFRC-1 e UHPFRC-2.

Para gerar as malhas das fibras, foi definido um coeficiente de orientação $\left(\eta_{\theta}\right)$ igual a 0,75 , com base em valores encontrados na literatura para prismas produzidos com UHPFRC (KANG et al., 2011; YOO et al., 2014; WILLE et al., 2014b; DUQUE; GRAYBEAL, 2017).

A Figura 5.13 apresenta a malha tridimensional de elementos finitos utilizada para modelar a matriz cimentícia (Figura 5.13a) e as fibras de aço do UHPFRC-1 (Figura 5.13b). Ressalta-se que, durante o processo de geração das fibras, as que atravessam o entalhe foram excluídas (ou seja, não foram incluídas na malha de elementos finitos).

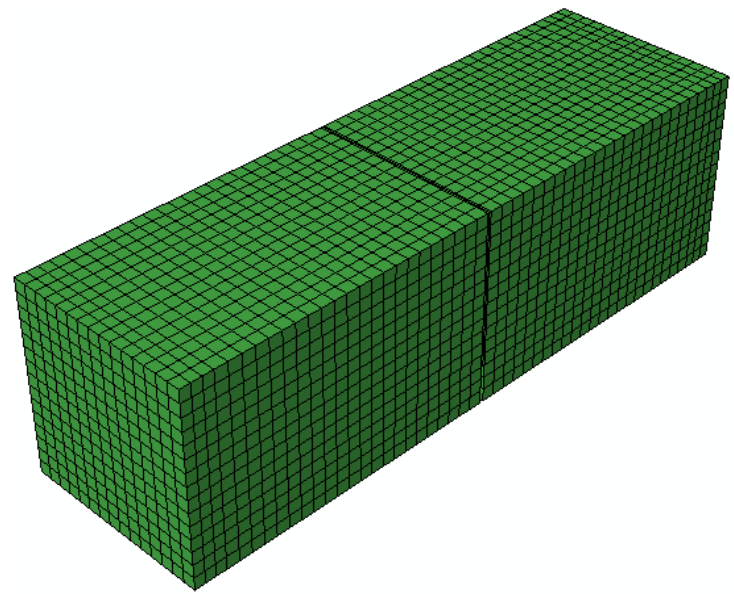

(a)

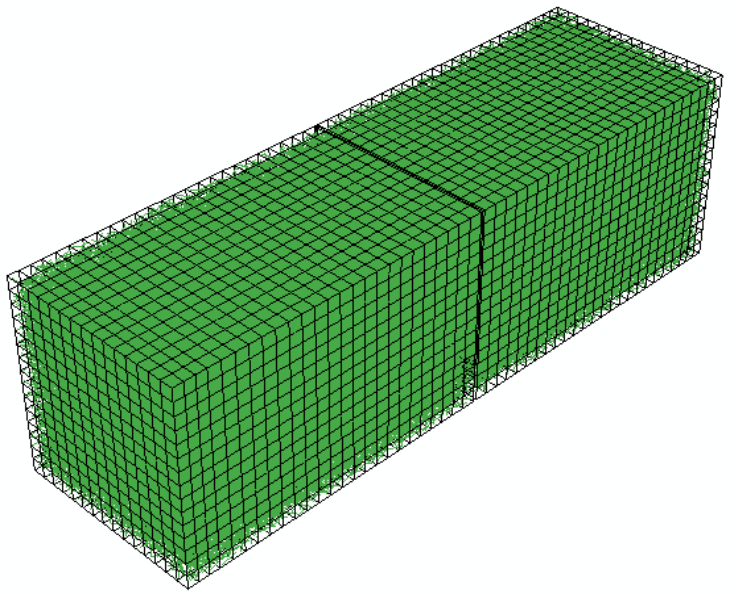

(b)

Figura 5.13 - Malha tridimensional de elementos finitos do ensaio de flexão a três pontos: (a) matriz cimentícia e (b) fibras de aço discretizadas $\left(V_{f}=1 \%\right)$ 
A Figura 5.14 apresenta as condições de contorno de deslocamento aplicadas no modelo numérico, de modo a se assemelhar à configuração experimental. No apoio do lado esquerdo, foram restritos os deslocamentos nas direções $x, y$ e $z$; no direito, apenas nas direções $x$ e $y$, simulando-se assim, respectivamente, um apoio fixo e um móvel. Na região central, um deslocamento incremental na direção $y$ foi imposto.

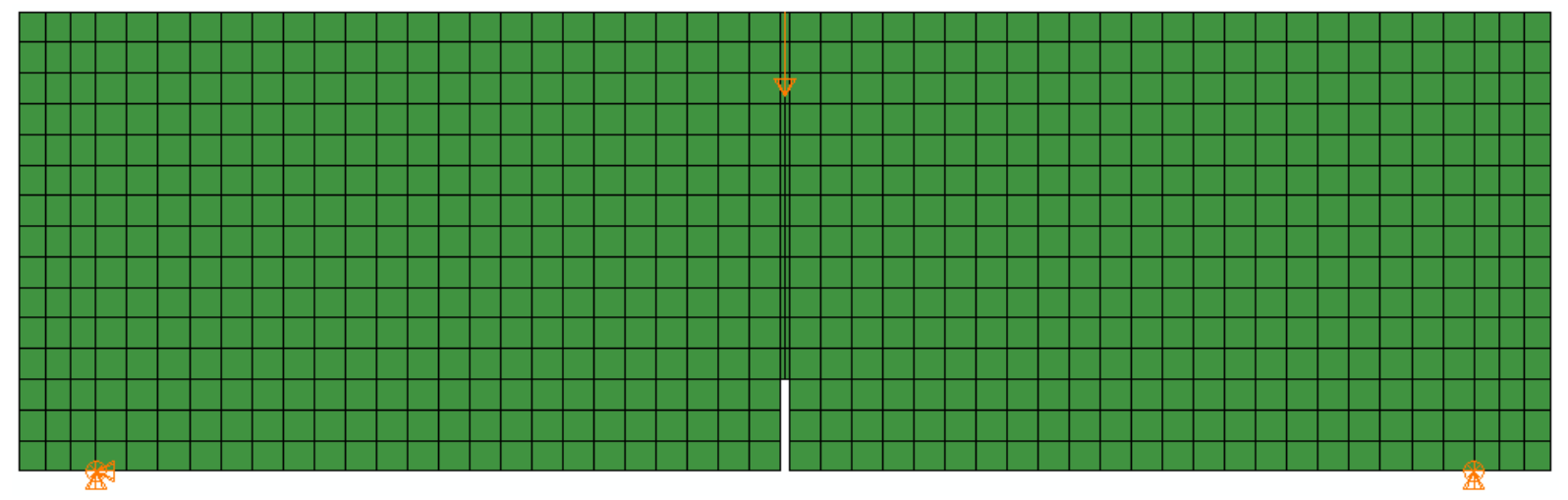

Figura 5.14 - Condições de contorno do ensaio de flexão a três pontos no prisma com entalhe

\subsubsection{Simulação numérica do ensaio de flexão a quatro pontos}

A fim de validar o modelo numérico em um elemento estrutural em escala real, as vigas de UHPFRC-1 e UHPFRC-2 submetidas ao ensaio de flexão a quatro pontos, conforme Seção 3.2.4, foram simuladas numericamente.

As malhas das fibras foram geradas utilizando os coeficientes de orientação médios $\left(\eta_{\theta}\right)$ determinados nesta pesquisa por meio da análise de imagem por fotografia de alta resolução, como abordado na Seção 4. Os valores de tais coeficientes serão expostos na Seção 6.2.

A Figura 5.15 apresenta a malha tridimensional de elementos finitos utilizada para modelar a matriz cimentícia (Figura 5.15a), as fibras de aço do UHPFRC-1 (Figura 5.15b) e as armaduras longitudinais e transversais (Figura 5.15c). Como pode ser observado na Figura $5.15 \mathrm{~b}$, as fibras foram distribuídas ao longo da viga (de apoio a apoio). Nesse caso, não foi possível distribuir as fibras apenas na região central, na tentativa de um menor custo computacional, pois todo o vão útil está sujeito à fissuração. Além disso, não foi empregada simetria ao modelo, para que informações a respeito da distribuição das fibras não fossem perdidas. 


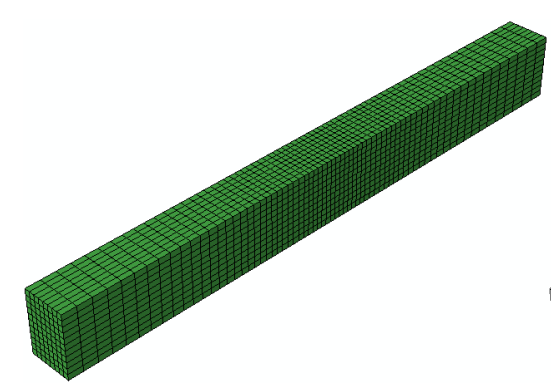

(a)

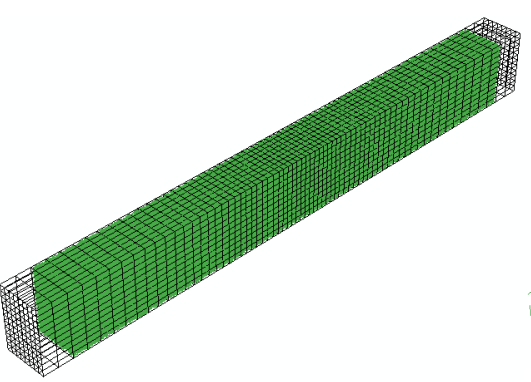

(b)

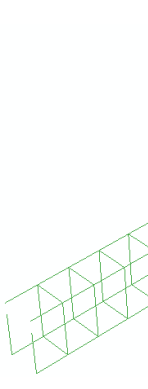

(c)

Figura 5.15 - Malha tridimensional de elementos finitos do ensaio de flexão a quanto pontos: (a) matriz, (b) fibras de aço discretizadas $\left(V_{f}=1 \%\right)$ e (c) armaduras longitudinais e transversais

Buscando-se a representação numérica da configuração experimental do ensaio de flexão a quatro pontos das vigas, a Figura 5.16 apresenta as condições de contorno de deslocamento aplicadas no modelo numérico. No apoio do lado esquerdo, foram restritos os deslocamentos nas direções $x, y$ e $z$; no direito, apenas nas direções $x$ e $y$, simulando-se assim um apoio fixo e um móvel, respectivamente. Essa representação não provocou problemas referentes a concentração de tensões nos apoios, pois as vigas foram dimensionadas para falharem por flexão, o que inibe a ocorrência de elevadas tensões nos apoios. Com relação à aplicação da força, um deslocamento incremental na direção $y$ foi imposto em pontos de referência (RP-1 e RP-2), como mostrado na Figura 5.16. A restrição MPC Beam foi utilizada para transferir os deslocamentos para a viga na área projetada dos apoios superiores. Essa representação foi empregada a fim de evitar concentração de tensões e objetivando distribuir igualmente as forças (deslocamentos impostos) nas áreas carregadas, como no experimental.
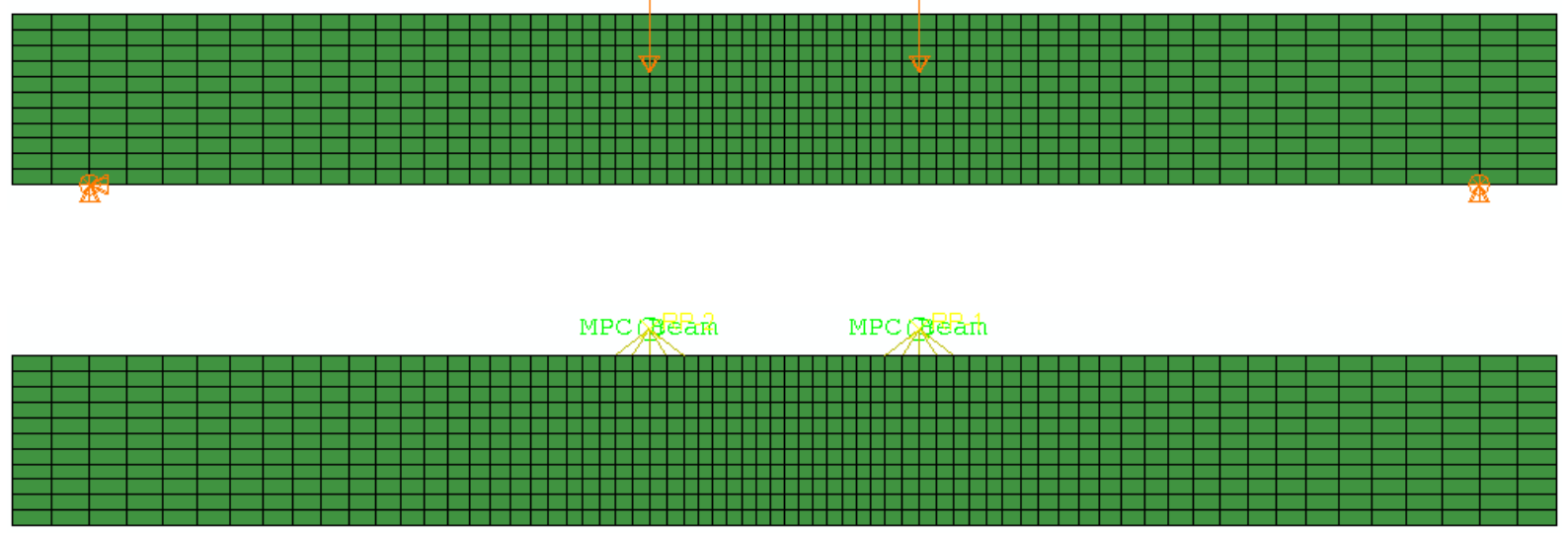

Figura 5.16 - Condições de contorno do ensaio de flexão a quatro pontos na viga 



\section{RESULTADOS E DISCUSSÕES}

Esta seção trata dos resultados e discussões desta pesquisa, oriundos da análise experimental (caracterização dos concretos e do comportamento à flexão das vigas), da análise de imagem (distribuição das fibras nas vigas) e da análise numérica (aplicação e validação do modelo numérico proposto).

\subsection{Resultados da Análise Experimental}

\subsubsection{Ensaios de caracterização do UHPC e UHPFRC}

A Tabela 6.1 lista as características dos concretos obtidas nos ensaios de caracterização. De modo geral, os concretos apresentaram propriedades aceitáveis para UHPC e UHPFRC em condições de cura úmida e alta fluidez, mas não fluidez de um concreto autoadensável (CAA), o que impossibilita eliminar a vibração.

A resistência à compressão $\left(f_{c}\right)$ e o módulo de elasticidade $\left(E_{c}\right)$ dos concretos estão dentro da faixa esperada e relatada em outros estudos. Na Tabela 6.1, é possível observar que, em relação ao UHPC, a resistência à compressão do UHPFRC-1 e UHPFRC-2 aumentou 3\% e 10,8\%, respectivamente. Já o módulo de elasticidade teve um acréscimo de 1,9\% e 5,1\% para o UHPFRC-1 e UHPFRC-2, respectivamente. Isso indica que a incorporação das fibras de aço teve pouca influência sobre a resistência à compressão e módulo de elasticidade do UHPFRC, o que concorda com as conclusões de Hoang e Fehling (2017). Além disso, como já exposto, os ensaios de caracterização foram realizados aproximadamente aos 56 dias de idade (próximo da data dos ensaios de flexão das vigas); porém, como referência, a resistência à compressão também foi avaliada aos 28 dias, apresentando valores de 127,4 $\mathrm{MPa}, 130,5 \mathrm{MPa}$ e 140,9 $\mathrm{MPa}$ para o UHPC, UHPFRC-1 e UHPFRC-2, respectivamente. 
Tabela 6.1 - Características dos concretos aos 56 dias: UHPC, UHPFRC-1 e UHPFRC-2

\begin{tabular}{|c|c|c|c|c|c|}
\hline \multirow{2}{*}{ Ensaio } & \multirow{2}{*}{ Característica } & \multirow{2}{*}{ Unid. } & \multicolumn{3}{|c|}{ Concreto } \\
\hline & & & UHPC & UHPFRC-1 & UHPFRC-2 \\
\hline \multirow[t]{3}{*}{ Compressão uniaxial } & $f_{c}$ & $\mathrm{MPa}$ & $\begin{array}{c}131,5 \\
(7,2)\end{array}$ & $\begin{array}{c}135,5 \\
(4,8)\end{array}$ & $\begin{array}{l}145,7 \\
(4,2)\end{array}$ \\
\hline & $\varepsilon_{c}$ & $\mathrm{~mm} / \mathrm{mm}$ & $\begin{array}{c}0,0033 \\
(0,0001)\end{array}$ & $\begin{array}{c}0,0034 \\
(0,0002)\end{array}$ & $\begin{array}{c}0,0036 \\
(0,0002)\end{array}$ \\
\hline & $E_{c}$ & $\mathrm{MPa}$ & $\begin{array}{c}43965 \\
(801)\end{array}$ & $\begin{array}{l}44806 \\
(2099)\end{array}$ & $\begin{array}{l}46222 \\
(2324)\end{array}$ \\
\hline \multirow[t]{2}{*}{ Tração uniaxial } & $f_{t}$ & $\mathrm{MPa}$ & $\begin{array}{c}7,4 \\
(0,5)\end{array}$ & $\begin{array}{c}8,3 \\
(0,4)\end{array}$ & $\begin{array}{c}9,7 \\
(0,3)\end{array}$ \\
\hline & $G_{f}$ & $\mathrm{~N} / \mathrm{mm}$ & --- & $\begin{array}{l}11,1 \\
(1,9)\end{array}$ & $\begin{array}{l}14,5 \\
(1,5)\end{array}$ \\
\hline \multirow[t]{3}{*}{ Flexão a três pontos } & $f_{L O P}$ & $\mathrm{MPa}$ & $\begin{array}{c}5,2 \\
(0,3)\end{array}$ & $\begin{array}{c}7,2 \\
(0,2)\end{array}$ & $\begin{array}{c}9,3 \\
(2,0)\end{array}$ \\
\hline & $f_{M O R}$ & $\mathrm{MPa}$ & $\begin{array}{c}5,2 \\
(0,3) \\
\end{array}$ & $\begin{array}{c}8,7 \\
(1,2)\end{array}$ & $\begin{array}{l}15,6 \\
(3,9)\end{array}$ \\
\hline & $G_{f}$ & $\mathrm{~N} / \mathrm{mm}$ & $\begin{array}{c}0,05 \\
(0,01)\end{array}$ & $\begin{array}{c}5,7 \\
(0,5)\end{array}$ & $\begin{array}{c}9,5 \\
(2,1)\end{array}$ \\
\hline \multirow[t]{2}{*}{ Compressão diametral } & $f_{t, s p, c r}$ & $\mathrm{MPa}$ & $\begin{array}{c}7,6 \\
(1,2) \\
\end{array}$ & $\begin{array}{c}8,7 \\
(1,6)\end{array}$ & $\begin{array}{l}10,2 \\
(0,9)\end{array}$ \\
\hline & $f_{t, s p}$ & $\mathrm{MPa}$ & $\begin{array}{c}7,6 \\
(1,2)\end{array}$ & $\begin{array}{l}11,8 \\
(0,8)\end{array}$ & $\begin{array}{l}13,6 \\
(1,3)\end{array}$ \\
\hline
\end{tabular}

sendo: $f_{c}$ a resistência à compressão, $\varepsilon_{c}$ a deformação em $f_{c}, E_{c}$ o módulo de elasticidade, $f_{t}$ a resistência à tração, $G_{f}$ a energia de fratura, $f_{L O P}$ a resistência à primeira fissura na flexão, $f_{M O R}$ a resistência à flexão, $f_{t, s p, c r}$ a resistência à primeira fissura na compressão diametral e $f_{t, s p}$ a resistência à tração por compressão diametral. A tabela apresenta os valores médios e (xxxx) denota o desvio padrão.

No ensaio de tração uniaxial, como pode ser observado na Tabela 6.1, a incorporação das fibras de aço no UHPC proporcionou um aumento da resistência à tração $\left(f_{t}\right)$ de $12,2 \%$ e 31,1\% para o UHPFRC-1 e UHPFRC-2, respectivamente. Esse acréscimo está relacionado à atuação das fibras como ponte de transferência de tensões pelas fissuras, o que inibe a propagação das fissuras e, consequentemente, aumenta a resistência à tração do concreto. A capacidade de transferência de tensões das fibras é influenciada por vários fatores, como a quantidade e orientação das fibras. Assim, em comparação com o UHPFRC-1, o maior aumento da resistência à tração do UHPFRC-2 pode ser atribuído a uma maior capacidade de transferência de tensões das fibras em função da maior quantidade de fibras de aço.

No ensaio de flexão, foram determinadas as resistências à primeira fissura $\left(f_{L O P}\right)$ e à flexão $\left(f_{M O R}\right)$, sendo, neste estudo, o LOP (limite de proporcionalidade) definido como o limite do trecho elástico linear devido à primeira fissura, enquanto o MOR (módulo de ruptura) é 
definido como o ponto em que ocorre a máxima tensão de flexão. Na Tabela 6.1, é possível observar que a resistência à flexão dos concretos aumentou gradualmente com o aumento da quantidade de fibras de aço. Isso está relacionado à atuação das fibras como ponte de transferência de tensões pelas fissuras, como já era esperado e explicado acima. Além disso, sabe-se que a resistência à flexão do concreto é superior à resistência à tração uniaxial; todavia, neste estudo, o UHPC apresentou resistência à flexão abaixo da resistência à tração uniaxial, o que também foi observado no estudo de Krahl (2018). A razão da baixa resistência à flexão do UHPC e, consequentemente, do UHPFRC-1 e UHPFRC-2, pode ser atribuída ao efeito de escala, uma vez que, neste estudo, o ensaio de flexão foi realizado em prismas $150 \times 150 \times 450$ $\mathrm{mm}$, sendo mais usuais prismas de $100 \times 100 \times 300 \mathrm{~mm}$. Segundo Nguyen et al. (2013) e Fehling et al. (2014), o $f_{L O P}$ e o $f_{M O R}$ são sensíveis ao tamanho do corpo de prova prismático: à medida que o tamanho do prisma aumenta, as resistências $f_{L O P}$ e $f_{M O R}$ diminuem. Um outro ponto que pode ser observado na Tabela 6.1 é o efeito das fibras de aço sobre a resistência à primeira fissura. A incorporação das fibras de aço provocou um aumento considerável do $f_{L O P}$ em relação ao UHPC, cerca de 38\% e 79\% para o UHPFRC-1 e UHPFRC-2, respectivamente. Apesar de alguns estudos apontarem que a incorporação de fibras tem pouca influência sobre $f_{L O P}$, sugerindo que as tensões de flexão até a primeira fissura são resistidas principalmente pela matriz (WU et al., 2016; REN et al., 2018), é possível observar no estudo de Nguyen et al. (2013) que o aumento da quantidade de fibras provocou um aumento significativo do $f_{L O P} \mathrm{em}$ prisma de $150 \times 150 \times 450 \mathrm{~mm}$; no entanto, esse efeito não foi presenciado em prismas menores, ficando clara a influência do efeito de escala.

Com relação à energia de fratura $\left(G_{f}\right)$, tanto no ensaio de tração uniaxial quanto no ensaio de flexão a três pontos, houve uma melhora dessa propriedade com o aumento da quantidade de fibras de aço, como pode ser observado na Tabela 6.1. Porém, nota-se uma diferença entre os valores obtidos no ensaio de tração uniaxial e no de flexão a três pontos. $\mathrm{O}$ UHPPFRC-1 e UHPFRC-2 apresentaram energia de fratura menor no ensaio de flexão; entretanto, deve-se ressaltar que a limitação do curso do clip-gage não permitiu a completa separação das bordas da fissura dos concretos; assim, a energia de fratura obtida no ensaio de flexão para o UHPFRC-1 e UHPFRC-2 certamente é maior que os valores apresentados na Tabela 6.1. No caso do UHPC, não foi possível determinar a sua energia de fratura pelo ensaio de tração uniaxial, pois, ao atingir a tensão máxima de tração, ocorreu a falha do material, o que impossibilitou medir o trecho pós-pico da curva tensão-deslocamento longitudinal. Já no ensaio de flexão do UHPC, que foi conduzido até a completa separação das bordas da fissura, 
a energia de fratura obtida $\left(G_{f}=0,05 \mathrm{~N} / \mathrm{mm}\right.$ ) está dentro do esperado (FEHLING et al., 2004; XU; WILLE, 2015).

No ensaio de compressão diametral, foram determinadas as resistências à primeira fissura $\left(f_{t, s p, c r}\right)$ e à tração por compressão diametral $\left(f_{t, s p}\right)$, sendo esta última a máxima tensão observada no ensaio. Na Tabela 6.1, nota-se que a resistência à tração por compressão diametral do UHPC apresentou-se próxima da resistência à tração uniaxial: diferença de apenas $2,7 \%$. Já para o UHPFRC-1 e UHPFRC-2, essa diferença foi significativamente maior: cerca de 40\% para ambos os concretos. Por outro lado, a resistência à primeira fissura, quando comparada à resistência à tração uniaxial, apresentou um acréscimo de 4,8\% e 5,2\% para o UHPFRC-1 e UHPFRC-2, respectivamente. Assim, em ensaios de compressão diametral para o UHPFRC, parece ser mais adequado correlacionar a resistência à primeira fissura com a resistência à tração uniaxial, como sugerido por Graybeal (2005) e Shafieifar et al. (2017).

Além da obtenção das propriedades apresentadas na Tabela 6.1, o comportamento mecânico dos concretos na compressão e na tração (tração uniaxial, flexão e compressão diametral) também foi avaliado e é apresentado em sequência.

\subsubsection{Comportamento na compressão uniaxial}

A Figura 6.1 apresenta as curvas tensão-deformação na compressão uniaxial dos concretos. Observa-se que o UHPC apresentou um comportamento quase linear até atingir a resistência à compressão, que é acompanhada por uma falha brusca e explosiva; portanto, sem trecho descendente. A incorporação das fibras de aço proporcionou ao UHPFRC-1 e UHPFRC-2 um comportamento dúctil, que pode ser evidenciado pela presença do trecho descendente (pós-pico). Nesse caso, com o surgimento das fissuras, as fibras restringiram a expansão lateral do corpo de prova, levando a uma maior tolerância à deformação axial. Analisando-se a Figura 6.1, pode-se inferir que a incorporação das fibras teve pouca influência sobre o trecho ascendente da curva-tensão deformação. Por outro lado, como esperado, o trecho descendente do UHPFRC-1 e UHPFRC-2 apresentou dispersão causada pela quantidade e orientação das fibras. 

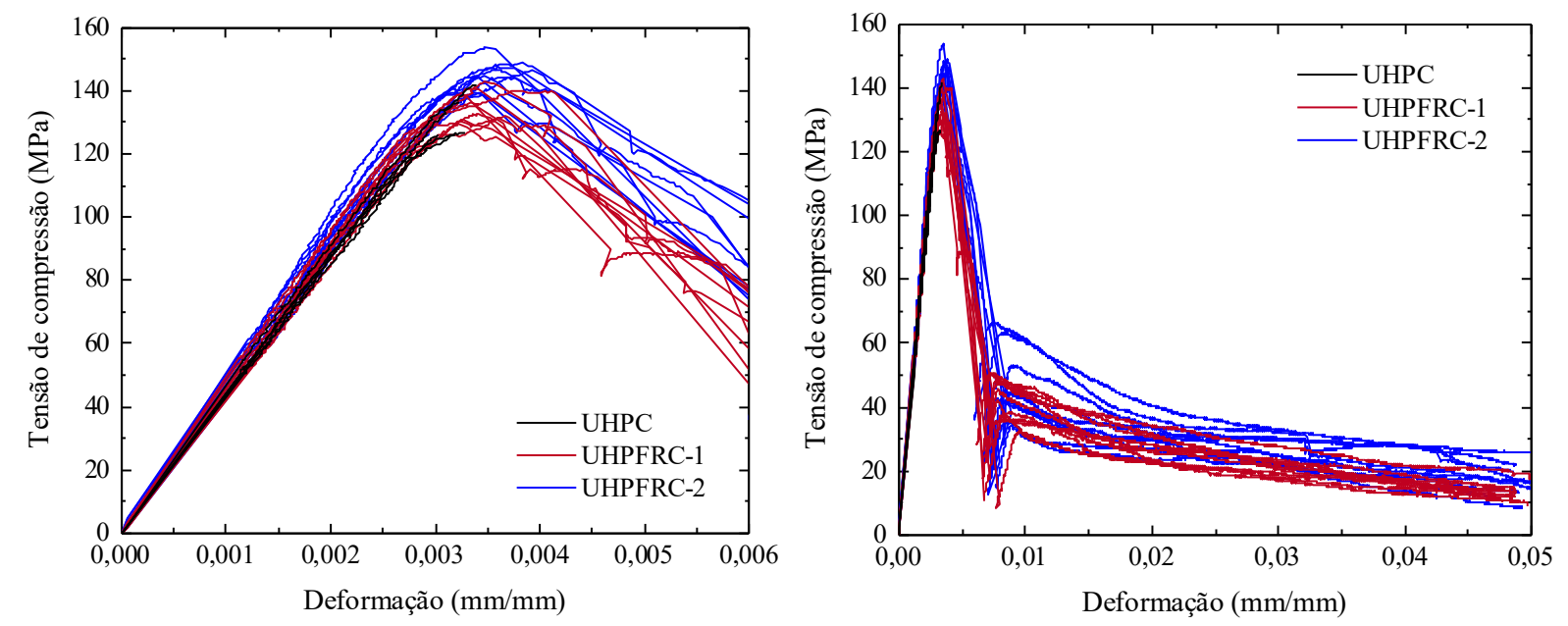

Figura 6.1 - Curvas tensão-deformação na compressão uniaxial do UHPC, UHPFRC-1 e UHPFRC-2

O padrão de falha dos concretos no ensaio de compressão uniaxial é apresentado na Figura 6.2. Nota-se que a falha do UHPC foi típica de um comportamento frágil (explosivo), ao contrário do UHPFRC-1 e UHPFRC-2, que permaneceram praticamente íntegros ao fim do ensaio.

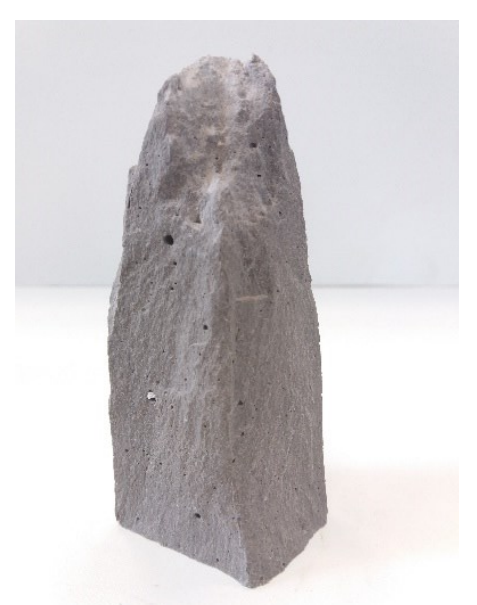

(a)

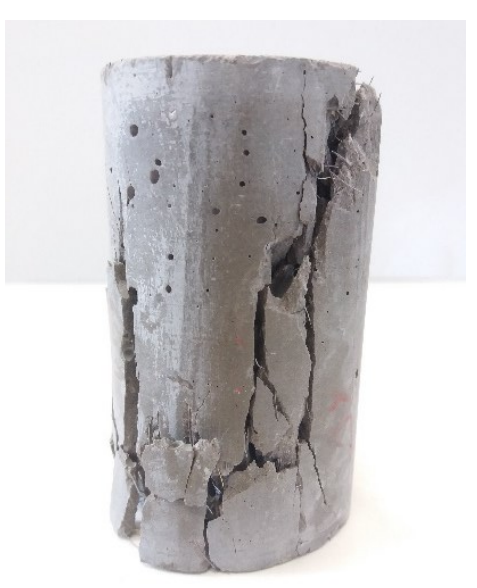

(b)

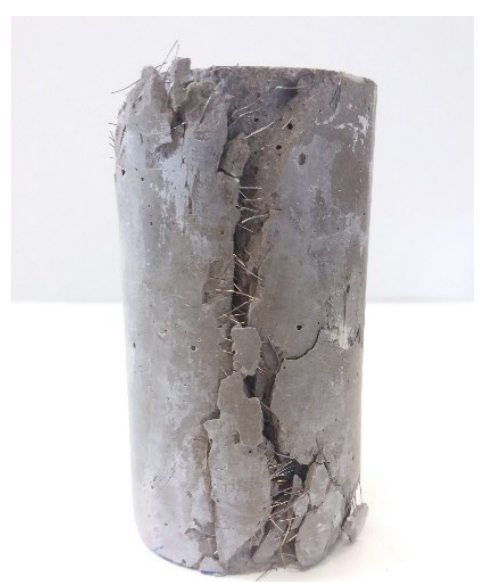

(c)

Figura 6.2 - Padrão de falha na compressão uniaxial do (a) UHPC, (b) UHPFRC-1 e (c) UHPFRC-2

\subsubsection{Comportamento na tração uniaxial}

A Figura 6.3 apresenta as curvas tensão-deformação na tração uniaxial dos concretos. Como pode ser observado, todos os concretos apresentaram um comportamento elástico linear até a primeira fissura. No caso do UHPC, o comportamento frágil na tração provocou a falha brusca do material logo após o surgimento da primeira fissura. Com a incorporação das fibras 
de aço, o UHPFRC-1 e UHPFRC-2 passaram a exibir um comportamento dúctil. Além disso, é possível observar na Figura 6.3 que o UHPFRC-2, após a primeira fissura, apresentou um comportamento de enrijecimento, ou seja, houve um aumento da tensão de tração por conta da atuação das fibras como ponte de transferência de tensões pelas fissuras. Após a tensão de tração atingir seu valor máximo, foi evidenciado um comportamento de suavização, que pode ser atribuído ao desenvolvimento de uma macrofissura e, consequentemente, ao arrancamento das fibras. Já o UHPFRC-1, após a primeira fissura, exibiu um comportamento de suavização, o que indica que a quantidade e orientação das fibras reduziram a capacidade de transferência de tensões das fibras.
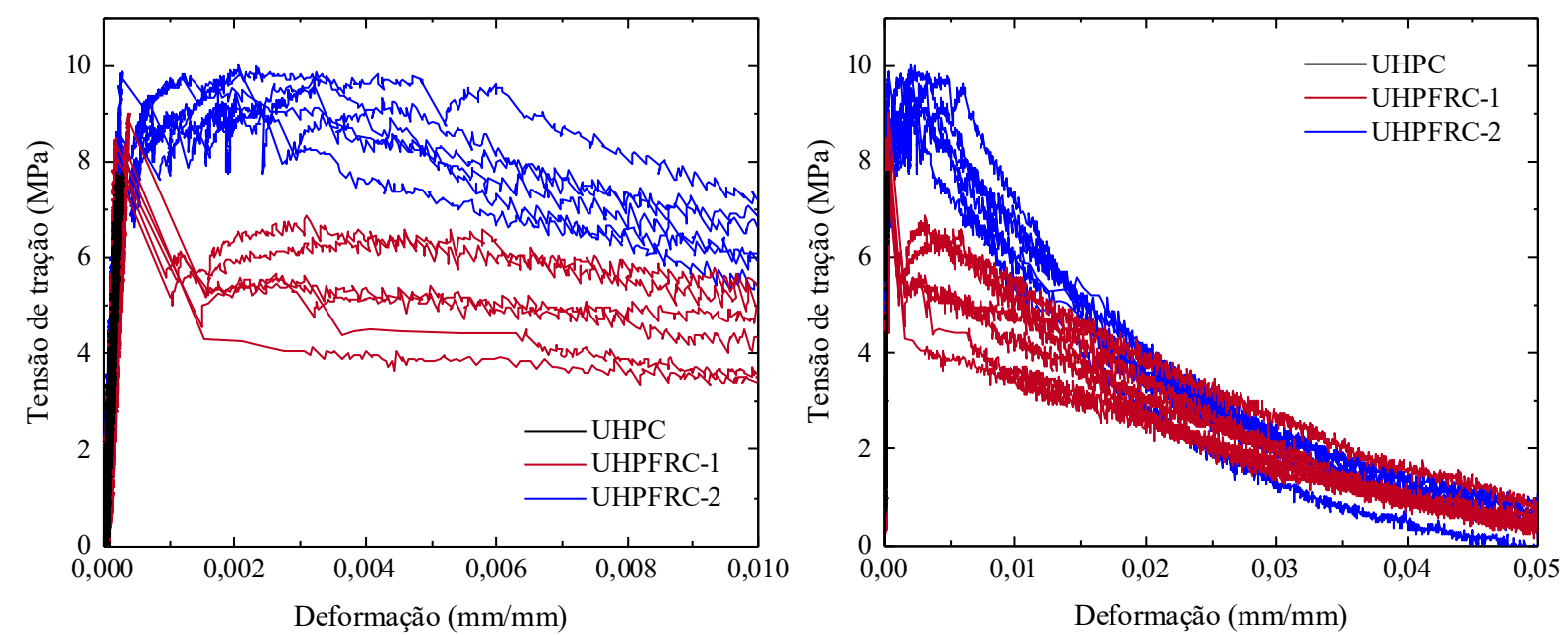

Figura 6.3 - Curvas tensão-deformação na tração uniaxial do UHPC, UHPFRC-1 e UHPFRC-2

A Figura 6.4 mostra o padrão de falha dos concretos no ensaio de tração uniaxial sem entalhe. Observou-se que o UHPFRC-2 apresentou, além da fissura principal (macrofissura), múltiplas microfissuras, característica comum em UHPFRC devido à capacidade das fibras de atuar como ponte de transferência de tensões. Já no UHPFRC-1, essa característica não foi presenciada, pois apresentou uma única fissura, como no UHPC, confirmando que a capacidade das fibras de transferir as tensões foi reduzida com o decréscimo da quantidade de fibras. 


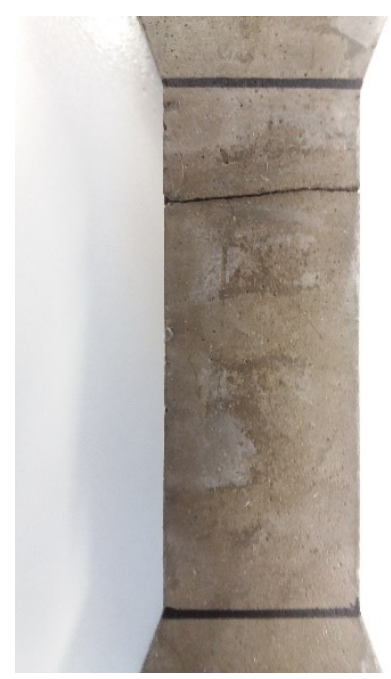

(a)

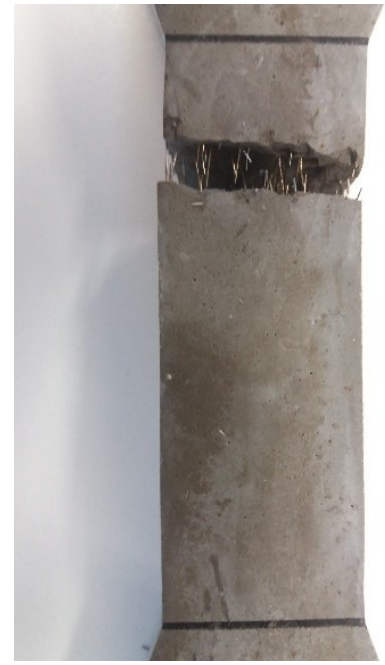

(b)

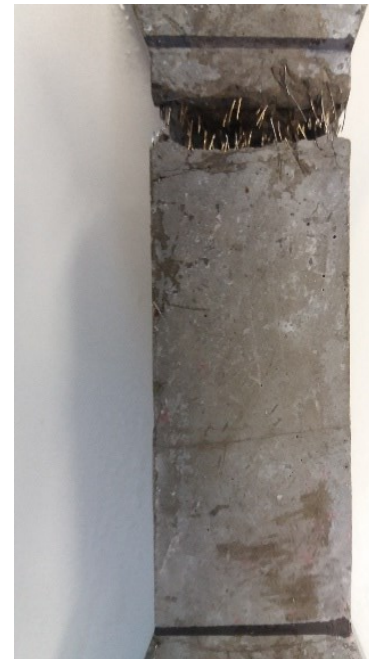

(c)

Figura 6.4 - Padrão de falha na tração uniaxial do (a) UHPC, (b) UHPFRC-1 e (c) UHPFRC-2

\subsubsection{Comportamento na flexão a três pontos}

A Figura 6.5 e a Figura 6.6 apresentam as curvas força-abertura de fissura e forçadeslocamento vertical no meio do vão na flexão a três pontos dos concretos, respectivamente. Como pode ser observado, todos os concretos apresentaram um comportamento linear até a primeira fissura. No caso do UHPC, alguns estudos (WU et al., 2016; KRAHL et al., 2018) relataram a presença de uma falha brusca após o surgimento da primeira fissura; porém, neste estudo, o ensaio de flexão foi controlado pelo deslocamento da abertura de fissura, o que possibilitou registrar o trecho descendente das curvas força-abertura de fissura e forçadeslocamento vertical no meio do vão. Após a primeira fissura, o UHPC apresentou um comportamento de suavização. Já o UHPFRC-1 e UHPFRC-2 apresentaram um comportamento de enrijecimento devido à presença das fibras. Além disso, o UHPFRC-1 mostrou uma pequena queda após a primeira fissura e depois enrijeceu, refletindo a influência da quantidade de fibras, assim como observado nos resultados de tração uniaxial. A dispersão observada após a primeira fissura, principalmente no UHPFRC-2, pode ser atribuída à orientação das fibras. 

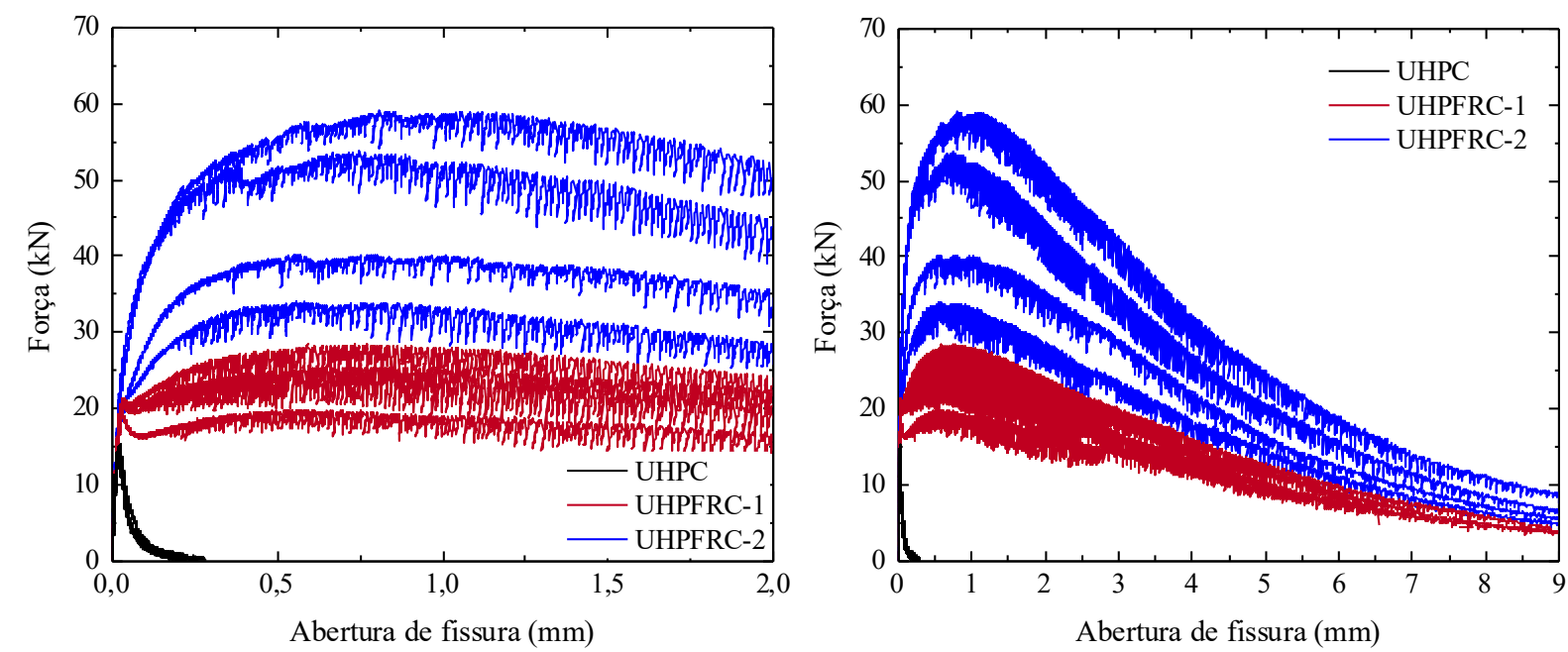

Figura 6.5 - Curvas força-abertura de fissura na flexão a três pontos com entalhe do UHPC,

UHPFRC-1 e UHPFRC-2
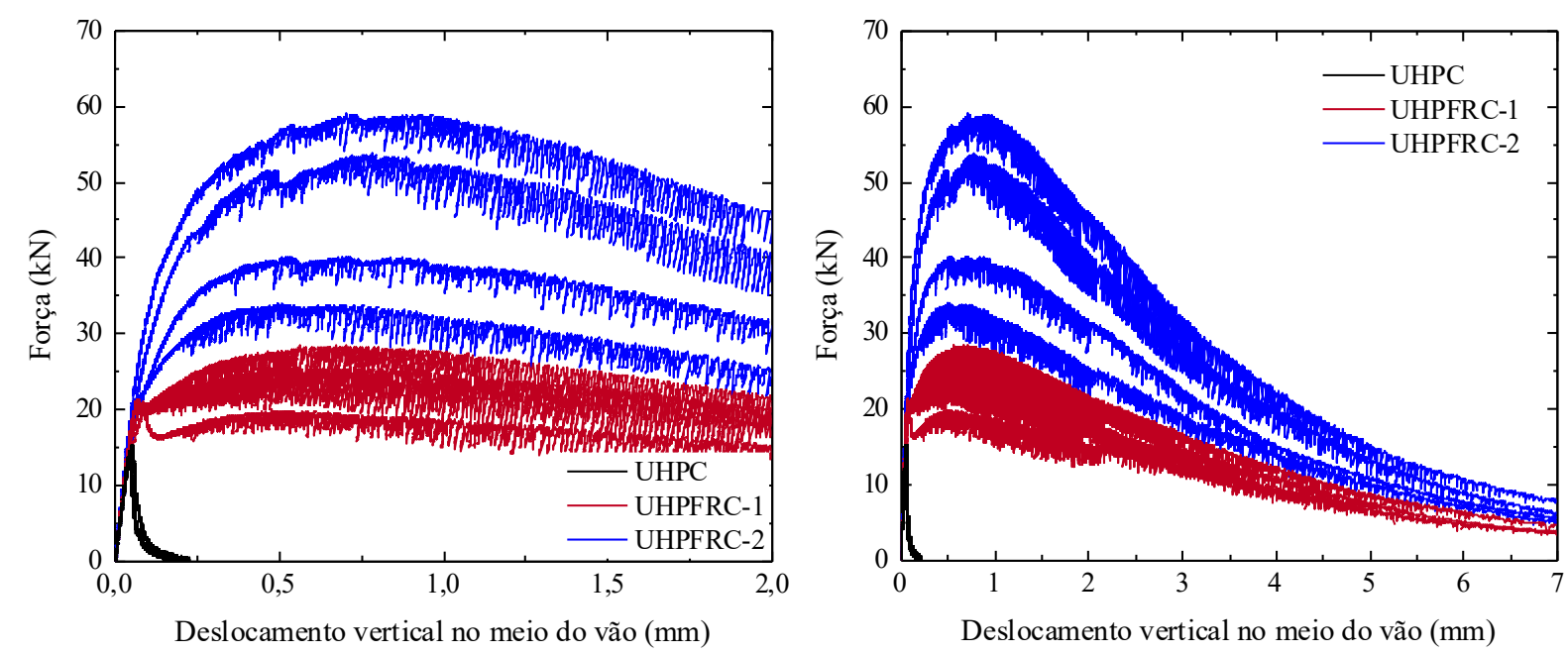

Figura 6.6 - Curvas força-deslocamento vertical no meio do vão na flexão a três pontos com entalhe do UHPC, UHPFRC-1 e UHPFRC-2

O padrão de falha dos concretos no ensaio de flexão a três pontos com entalhe é apresentado na Figura 6.7. Nota-se que o UHPC e UHPFRC-1 apresentaram uma única fissura, induzida pelo entalhe. No UHPFRC-2, além da fissura principal (na região do entalhe), também foi observada a formação de algumas microfissuras, assim como ocorrido no ensaio de tração uniaxial. 


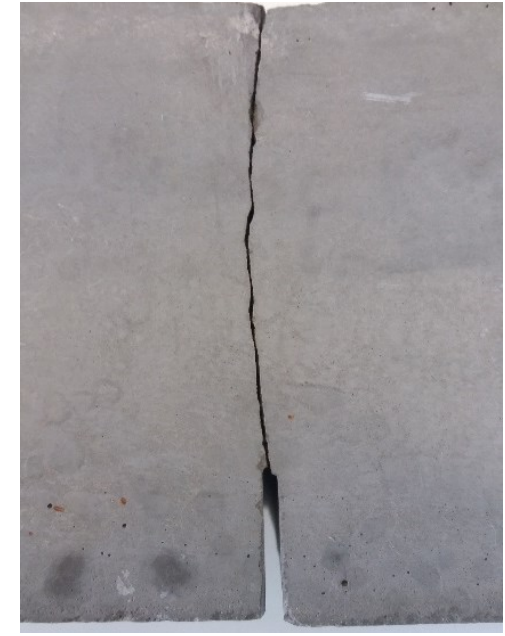

(a)

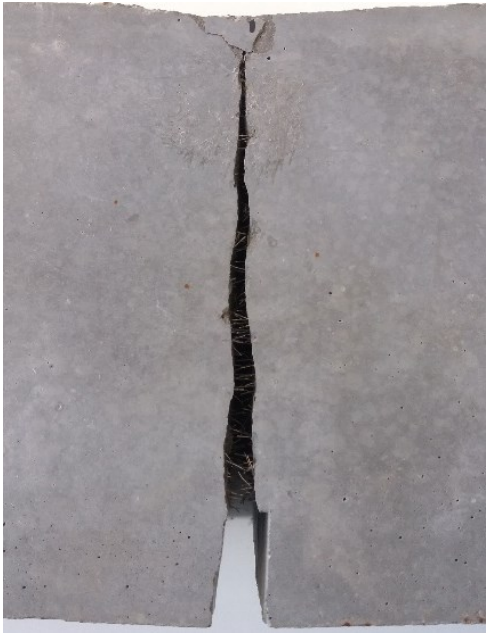

(b)

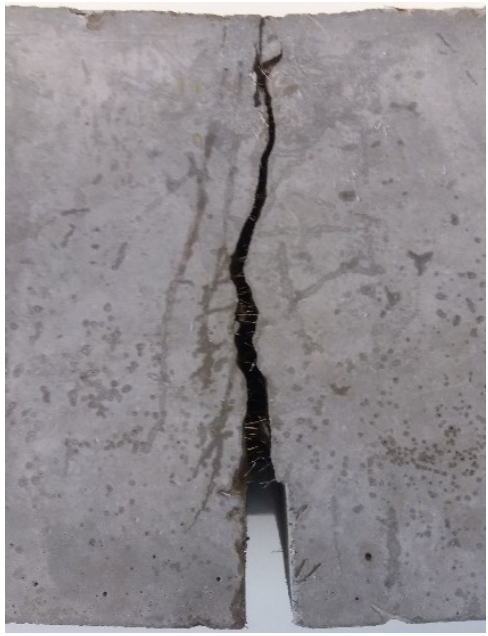

(c)

Figura 6.7 - Padrão de falha na flexão a três pontos do (a) UHPC, (b) UHPFRC-1 e (c) UHPFRC-2

\subsubsection{Comportamento na compressão diametral}

A Figura 6.8 apresenta as curvas tensão-deslocamento vertical na compressão diametral dos concretos. Observa-se que todos os concretos apresentaram um comportamento praticamente linear até a primeira fissura. O UHPC, caracterizado por um comportamento frágil, falhou logo após o surgimento da primeira fissura. No caso do UHPFRC-1 e UHPFRC-2, a presença das fibras impediu a falha frágil do material, que seria identificada pela divisão do corpo de prova em duas partes e, consequentemente, pela queda de tensão após a primeira fissura. Assim, é possível observar nas curvas do UHPFRC-1 (Figura 6.8a) e UHPFRC-2 (Figura 6.8b) uma descontinuidade no instante da primeira fissura, seguida de um aumento de tensão até seu valor máximo. É importante ressaltar que o trecho descendente (póspico) das curvas tensão-deslocamento vertical do UHPFRC-1 e UHPFRC-2 não foi registrado, pois o ensaio foi realizado sob o controle de força. 


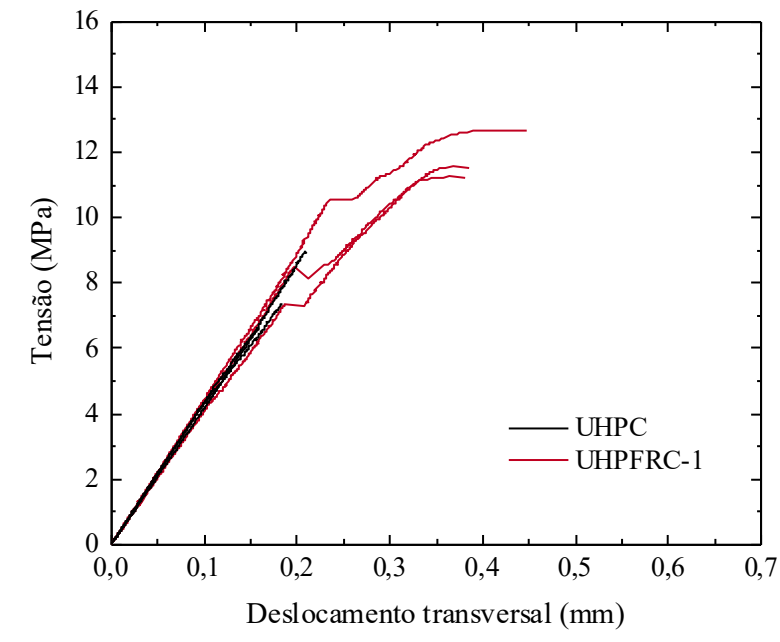

(a)

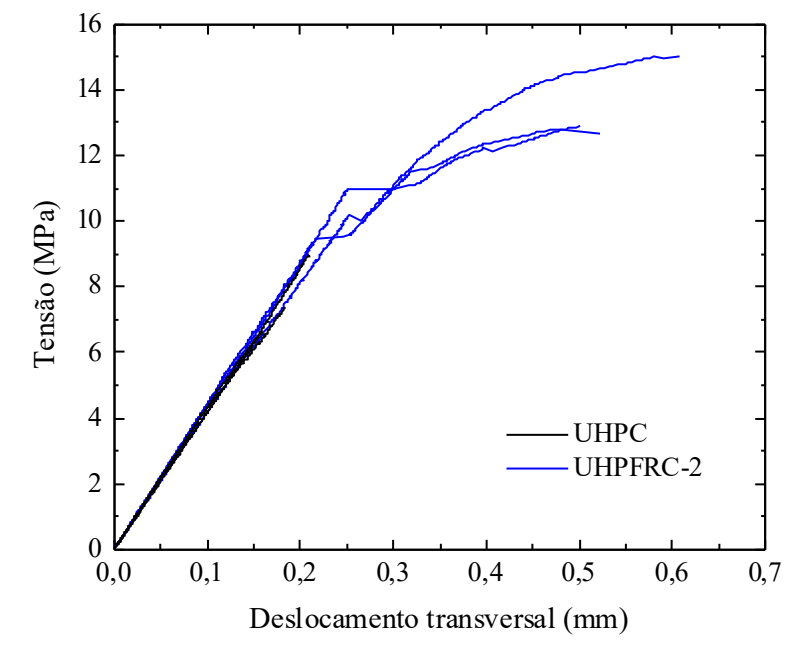

(b)

Figura 6.8 - Curvas força-deslocamento vertical na compressão diametral do (a) UHPC e UHPFRC-1 e (b) UHPC e UHPFRC-2

A Figura 6.9 apresenta o padrão de falha dos concretos no ensaio de compressão diametral. Observa-se que o UHPC apresentou uma falha frágil (divisão do corpo de prova em duas partes). No caso do UHPFRC-1 e UHPFRC-2, é perceptível que as fibras limitaram a abertura de fissura, o que permitiu que os corpos de prova permanecessem resistindo às tensões de compressão diametral, ocorrendo o esmagamento do concreto.

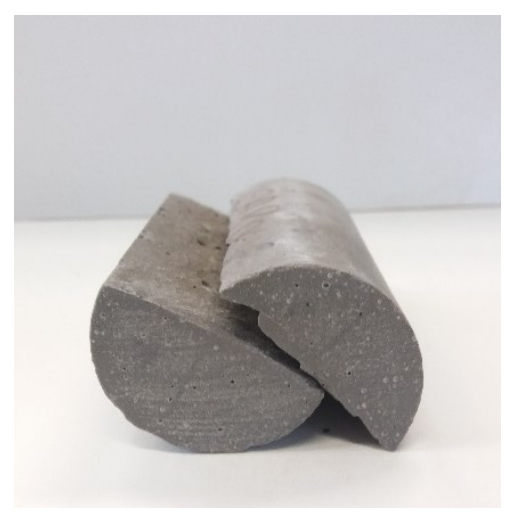

(a)

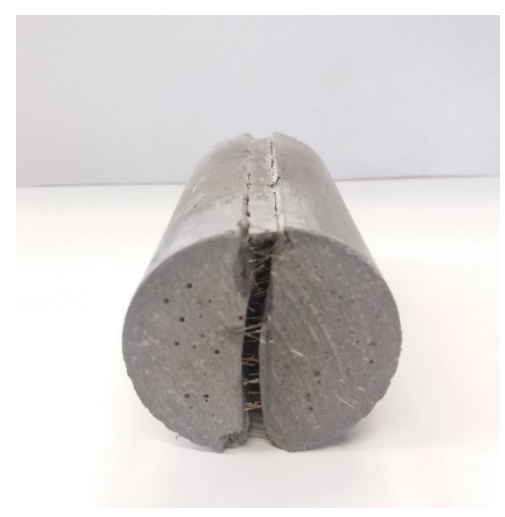

(b)

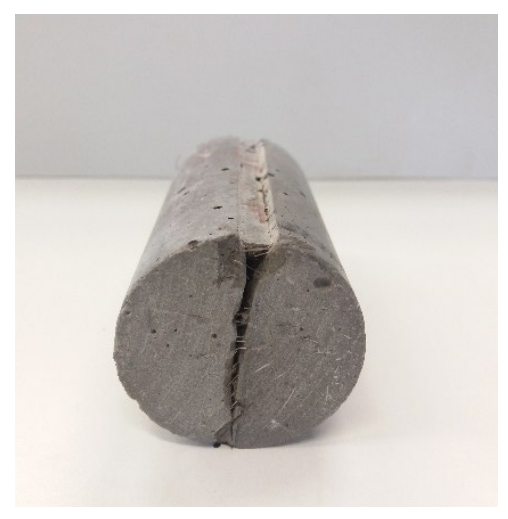

(c)

Figura 6.9 - Padrão de falha na compressão diametral do (a) UHPC, (b) UHPFRC-1 e (c) UHPFRC-2 


\subsubsection{Ensaio de flexão das vigas de UHPC e UHPFRC}

Os resultados dos ensaios de flexão a quatro pontos com carregamento monotônico caracterizaram o comportamento à flexão das vigas de UHPC e UHPFRC. Nesta pesquisa, o comportamento à flexão abrangeu: o padrão de fissuração, o modo de falha, a ductilidade e as curvas força-deslocamento vertical no meio do vão, força-deformação e momento-curvatura, sendo o foco principal dos ensaios fornecer informações para validar o modelo numérico proposto.

6.1.2.1 Padrão de fissuração e modo de falha

A Figura 6.10 mostra os padrões de fissuração das vigas de UHPC (V0), UHPFRC-1 (V1-1 e V1-2) e UHPFRC-2 (V2-1 e V2-2), após o término dos ensaios de flexão.

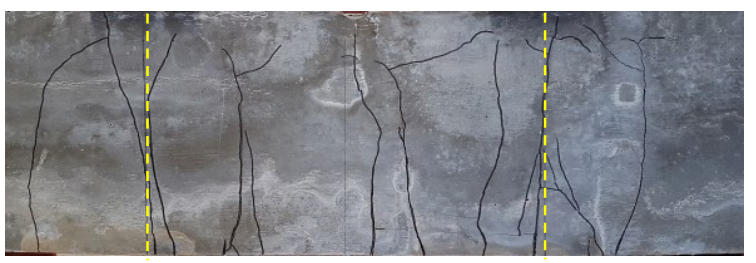

(a)

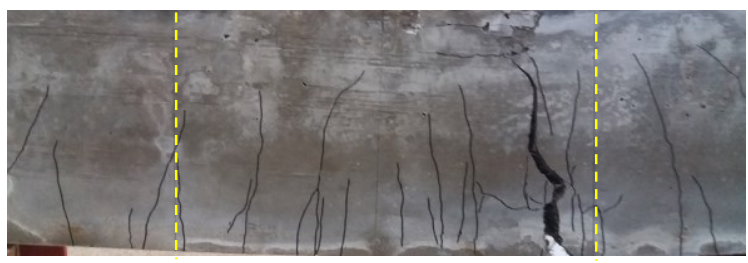

(b)

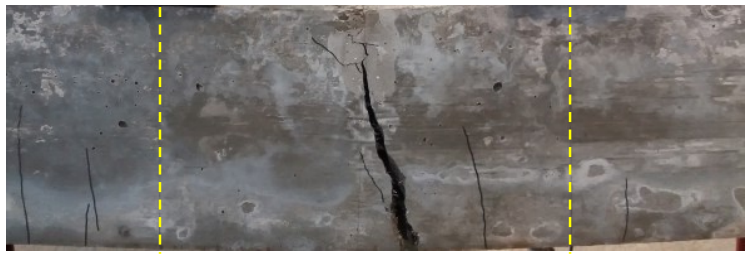

(d)
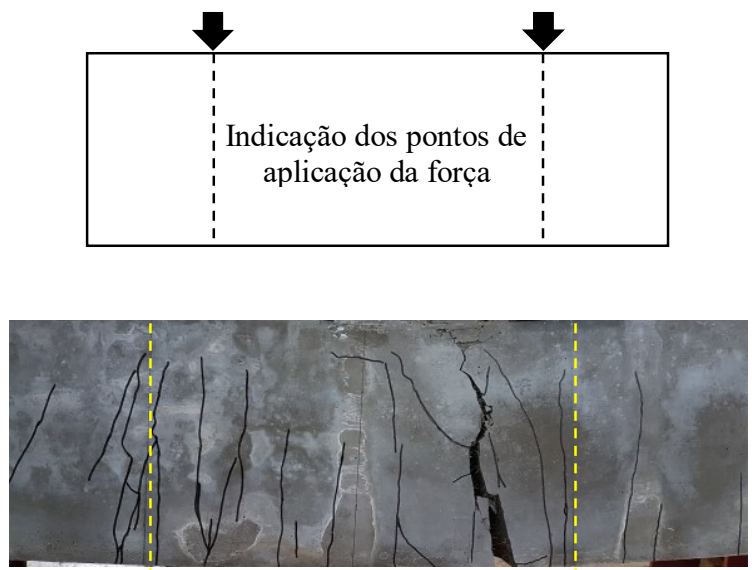

(c)

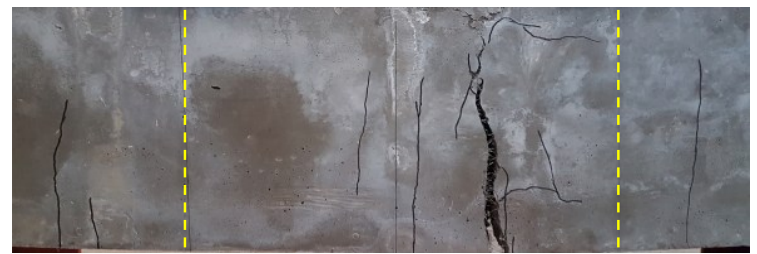

(e)

Figura 6.10 - Padrão de fissuração das vigas de UHPC, UHPFRC-1 e UHPFRC-2 no ensaio de flexão a quatro pontos: (a) V0, (b) V1-1, (c) V1-2, (d) V2-1 e (e) V2-2

Em geral, foi observada nos ensaios a formação de fissuras perpendiculares às tensões de tração na face inferior das vigas (face tracionada), inicialmente entre os pontos de aplicação da força. No decorrer dos ensaios, as fissuras propagaram-se em direção à face superior das 
vigas (face comprimida). No entanto, nota-se na Figura 6.10 que as fissuras da viga de UHPC aproximaram-se mais da face superior do que as das vigas reforçadas com fibras. Isso mostra que a propagação das fissuras nas vigas de UHPFRC-1 e UHPFRC-2 foi efetivamente restringida pela atuação das fibras como ponte de transferência de tensões. Além disso, observou-se ao fim dos ensaios que a abertura das fissuras nas vigas de UHPFRC-1 e UHPFRC-2 foi menor do que a da viga de UHPC, comprovando a eficiência das fibras no controle de fissuração. É importante ressaltar que as fissuras detectadas e apresentadas na Figura 6.10 foram apenas as visíveis a olho nu. Assim, provavelmente, as vigas de UHPFRC-1 e, principalmente, as de UHPFRC-2 apresentaram uma quantidade maior de microfissuras, que não puderam ser identificadas visivelmente, pois se sabe que redistribuição das tensões de tração proporcionada pelas fibras induz a formação de múltiplas fissuras no UHPFRC.

Nas vigas de UHPFRC-1 e UHPFRC-2, próximo à força máxima, a abertura de uma fissura específica começou a aumentar significativamente, provocando o desenvolvimento de uma macrofissura (ver Figura 6.10) e, consequentemente, o arrancamento das fibras da matriz (evidenciado por sinal sonoro durante os ensaios). Assim, a deformação da armadura longitudinal passou a ser concentrada no local de formação da macrofissura, levando à estricção (redução da seção transversal) da mesma.

As vigas de UHPFRC-1 e UHPFRC-2 foram ensaiadas até a ruptura e apresentaram falha por flexão devido à ruptura da armadura longitudinal. A viga de UHPC, por sua vez, mostrou-se instável com o aumento da força aplicada (extensômetros da armadura longitudinal com medição no limite superior do fabricante); assim, para preservar os equipamentos, o ensaio foi interrompido antes da ruptura da viga, não sendo possível relatar o seu modo de falha.

\subsubsection{Curva força-deslocamento vertical no meio do vão}

As curvas força-deslocamento vertical no meio do vão das vigas de UHPC, UHPFRC-1 e UHPFRC-2 solicitadas à flexão são apresentadas na Figura 6.11. Além disso, a Tabela 6.2 lista algumas características relevantes do comportamento à flexão das vigas. Salienta-se que, para a obtenção do deslocamento vertical no meio do vão, foi descontado do deslocamento registrado no meio do vão (LVDT-1) a média dos deslocamentos medidos nos apoios (LVDT-4 e LVDT-5, ver Figura 3.9). 


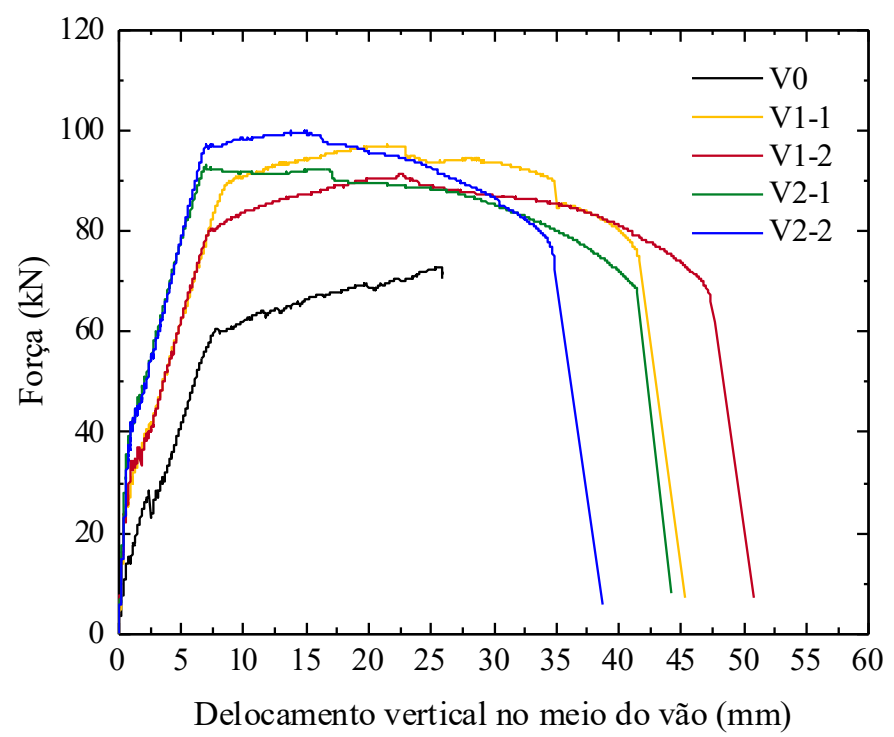

Figura 6.11 - Curvas força-deslocamento vertical no meio do vão no ensaio de flexão a quatro pontos das vigas de UHPC (V0), UHPFRC-1 (V1-1 e V1-2) e UHPFRC-2 (V2-1 e V2-2)

Tabela 6.2 - Características do comportamento à flexão a quatro pontos das vigas de UHPC (V0), UHPFRC-1 (V1-1 e V1-2) e UHPFRC-2 (V2-1 e V2-2)

\begin{tabular}{|c|c|c|c|c|c|c|c|c|}
\hline \multirow{2}{*}{ Viga } & \multicolumn{2}{|c|}{$\begin{array}{l}\text { Primeira } \\
\text { fissura }\end{array}$} & \multicolumn{2}{|c|}{$\begin{array}{l}\text { Estado de } \\
\text { escoamento }\end{array}$} & \multicolumn{2}{|c|}{ Estado de pico } & \multirow{2}{*}{$\begin{array}{c}\begin{array}{c}\text { Estado } \\
\text { último }\end{array} \\
\begin{array}{c}\delta_{u} \\
(\mathrm{~mm})\end{array}\end{array}$} & \multirow{2}{*}{$\begin{array}{c}\begin{array}{c}\text { Índice de } \\
\text { ductilidade }\end{array} \\
\delta_{u} / \delta_{y}\end{array}$} \\
\hline & $\begin{array}{c}F_{c r} \\
(\mathrm{kN})\end{array}$ & $\begin{array}{c}\delta_{c r} \\
(\mathrm{~mm})\end{array}$ & $\begin{array}{c}F_{y} \\
(\mathrm{kN})\end{array}$ & $\begin{array}{c}\delta_{y} \\
(\mathrm{~mm})\end{array}$ & $\begin{array}{l}F_{\max } \\
(\mathrm{kN})\end{array}$ & $\begin{array}{l}\delta_{\max } \\
(\mathrm{mm})\end{array}$ & & \\
\hline V0 & 27,8 & 2,49 & 59,6 & 7,59 & $--^{\mathrm{a}}$ & $--^{a}$ & $--^{a}$ & $--^{a}$ \\
\hline V1-1 & 29,9 & 1,08 & 87,5 & 8,23 & 97,0 & 21,41 & 41,59 & 5,05 \\
\hline V1-2 & 32,7 & 1,10 & 79,9 & 7,55 & 91,4 & 22,53 & 47,34 & 6,27 \\
\hline V2-1 & 41,1 & 1,13 & 90,1 & 6,57 & 93,0 & 15,91 & 41,52 & 6,32 \\
\hline V2-2 & 40,6 & 1,10 & 95,6 & 6,78 & 99,8 & 14,97 & 34,87 & 5,14 \\
\hline
\end{tabular}

sendo: $F_{c r}$ a força na primeira fissura, $\delta_{c r}$ o deslocamento em $F_{c r}, F_{y}$ a força no início do escoamento da armadura longitudinal, $\delta_{y}$ o deslocamento em $F_{y}, F_{\max }$ a força máxima, $\delta_{\max }$ o deslocamento em $F_{\max }$ e $\delta_{u}$ o deslocamento último (ruptura). ${ }^{\text {a }}$ Dados não determinados (viga não ensaiada até a ruptura).

Como pode ser observado na Figura 6.11, a incorporação das fibras de aço, como esperado, proporcionou maior rigidez e capacidade de força às vigas de UHPFRC-1 e UHPFRC-2, quando comparadas à viga de UHPC. Porém, com o aumento da quantidade de fibras de $1 \%$ para $2 \%$, não foi observada melhora significativa da força máxima $\left(F_{\max }\right)$ : as vigas de UHPFRC-1 e UHPFRC-2 apresentaram força máxima média de 94,2 kN e 96,4 kN, respectivamente, ou seja, um acréscimo de apenas 2,3\%. Esse resultado sugere que, no ensaio de flexão dessas vigas, com o desenvolvimento da macrofissura, a contribuição das fibras no 
comportamento pós-fissuração ${ }^{1}$ foi compensada pela atuação preponderante da armadura longitudinal. Além disso, a eficiência das fibras é influenciada pela sua quantidade e orientação. Segundo Cunha (2010), o aumento da quantidade de fibras pode provocar agrupamentos, o que promove maior interação entre as fibras e, consequentemente, reduz a sua resistência ao arrancamento. Provavelmente, por essa razão, o aumento da quantidade de fibras não teve influência significativa na força máxima das vigas. Destaca-se que a orientação das fibras foi descartada como provável causa, pois a análise de imagem realizada nas vigas após os ensaios de flexão mostrou um padrão de orientação similar para as vigas de UHPFRC-1 e UHPFRC-2.

Na Figura 6.11, nota-se também que as vigas UHPFRC-1 e UHPFRC-2 sofreram uma queda repentina da força, que pode ser atribuída ao instante da ruptura da armadura longitudinal, provocando a falha da viga por flexão. No caso da viga de UHPC, como já exposto, o ensaio foi encerrado antes da falha da viga, não podendo ser identificado seus instantes de força máxima e de ruptura.

\subsubsection{Ductilidade}

A ductilidade das vigas de UHPFRC-1 e UHPFRC-2 foi quantificada por meio do índice de ductilidade de deslocamento vertical no meio do vão, como realizado por Yoo e Yoon (2015), Singh et al. (2017) e Hasgul et al. (2018). Os índices de ductilidade foram determinados pela Equação (6.1), conforme proposto por Shin et al. (1989), e apresentados na Tabela 6.2.

$$
\mu=\frac{\delta_{u}}{\delta_{y}}
$$

sendo: $\mu$ o índice de ductilidade de deslocamento, $\delta_{u}$ o deslocamento último (ruptura) e $\delta_{y}$ o deslocamento correspondente à força no início do escoamento da armadura longitudinal.

O índice de ductilidade médio das vigas de UHPFRC-1 e UHPFRC-2 foi 5,66 e 5,73, respectivamente. Sabe-se que o UHPFRC é um material com excelente ductilidade pósfissuração sob tensão de tração na flexão. Porém, de acordo com os resultados, o aumento da quantidade de fibras de aço de $1 \%$ para $2 \%$ não proporcionou melhora significativa na ductilidade das vigas. Como supracitado, o comportamento pós-fissuração das vigas na flexão provavelmente foi governado pela armadura longitudinal, e não pela das fibras de aço. Em função disso, a quantidade de fibras não influiu significativamente na ductilidade das vigas.

\footnotetext{
${ }^{1} \mathrm{O}$ termo "pós-fissuração" para as vigas de UHPFRC corresponde, na curva força-deslocamento vertical no meio do vão, ao trecho entre o início do escoamento da armadura longitudinal $\left(\delta_{y}\right)$ e a falha da viga $\left(\delta_{u}\right)$.
} 


\subsubsection{Curva força-deformação}

As curvas força-deformação das vigas de UHPC, UHPFRC-1 e UHPFRC-2 são apresentadas na Figura 6.12, Figura 6.13 e Figura 6.14, respectivamente. As deformações médias foram avaliadas com base nas medidas fornecidas pelos extensômetros (Ext-1/2 e Ext-3/4) e pelos transdutores de deslocamento (LVDT-6/7 e LVDT-8/9), posicionados nas superfícies do concreto e nas armaduras longitudinais (ver Figura 6.12). Deformações negativas representam compressão, enquanto deformações positivas, tração.

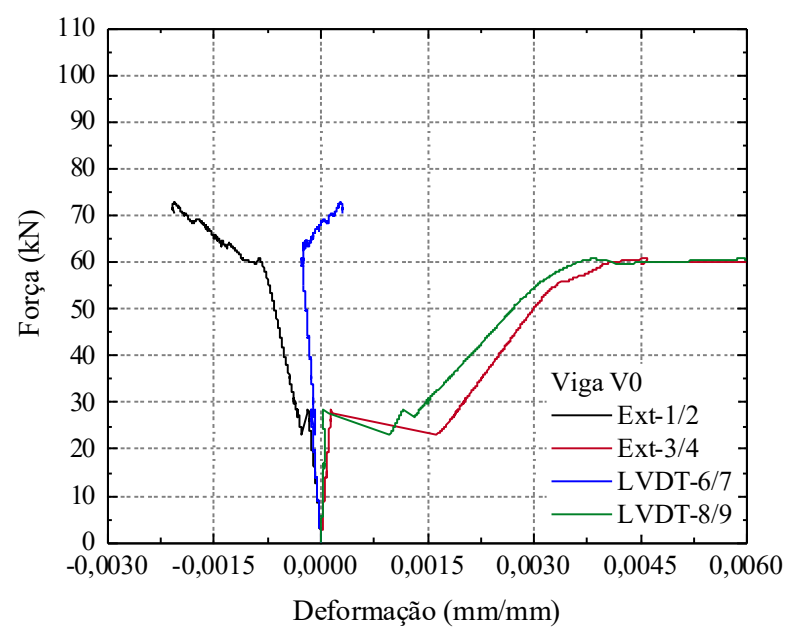

Detalhe da instrumentação na região central das vigas

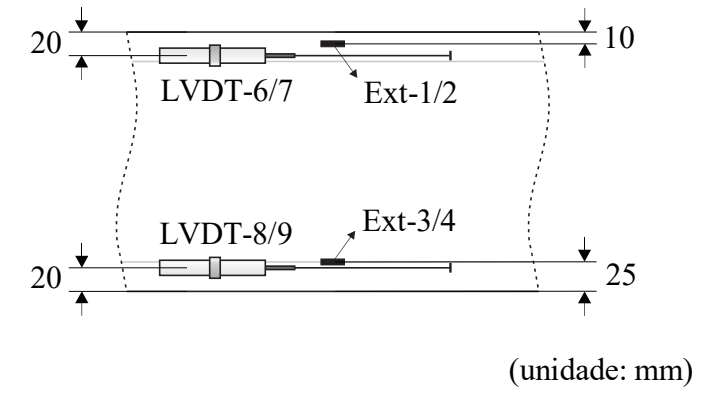

Figura 6.12 - Curvas força-deformação da viga de UHPC (V0) no ensaio de flexão a quatro pontos

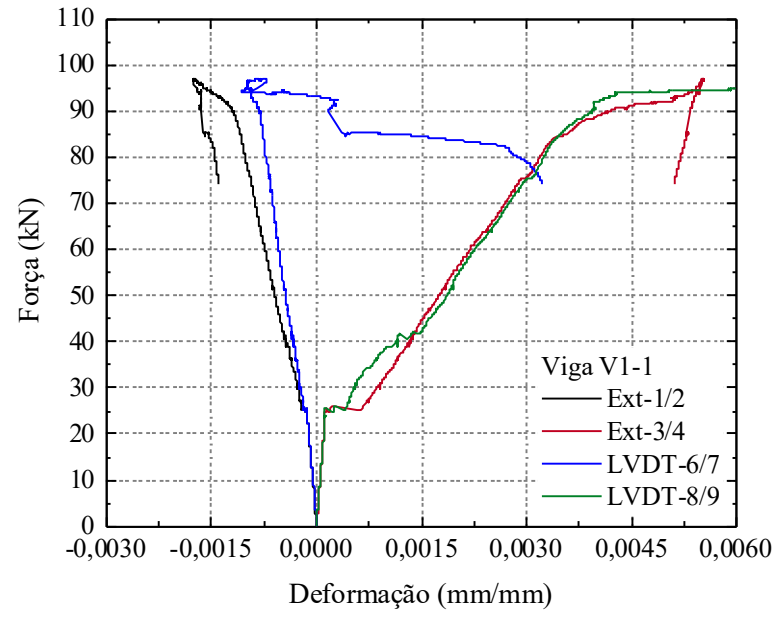

(a)

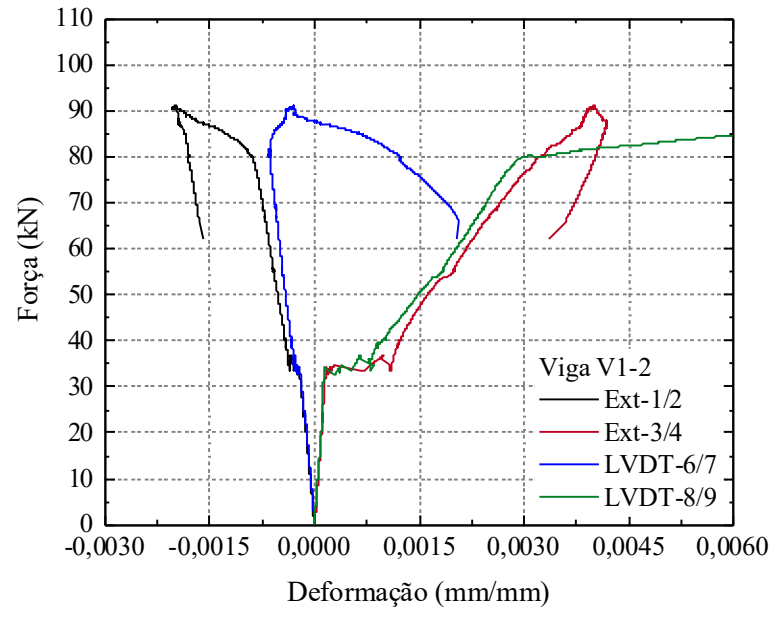

(b)

Figura 6.13 - Curvas força-deformação das vigas de UHPFRC-1 no ensaio de flexão a quatro pontos:

(a) V1-1 e (b) V1-2 


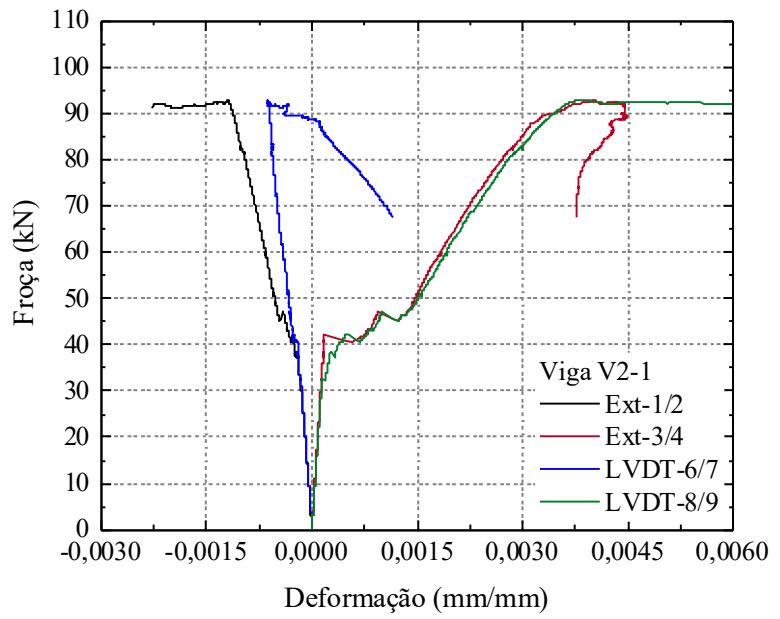

(a)

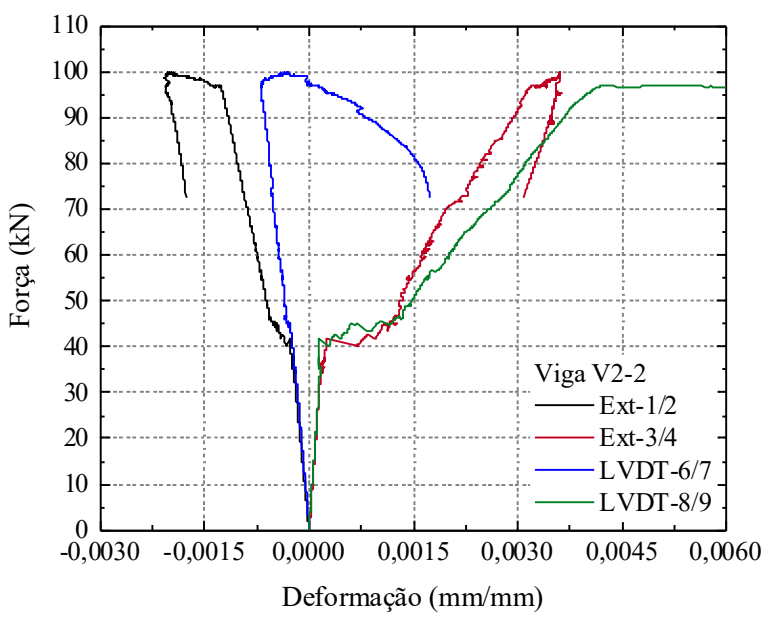

(b)

Figura 6.14 - Curvas força-deformação das vigas de UHPFRC-2 no ensaio de flexão a quatro pontos:

(a) V2-1 e (b) V2-2

No início dos ensaios, observa-se que as vigas de UHPC, UHPFRC-1 e UHPFRC-2 exibiram deformações de compressão na face superior, nas posições dos extensômetros 1 e 2 (Ext-1/2) e dos transdutores de deslocamento 6 e 7 (LVDT-6/7). Após atingir a força máxima, as deformações medidas pelo LVDT-6/7 mudaram de compressão para tração. Segundo Yang et al. (2010), esse tipo de mudança pode ser causado pela propagação das fissuras da face inferior para a face superior das vigas e, por conseguinte, pelo deslocamento (para cima) da linha neutra na seção transversal. Porém, é importante ressaltar que as medidas de deformação obtidas pelos LVDTs nas vigas de UHPFRC-1 e UHPFRC-2 (tanto na face superior quanto na inferior), após a força máxima, não são totalmente confiáveis, pois elas passam a sofrer influência significativa da abertura da macrofissura, que começa a se desenvolver nesse estágio dos ensaios.

Nota-se também que as deformações medidas na face inferior das vigas, por meio dos transdutores de deslocamento 8 e 9 (LVDT-8/9), e no centro das armaduras longitudinais, por meio dos extensômetros 3 e 4 (Ext-3/4), foram de tração ao longo de todos os ensaios, como esperado. É importante destacar que as altas deformações nas armaduras longitudinais das vigas de UHPFRC-1 e UHPFRC-2 não foram registradas pelos extensômetros 3 e 4, uma vez que o local de desenvolvimento da macrofissura (que é onde ocorre a concentração da deformação da armadura) ocorreu fora da posição dos extensômetros.

Além do que foi exposto, para um mesmo nível de força, observa-se que as vigas de UHPFRC-1 e UHPFRC-2 apresentaram, em geral, menores deformações de tração, quando comparadas à viga de UHPC. Isso está associado à atuação das fibras como ponte de 
transferência de tensões de tração pelas fissuras, que provoca a redistribuição das tensões e, consequentemente, diminui as deformações no concreto e na armadura, consolidando o efeito positivo da incorporação das fibras de aço no concreto.

\subsubsection{Curva momento-curvatura}

As curvas momento-curvatura das vigas de UHPC, UHPFRC-1 e UHPFRC-2 são apresentadas na Figura 6.15. A curvatura da seção transversal das vigas foi determinada pela Equação (6.2).

$$
\frac{1}{\rho}=\frac{2\left(\delta_{L V D T 1}-\delta_{L V D T 2 / 3}\right)}{\left(\delta_{L V D T 1}-\delta_{L V D T 2 / 3}\right)^{2}+\left(\frac{l}{2}\right)^{2}}
$$

sendo: $1 / \rho$ a curvatura da seção transversal, $\delta_{L V D T 1}$ o deslocamento medido pelo LVDT-1, $\delta_{L V D T 2 / 3}$ a média dos deslocamentos medidos pelo LVDT-2 e LVDT-3 e $l$ a distância entre os pontos de aplicação da força (ver Figura 3.9).

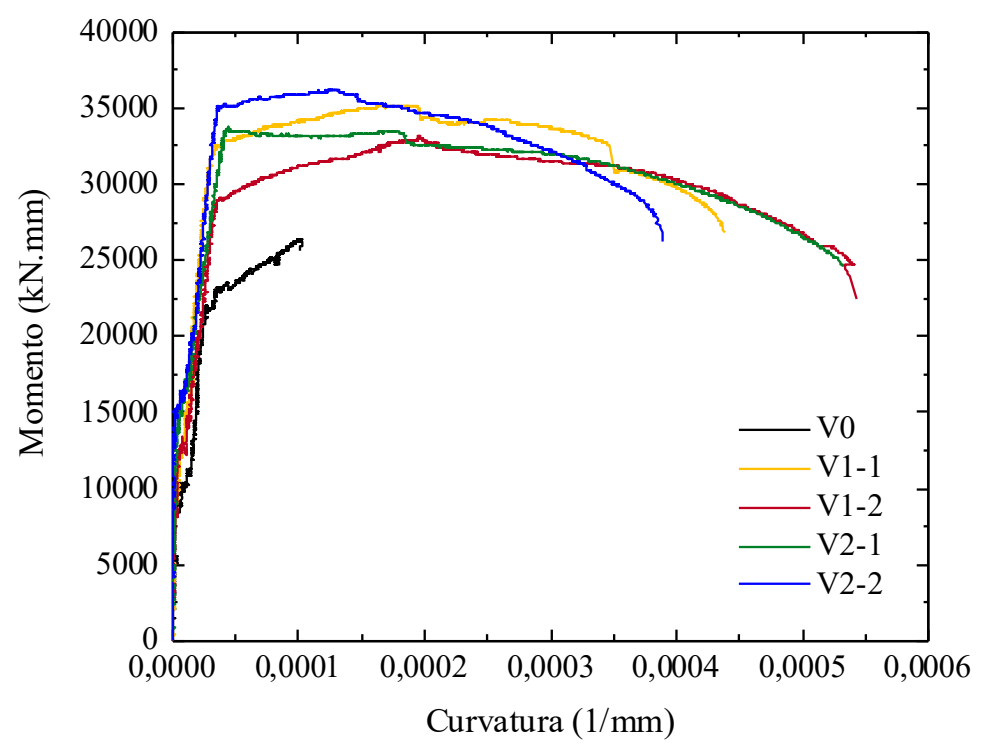

Figura 6.15 - Curvas momento-curvatura no ensaio de flexão a quatro pontos das vigas de UHPC (V0), UHPFRC-1 (V1-1 e V1-2) e UHPFRC-2 (V2-1 e V2-2)

As curvas momento-curvatura das vigas de UHPC, UHPFRC-1 e UHPFRC-2 apresentaram-se lineares até o início da fissuração. Os momentos de flexão correspondentes à primeira fissura, ao início de escoamento da armadura longitudinal e ao momento máximo correspondem aproximadamente e estão coerentes com as forças encontradas nas curvas forçadeslocamento vertical no meio do vão, bem como com os respectivos fenômenos observados. 


\subsection{Resultados da Análise de Imagem}

As imagens binárias dos planos corte próximos aos planos de fissuração principais das vigas de UHPFRC-1 e UHPFRC-2 são apresentadas na Figura 6.16, Figura 6.17, Figura 6.18 e Figura 6.19. Em geral, pode ser observado que as fibras apresentaram-se dispersas de forma mais homogênea do que polarizada e alinharam-se mais paralelamente à direção normal ao plano de corte. Essas características de orientação e dispersão são bastante comuns no UHPFRC, devido à sua fluidez e ausência de agregado graúdo. Além disso, o emprego da vibração de mesa durante a moldagem das vigas, provavelmente, contribuiu para o alinhamento das fibras.

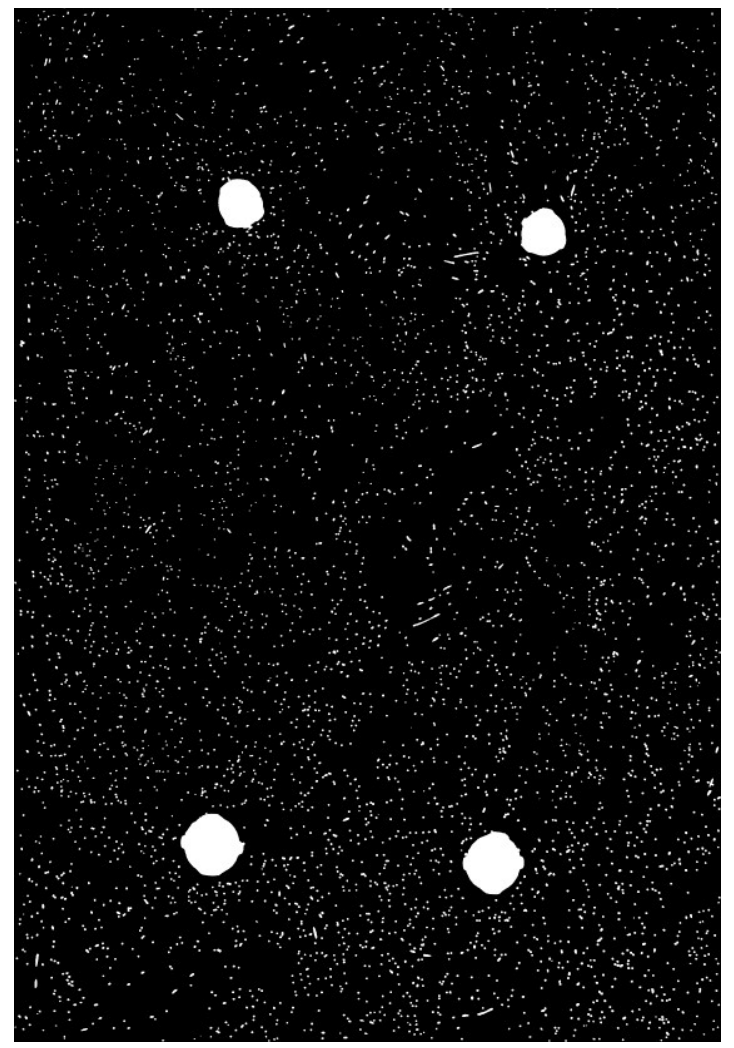

(a)

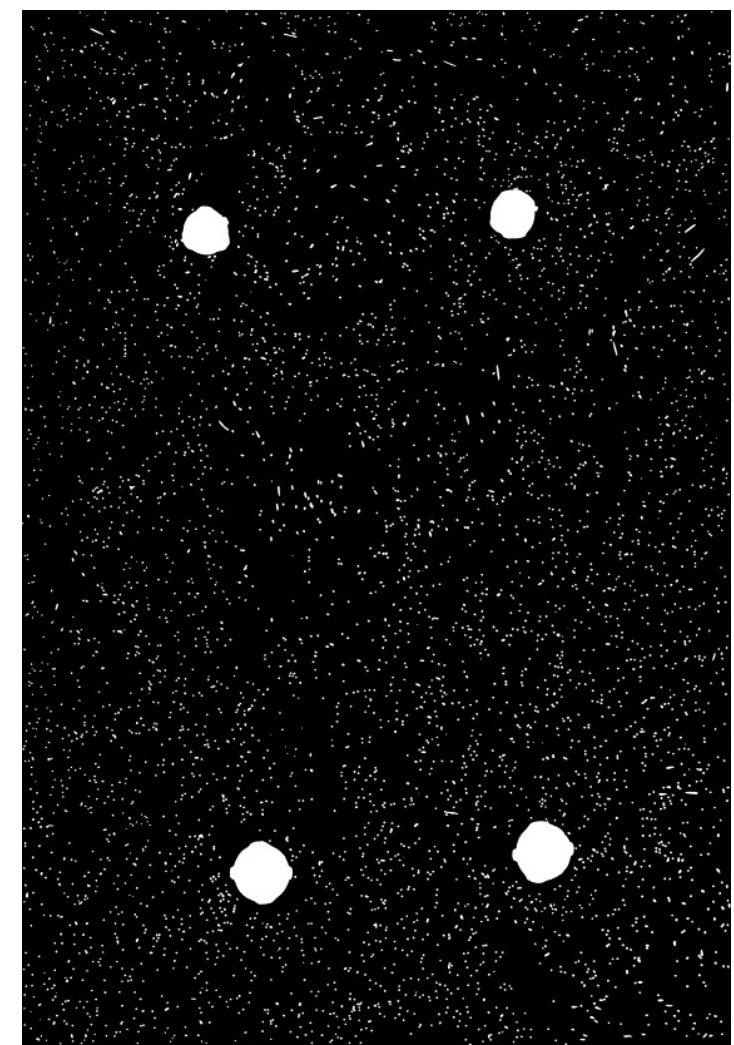

(b)

Figura 6.16 - Imagens binárias da viga V1-1 de UHPFRC-1: (a) plano de corte 1 e (b) plano de corte 2 


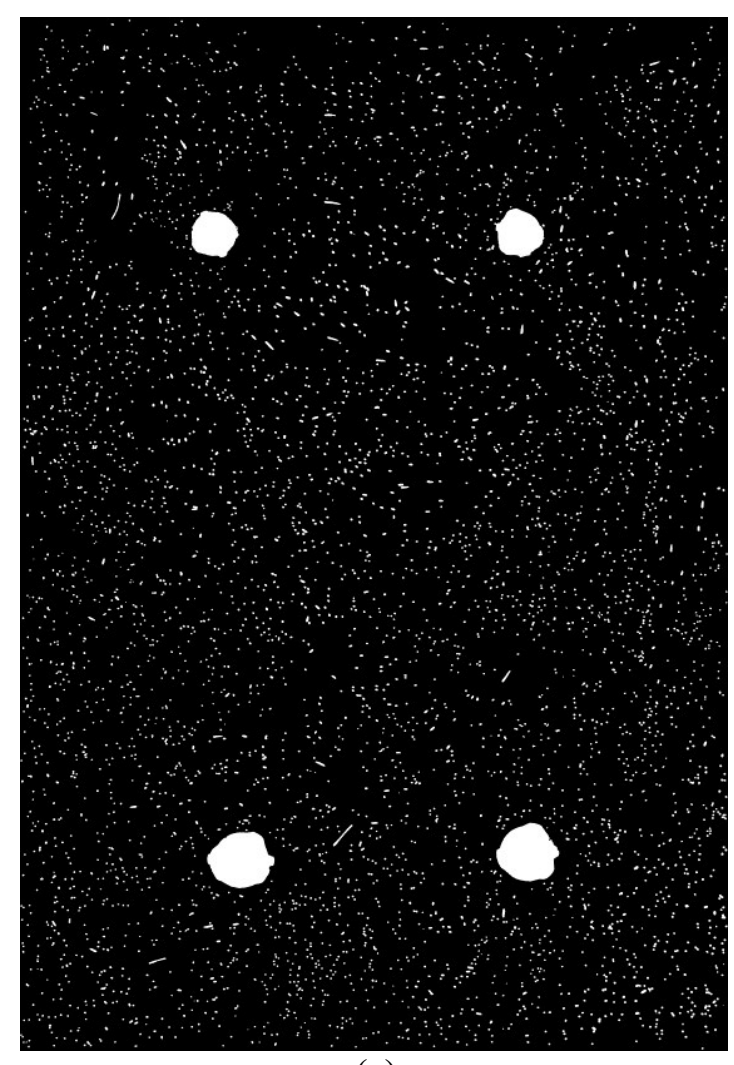

(a)

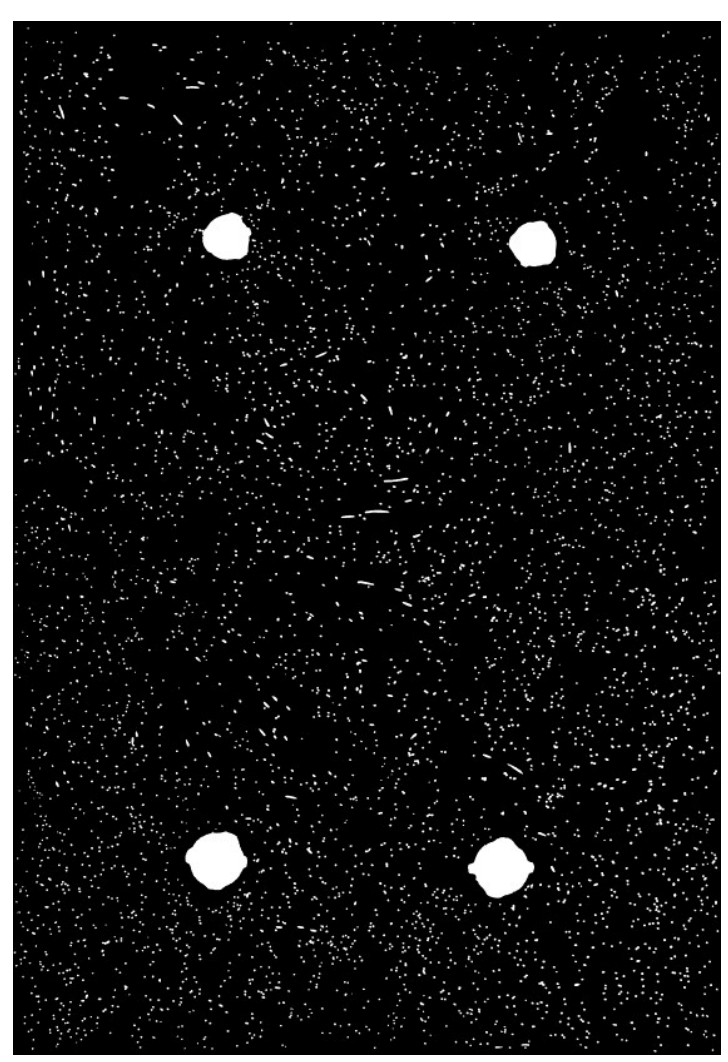

(b)

Figura 6.17 - Imagens binárias da viga V1-2 de UHPFRC-1: (a) plano de corte 1 e (b) plano de corte 2

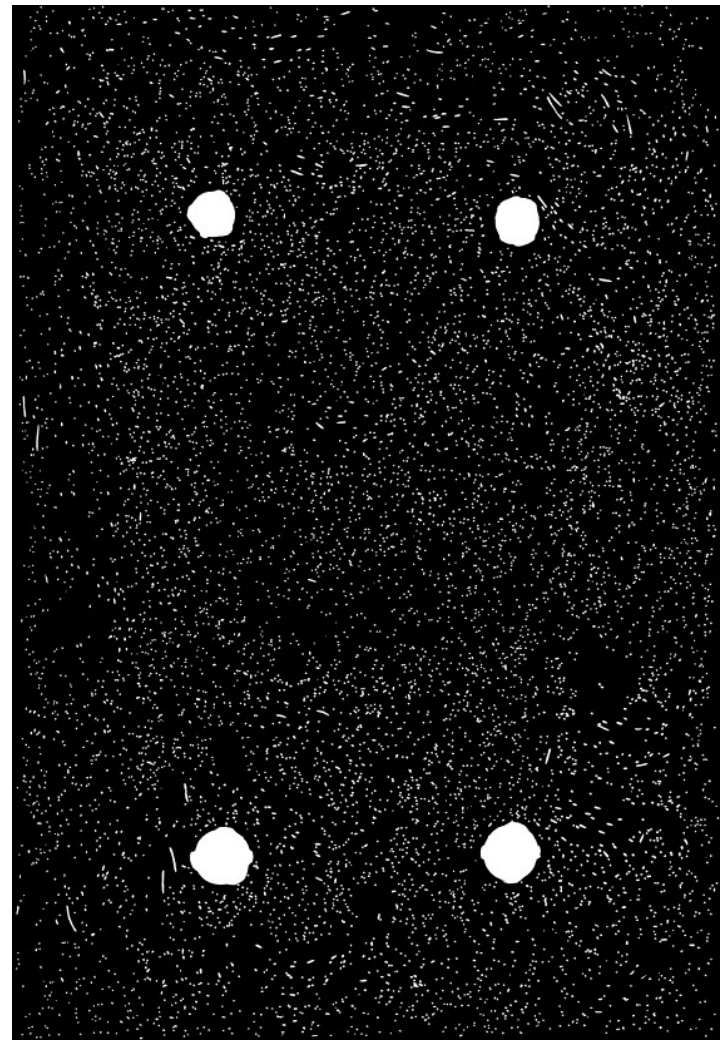

(a)

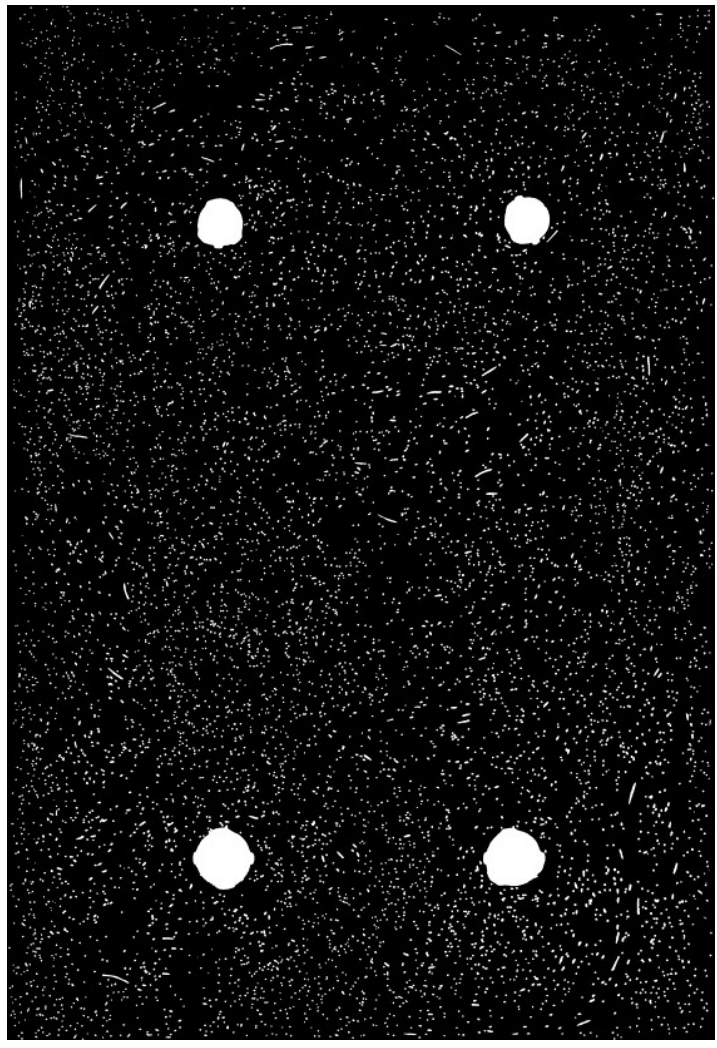

(b)

Figura 6.18 - Imagens binárias da viga V2-1 de UHPFRC-2: (a) plano de corte 1 e (b) plano de corte 2 


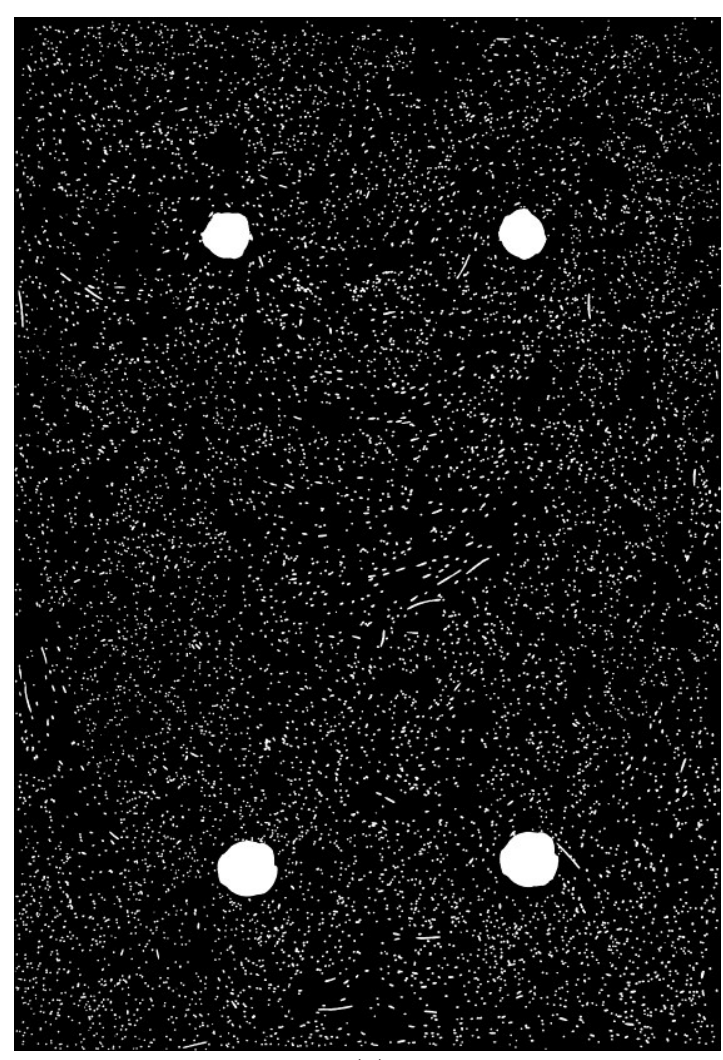

(a)

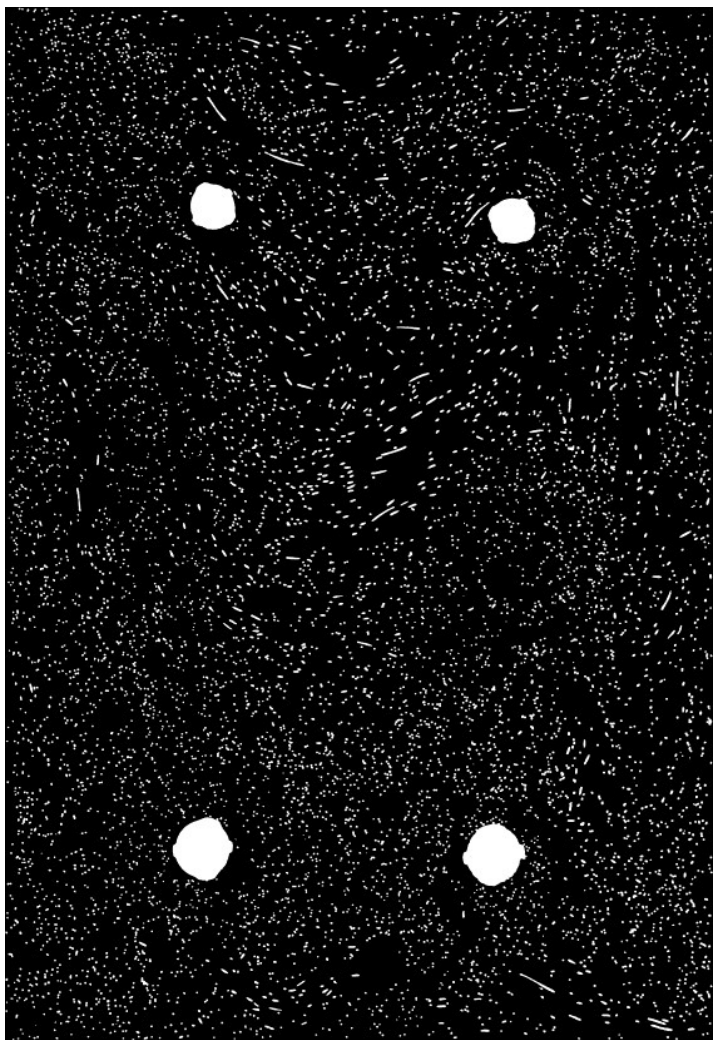

(b)

Figura 6.19 - Imagens binárias da viga V2-2 de UHPFRC-2: (a) plano de corte 1 e (b) plano de corte 2

A Tabela 6.3 apresenta as características de distribuição das fibras nos planos de corte das vigas de UHPFRC-1 e UHPFRC-2, determinadas quantitativamente por meio da análise de imagem descrita na Seção 4.2. É possível observar que o número de fibras por unidade de área $\left(F_{n}\right)$ das vigas de UHPFRC-2 foi aproximadamente 50\% maior do que das vigas de UHPFRC-1, o que condiz com o aumento da quantidade de fibras de $1 \%$ para $2 \%$ durante a produção dos concretos. Com relação ao coeficiente de orientação da fibras $\left(\eta_{\theta}\right)$, as vigas de UHPFRC-1 e UHPFRC-2 apresentaram valores mais próximos de 1 do que de 0 , indicando que as fibras alinharam-se mais paralelamente à direção normal ao plano de corte, como observado visualmente nas imagens binárias. Além disso, o coeficiente de orientação foi influenciado de forma insignificativa com o aumento da quantidade de fibras de $1 \%$ para $2 \%$ : as vigas de UHPFRC-1 e UHPFRC-2 apresentaram coeficiente de orientação médio de 0,815 e 0,788, respectivamente, ou seja, uma redução de apenas 3,3\%. Tal redução já era esperada, pois, segundo Yoo et al. (2016a), uma maior quantidade de fibras provoca uma redução no coeficiente de orientação, devido à maior probabilidade de interação entre as fibras durante o processo de moldagem do elemento. 
Tabela 6.3 - Características de distribuição das fibras nos planos de corte das vigas de UHPFRC-1 (V1-1 e V1-2) e UHPFRC-2 (V2-1 e V2-2)

\begin{tabular}{|c|c|c|c|c|c|c|}
\hline Viga & Plano de corte & $n_{f}$ & $F_{n}\left(\right.$ fibras $\left./ \mathrm{mm}^{2}\right)$ & $\theta_{m}\left({ }^{\circ}\right)$ & $\sigma_{\theta}\left({ }^{\circ}\right)$ & $\eta_{\theta}$ \\
\hline \multirow{2}{*}{ V1-1 } & 1 & 4857 & 0,147 & 32,6 & 13,6 & 0,820 \\
\hline & 2 & 4813 & 0,146 & 32,4 & 13,5 & 0,822 \\
\hline \multirow{2}{*}{ V1-2 } & 1 & 4760 & 0,144 & 34,2 & 13,3 & 0,806 \\
\hline & 2 & 4699 & 0,142 & 33,8 & 12,9 & 0,811 \\
\hline \multicolumn{2}{|c|}{$\begin{array}{l}\text { Média } \\
\text { (Desvio padrão) }\end{array}$} & $\begin{array}{l}4757 \\
(57)\end{array}$ & $\begin{array}{c}\mathbf{0 , 1 4 5} \\
(0,002)\end{array}$ & $\begin{array}{l}\mathbf{3 3 , 3} \\
(0,9)\end{array}$ & $\begin{array}{l}\mathbf{1 3 , 3} \\
(0,3)\end{array}$ & $\begin{array}{c}\mathbf{0 , 8 1 5} \\
(0,008)\end{array}$ \\
\hline \multirow{2}{*}{ V2-1 } & 1 & 8377 & 0,254 & 34,3 & 14,5 & 0,801 \\
\hline & 2 & 8220 & 0,249 & 35,7 & 14,3 & 0,788 \\
\hline \multirow{2}{*}{ V2-2 } & 1 & 8629 & 0,262 & 35,5 & 14,7 & 0,788 \\
\hline & 2 & 7801 & 0,236 & 36,6 & 15,3 & 0,775 \\
\hline \multicolumn{2}{|c|}{$\begin{array}{l}\text { Média } \\
\text { (Desvio padrão) }\end{array}$} & $\begin{array}{l}8257 \\
(347)\end{array}$ & $\begin{array}{c}\mathbf{0 , 2 5 0} \\
(0,011)\end{array}$ & $\begin{array}{l}\mathbf{3 5 , 5} \\
(0,9)\end{array}$ & $\begin{array}{l}\mathbf{1 4 , 7} \\
(0,4)\end{array}$ & $\begin{array}{c}\mathbf{0 , 7 8 8} \\
(0,011)\end{array}$ \\
\hline
\end{tabular}

sendo: $n_{f}$ o número total de fibras, $F_{n}$ o número de fibras por unidade de área, $\theta_{m} \mathrm{o}$ ângulo de orientação médio das fibras, $\sigma_{\theta}$ o desvio padrão de $\theta$ e $\eta_{\theta}$ o coeficiente de orientação das fibras (Equação (2.6)).

A partir das Equações (2.39) e (2.40), propostas por Laranjeira et al. (2011), e do coeficiente de orientação médio $\left(\eta_{\theta}\right)$ obtido na análise de imagem (Tabela 6.3), foram estimados o ângulo de orientação médio das fibras $\left(\theta_{m}\right)$ e o desvio padrão $\left(\sigma_{\theta}\right)$ para as vigas UHPFRC-1 e UHPFRC-2 (Tabela 6.4). Com base no erro relativo apresentado, na falta de resultados experimentais e assumindo corretamente o valor de $\eta_{\theta}$, as equações de Laranjeira et al. (2011) podem ser aplicadas ao UHPFRC.

Tabela 6.4 - Ângulo de orientação médio das fibras e desvio padrão para as vigas de UHPFRC-1 e UHPFRC-2 segundo as equações de Laranjeira et al. (2011)

\begin{tabular}{cccccccc}
\hline Viga & $\eta_{\theta}$ & $\theta_{m, \exp }\left({ }^{\circ}\right)$ & $\theta_{m, \text { teórico }}\left({ }^{\circ}\right)$ & Erro & $\sigma_{\theta, \exp }\left({ }^{\circ}\right)$ & $\sigma_{\theta, \text { teórico }}\left({ }^{\circ}\right)$ & Erro \\
\hline UHPFRC-1 & 0,815 & 33,3 & 35,4 & $5,9 \%$ & 13,3 & 13,6 & $2,2 \%$ \\
\hline UHPFRC-2 & 0,788 & 35,5 & 37,9 & $6,3 \%$ & 14,7 & 15,0 & $2,0 \%$ \\
\hline
\end{tabular}

$\operatorname{Erro}(\%)=\frac{\mid \text { Teórico }- \text { Experimental } \mid}{\text { Teórico }} \times 100$ 
A Figura 6.20 e a Figura 6.21 apresentam a distribuição da função densidade de probabilidade da orientação das fibras (FDP) para os planos de corte das vigas de UHPFRC-1 e UHPFRC-2, respectivamente. Nota-se que as distribuições FDP de todas as vigas estão deslocadas mais para esquerda, indicando que as fibras possuem uma tendência ao alinhamento mais paralelo à direção normal ao plano de corte. Além disso, a partir dessas distribuições, observa-se que elas aproximam-se mais de uma distribuição normal do que uniforme. Por essa razão, no modelo numérico foi considerada uma distribuição normal do ângulo de orientação das fibras.

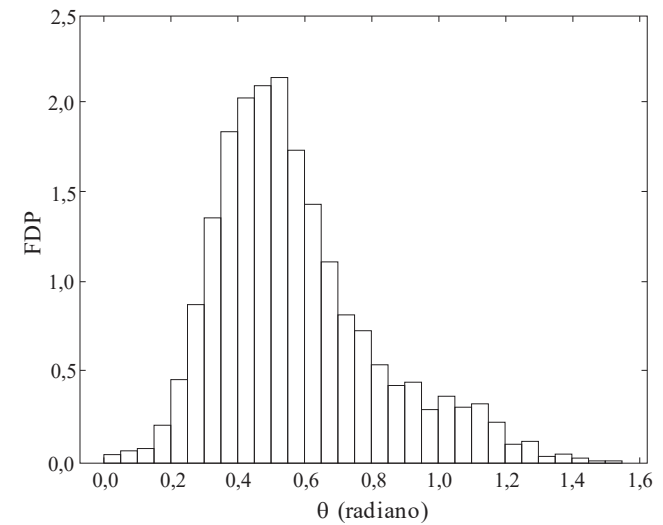

(a)

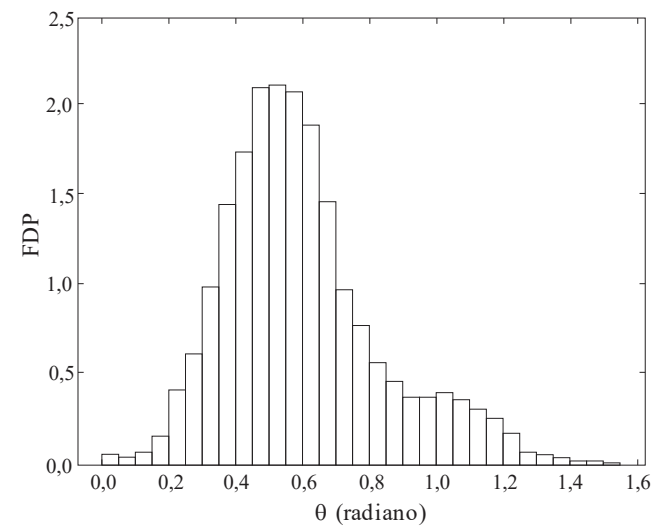

(c)

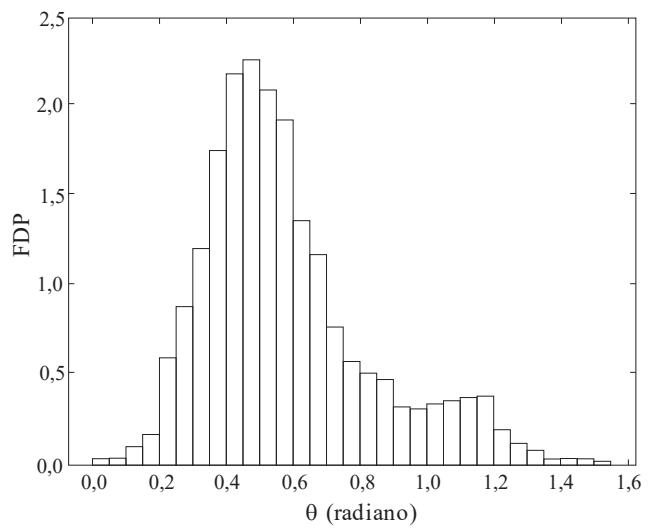

(b)

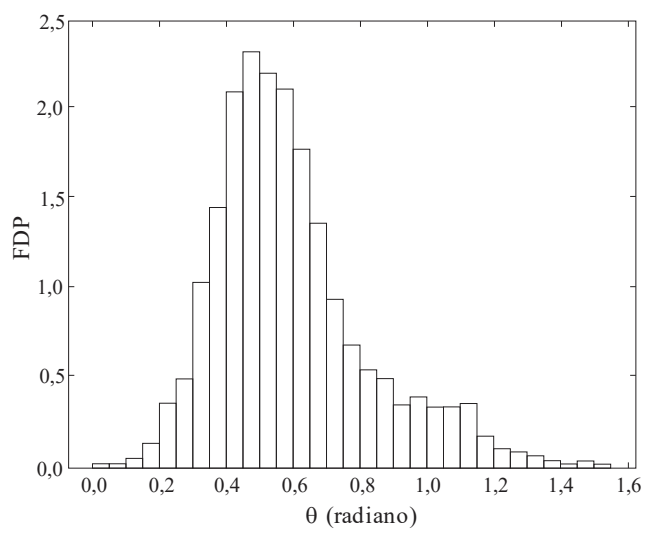

(d)

Figura 6.20 - Distribuição FDP das vigas de UHPFRC-1: (a) plano de corte 1 da V1-1, (b) plano de corte 2 da V1-1, (c) plano de corte 1 da V1-2 e (d) plano de corte 2 da V1-2 


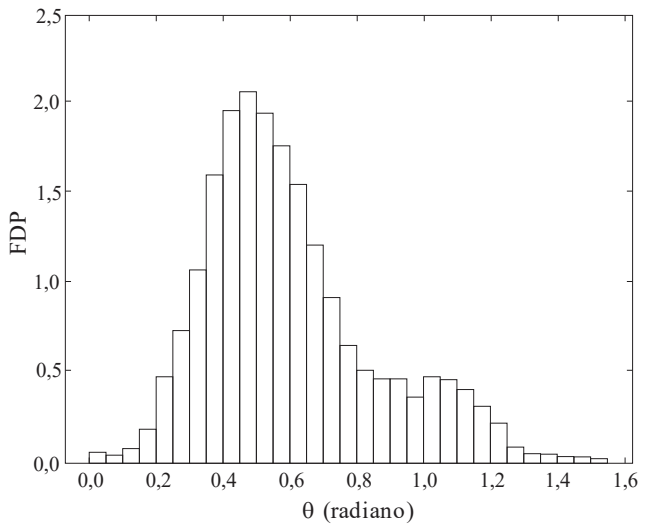

(a)

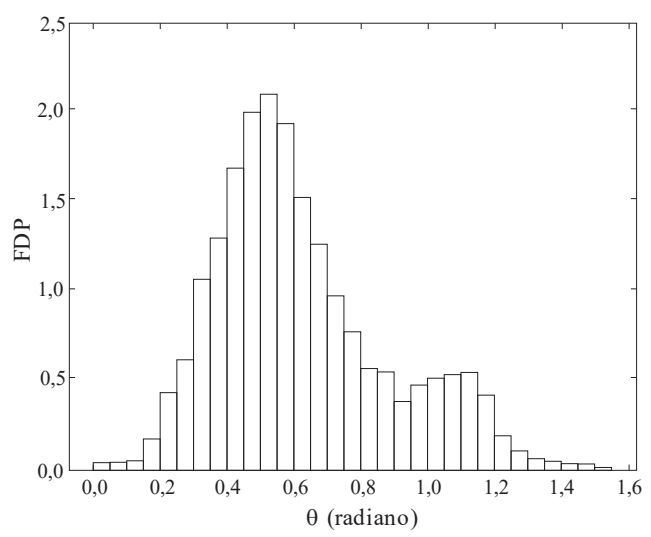

(c)

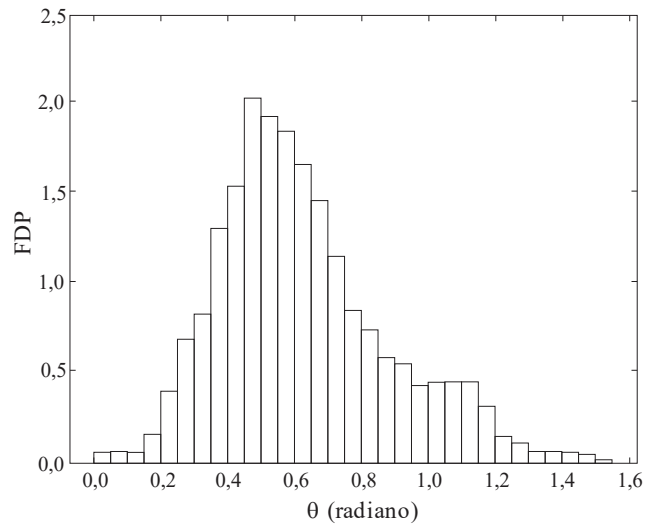

(b)

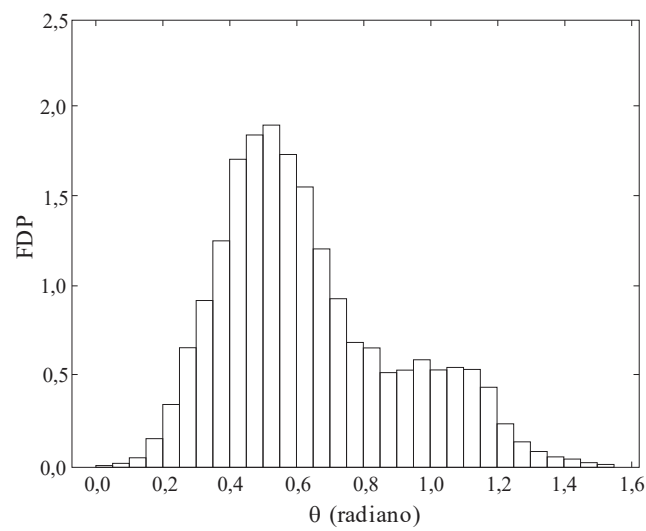

(d)

Figura 6.21 - Distribuição FDP das vigas de UHPFRC-2: (a) plano de corte 1 da V2-1, (b) plano de corte 2 da V2-1, (c) plano de corte 1 da V2-2 e (d) plano de corte 2 da V2-2

\subsection{Resultados da Análise Numérica}

Como já exposto, o modelo numérico proposto para o UHPFRC com fibras discretizadas e embutidas (material bifásico) foi aplicado e validado por meio das simulações dos ensaios de caracterização de tração uniaxial e de flexão a três pontos, e do ensaio de flexão a quatro pontos das vigas. Os resultados da análise numérica são apresentados a seguir.

\subsubsection{Simulação numérica do ensaio de tração uniaxial}

A Figura 6.22 apresenta as curvas tensão-deformação obtidas nas simulações dos dogbones de UHPFRC-1 e UHPFRC-2 submetidos ao ensaio de tração uniaxial. Para cada 
concreto, três modelos numéricos foram simulados considerando o mesmo coeficiente de orientação $\left(\eta_{\theta}\right)$ para a geração da malha das fibras.

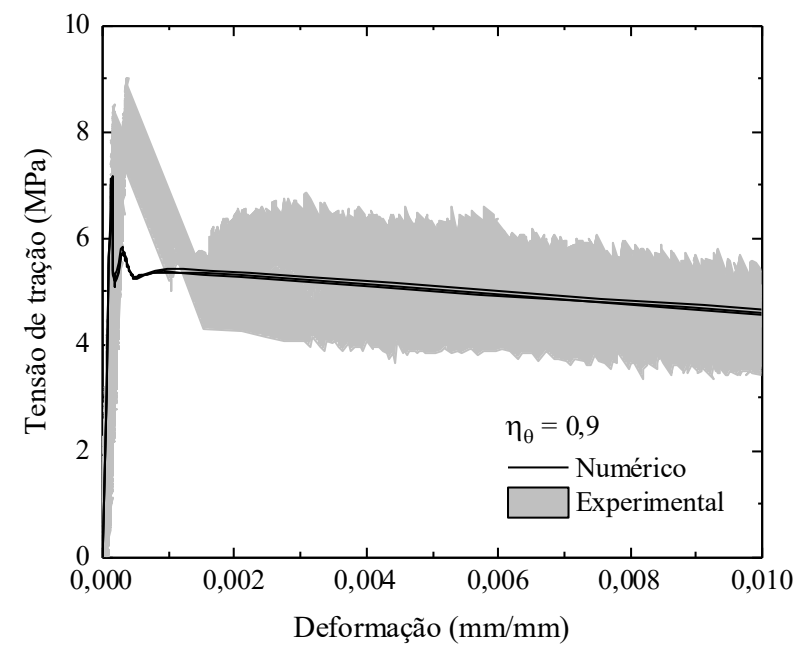

(a)

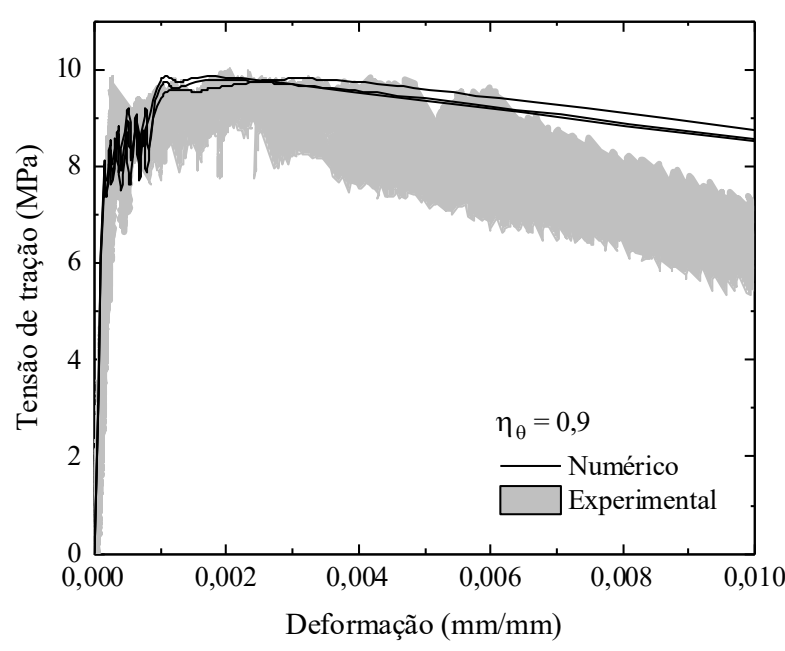

(b)

Figura 6.22 - Curvas tensão-deformação numéricas e experimentais do ensaio de tração uniaxial nos dog-bones de: (a) UHPFRC-1 e (b) UHPFRC-2

Como pode ser observado na Figura 6.22, as curvas numéricas e experimentais do UHPFRC-1 e UHPFRC-2 apresentaram uma boa correlação até a tensão máxima, sendo o modelo numérico capaz de predizer satisfatoriamente a resistência à tração dos concretos. Para o UHPFRC-1 (Figura 6.22a), após a tensão máxima, o modelo numérico conseguiu representar a queda brusca da tensão, causada pela falha da matriz (surgimento da primeira fissura), seguida por um leve comportamento de enrijecimento, provocado pela ativação ${ }^{2}$ das fibras no modelo. Para o UHPFRC-2 (Figura 6.22b), o modelo numérico representou de forma adequada o comportamento de enrijecimento após a primeira fissura, mas superestimou as tensões de tração após a tensão máxima.

Essa superestimação das tensões, também observada no trabalho de Soetens e Matthys (2014), pode ser atribuída à interação entre as fibras durante o processo de arrancamento, fenômeno que não é considerado no modelo numérico, mas possivelmente ocorre no experimental: experimentalmente, o arrancamento de uma única fibra, na fase de descolagem, provoca a danificação da interface fibra/matriz e, por consequência, da matriz circundante. Porém, quando se têm fibras agrupadas, ou seja, muitos próximas, a interação entre elas pode

\footnotetext{
${ }^{2}$ O termo "ativação" refere-se a quando as fibras, após a falha da matriz, passam a ter preponderante contribuição na rigidez dos elementos finitos em que estão embutidas e, por conseguinte, na rigidez total do elemento estrutural.
} 
intensificar a danificação da matriz. Espera-se, assim, que a pressão exercida pela matriz sobre as fibras seja aliviada, reduzindo o atrito entre os dois materiais e, consequentemente, provocando uma redução da eficiência das fibras na fase de arrancamento. Dessa forma, o comportamento de arrancamento de uma única fibra, que é o empregado para definir a lei constitutiva das fibras no modelo numérico proposto nesta pesquisa, deixa de ser representativo para o caso de fibras agrupadas na fase de arrancamento.

Ressalta-se que, quanto maior a quantidade de fibras de aço distribuídas na matriz de UHPFRC, maior é a tendência de agrupamento, tornando-se, portanto, mais significativo esse efeito de interação. Possivelmente por essa razão, as tensões numéricas do UHPFRC-2, após a tensão máxima, apresentaram-se superiores às experimentais.

Como forma de demonstrar no modelo numérico o efeito da interação das fibras agrupadas, a Figura 6.23a apresenta uma curva tensão-deformação idealizada ${ }^{3}$, obtida a partir da alteração dos parâmetros relacionados à fase de arrancamento da fibra (como, por exemplo, a redução do coeficiente de atrito) no modelo de Lee et al. (2010). Essa consideração pode ser, a princípio, um meio de representar o efeito em questão. Assim, a Figura $6.23 \mathrm{~b}$ mostra a resposta numérica do UHPFRC-2 obtida utilizando-se, no modelo constitutivo das fibras, tal idealização. Além disso, as figuras também expõem, analogamente, a curva não idealizada (Figura 6.23a) e sua respectiva resposta numérica (Figura 6.23b), a fim de comparação.

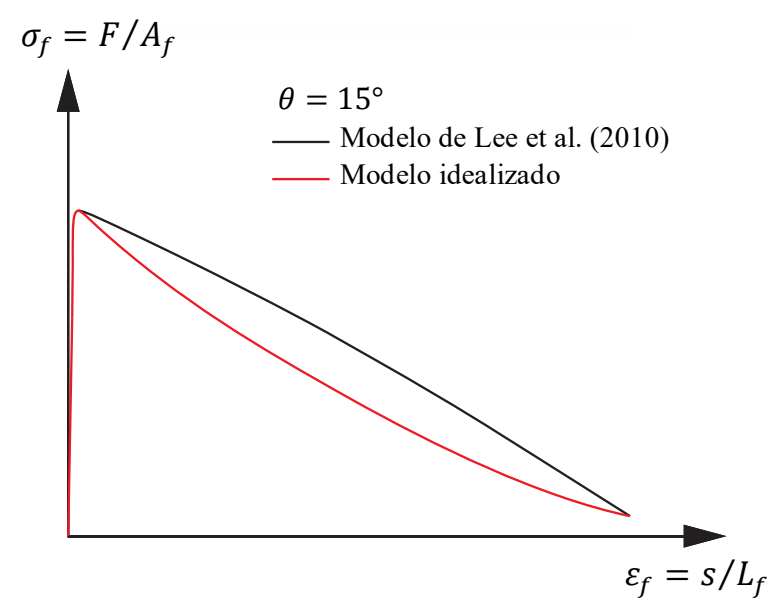

(a)

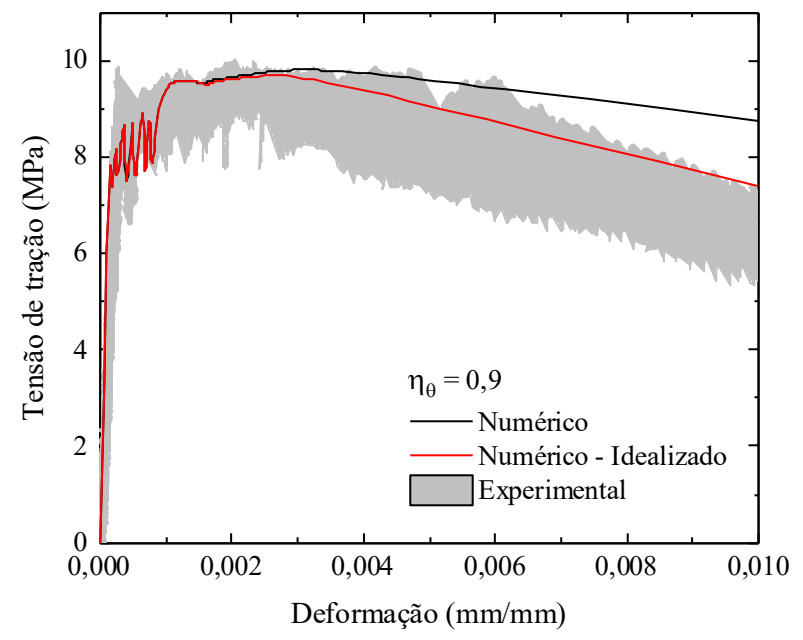

(b)

Figura 6.23 - (a) Modelo constitutivo idealizado e não idealizado das fibras, para $\theta=15^{\circ} \mathrm{e}$ (b) curva tensão-deformação numérica empregando ambos os modelos constitutivos

\footnotetext{
${ }^{3}$ A Figura 6.23a expõe apenas a curva referente a $\theta=15^{\circ}$, que representa o grupo de fibras com o ângulo de inclinação em relação ao plano de fissuração no intervalo $\left[15^{\circ}, 30^{\circ}\right.$. Entretanto, realizou-se o mesmo procedimento de idealização para todos os demais intervalos (apresentados na Seção 5.3.2).
} 
Observa-se na Figura 6.23 b que, como resultado da utilização da curva idealizada, o comportamento numérico após a tensão máxima aproximou-se mais do experimental. Isso é um indício de que o efeito da interação das fibras agrupadas pode ser relevante para que o modelo numérico melhor represente o experimental. Contudo, é necessário realizar um estudo experimental-numérico mais aprofundado a fim de investigar detalhadamente o comportamento de arrancamento das fibras agrupadas e validar tal questão aqui levantada.

A Figura 6.24 apresenta a ativação das fibras em um dos três modelos numéricos simulados (tomado como representativo) para o UHPFRC-1 e para o UHPFRC-2.

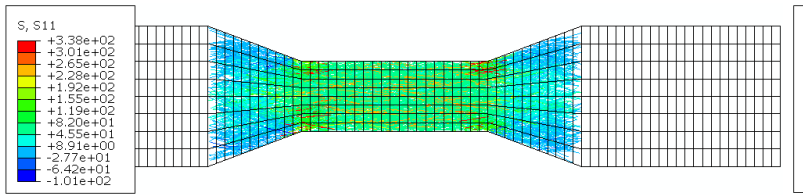

Primeira fissura (tensão máxima)

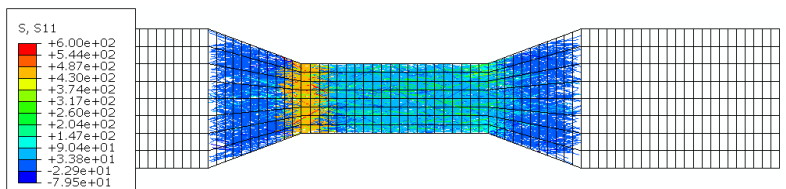

Após tensão máxima

(a)

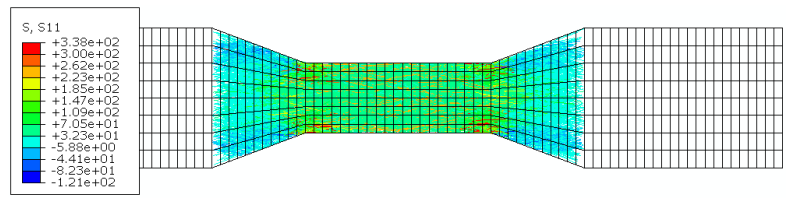

Primeira fissura
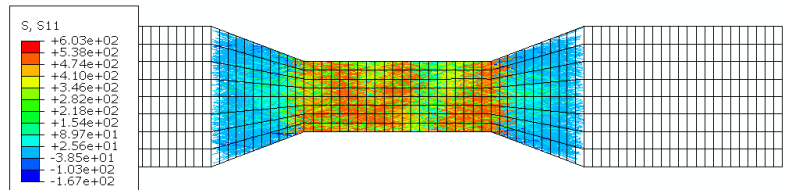

Tensão máxima
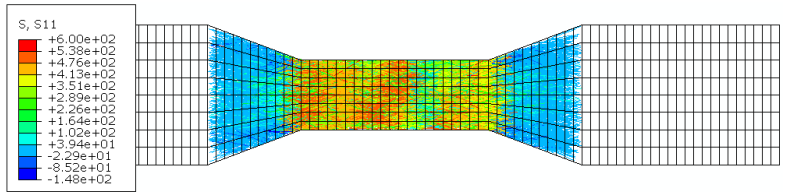

Após tensão máxima

(b)

Figura 6.24 - Ativação das fibras no modelo numérico do ensaio de tração uniaxial: (a) dog-bone de UHPFRC-1 e (b) dog-bone de UHPFRC-2

Nota-se na Figura 6.24 que a ativação efetiva das fibras no UHPFRC-1 e UHPFRC-2 ocorre após a primeira fissura, contribuindo significativamente com a rigidez dos elementos nos quais elas estão embutidas. No UHPFRC-1 (Figura 6.24a), nota-se que a ativação das fibras concentra-se apenas em uma região, que pode ser interpretada como o local de desenvolvimento da macrofissura. Isso demonstra que esse concreto apresenta uma menor capacidade de redistribuição das tensões (devido à menor quantidade de fibras), o que reduz a formação de múltiplas fissuras e, consequentemente, impossibilita o aumento da tensão de tração após a primeira fissura, conforme observado nos resultados experimentais. Em contrapartida, no UHPFRC-2 (Figura 6.24b), observa-se que, no instante da tensão máxima, as fibras estão 
ativadas em mais de uma região, simulando a maior capacidade de redistribuição das tensões e caracterizando a formação de múltiplas fissuras no concreto, como também observado experimentalmente. Após a tensão máxima, ocorre uma maior concentração de tensões em uma determinada região, o que caracteriza a formação da macrofissura. Nessa região, ocorre a queda de tensão nas fibras, representando o seu arrancamento da matriz; desse modo, essas fibras passam a contribuir menos com a rigidez dos elementos, provocando a queda de tensão no modelo como um todo.

\subsubsection{Simulação numérica do ensaio de flexão a três pontos}

A Figura 6.25 apresenta as curvas força-deslocamento vertical no meio do vão obtidas nas simulações dos prismas entalhados de UHPFRC-1 e UHPFRC-2 submetidos ao ensaio de flexão a três pontos. Para cada concreto, dois modelos numéricos foram simulados considerando o mesmo coeficiente de orientação $\left(\eta_{\theta}\right)$ para a geração da malha das fibras.

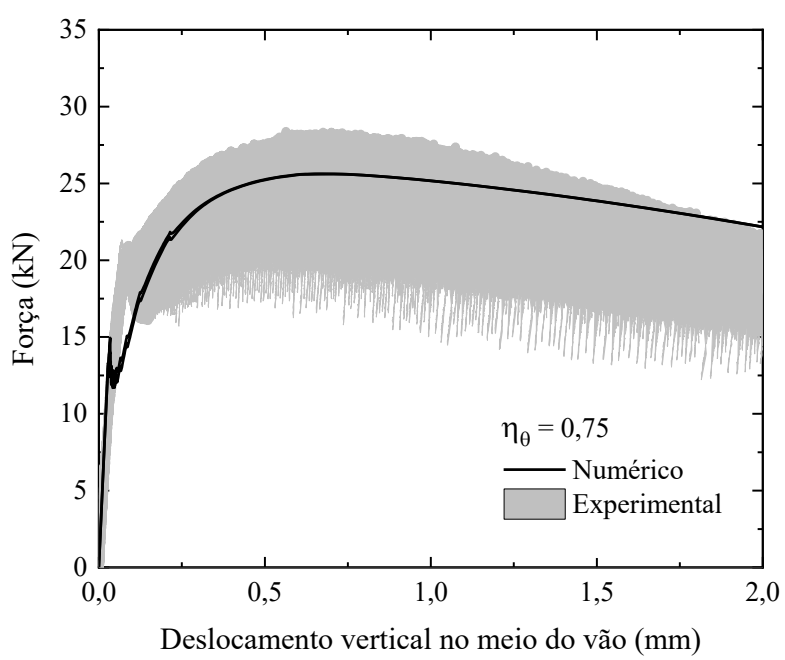

(a)

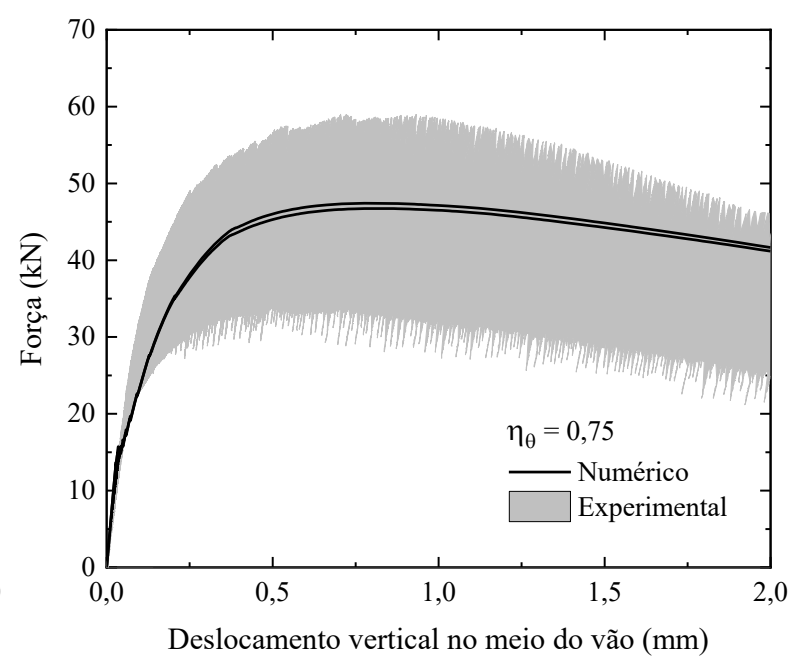

(b)

Figura 6.25 - Curvas força-deslocamento vertical no meio do vão numéricas e experimentais do ensaio de flexão a três pontos nos prismas entalhados de: (a) UHPFRC-1 e (b) UHPFRC-2

De modo geral, as curvas numéricas do UHPFRC-1 e UHPFRC-2 apresentaram uma boa concordância com as curvas experimentais. Observa-se na Figura 6.25a e Figura 6.25b que a força máxima prevista numericamente para os concretos encontrou-se dentro da envoltória experimental. Porém, para maiores deslocamentos, o modelo numérico tendeu a uma maior capacidade de força em relação ao experimental. Essa divergência após a força máxima pode 
ser atribuída à interação entre as fibras agrupadas, que intensifica a danificação da matriz e, consequentemente, reduz a eficiência das fibras na fase de arrancamento. Tal fenômeno, como já exposto, não é considerado no modelo numérico, impedindo, assim, uma queda mais significativa da força.

A Figura 6.26 apresenta a ativação das fibras em um dos dois modelos numéricos simulados (tomado como representativo) para o UHPFRC-1 e para o UHPFRC-2. Como pode ser observado em ambos os modelos, a presença do entalhe induz a concentração de tensões, ativando as fibras apenas nessa região, caracterizando o início da primeira fissura e, posteriormente, resultando no desenvolvimento da macrofissura, como esperado. Além disso, nota-se que, após a força máxima, as fibras próximas à ponta do entalhe começam a apresentar uma queda de tensão, representando a fase de arrancamento da matriz. Assim, a contribuição das fibras na rigidez dos elementos em que estão embutidas é reduzida, o que ocasiona a queda de força no modelo.

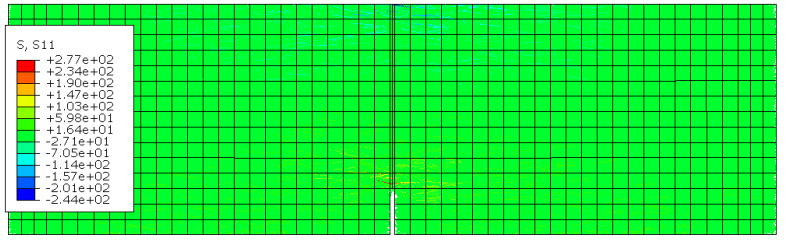

Primeira fissura

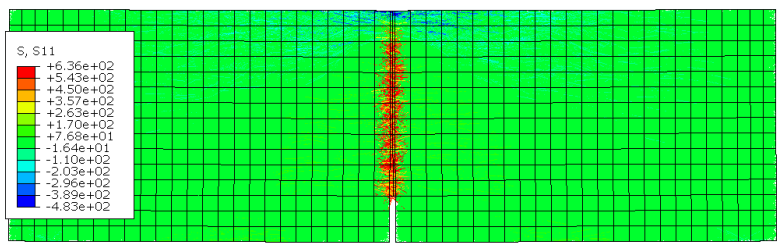

Tensão máxima

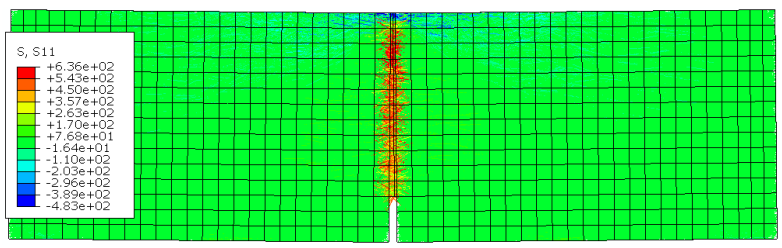

Após tensão máxima

(a)

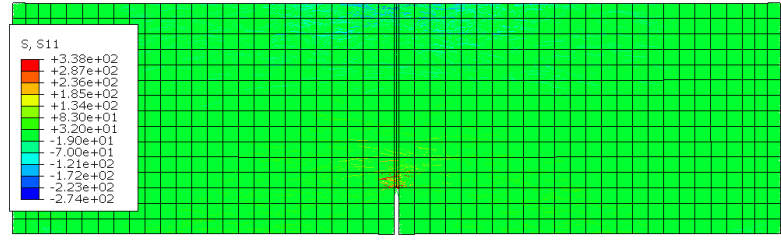

Primeira fissura

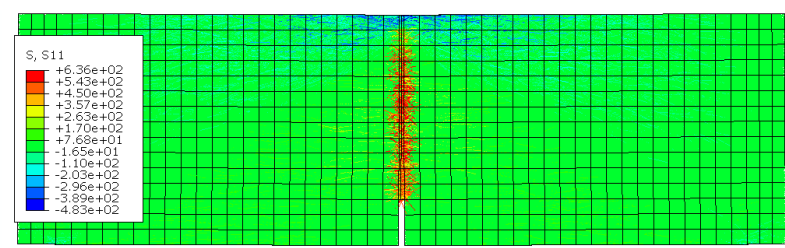

Tensão máxima

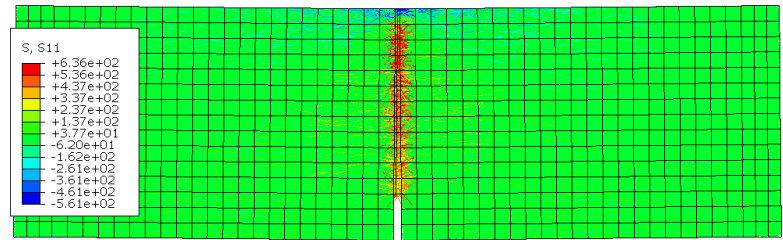

Após tensão máxima

(b)

Figura 6.26 - Ativação das fibras no modelo numérico do ensaio de flexão a três pontos com entalhe:

(a) prisma de UHPFRC-1 e (b) prisma de UHPFRC-2 


\subsubsection{Simulação numérica do ensaio de flexão a quatro pontos}

A Figura 6.27 apresenta as curvas força-deslocamento vertical no meio do vão obtidas nas simulações das vigas de UHPFRC-1 e UHPFRC-2 submetidas ao ensaio de flexão a quatro pontos. Para cada concreto, devido ao tempo computacional, um único modelo numérico foi simulado. As simulações das vigas de UHPFRC-1 e UHPFRC-2, realizadas em um computador alta performance, demoraram cerca de 4 e 10 dias, respectivamente.

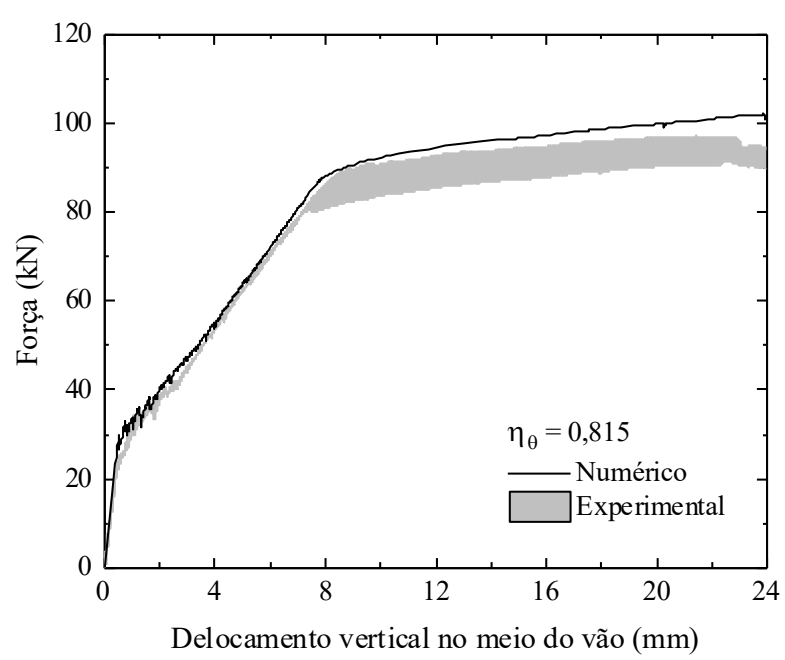

(a)

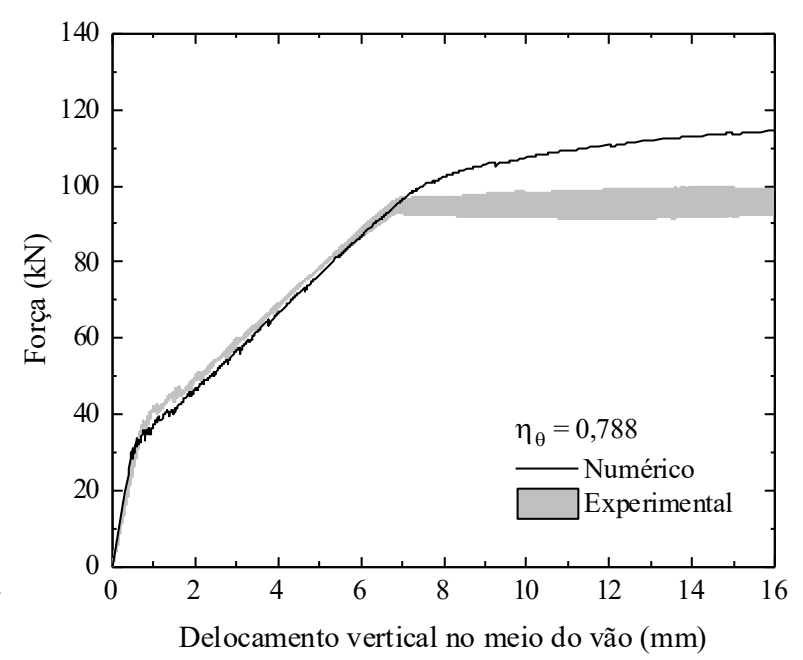

(b)

Figura 6.27 - Curvas força-deslocamento vertical no meio do vão numéricas e experimentais do ensaio de flexão a quatro pontos nas vigas de: (a) UHPFRC-1 e (b) UHPFRC-2

Como pode ser observado na Figura 6.27, as curvas numéricas e experimentais das vigas de UHPFRC-1 e UHPFRC-2 apresentaram uma boa correlação até o ponto de início de escoamento da armadura, sendo o modelo numérico capaz de estimar adequadamente as forças e deslocamentos nos pontos de primeira fissura e de início de escoamento. Após o início de escoamento, os modelos numéricos apresentaram uma maior capacidade de força (maior rigidez). As forças máximas previstas numericamente foram superestimadas em 7,7\% e 18,6\% para as vigas de UHPFRC-1 e UHPFRC-2, respectivamente, em comparação aos valores médios experimentais.

Como já exposto, uma das possíveis causas da superestimação numérica pode estar relacionada à não consideração da interação entre as fibras durante o processo de arrancamento, que, experimentalmente, pode acentuar a danificação da matriz, resultando na redução da eficiência das fibras. O fato de a viga de UHPFRC-2 apresentar uma superestimação mais 
expressiva pode ser atribuído à maior quantidade de fibras, que tende a aumentar a ocorrência de agrupamentos (conforme observado nas imagens dos planos de corte das vigas, Figura 6.18 e Figura 6.19), e assim intensificando o efeito de interação entre as fibras.

Além disso, após o início de escoamento, com o desenvolvimento da macrofissura, o deslizamento relativo entre a armadura longitudinal e a matriz passa a ser significativo, resultando, experimentalmente, em uma menor capacidade de força (menor rigidez). No entanto, nos modelos numéricos, as armaduras longitudinais estão aderidas perfeitamente à matriz, e nenhuma consideração de deslizamento entre esses dois materiais é realizada, o que leva a uma maior rigidez numericamente.

A Figura 6.28 apresenta a ativação das fibras nos modelos numéricos simulados para as vigas de UHPFRC-1 e UHPFRC-2.

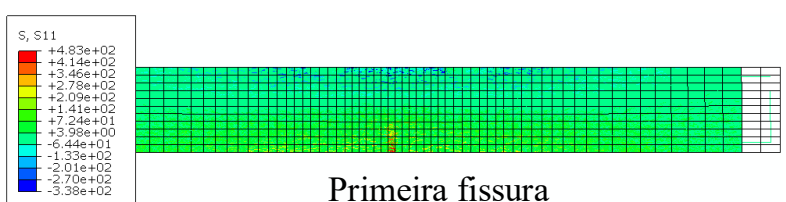

Primeira fissura
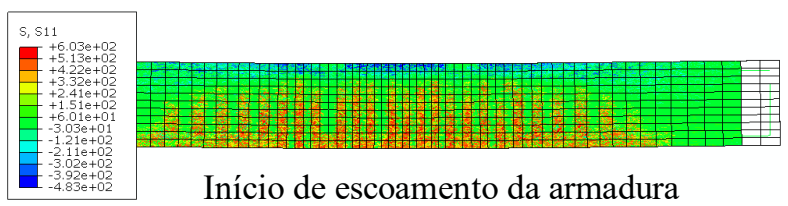

Início de escoamento da armadura

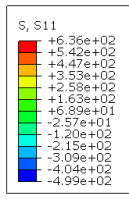

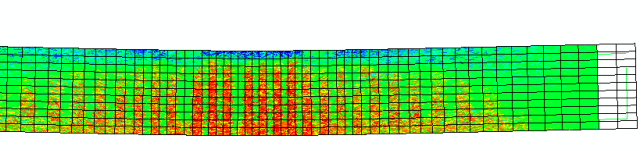

Após início de escoamento da armadura

(a)
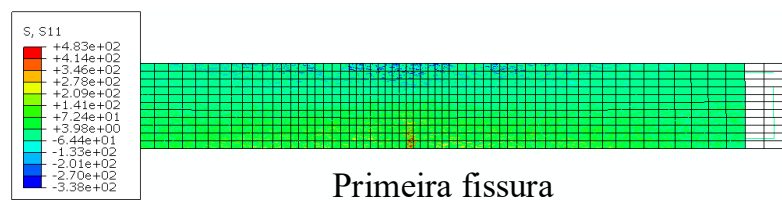

Primeira fissura
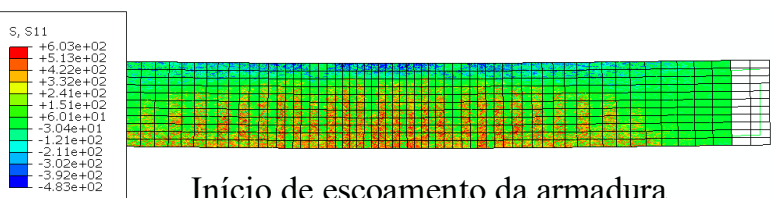

Início de escoamento da armadura

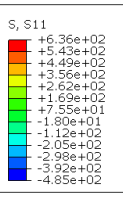

Após início de escoamento da armadura

(b)

Figura 6.28 - Ativação das fibras no modelo numérico do ensaio de flexão a quatro pontos: (a) viga de UHPFRC-1 e (b) viga de UHPFRC-2

É possível observar nas vigas de UHPFRC-1 (Figura 6.28a) e UHPFRC-2 (Figura 6.28b) que as fibras são efetivamente ativadas no instante e local da primeira fissura, passando a contribuir significativamente com a rigidez dos elementos em que estão embutidas. Após a primeira fissura, a ativação das fibras propaga-se ao longo do comprimento das vigas, simulando a capacidade de redistribuição das tensões (formação de múltiplas fissuras), proporcionada tanto pelas fibras quanto pelas armaduras longitudinais. Tal comportamento de 
redistribuição das tensões pode ser visto na Figura 6.28a e Figura 6.28b, no início de escoamento da armadura.

Nos modelos experimentais, após o início de escoamento da armadura, ocorre a concentração de tensões no local de formação da macrofissura, provocando a queda de força proveniente do arrancamento das fibras e do deslizamento da armadura em relação à matriz. Já nos modelos numéricos, observa-se na Figura 6.28a e Figura 6.28b que a concentração de tensões ocorre na região central das vigas (região de momento fletor máximo), ou seja, o modelo numérico proporciona, em comparação ao experimental, uma concentração de tensões menos localizada após o início de escoamento da armadura, resultando, numericamente, em uma maior capacidade de força.

Com relação às deformações no centro das armaduras longitudinais das vigas de UHPFRC-1 e UHPFRC-2, a Tabela 6.5 apresenta a comparação entre as deformações experimentais (valores médios) e as numéricas. Nota-se que, na primeira fissura e no início do escoamento da armadura, os valores experimentais e numéricos apresentaram-se próximos. Por outro lado, no instante da força máxima nos modelos experimentais, o desenvolvimento da macrofissura ocorreu fora da posição dos extensômetros, não sendo registradas, portanto, as altas deformações das armaduras e, consequentemente, impossibilitando confrontar os valores experimentais e numéricos nesse instante.

Tabela 6.5 - Deformações experimentais e numéricas no centro das armaduras longitudinais das vigas de UHPFRC-1 e UHPFRC-2

\begin{tabular}{|c|c|c|c|c|c|c|}
\hline \multirow{2}{*}{ Viga } & \multicolumn{2}{|c|}{ Primeira fissura } & \multicolumn{2}{|c|}{ Estado de escoamento } & \multicolumn{2}{|c|}{ Estado de pico } \\
\hline & $\begin{array}{c}\mathcal{E}_{c r, \exp } \\
(\mathrm{mm} / \mathrm{mm})\end{array}$ & $\begin{array}{c}\varepsilon_{\text {cr, num }} \\
(\mathrm{mm} / \mathrm{mm})\end{array}$ & $\begin{array}{c}\varepsilon_{y, \exp } \\
(\mathrm{mm} / \mathrm{mm})\end{array}$ & $\begin{array}{c}\varepsilon_{y, n u m} \\
(\mathrm{~mm} / \mathrm{mm})\end{array}$ & $\begin{array}{c}\varepsilon_{\max , \exp } \\
(\mathrm{mm} / \mathrm{mm})\end{array}$ & $\begin{array}{c}\varepsilon_{\max , n u m} \\
(\mathrm{~mm} / \mathrm{mm})\end{array}$ \\
\hline UHPFRC-1 & $6,24 \cdot 10^{-4}$ & $5,80.10^{-4}$ & $3,45 \cdot 10^{-3}$ & $3,48.10^{-3}$ & $4,75 \cdot 10^{-3}$ & $2,85 \cdot 10^{-2}$ \\
\hline UHPFRC-2 & $6,56.10^{-4}$ & $6,04 \cdot 10^{-4}$ & $3,79.10^{-3}$ & $3,71.10^{-3}$ & $4,30 \cdot 10^{-3}$ & $2,93 \cdot 10^{-2}$ \\
\hline
\end{tabular}

sendo: $\varepsilon_{c r}$ a deformação na primeira fissura, $\varepsilon_{y}$ a deformação no início do escoamento da armadura longitudinal e $\varepsilon_{\max }$ a deformação na força máxima. 



\section{CONCLUSÕES E TRABALHOS FUTUROS}

Esta pesquisa teve como objetivo investigar a influência das fibras sobre o comportamento mecânico e estrutural do UHPFRC e desenvolver, para esse concreto, um modelo numérico em elementos finitos com fibras discretizadas e embutidas na matriz cimentícia, tratando-o como um material bifásico. Para tanto, análises experimentais, de imagem e numéricas foram conduzidas. A seguir, são apresentadas as principais conclusões acerca dessas análises e, por fim, os trabalhos futuros que podem ser realizados em continuidade aos resultados e conclusões aqui obtidos.

\subsection{Conclusões}

$\mathrm{Na}$ análise experimental, foram realizados os ensaios de caracterização dos concretos (UHPC, UHPFRC-1 e UHPFRC-2) e o ensaio de flexão a quatro pontos das respectivas vigas, a fim de investigar o comportamento material e estrutural, bem como validar o modelo numérico proposto nesta pesquisa.

Quanto aos ensaios de caracterização, os concretos apresentaram propriedades mecânicas aceitáveis para UHPC e UHPFRC. Foi observado que a incorporação de fibras de aço teve pouca influência sobre a resistência à compressão e módulo de elasticidade, mas possibilitou o aumento das resistências à tração e à flexão, bem como a melhora da ductilidade e da energia de fratura, devido à atuação das fibras como ponte de transferência de tensões pelas fissuras. Além disso, foi verificado que, no ensaio de compressão diametral, é mais adequado correlacionar a resistência à tração do UHPFRC-1 e do UHPFRC-2 com a tensão da primeira fissura em vez da tensão máxima, pois, após a primeira fissura, ocorre o esmagamento desses concretos, e o acréscimo de tensão está mais relacionado à tenacidade do que ao aumento da resistência à tração.

Quanto ao ensaio de flexão das vigas, a incorporação das fibras de aço proporcionou um maior controle de fissuração, inibindo a propagação e a abertura de fissura. Como consequência, as vigas de UHPFRC-1 e UHPFRC-2 apresentaram maior rigidez e capacidade de força. 
Entretanto, o aumento da quantidade de fibras de $1 \%$ para $2 \%$ não resultou em uma melhora significativa da força máxima (acréscimo médio de 2,3\%) e da ductilidade (acréscimo médio de 1,24\%). Assim, o comportamento pós-fissuração dessas vigas provavelmente foi governado pela armadura longitudinal, e não pelas fibras de aço, isso porque, com o desenvolvimento da macrofissura, ocorre o arrancamento das fibras da matriz, o que reduz a sua contribuição na resistência das vigas. Além disso, o agrupamento das fibras, provocado pelo aumento da sua quantidade, possivelmente reduziu a eficiência das fibras durante o arrancamento, devido à maior interação entre elas.

Após o ensaio de flexão, foi realizada a análise de imagem nas vigas objetivando investigar os padrões de orientação das fibras e utilizá-los no modelo numérico proposto. As vigas de UHPFRC-1 e UHPFRC-2, próximo ao plano de fissuração principal, apresentaram características similares de distribuição das fibras: dispersas de forma mais homogênea e alinhadas mais paralelamente à direção normal ao plano de corte, sendo essa última característica confirmada por meio do coeficiente de orientação, que se mostrou próximo de 1 (0,815 e 0,788 para o UHPFRC-1 e para o UHPFRC-2, respectivamente).

$\mathrm{Na}$ análise numérica, foi proposta uma abordagem bastante recente (especialmente em elementos estruturais em escala real) em que o UHPFRC é modelado como um material heterogêneo composto pelas fases matriz cimentícia e fibras de aço, sendo o deslizamento relativo entre esses dois materiais considerado no modelo constitutivo das fibras, por meio de uma lei tensão-deformação equivalente baseada no comportamento de arrancamento da fibra. Com o intuito de validar essa abordagem, foram simulados modelos referentes aos ensaios de caracterização (tração uniaxial e flexão a três pontos) e de flexão a quatro pontos das vigas.

Quanto aos modelos numéricos relativos aos ensaios de caracterização, foi observada uma boa correlação com os resultados experimentais até a força (ou tensão) máxima. Após esse instante, obteve-se uma superestimação das forças numéricas (mais pronunciada nos modelos com maior quantidade de fibras), possivelmente ocasionada por um fenômeno não considerado no modelo numérico: a interação entre as fibras agrupadas, que intensifica a danificação da matriz e, por consequência, reduz a eficiência das mesmas durante a fase de arrancamento, implicando menor rigidez ao modelo experimental.

Quanto ao modelo numérico relativo ao ensaio de flexão das vigas, as curvas forçadeslocamento vertical no meio do vão apresentaram uma boa estimativa até o ponto de início de escoamento da armadura; entretanto, nos pontos seguintes, houve uma superestimação das forças, sendo as máximas acrescidas de 7,7\% e 18,6\% para as vigas de UHPFRC-1 e UHPFRC-2, respectivamente, em relação ao valores médios experimentais. Como prováveis 
causas, têm-se a não consideração da interação entre as fibras agrupadas (assim como exposto no parágrafo anterior) e a atribuição da aderência perfeita entre a armadura longitudinal e a matriz, que impossibilita o deslizamento relativo entre esses dois materiais, levando a uma maior rigidez numérica.

De modo geral, pode-se concluir que o modelo numérico proposto representou de forma satisfatória o modelo experimental, apesar de se apresentar mais rígido à medida em que se forma a macrofissura experimentalmente. Assim, a adoção da lei constitutiva equivalente para as fibras, que inclui os efeitos de deslizamento relativo entre as fibras e a matriz, bem como os efeitos ocorrentes nas fibras inclinadas (pino e fragmentação), pode ser empregada para substituir a necessidade de considerar no modelo numérico molas ou elementos de interface fibra/matriz. Contudo, para que o modelo numérico melhor represente o experimental, algumas sugestões são apontadas na Seção 7.2.

Além disso, quanto ao custo computacional, apesar do modelo numérico proposto apresentar um alto tempo de processamento (especialmente nos casos das vigas), pode-se dizer que, em comparação ao tempo dispendido nos ensaios experimentais, ele torna-se viável. Acredita-se que, com o desenvolvimento tecnológico-computacional, o tempo de processamento será reduzido e, assim, viabilizando ainda mais a aplicação do modelo numérico proposto.

\subsection{Sugestões para Trabalhos Futuros}

Com o intuito de aprimorar o modelo numérico proposto nesta pesquisa, são apresentas as seguintes propostas para trabalhos futuros:

- Investigar experimentalmente o comportamento de arrancamento das fibras agrupadas, com o objetivo de verificar e quantificar a possível redução de eficiência das fibras na fase de arrancamento, causada pela interação entre elas;

- Implementar no modelo numérico, mais especificamente na lei constitutiva das fibras, o comportamento de arrancamento das fibras agrupadas investigado experimentalmente, para os casos em que o efeito de interação seja mais pronunciado (como, por exemplo, no UHPFRC-2); 
- Implementar no modelo numérico os efeitos de deslizamento relativo entre a armadura longitudinal e a matriz cimentícia. Como exemplo, tem-se a abordagem proposta por Terán e Haach (2018). Para tanto, faz-se necessário investigar experimentalmente o comportamento de arrancamento das barras de aço em matrizes de UHPFRC; e

- Estender o modelo numérico proposto para elementos estruturais com outras geometrias, condições de carregamento e apoio. 


\section{REFERÊNCIAS}

ABRISHAMBAF, A.; PIMENTEL, M.; NUNES, S. Influence of fibre orientation on the tensile behaviour of ultra-high performance fibre reinforced cementitious composites. Cement and Concrete Research, v.97, p.28-40, 2017.

AL-OSTA, M. A.; ISA, M. N.; BALUCH, M. H.; RAHMAN, M. K. Flexural behavior of reinforced concrete beams strengthened with ultra-high performance fiber reinforced concrete. Construction and Building Materials, v.134, p.279-296, 2017.

ASSOCIAÇÃO BRASILEIRA DE NORMAS TÉCNICAS. NBR 7480: Aço destinado a armaduras para estruturas de concreto armado - Especificação. Rio de Janeiro, 2007. 13 p.

ASSOCIAÇÃO BRASILEIRA DE NORMAS TÉCNICAS. NBR 7222: Concreto e argamassa - Determinação da resistência à tração por compressão diametral de corpos de prova cilíndricos. Rio de Janeiro, 2011. 9 p.

ALWAN, J. M.; NAAMAN, A. E., GUERRERO, P. Effect of mechanical clamping on the pullout response of hooked steel fibers embedded in cementitious matrices. Concrete Science and Engineering, v.1, p.15-25, 1999.

AMERICAN SOCIETY FOR TESTING AND MATERIALS. ASTM C496/C496M-04: Standard Test Method for Splitting Tensile Strength of Cylindrical Concrete Specimens. West Conshohocken, Pennsylvania, United States of America, 2004. 5 p.

AMERICAN SOCIETY FOR TESTING AND MATERIALS. ASTM C1609/C1609M-12: Standard Test Method for Flexural Performance of Fiber-Reinforced Concrete (Using Beam With Third-Point Loading). West Conshohocken, Pennsylvania, United States of America, 2012. 9 p.

AMERICAN SOCIETY FOR TESTING AND MATERIALS. ASTM C469/C469M - 14: Standard Test Method for Static Modulus of Elasticity and Poisson's Ratio of Concrete in Compression. West Conshohocken, Pennsylvania, United States of America, 2014. 5 p.

ASSOCIATION FRANÇAISE DE GÉNIE CIVIL. AFGC/SETRA: Bétons fibrés à ultrahautes performances - Recommandations provisoires. Documents scientifiques et techniques. France, 2002. 98 p.

ASSOCIATION FRANÇAISE DE GÉNIE CIVIL. AFGC/SETRA: Bétons fibrés à ultrahautes performances - Recommandations. Documents scientifiques et techniques. France, 2013. 359 p.

ASSOCIATION FRANÇAISE DE NORMALISATION. NF P 18-470: Bétons fibrés à ultrahautes performances - Spécification, performance, production et conformité. Paris, 2016. 94 p. 
ASSOCIATION FRANÇAISE DE NORMALISATION. NF P 18-710: Complément national à l'Eurocode 2 - Calcul des structures en béton: règles spécifiques pour les Bétons Fibrés à Ultra-Hautes Performances (BFUP). Paris, 2016. 136 p.

AWINDA, K.; CHEN, J.; BARNETT, S. J. Investigating geometrical size effect on the flexural strength of the ultra high performance fibre reinforced concrete using the cohesive crack model. Construction and Building Materials, v.105, p.123-131, 2016.

BAHIJ, S.; ADEKUNLE, S. K.; AL-OSTA, M.; AHMAD, S.; AL-DULAIJAN, S. U.; RAHMAN, M. K. Numerical investigation of the shear behavior of reinforced ultra-highperformance concrete beams. Structural Concrete, v.19, p.305-317, 2018.

BARNETT, S. J.; LATASTE, J.; PARRY, T.; MILLARD, S. G.; SOUTSOS, M. N. Assessment of fibre orientation in ultra high performance fibre reinforced concrete and its effect on flexural strength. Materials and Structures, v.43, p.1009-1023, 2010.

BOULEKBACHE, B.; HAMRAT, M.; CHEMROUK, M.; AMZIANE, S. Flexural behaviour of steel fibre-reinforced concrete under cyclic loading. Construction and Building Materials, v.126, p.253-262, 2016.

BRANDÃO, J. H. Análise experimental e numérica de cascas de concreto de ultra-alto desempenho reforçado com fibras. 2005. 144p. Tese (Doutorado em Engenharia Civil) COPPE, Universidade Federal do Rio de Janeiro, Rio de Janeiro, 2005.

CARREIRA, D. J.; CHU, K. Stress-Strain Relationship for Plain Concrete in Compression. ACI Journal, v.82, n.6, p.797-804, 1985.

CHEN, L.; GRAYBEAL, B. A. Modeling Structural Performance of Ultrahigh Performance Concrete I-Girders. Journal of Bridge Engineering, v.17, n.5, p.754-764, 2012.

CHRIST, R. Compósitos cimentícios avançados à base de pós-reativos com misturas híbridas de fibras e reduzindo impacto ambiental. 2014. 109p. Dissertação (Mestrado em Engenharia Civil) - Universidade do Vale do Rio dos Sinos, São Leopoldo, 2014.

CUNHA, V. M. C. F. Steel Fibre Reinforced Self Compacting Concrete (from MicroMechanics to Composite Behaviour). 2010. 365p. Thesis (Ph.D.) - University of Minho, Portugal, 2010.

CUNHA, V. M. C. F.; BARROS, J. A. O.; SENA-CRUZ, J. M. An integrated approach for modelling the tensile behaviour of steel fibre reinforced self-compacting concrete. Cement and Concrete Research, v.41, p.64-76, 2011.

CUNHA, V. M. C. F.; BARROS, J. A. O.; SENA-CRUZ, J. M. A finite element model with discrete embedded elements for fibre reinforced composites. Computers and Structures, v.9495, p.22-33, 2012.

DENG, F.; DING, X.; CHI, Y.; XU, L.; WANG, L. The pull-out behavior of straight and hooked-end steel fiber from hybrid fiber reinforced cementitious composite: Experimental study and analytical modelling. Composite Structures, v.206, p.693-712, 2018. 
DEUTSCHE AUSSCHUSS FÜR STAHLBETON. DAfStb 561: Ultrahochfester Beton Sachstandsbericht. Berlin, 2008. 144 p.

DUPONT, D.; VANDEWALLE, L. Distribution of steel fibres in rectangular sections. Cement and Concrete Composites, v.27:3, p.391-398, 2005.

DUQUE, L. F. M.; GRAYBEAL, B. Fiber orientation distribution and tensile mechanical response in UHPFRC. Materials and Structures, v.50:55, p.1-17, 2017.

EL DEBS, M. K. Concreto pré-moldado: fundamentos e aplicações. São Carlos: EESCUSP, 2000.

FEHLING, E.; LEUTBECHER, T.; BUNJE, K. Design relevant properties of hardened Ultra High Performance Concrete. In: International Symposium on Ultra High Performance Concrete. Proceedings... Kassel, Germany, 2004. p.327-338.

FEHLING, E.; SCHMIDT, M.; WALRAVEN, J.; LEUTBECHER, T.; FRÖHLICH, S. UltraHigh Performance Concrete UHPC. Berlin, Germany: Wilhelm Ernst \& Sohn, 2014.

FOGLAR, M.; HAJEK, R.; FLADR, J.; PACHMAN, J.; STOLLER, J. Full-scale experimental testing of the blast resistance of HPFRC and UHPFRC bridge decks. Construction and Building Materials, v.145, p.588-601, 2017.

GETTU, R.; GARDNER, D. R.; SALDÍVAR, H.; BARRAGÁN, B. E. Study of the distribution and orientation of fibers in SFRC specimens. Materials and Structures, v.38, p.31-37, 2005.

GRAYBEAL, B. A. Characterization of the behavior of ultra-high performance concrete. 2005. 377p. Dissertation (Ph.D.) - University of Maryland, United States of America, 2005.

GRAYBEAL, B. A. Compressive Behavior of Ultra-High-Performance Fiber-Reinforced Concrete. ACI Materials Journal. n.104-M17, p.146-152, 2007.

GRAYBEAL, B. A; BABY, F. (2013). Development of Direct Tension Test Method for UltraHigh-Performance Fiber-Reinforced Concrete. ACI Materials Journal. n.110-M17, p.177$186,2013$.

GU, C.; YE, G.; SUN, W. Ultrahigh performance concrete-properties, applications and perspectives. Science China Technological Sciences, v.58, n.4, p.587-599, 2015.

GU, H.; WANG, J.; YU, C. Three-dimensional Modeling of Percolation Behavior of Electrical Conductivity in Segregated Network Polymer Nanocomposites Using Monte Carlo Method. Advances in Materials, v.5(1), p.1-8, 2016.

HASGUL, U.; TURKER, K.; BIROL, T.; YAVAS, A. Flexural behavior of ultra-highperformance fiber reinforced concrete beams with low and high reinforcement ratios. Structural Concrete, p.1-14, 2018.

HASSAN, A. M. T.; JONES, S.W., MAHMUD, G. H. Experimental test methods to determine the uniaxial tensile and compressive behaviour of ultra high performance fibre reinforced concrete (UHPFRC). Construction and Building Materials, v.37, p.874-882, 2012. 
HOANG, A.L.; FEHLING, E. Influence of steel fiber content and aspect ratio on the uniaxial tensile and compressive behavior of ultra high performance concrete. Construction and Building Materials, v.153, p.790-806, 2017.

HORDIJK, D. A. Local approach to fatigue of concrete. 1991. 216p. Thesis (Ph.D.) Technische Universiteit Delft, Delft, 1991.

HUSSEIN, L.; AMLEH, L. Size effect of ultra-high performance fiber reinforced concrete composite beams in shear. Structural Concrete, v.19, p.141-151, 2018.

JAPAN SOCIETY OF CIVIL ENGINEERS. JSCE: Recommendations for design and construction of high performance fiber reinforced cement composites with multiple fine cranks (HPFRCC). Japan, 2008. 113p.

KANG, S.; LEE, B. Y.; KIM, J.; KIM, Y. Y. The effect of fibre distribution characteristics on the flexural strength of steel fibre-reinforced ultra high strength concrete. Construction and Building Materials, v.25, p.2450-2467, 2011.

KANG, S.; KIM, J. The relation between fiber orientation and tensile behavior in an Ultra High Performance Fiber Reinforced Cementitious Composites (UHPFRCC). Cement and Concrete Research, v.41, p.1001-1014, 2011.

KANG, S.; KIM, J. Investigation on the flexural behavior of UHPCC considering the effect of fiber orientation distribution. Construction and Building Materials, v.28, p.57-65, 2012.

KRAHL, P. A.; CARRAZEDO, R.; EL DEBS, M. K. Mechanical damage evolution in UHPFRC: Experimental and numerical investigation. Engineering Structures, v.170, p.63$77,2018$.

KRAHL, P. A. Lateral stability of ultra-high performance fiber-reinforced concrete beams with emphasis in transitory phases. 2018. 191p. Thesis (Ph.D.) - School of Engineering of São Carlos, University of São Paulo, São Carlos, 2018.

LARANJEIRA, F.; GRÜNEWALD, S.; WALRAVEN, J.; BLOM, C.; MOLINS, C.; AGUADO, A. Characterization of the orientation profile of steel fiber reinforced concrete. Materials and Structures, v.44, p.1093-1111, 2011.

LEE, J.; FENVES, G. L. Plastic-Damage Model for Cyclic Loading of Concrete Structures. Journal of Engineering Mechanics, v.124, n.8, p.892-900, 1998.

LEE, B. Y.; KIM, J.; KIM, J.; KIM, Y. Y. Quantitative evaluation technique of Polyvinyl Alcohol (PVA) fiber dispersion in engineered cementitious composites. Cement \& Concrete Composites, v.31, p.408-417, 2009.

LEE, Y., KANG, S. KIM, J. Pullout behavior of inclined steel fiber in an ultra-high strength cementitious matrix. Construction and Building Materials, v.24, p.2030-2041, 2010.

LUBLINER, J.; OLIVER, J.; OLLER, S.; OÑATE, E. A Plastic-Damage Model for Concrete. International Journal of Solids and Structures, v.25, p.299-329, 1989. 
MA, J.; DEHN, F.; TUE, N. V.; ORGASS, M.; SCHMIDT, D. Comparative Investigations on Ultra-High Performance Concrete with and without Coarse Aggregates. In: International Symposium on Ultra High Performance Concrete. Proceedings... Kassel, Germany, 2004. p.205-212.

MA, J. Faserfreier Ultrahochfester Beton - Entwicklung und Materialeigenschaften. 2010. 246p. Dissertation (Ph.D.) - University of Leipzig, Germany, 2010.

MÁCA, P.; SOVJÁK, R.; VAVRINÍK, T. Experimental Investigation of Mechanical Properties of UHPFRC. Procedia Engineering, v.65, p.14-19, 2013.

MAHMUD, G. H.; YANG, Z.; HASSAN, A. M. T. Experimental and numerical studies of size effects of Ultra High Performance Steel Fibre Reinforced Concrete (UHPFRC) beams. Construction and Building Materials, v.48, p.1027-1034, 2013.

MAO, L.; BARNETT, S.; BEGG, D.; SCHLEYER, G.; WIGHT, G. Numerical simulation of ultra high performance fibre reinforced concrete panel subjected to blast loading. International Journal of Impact Engineering, v.64, p.91-100, 2014.

MEHTA, P. K.; MONTEIRO, P. J. M. Concreto: microestrutura, propriedades e materiais. São Paulo: IBRACON, 2008.

MENG, W.; KHAYAT, K. H. Mechanical properties of ultra-high-performance concrete enhanced with graphite nanoplatelets and carbon nanofibers. Composites Part B, v.107, p.113$122,2016$.

MEYER, F. Topographic distance and watershed lines. Signal Processing, v.38, p.113-125, 1994.

NAAMAN, A. E.; NAMUR, G. G.; ALWAN, J. M.; NAJM, H. S. Fiber pullout and bond slip. I: Analytical study. Journal of Structural Engineering, v.117, n.9, p. 2769-2790, 1991a.

NAAMAN, A. E.; NAMUR, G. G.; ALWAN, J. M.; NAJM, H. S. Fiber pullout and bond slip. II: Experimental validation. Journal of Structural Engineering, v.117, n.9, p. 2791-2800, $1991 b$.

NAAMAN, A. E.; NAJM, H. Bond-Slip Mechanisms of Steel Fibers in Concrete. ACI Materials Journal, n.88, p.135-145, 1991.

NAAMAN, A. E. Fiber Reinforced Concrete: Five Decades of Progress. In: 4th Brazilian Conference on Composite Materials. Proceedings... Brazil, 2018. p. 1-22.

NAMMUR, G.; NAAMAN, A. E. A bond stress model for fiber reinforced concrete based on bond stress slip relationship. ACI Materials Journal, v. 86, p.45-57, 1989.

NGUYEN, D. L.; KIM, D.; RYU, G. S.; KOH, K. T. Size effect on flexural behavior of ultrahigh-performance hybrid fiber-reinforced concrete. Composites: Part B, v.45, p.1104-1116, 2013. 
NUNES, N. L.; AGOPYAN, V. A influência do Fator de Forma da Fibra na Tenacidade à Flexão do Concreto Reforçado com Fibras de Aço. Boletim Técnico da Escola Politécnica da USP, BT/PCC/225, 18 p., 1998.

OSORIO, E.; BAIRÁN, J. M.; MARÍ, A. R. Lateral behavior of concrete under uniaxial compressive cyclic loading. Materials and Structures, v.46, p.709-724, 2013.

OTSU, N. A Threshold Selection Method from Gray-Level Histograms. IEEE Transactions on Systems, Man, and Cybernetics, v.9, n.1, p.62-66, 1979.

PARK, S. H.; RYU, G. S.; KOH, K. T.; KIM, D. J. Effect of shrinkage reducing agent on pullout resistance of high-strength steel fibers embedded in ultra-high-performance concrete. Cement \& Concrete Composites, v.49, p.59-69, 2014.

QSYMAH, A. M. In-situ X-ray Computed Tomography Tests and Numerical Modelling of Ultra High Performance Fibre Reinforced Concrete. 2016. 170p. Thesis (Ph.D.) - School of Mechanical, Aerospace and Civil Engineering, University of Manchester, United Kingdom, 2016.

REN, G. M.; WU, H.; FANG, Q.; LIU, J. Z. Effects of steel fiber content and type on static mechanical properties of UHPCC. Construction and Building Materials, v.163, p.826-839, 2018.

RICHARD, P.; CHEYREZY, M. Composition of reactive powder concretes. Cement and Concrete Research, v.25, n.7, p.1501-1511, 1995.

RÉUNION INTERNATIONALE DES LABORATOIRES ET EXPERTS DES MATÉRIAUX. RILEM TC 162-TDF: Test and Design Methods for Steel Fibre Reinforced Concrete Bending Test. Materials and Structures, v.35, p.579-582, 2002.

RÉUNION INTERNATIONALE DES LABORATOIRES ET EXPERTS DES MATÉRIAUX. RILEM 50 FMC: Determination of the fracture energy of mortar and concrete by means of three-point bend tests on notched beams. Materials and Structures, v.18, p.285-290, 1985.

SHAFIEIFAR, M.; FARZAD, M.; AZIZINAMINI, A. Experimental and numerical study on mechanical properties of Ultra High Performance Concrete (UHPC). Construction and Building Materials, v. 156, p.402-411, 2017.

SHI, C.; WU, Z.; XIAO, J.; WANG, D.; HUANG, Z.; FANG, Z. A review on ultra high performance concrete: Part I. Raw materials and mixture design. Construction and Building Materials, v.101, p.741-751, 2015.

SHIN, SW; GHOSH, S. K.; MORENO, J. Flexural Ductility of Ultra-High-Strength Concrete Members. ACI Structural Journal, v.86, p.394-400, 1989.

SINGH, M.; SHEIKH, A. H.; MOHAMED ALI, M. S.; VISINTIN, P.; GRIFFITH, M. C. Experimental and numerical study of the flexural behaviour of ultra-high performance fibre reinforced concrete beams. Construction and Building Materials, v.138, p.12-25, 2017. 
SOBUZ, H. R.; VISINTIN, P.; MOHAMED ALI, M. S.; SINGH, M.; GRIFFITH, M. C.; SHEIKH, A. H. Manufacturing ultra-high performance concrete utilising conventional materials and production methods. Construction and Building Materials, v. 111, p. 251-261, 2016.

SOETENS, T.; MATTHYS, S. TAERWE, L.; VAN GYSEL, A. Basis of a Finite-Element Simulation Tool to Predict the Flexural Behavior of SFRC Prisms. High Performance Fiber Reinforced Cement Composites 6 (HPFRCC 6) RILEM, v.2, p.91-98, 2012.

SOETENS, T.; MATTHYS, S. Implementation of fibre pull-out behaviour in a finite element model for SFRC. In: Bond in Concrete 2012 - Bond, Anchorage, Detailing, Proceedings... Brescia, Italy, 2012. p.941-945.

SOETENS, T.; MATTHYS, S. Different methods to model the post-cracking behaviour of hooked-end steel fibre reinforced concrete. Construction and Building Materials, v.73, p.458-471, 2014.

SUJIVORAKUL, C.; WAAS, A. M.; GUERRERO, P. Pull-out of a smooth fiber with an end anchorage. Journal of Materials in Civil Engineering, v.126, n.9, p.986-993, 2000.

TAI, Y.; EL-TAWIL, S.; CHUNG, T. Performance of deformed steel fibers embedded in ultrahigh performance concrete subjected to various pullout rates. Cement and Concrete Research, v.89, p.1-13, 2016.

TERÁN, J. R. D.; HAACH, V. G. Equivalent stress-strain law for embedded reinforcements considering bondslip effects. Engineering Structures, v. 165, p.247-253, 2018.

THAI, D.; KIM, S. Prediction of UHPFRC panels thickness subjected to aircraftengine impact. Case Studies in Structural Engineering, v.5, p.38-53, 2016.

TUTIKIAN, B. F.; ISAIA, G. C.; HELENE, P. Concreto de alto e ultra-alto desempenho. In: ISAIA, G. C. et. al. Concreto: ciência e tecnologia. São Paulo: IBRACON, 2011. 2v. Cap.36, p.1283-1325.

VANALLI, L.; CODA, H. B. O MEC e o MEF aplicados à análise de problemas viscoplásticos em meios anisotrópicos e compostos. Cadernos de Engenharia de Estruturas, v.8, p.83-114, 2006.

VANDERLEI, R. D. Análise experimental do concreto de pós reativos: dosagem e propriedades mecânicas. 2004. 168p. Tese (Doutorado em Engenharia de Estruturas) - Escola de Engenharia de São Carlos, Universidade de São Paulo, São Carlos, 2004.

VOO, Y. L.; FOSTER, S. J. Characteristics of ultra-high performance 'ductile' concrete and its impact on sustainable construction. The IES Journal Part A: Civil \& Structural Engineering, v.3, n.3, p.168-189, 2010.

WANG, D.; SHI, C.; WU, Z; XIAO; J.; HUANG, Z; FANG, Z. A review on ultra high performance concrete: Part II. Hydration, microstructure and properties. Construction and Building Materials, v.96, p.368-377, 2015. 
WILLE, K.; NAAMAN, A. E. Fracture energy of UHP-FRC under direct tensile loading. In: Fracture mechanics of concrete and concrete structures - Recent Advances in Fracture Mechanics of Concrete. Proceedings... Korea, 2010. p. 65-72.

WILLE, K.; NAAMAN, A. E. Pullout Behavior of High-Strength Steel Fibers Embedded in Ultra-High-Performance Concrete. ACI Materials Journal, n.109, p.479-487, 2012.

WILLE, K.; EL-TAWIL, S.; NAAMAN, A. E. Properties of strain hardening ultra high performance fiber reinforced concrete (UHP-FRC) under direct tensile loading. Cement \& Concrete Composites, v.48, p.53-66, 2014a.

WILLE, K.; TUE, N., V.; PARRA-MONTESINOS, G. J. Fiber distribution and orientation in UHP-FRC beams and their effect on backward analysis. Materials and Structures, v.47, p.1825-1838, 2014b.

WU, Z.; SHI, C.; HE, W.; WU, Z. Effects of steel fiber content and shape on mechanical properties of ultra high performance concrete. Construction and Building Materials, v.103, p.8-14, 2016.

WU, Z.; KHAYAT, K. H.; SHI, C. How do fiber shape and matrix composition affect fiber pullout behavior and flexural properties of UHPC?. Cement and Concrete Composites, v.90, p.193-201, 2018.

XU, M.; WILLE, K. Fracture energy of UHP-FRC under direct tensile loading applied at low strain rates. Composites: Part B, v.80, p.116-125, 2015.

XU, M.; HALLINAN, B.; WILLE, K. Effect of loading rates on pullout behavior of high strength steel fibers embedded in ultra-high performance concrete. Cement and Concrete Composites, v.70, p.98-109, 2016.

YANG, I.; JOH, C.; KIM, B. Structural behavior of ultra high performance concrete beams subjected to bending. Engineering Structures, v.32, p.3478-3487, 2010.

YANG, I.; JOH, C.; KIM, K. A Comparative Experimental Study on the Flexural Behavior of High-Strength Fiber-Reinforced Concrete and High-Strength Concrete Beams. Advances in Materials Science and Engineering, v.2018, p.1-13, 2018.

YOO, D.; KANG, S.; LEE, J.; YOON, Y. Effect of shrinkage reducing admixture on tensile and flexural behaviors of UHPFRC considering fiber distribution characteristics. Cement and Concrete Research, v.54, p.180-190, 2013.

YOO, D. Performance Enhancement of Ultra-High-Performance Fiber-Reinforced Concrete and Model Development for Practical Utilization. 20114. 628p. Thesis (Ph.D.) Graduate School, Korea University, Korea, 2014.

YOO, D.; KANG, S.; YOON, Y. Effect of fiber length and placement method on flexural behavior, tension-softening curve, and fiber distribution characteristics of UHPFRC. Construction and Building Materials, v.64, p.67-81, 2014. 
YOO, D.; ZI, G.; KANG, S.; YOON, Y. Biaxial flexural behavior of ultra-high-performance fiber-reinforced concrete with different fiber lengths and placement methods. Cement and Concrete Composites, v.63, p.51-66, 2015.

YOO, D.; YOON, Y. Structural performance of ultra-high-performance concrete beams with different steel fibers. Engineering Structures, v.102, p.409-423, 2015.

YOO, D.; KANG, S.; YOON, Y. Enhancing the flexural performance of ultra-highperformance concrete using long steel fibers. Composite Structures, v.147, p.220-230, 2016 a.

YOO, D.; BANTHIA, N.; YOON, Y. Flexural behavior of ultra-high-performance fiberreinforced concrete beams reinforced with GFRP and steel rebars. Engineering Structures, v.111, p.246-262, $2016 b$.

YOO, D.; BANTHIA, N.; KANG, S.; YOON, Y. Effect of fiber orientation on the ratedependent flexural behavior of ultra-high-performance fiber-reinforced concrete. Composite Structures, v.157, p.62-70, 2016c.

YOO, D.; BANTHIA, N.; YOON, Y. Predicting the flexural behavior of ultra-highperformance fiber-reinforced concrete. Cement and Concrete Composites, v.74, p.71-87, 2016d.

YOO, D.; PARK, J.; KIM, S. Fiber pullout behavior of HPFRCC: Effects of matrix strength and fiber type. Composite Structures, v.174, p.263-276, 2017.

ZHAN, Y.; MESCHKE, G. Analytical Model for the Pullout Behavior of Straight and HookedEnd Steel Fibers. Journal of Engineering Mechanics, v.140, n. 12, p. 04014091, 2014.

ZHANG, H.; HUANG, Y. J.; YANG, Z. J.; XU, S. L.; CHEN, X. W. A discrete-continuum coupled finite element modelling approach for fibre reinforced concrete. Cement and Concrete Research, v.106, p.130-143, 2018.

ZHOU, B.; UCHIDA Y. Influence of flowability, casting time and formwork geometry on fiber orientation and mechanical properties of UHPFRC. Cement and Concrete Research, v.95, p.164-177, 2017. 